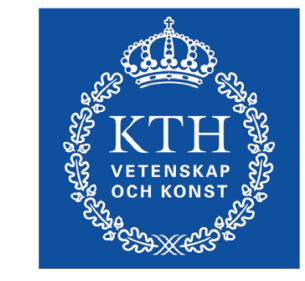

KTH Engineering Sciences

\title{
Effective Spatial Mapping for Coupled Code Analysis of Thermal-Hydraulics/Neutron-Kinetics of Boiling Water Reactors
}

\author{
Doctoral Thesis \\ by \\ JOANNA PELTONEN
}

School of Engineering Sciences

Department of Physics

Division of Nuclear Power Safety

Stockholm, Sweden 2013 


\title{
KUNGLIGA TEKNISKA HÖGSKOLAN \\ Royal Institute of Technology
}

\section{Avdelningen för Kärnkraftsäkerhet}

Division of Nuclear Power Safety

\author{
Post Address: AlbaNova University Center, \\ Roslagstullsbacken 21, \\ STOCKHOLM 10691, Sweden \\ http://www.physics.kth.se/
}

Date and Time of Public Dissertation: 2013-06-05, 10:00 o'clock.

Place: room: Fa32, AlbaNova University Center.

TRITA-FYS 2013:05

ISSN 0280-316X

ISRN KTH/FYS/-13:05-SE

ISBN 978-91-7501-661-0 


\section{Doktorsavhandlingsammanfattning}

Modern säkerhetsanalys av kärnkraftsreaktorer kräver koppling av neutronkinetiska $(\mathrm{NK})$ och termohydrauliska $(\mathrm{TH})$ beräkningsprogram så kallade koder. Att använda kompletta tredimensionella härdmodeller i både NK och TH koder kräver enorma datorresurser och lång beräkningstid. Trots att de senaste framstegen inom datorteknik erbjuder snabbare och stabilare datorer, för att erhålla sanningsenligt resultat inom en rimlig datortid, krävs att sammankopplade TH och NK koder använder olika spatiösa beskrivningar av reaktorhärden. Därutav TH koden använder få, vanligtvis 5 till $20 \mathrm{TH}$ kanaler som representerar hela reaktorhärden medan NK koden använder explicita noder för varje bränslepatron, därför en spatiöskoppling (mapping) av de grova noder i TH och de förfinade noder i NK domän är nödvändigt. Eventuell felaktig mapping mellan $\mathrm{TH}$ och NK koder kan resultera i en förlust av värdefull information, vilket leder till en felaktig prognos av säkerhetsparametrar.

Det huvudsakliga syftet med denna avhandling är att studera effektiviteten av metodiken för spatiöskoppling (nodförfining och spatiöskartläggning) samt utveckla rekommendationer för NK/TH spatiöskoppling för säkerhetsanalys. Dessutom har känsligheten av härdstabiliteten (mätt genom dämpkvot och frekvens) analyserats med hjälp av tillgängliga data från OECD/NEA Ringhals-1 stabilitet benchmark. Forskningsmetodiken innebär en konvergensstudie av spatiöskoppling genom att öka antalet TH kanaler och variera spatiöskopplingar upp till och inklusive ett referensfall. Referensfallet består av en ett till ett spatiöskoppling: en TH kanal per bränslepatron. Jämförelser av resultaten görs både för jämviktstillstånd och störningar.

I denna avhandling föreslås definitionen för mapping (spatiöskoppling) och de befintliga spatiöskopplingsmetoder granskas. Ett stort antal av 
simuleringar utförs och resultaten av dessa simuleringar analyseras och presenteras. Dessutom, för att öka effektiviteten och användbarheten av spatiöskopplingskonvergensen, en ny metod för spatiöskoppling har föreslagits. Den föreslagna metoden bygger på den hierarkiska klustringsmetodiken, metoden för lärande utan tillsyn. På grund av sin inneboende flexibilitet och robusthet används denna metodik i olika vetenskapliga områden. Den föreslagna spatiöskopplingsmetoden visar mycket uppmuntrande resultat. Möjligheten att helt automatisera spatiöskopplingen möjliggör betydande tidreducering under spatiöskopplingskonvergensanalyser.

Dessutom presenteras erhållna jämviktresultaten från de tre kärnkraftverksmodellerna för olika undersökta störningsfall. Alla modeler uppnådde ett välkonvergerat jämviktstillstånd och efter en jämförelse av lokala parametrar, konstaterades det att en fast grund för vidare störningsanalyser förekommer. För att erhålla den bästa jämviktstillståndsprestationen rekommenderas sådana spatiöskopplings metoder som inkluderar effektformfaktorer antingen ensam eller i kombination med andra härdens kännetecken. Därtill är det viktigt att bibehålla hardenssymmetri.

Majoriteten av den bedrivna forskningen ägnades åt störningsanalyser. Valet av scenarier gjordes så att det täcker ett brett spektrum av störningar. Avsikten var att samlad kunskap skulle vara tillämbar för alla typer av störningar. Fallande styrstav valdes som företrädare för en lokal störning. En speciell matarvattenstörning valdes för att representera en regional störning och en turbin tripp som ett exempel på en global störning.

Vid lokala störningen var antalet av TH kanaler mindre viktig än det spatiöskopplingsmetodiken därför ett stort antal TH kanaler garanterar inte förbättrade resultat. För att undvika fel och uppnå den bästa resultaten, kanalen och härdenszon där störningen inträffar bör alltid separeras från resten av härden. Bästa prestationen uppnås när spatiöskopplingsmetod 
med effektformfaktorer används och därför rekommenderas den för denna typ avstörningar. Den regionala störningen har visat sig vara mest utmanande. Denna typ av störning är starkt beroende av sådana spatiöskopplingsmetoder som kan påverka hastigheten av effektökningen, snabbstopptid, uppkomsten av instabilitet, typ av limit cykel, etc. Man har också dragit slutsatsen att förberedelser av indatamodell för denna typ av störningar kräver mer insatser med särskild uppmärksamhet på detaljer. I kontrast till den regionala störningen, den globala störningen befanns vara den minst krävande. Här, har antalet TH kanaler eller/och typ av spatiöskopplingsmetodiken inte betydande inverkan på genomsnittliga modellens beteende - allmänna störningsresultaten är alltid väl återskapade.

En särskild uppmärksamhet har också ägnats åt att undersöka härdstabilitet, både globalt och regionalt. Det har konstaterats att vid instabil härd, få TH kanaler dämpar avsevärt instabilitet. För sådana fall är antalet av TH kanaler mycket viktig och minst hälften av härden måste modelleras för att ha ett förtroende för simulerade dämpkvot (DR) och frekvenser (FR). Vid regional instabilitet rekommenderas att använda fullskalig indatamodellspatiöskoppling av en TH kanal per bränslepatron för att få korrekta resultat. Om detta inte är möjligt, bör en spatiöskoppling som är en blandning av 1: a effektharmonisk och effektformfaktorer, användas.

Allmänna slutsatser och rekommendationer har sammanfattats i slutet av denna avhandling. Utveckling av dessa rekommendationer har varit ett av målen med denna studie. De bör beaktas när man skapar nya kopplade TH/NK modeller och väljer spatiöskoppling för en ny störningsanalys. Denna avhandling är helt och hållet skriven på engelska.

Sökord: kokvattenreaktor, reaktoranalys, RELAP5, TRACE, PARCS, TH/NK analys, turbin tripp, matarvatten transient, fallande styrstav, reaktor stabilitet, hierarkisk klustringsmetodik. 


\section{Abstract}

Analyses of nuclear reactor safety have increasingly required coupling of full three dimensional neutron kinetics (NK) core models with system transient thermal-hydraulics (TH) codes. In order to produce results within a reasonable computing time, the coupled codes use two different spatial description of the reactor core. The TH code uses few, typically 5 to 20 TH channels, which represent the core. The NK code uses explicit one node for each fuel assembly. Therefore, a spatial mapping of a coarse grid $\mathrm{TH}$ and a fine grid NK domain is necessary. However, improper mappings may result in loss of valuable information, thus causing inaccurate prediction of safety parameters.

The purpose of this thesis is to study the effectiveness of spatial coupling (channel refinement and spatial mapping) and develop recommendations for NK/TH mapping in simulation of safety transients. Additionally, sensitivity of stability (measured by Decay Ratio and Frequency) to the different types of mapping schemes, is analyzed against OECD/NEA Ringhals-1 Stability Benchmark data.

The research methodology consists of spatial coupling convergence study, by increasing the number of $\mathrm{TH}$ channels and varying mapping approaches, up to and including the reference case. The reference case consists of one-to-one mapping: one TH channel per one fuel assembly. The comparisons of the results are done for steady-state and transient results.

In this thesis mapping (spatial coupling) definition is formed and all the existing mapping approaches were gathered, analyzed and presented. Additionally, to increase the efficiency and applicability of spatial mapping convergence, a new mapping methodology has been proposed. The new 
mapping approach is based on hierarchical clustering method; the method of unsupervised learning that is adopted by many researchers in many different scientific fields, thanks to its flexibility and robustness. The proposed new mapping method turns out to be very successful for spatial coupling problem and can be fully automatized allowing for significant time reduction in mapping convergence study.

The steady-state results obtained from three different plant models for all the investigated cases are presented. All models achieved well converged steady-state and local parameters were compared and it was concluded that solid basis for further transient analysis was found. Analyzing the mapping performance, the best predictions for steady-state conditions are the mappings that include the power peaking factor feature alone or with any combination of other features. Additionally it is of value to keep the core symmetry (symmetry feature).

The big part of this research is devoted to transient analysis. The selection of transients was done such that it covers a wide range of transients and gathered knowledge may be used for other types of transients. As a representative of a local perturbation, Control Rod Drop Accident was chosen. A specially prepared Feedwater Transient was investigated as a regional perturbation and a Turbine Trip is an example of a global one.

In the case of local perturbation, it has been found that a number of $\mathrm{TH}$ channels is less important than the type of mapping, so a high number of TH channels does not guarantee improved results. To avoid unnecessary averaging and to obtain the best prediction, hot channel and core zone where accident happens should be always separated from the rest. The best performance is achieved with mapping according power peaking factors, and therefore this one is recommended for such type of perturbation.

The regional perturbation has been found to be more challenging than the others. This kind of perturbation is strongly dependent on mapping type 
that affects the power increase rate, SCRAM time, onset of instability, development of limit cycle, etc. It has been also concluded that a special effort is needed for input model preparation.

In contrast to the regional perturbation, the global perturbation is found to be the least demanding transient. Here, the number of $\mathrm{TH}$ channels and type of mapping do not have significant impact on average plant behaviour - general plant response is always well recreated.

A special effort has also been paid to investigate the core stability performance, in both global and regional mode. It has been found that in case of unstable cores, a low number of $\mathrm{TH}$ channels significantly suppresses the instability. For these cases number of TH channels is very important and therefore at least half of the core has to be modeled to have a confidence in predicted DR and FR.

In case of regional instability in order to get correct performance of out-ofphase oscillations, it is recommended to use full-scale model. If this is not possible, the mapping which is a mixture of $1^{\text {st }}$ power mode and power peaking factors, should be used.

The general conclusions and recommendations are summarized at the end of this thesis. Development of these recommendations was one of the purposes of this investigation and they should be taken into consideration while designing new coupled $\mathrm{TH} / \mathrm{NK}$ models and choosing mapping strategy for a new transient analysis.

Keywords: Boiling Water Reactor, RELAP5, TRACE, PARCS, Coupled TH/NK analysis, Spatial Mapping, Turbine Trip, Feedwater Transient, Control Rod Drop, Reactor Stability, Hierarchical Clustering. 


\section{Acknowledgment}

I am truly and deeply indebted to so many people that there is no way to acknowledge them all or even any of them properly. First of all I will try to thank my supervisors, Truc-Nam Dinh, Tomasz Kozlowski, and Weimin Ma. Nam, thank you for opportunity to work with such incredible people, you are amazing and knowledgeable person who was always keeping me focused, very motivated and in "correct tracks". Tomasz, thank you for your support in my project, thank you for all your time you spent to help me; you are the only person who was there for me from the very beginning to the very end and it looks like the adventure is going to come to the end. I have also a huge debt of gratitude to Weimin, you have taken care of me when all the others were gone from NPS, thank you for protecting me and my project so that I was able to finish my work in peace and quiet and I do appreciate it. Thank to all of you for believing in me, endless encouragement and sharing your vast knowledge with me during all this years; I have really learned here a lot!

I need also to thank all the people who helped me in proof reading of this thesis and gave me so valuable feedback. Special thanks to Prof. Bal Raj Sehgal and Prof. Sevostian Bechta for devoting their valuable time for reading my thesis, I really appreciate this.

Tita, Sean, Francesco, Ivan, Sebastian and others, my workmates and roommates, many thanks to all of you for never-ending talks, which changed my work to a pleasant time. Francesco and Ivan, special thanks to both of you for helping me with Linux and calculation machines; I was born as a "Windows child", so without you this project would be even more challenging. Also thank you Kajsa for always being there for me; you and Tita never fed up with me, which helped me to stay motivated to the very end. 
I need to thank also Wiktor Frid and Wojciech Cholewa, my former professors, it was because of both of you I came here; you influenced my path in life to unfold in such a successful way for me. So thank you and sorry for delay, sometimes we need more time to realize some things.

Last but not least is my family, you are the one who have suffered the most from my chronic lack of time, in spite of all of this, you have been all for me, my biggest supporters and encouragers, and therefore I lovingly dedicate this thesis to you, love you!

I would like to thank NORTHNET RM2 and SSM for financial support of my project.

At the end I sincerely hope that everyone who knows that they have influenced me feels satisfaction that they have helped me and does not feel remorse that either I did not get it right or then ungratefully omitted them from explicit mention, to those in the latter category I offer my sincerest apologies.

"As long as men are free to ask what they must, free to say what they think, free to think. what they will, freedom can never be lost and science can never regress..." 


\section{List of Publications}

I. Peltonen J., Cadinu F., Kozlowski T., Dinh N., "RELAP5 and TRACE codes comparison and validation under steady-state and transient conditions on the basis of NUPEC data." NURETH-12 Conference, 2007.

II. Kozlowski T., Peltonen J., Dinh T-N., "Spatial Coupling for BWR Stability Analysis", Trans. Am. Nuc. Soc., Anaheim, California, U.S.A. 2008.

III. Peltonen J., Kozlowski T., Dinh T-N., "Spatial coupling for Design Basis Accidents", PHYSOR'08 International Conference on Reactor Physics, Interlaken, Switzerland 2008.

IV. Peltonen J., 2009, "Development of Effective Algorithm for Coupled Thermal-Hydraulics - Neutron-Kinetics Analysis of Reactivity Transient", Licentiate thesis, ISBN 978-91-7415-397-2, Royal Institute of Technology (KTH) Stockholm 2009.

V. Kozlowski T., Peltonen J. "Qualification of the RELAP5/PARCS Code for BWR Stability Events Prediction", Journal of Nuclear Technology, Vol. 174, No. 1, p. 51-63, April 2011.

VI. Peltonen J., Kozlowski T. "Development of Effective Algorithm for Coupled Thermal-Hydraulic-Neutron-Kinetics Analysis of Reactivity Transient", Journal of Nuclear Technology, Vol. 176, No. 2, p. 195-210, November 2011.

VII. Kozlowski T., Peltonen J. Gajev I., Phung V-A., Roshan S. "Predicting Actual Reactor Conditions - Why Time Domain Simulations is Necessary for BWR Stability", International Journal of Nuclear Energy Science and Technology (Special Issue on: "Nuclear Energy and Nuclear Applications"), in press. 
xiv

VIII. Kouhia V., et al, "Benchmark Exercise on SBLOCA of PWR PACTEL Facility", Journal - Annals of Nuclear Energy, in press.

IX. Peltonen J., Ma W., Kozlowski T., "Effective Spatial Mapping for Coupled Code Analysis of Thermal-Hydraulics/Neutron-Kinetics of Boiling Water Reactors", Journal - Annals of Nuclear Energy, sent for publication. 


\section{Contents}

ABSTRACT (Swedish) ............................................................................. III

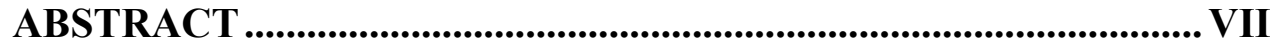

ACKNOWLEDGMENT........................................................................

LIST OF PUBLICATIONS.....................................................................XIII

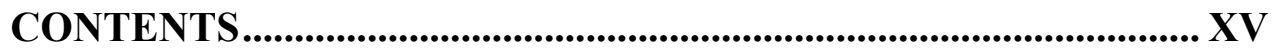

LIST OF FIGURES ............................................................................XIX

LIST OF TABLES ……........................................................................XXIII

LIST OF NOMENCLATURE ........................................................ XXV

CHAPTER 1: INTRODUCTION ............................................................ - 1 -

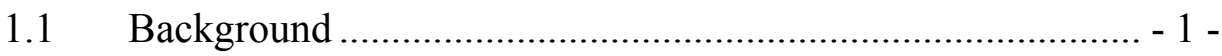

1.2 Objectives....................................................................... -2 -

1.3 Literature Review............................................................... - 3 -

1.4 Thesis Outline .......................................................................... - 9 -

\section{CHAPTER 2: COMPUTER PROGRAMS, REACTORS AND}

MODELS ........................................................................................ - 11 -

2.1 General BWR Information.................................................... - 11 -

2.2 RELAP5/PARCS Codes and Models ..................................... - 13 -

2.2.1 RELAP5 Code Description............................................................................. 13 -

2.2.2 RELAP5 Model Description ....................................................................... 13 -

2.2.3 RELAP5 Code Modifications ....................................................................... 18 -

2.2.4 Neutronics Code PARCS ............................................................................ 18 -

2.2.5 PARCS Model Description .................................................................. 19 -

2.2.6 PARCS Code Improvements ........................................................................ 19 -

2.2.7 RELAP5/PARCS Coupling Process ............................................................... - 20 -

2.3 TRACE/PARCS Codes and Models ...................................... - 22 -

2.4 Other Tools........................................................................... - 24 - 


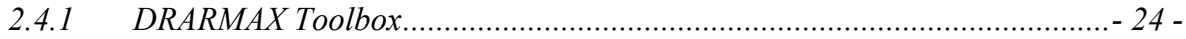

2.4.2 Matlab .................................................................................... 26 -

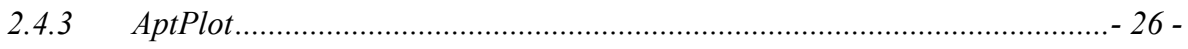

CHAPTER 3: MAPPING .................................................................- 27 -

3.1 Mapping Definition............................................................. 27 -

3.2 Types of Mapping …...................................................... 28 -

3.3 New Mapping Methodology .............................................. 32 -

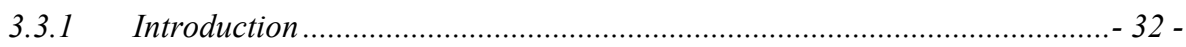

3.3.2 Clustering Method Selection.......................................................................... 33 -

3.3.3 Hierarchical Clustering Method .............................................................. 34 -

3.3.4 Input Data Pre-processing....................................................................... 38 -

3.3.5 Hierarchical Clustering Models ................................................................... 39 -

3.3.6 Hierarchical Clustering Evaluation ............................................................ 42 -

3.3.7 Hierarchical Clustering Approach and Results........................................... 42 -

3.3.8 Hierarchical Clustering Summary ................................................................ 49 -

3.4 Types of Mapping Used in the Code Input Models ................- 50 -

3.4.1 RELAP5/PARCS Models (BWR-1)............................................................. 50 -

3.4.2 TRACE/PARCS Model (BWR-2) ............................................................ 52 -

3.5 Inlet Orificing and Mapping …............................................. 55 -

CHAPTER 4: STEADY-STATE CALCULATION ........................... 59 -

4.1 RELAP5/PARCS Steady-State Results of BWR-1 .............. 59 -

4.1.1 BWR-1 Model I-Steady-State Results..................................................... 60 -

4.1.2 BWR-1 Model II - Steady-State Results ...................................................... 63 -

4.2 TRACE/PARCS Steady-State Results of BWR-2 ................ 66 -

4.3 Summary of Steady-State Results ........................................- 77 -

CHAPTER 5: TRANSIENT CALCULATIONS................................-81 -

5.1 RELAP5/PARCS Simulations of Transients ......................... 81 -

5.1.1 Control Rods Perturbation Transient (CRP) ............................................... 81 -

5.1.2 Control Rod Drop Accident (CRDA) ........................................................... 85 -

5.1.3 Turbine Trip Transient (TT) ................................................................. 88 -

5.1.4 Feedwater Transient (FT) ................................................................ 90 -

5.2 TRACE/PARCS Simulations of Transients............................ 97 -

5.2.1 Global Instability .................................................................................... 98 -

5.2.1 Regional Instability.......................................................................... 103 - 
CHAPTER 6: RECOMMENDATIONS.......................................... - 110 -

6.1 General Recommendations .............................................. - 110 -

6.2 Specific Recommendations for Steady-State Predictions .. - 111 -

6.3 Specific Recommendations for Transient Simulations ....... - 112 -

6.3.1 Local Perturbation …………………………................................. 112 -

6.3.2 Regional Perturbation ........................................................................... 112 -

6.3.3 Global Perturbation …………………………….................................. 113 -

6.3.4 Core Stability ................................................................................... 114 -

6.4 Mapping Convergence Recommendations ......................... - 115 -

CHAPTER 7: SUMMARY ................................................................ - 116 -

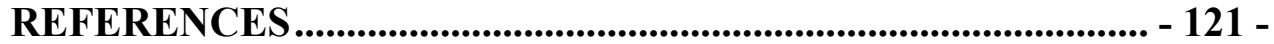

APPENDIX I................................................................................................. - 126 -

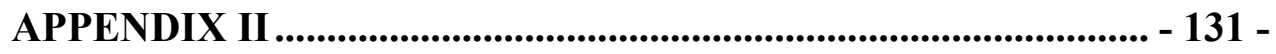

APPENDIX III ........................................................................ - 135 - 
xviii 


\section{List of Figures}

Figure 1: $\quad$ Loss of information due to incorrect mapping..................... - 2 -

Figure 2: Diagram of BWR plant.................................................. - 12 -

Figure 3: RELAP5 BWR-1 nodalization (Model I). ........................... - 15 -

Figure 4: RELAP5 BWR-1 nodalization (Model II)......................... - 16 -

Figure 5: RELAP5 BWR-1 steam lines nodalization (M I and II). ... - 17 -

Figure 6: Illustration of Control Rods location (BWR-1)................. - 19 -

Figure 7. RELAP5/PARCS temporal coupling. ................................ - 21 -

Figure 8: Coupled code calculation - General Interface ................... - 21 -

Figure 9: $\quad$ BWR-2 input (Ringhals-1) nodalization scheme. ............. - 23 -

Figure 10: DR definition................................................................ - 25 -

Figure 11: Mapping definition........................................................ 27 -

Figure 12: Inlet orificing and location mapping, 5 TH channels....... - 29 -

Figure 13: Exposure mapping, 5 TH channels. ................................. - 29 -

Figure 14: Power mapping, 5 TH channels....................................... - 30 -

Figure 15: Higher harmonic power mode mapping,

176 TH channels. .............................................................. - 30 -

Figure 16: Control Rod pattern mapping, 175 TH channels.............. - 31 -

Figure 17: Mixed mapping, 192 TH channels. ................................... - 31 -

Figure 18: Clustering illustration................................................... 32 -

Figure 19: Hierarchical clustering illustration. ................................ - 35 -

Figure 20: Dendrogram example................................................... - 35 -

Figure 21: The clustering results example .......................................... - 43 -

Figure 22: Example of grouping with the exposure input data and number of groups 5 and 50 (metric: city block, linkage: complete)....

Figure 23: Example of grouping with the power peaking factors input data and number of groups 5 and 20

(metric: Chebychev, linkage: weighted).

Figure 24: Example of grouping with the 1st power mode input data and number of groups 8 and 20

(metric: Chebychev, linkage: complete). .......................... - 49 -

Figure 25: The core zones used in Model II..................................... - 51 -

Figure 26: Distribution of inlet $k_{\text {loss }}$ for 700 TH channel model.......... - 55 - 
Figure 27: $k_{\text {loss }}$ numerical experiment models. ..................................- 57 -

Figure 28: Maximum radial power peaking factor (BWR-1 MI)........- 61 -

Figure 29: Maximum axial power peaking factor (BWR-1 M I)..........- 61 -

Figure 30: Average Fuel Centerline Temperature (BWR-1 M I).........- 62 -

Figure 31: Maximum radial power peaking factor (BWR-1 M II)....... 64 -

Figure 32: Maximum axial power peaking factor (BWR-1 M II)........- 65 -

Figure 33: Ringhals-1 Stability Benchmark,

power vs. flow history, c14.

Figure 34: Axial power profile vs. spatial convergence, point 1 of cycle 14. $-68-$

Figure 35: Comparison of axial power profile, point 1 of cycle 14.....- 70 -

Figure 36: Comparison of radial power distribution of

TRACE/PARCS BWR-2 full-scale with the reference, point 1 of cycle 14. $-70-$

Figure 37: Comparison of radial power distribution of

SIMULATE-3 with the reference, point 1 of cycle 14.....- 70 -

Figure 38: Comparison of radial power distribution of

SIMULATE-3 with the BWR-2 TRACE/PARCS,

point 1 of cycle 14.

Figure 39: Comparison of axial power profile, point 6 of cycle 14. ....- 71 -

Figure 40: Comparison of radial power distribution of

TRACE/PARCS BWR-2 full-scale with the reference,

point 6 of cycle 14.

Figure 41: Comparison of radial power distribution of

SIMULATE-3 with the reference, point 6 of cycle 14.

Figure 42: Comparison of radial power distribution of

SIMULATE-3 with the BWR-2 TRACE/PARCS full-scale,

point 6 of cycle 14. $-72-$

Figure 43: Comparison of axial power profile, point 9 of cycle 14.....- 73 -

Figure 44: Comparison of radial power distribution of BWR-2

TRACE/PARCS full scale with the reference,

point 9 of cycle 14

Figure 45: Comparison of radial power distribution of SIMULATE-3 with the reference, point 9 of cycle 14......- 73 -

Figure 46: Comparison of radial power distribution of

SIMULATE-3 with the BWR-2 TRACE/PARCS full-scale, point 9 of cycle 14 . 
Figure 47: Comparison of axial power profile; point 6 of cycle 14... - 75 Figure 48: Groups of Control Rods involved in the CRP transient.... - 82 Figure 49: Decay Ratio - CRP transient........................................... - 84 Figure 50: Frequency - CRP transient ............................................ - 84 -

Figure 51: Location of Control Rod drop......................................... - 85 -

Figure 52: Maximum power peak during CRDA............................. - 87 -

Figure 53: Maximum enthalpy rise during CRDA............................. - 87 -

Figure 54: Power fluctuation during TT transient. ............................. - 89 -

Figure 55: Maximum power peak during TT transient...................... - 90 -

Figure 56: Average power during FT - Scenario I. ........................... - 92 -

Figure 57: Radial power distribution during FT-Scenario I. ........... - 92 -

Figure 58: Average power during FT - Scenario II. .......................... - 93 -

Figure 59: Mass flow rate oscillations during FT - Scenario II. ........ - 94 -

Figure 60: Location of selected channels in the core ......................... - 95 -

Figure 61: DR deviation, point 6 of cycle 14.................................... - 99 -

Figure 62: FR deviation, point 6 of cycle 14..................................... - 99 -

Figure 63: DR deviation, point 1 of cycle 14................................... - 100 -

Figure 64: FR deviation, point 1 of cycle 14................................... - 101 -

Figure 65: DR deviation, point 9 of cycle 14.................................. - 102 -

Figure 66: FR deviation, point 9 of cycle 14.................................... - 102 -

Figure 67: Out-of-phase oscillations, point 9 of cycle 14................ - 105 -

Figure 68: Regional DR calculations, point 6 of cycle 14................ - 106 -

Figure 69: Regional DR calculations, point 9 of cycle 14................ - 107 -

Figure 70: Regional FR, point 6 of cycle 14.................................... - 107 -

Figure 71: Regional FR, point 9 of cycle 14.................................... - 108 -

Figure A2.1: Feature: power $1^{\text {st }}$ mode, point 1 of cycle 14............... - 132 -

Figure A2.2: Feature: exposure, cycle 14. ...................................... - 132 -

Figure A2.3: Feature: power peaking factor, point 1 of cycle 14. ... - 132 -

Figure A2.4: Feature: control rod groups, cycle 14........................ - 132 -

Figure A2.5: Feature: fuel kinds and geometry.............................. - 133 -

Figure A2.6: Feature: fuel kinds, cycle 14. ................................... - 133 -

Figure A2.7: Feature: core symmetry........................................... - 133 -

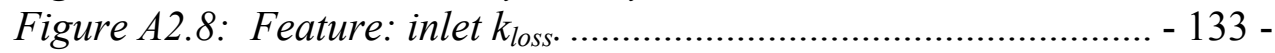

Figure A2.9: Feature: poles separation-special case of $1^{\text {st }}$

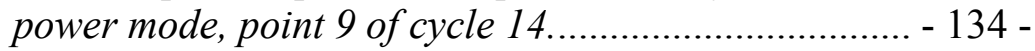

Figure A3.1: RMSE Axial Power, point 1 of cycle 14. ...................... - 135 -

Figure A3.2: RMSE Axial Power, point 6 of cycle 14. ..................... - 136 - 
XXii

Figure A3.3: $\quad$ RMSE Axial Power, point 9 of cycle 14.....................- 136 -

Figure A3.4: RMSE Radial Power, point 1 of cycle 14....................- 137 -

Figure A3.5: $\quad$ RMSE Radial Power, point 6 of cycle 14...................- 137 -

Figure A3.6: $\quad$ RMSE Radial Power, point 9 of cycle 14...................- 138 -

Figure A3.7: RMSE Nodal Power, point 1 of cycle 14....................- 138 -

Figure A3.8: RMSE Nodal Power, point 6 of cycle 14....................- 139 -

Figure A3.9: $\quad$ RMSE Nodal Power, point 9 of cycle 14..................... 139 -

Figure A3.10: Maximum radial peaking factor (Pxy), point 1 of cycle 14.......................................................- 140 -

Figure A3.11: Maximum radial peaking factor (Pxy), point 6 of cycle 14......................................................- 140 -

Figure A3.12: Maximum radial peaking factor (Pxy), point 9 of cycle 14........................................................- 141 -

Figure A3.13: Maximum axial peaking factor (Pz), point 1 of cycle 14.........................................................- 141 -

Figure A3.14: Maximum axial peaking factor $(\mathrm{Pz})$, point 6 of cycle 14....................................................... 142 -

Figure A3.15: Maximum axial peaking factor $(\mathrm{Pz})$, point 9 of cycle 14......................................................- 142 -

Figure A3.16: Maximum centerline fuel temperature, point 1 of cycle 14 ........................................................- 143 -

Figure A3.17: Maximum centerline fuel temperature, point 6 of cycle 14. $-143-$

Figure A3.18: Maximum centerline fuel temperature, point 9 of cycle 14. $-144-$

Figure A3.19: Average fuel Doppler temperature, point 1 of cycle 14. $-144-$

Figure A3.20: Average fuel Doppler temperature, point 6 of cycle 14. $-145-$

Figure A3.21: Average fuel Doppler temperature, point 9 of cycle 14. $-145-$

Figure A3.22: Average moderator density, point 1 of cycle 14..........- 146 Figure A3.23: Average moderator density, point 6 of cycle 14..........- 146 Figure A3.24: Average moderator density, point 9 of cycle 14..........- 147 -

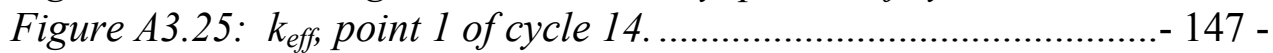

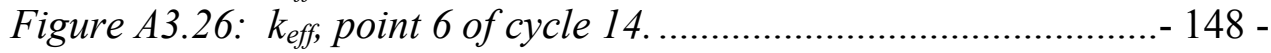

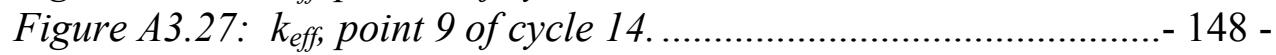




\section{List of Tables}

Table 1: Main technical data for BWR. .......................................... - 12 -

Table 2: Types of linkages................................................................. - 41 -

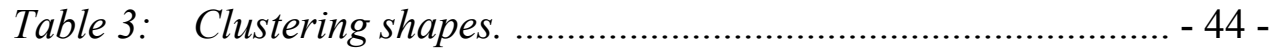

Table 4: $\quad$ Mapping schemes used in BWR-1 Model I. ....................... - 51 -

Table 5: $\quad$ Mapping schemes used in BWR-1 Model II........................ - 51 -

Table 6: Fuel bundle feature combinations..................................... - 53 -

Table 7: $\quad k_{\text {loss }}$ results from numerical experiment.............................. - 57 -

Table 8: Comparison of steady-state results (BWR-1 Model I)........ - 62 -

Table 9: Comparison of steady-state results (BWR-1 Model II). ..... - 65 -

Table 10: Steady-state RMSE of TRACE and SIMULATE-3

for the full scales models..................................................... - 69 -

Table 11: Steady-state spatial coupling convergence of TH and NK parameters. ................................................... - 78 -

Table 12: Control Rods movement during CRP transient ................... - 82 -

Table 13: Control Rod movement during CRDA............................... - 85 -

Table 14: Feedwater Transient results - Scenario II. ......................... - 96 -

Table 15: Ringhals-1 BOC cycle 14 Stability Test Results. ................ - 97 -

Table 16: In-phase oscillation results for full-scale models............... - 98 -

Table 17: Out-of-phase results for full-scale models........................ - 104 -

Table A1.1: Component number series in the RELAP5 input deck. .. - 126 -

Table A1.2: Component description and numbers in the RELAP5 input deck. ................................................................. - 127 -

Table A2.1: Fundamental and higher flux mode explanations. ......... - 131 - 
xxiv 


\section{List of Nomenclature}

\begin{tabular}{|c|c|}
\hline$A C F$ & autocorrelation function \\
\hline$A T W S$ & anticipated transient without SCRAM \\
\hline$B O C$ & beginning of the fuel cycle \\
\hline$B W R$ & boiling water reactor \\
\hline$B W R-1$ & adapted name for RELAP5/PARCS input model used in thesis \\
\hline$B W R-2$ & adapted name for TRACE/PARCS input model used in thesis \\
\hline$B W R-3000$ & type of $B W R$ reactor \\
\hline$C E A$ & French Atomic Energy Commission \\
\hline$C R$ & control rod \\
\hline$C R D A$ & control rod drop accident \\
\hline$C R P$ & control rods perturbation \\
\hline$D R$ & decay ratio \\
\hline$E O C$ & end of fuel cycle \\
\hline$F R$ & frequency \\
\hline$F T$ & feedwater transient \\
\hline$G I$ & general interface \\
\hline$H F P$ & hot full power \\
\hline$H Z P$ & hot zero power \\
\hline$I R F$ & impulse response function \\
\hline$k_{\text {eff }}$ & multiplication factor \\
\hline$k_{\text {loss }}$ & $\begin{array}{l}\text { fuel bundles inlet orificing factors applied in RELAP5, } \\
\text { corresponds to } k_{\text {factor }} \text { in TRACE }\end{array}$ \\
\hline KTH & Royal Institute of Technology (Kungliga Tekniska högskolan) \\
\hline$L O C A$ & loss-of-coolant-accident \\
\hline$L P R M$ & local power range monitor \\
\hline$L W R$ & light water reactor \\
\hline$M I, M I I$ & $\begin{array}{l}\text { adopted name for BWR-1 code input models of NPP used } \\
\text { in thesis }\end{array}$ \\
\hline$M S L B$ & main steam line break \\
\hline
\end{tabular}


xxvi

$N E A$

$N K$

$N P P$

$N P S$

$N R C$

OECD

PBMR

$P S U$

$P V M$

$P W R$

$P x y$

$P z$

REA

RIA

RMSE

SCRAM

SIMULATE-3

SNAP

$S S$

$S S M$

STD

TH

TMI-1

TT

U.S. NRC

WYSIWYG

VVER

$1 D$

$2 D$

$3 D$

$a$
Nuclear Energy Agency

neutronics, neutron-kinetics

nuclear power plant

division of Nuclear Power Safety, KTH

Nuclear Regulatory Commission

Organization for Economic Co-operation and Development

pebble bed modular reactor

Pennsylvania State University

parallel virtual machine

pressurized water reactor

maximum radial power peaking factor

maximum axial power peaking factor

rod ejection accident

reactivity insertion accident

root mean square error

emergency shutdown of a nuclear reactor

Studsvik's nodal code used for LWR reactor analysis

Symbolic Nuclear Analysis Package

steady-state

Swedish Radiation Safety Authority (Strål Säkerhets

myndigheten)

standard deviation

thermal-hydraulic

Three Mile Island NPP Unit 1

turbine trip

United States Nuclear Regulatory Commission is an acronym of "what you see is what you get" water-water energetic reactor

one dimensional

two dimensional

three dimensional

point in a metric space 


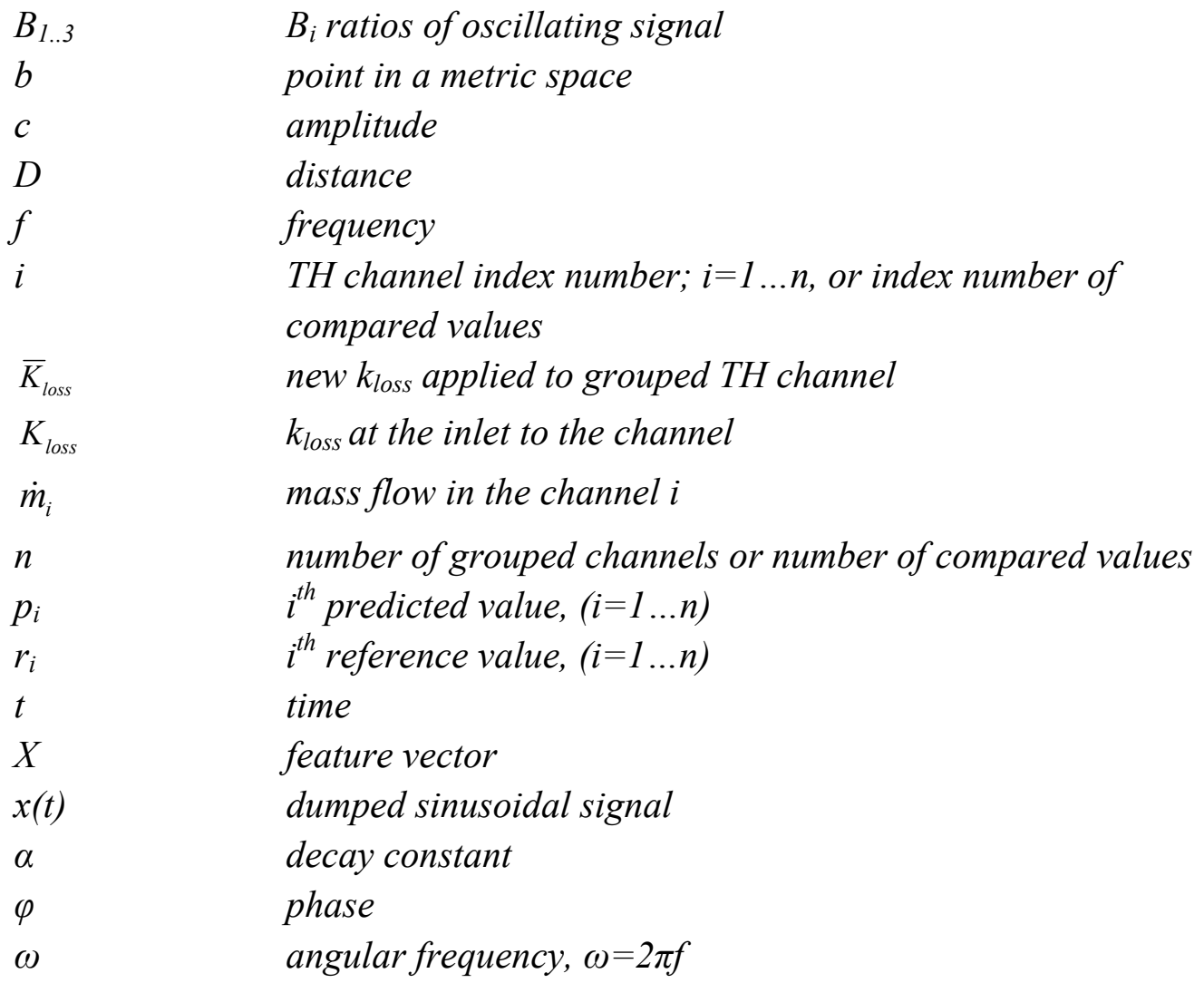


Xxviii 


\section{Chapter 1: Introduction}

\subsection{Background}

Current computational tools allow for coupling of full three dimensional core neutronic models with system transient thermal-hydraulic codes, which gives the advantage of understanding the interaction between reactor core reactivity behaviour and plant dynamics. The coupling of ThermalHydraulics/Neutron-Kinetics (TH/NK) provides new capabilities for understanding a Nuclear Power Plant (NPP) as a whole system including proper neutronic feedbacks. Among unresolved issues is the spatial mapping of the reactor core between $\mathrm{TH}$ and NK models. The $\mathrm{TH}$ code (e.g. RELAP5, TRACE) uses few, typically 5 to 20, TH channels to represent the core, while the NK code (e.g. PARCS) uses one explicit node for each fuel assembly. Therefore a mapping between TH and NK is necessary.

A BWR core has a large number of fuel assemblies (about 700 for a $\sim 1000$ MWe reactor). The one channel per fuel assembly coupling of TH with NK models for such a core requires significant computational resources; such calculation could take even one week of calculation time. Thus, there is a great interest in mapping optimization, to reduce the number of $\mathrm{TH}$ channels, while still maintaining desired accuracy.

The mapping can be defined as a spatial grouping of neutronic nodes with $\mathrm{TH}$ channels and if it is not a full-scale (one fuel bundle - to - one TH channel), it usually entails loss of important information in both directions $\mathrm{TH} \leftrightarrow \mathrm{NK}$, as described in Figure 1. The increase of number of the $\mathrm{TH}$ 
channels leads to loss of computational efficiency and in case of reactivity transients, these limitations can become significant.

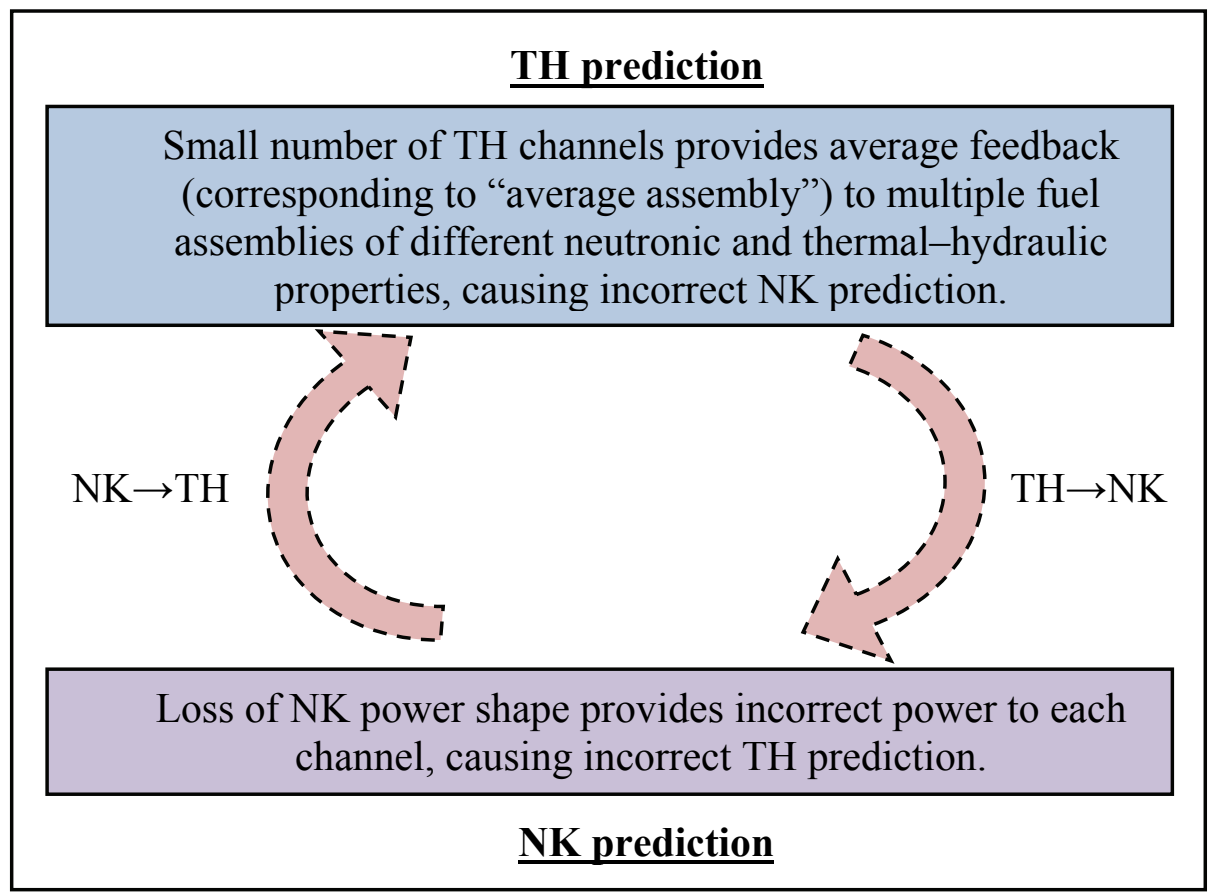

Figure 1: Loss of information due to incorrect mapping.

\subsection{Objectives}

This investigation concerns with the effectiveness and accuracy of coupled system codes for Thermal-Hydraulics/Neutron-Kinetics (TH/NK) analysis of boiling water reactors (BWRs). This research is limited to BWR reactors because these, in particular, need the coupling since the change in $\mathrm{TH}$ conditions affects the neutronics greatly in most transients. 
When developing a new input model, system codes users usually focus on time and space convergence of thermal-hydraulics while paying little attention to the influence of the spatial mapping between the thermalhydraulics and neutron-kinetics nodes. This is why the main objective of this research is to develop and validate an approach for spatial mapping between the coupled $\mathrm{TH} / \mathrm{NK}$ codes that enables higher confidence in results as well computational efficiency in predicting the transients and accidents of safety importance. The aim is to establish an effective treatment of core thermal-hydraulics with a small number of representative channels while using full 3D neutron-kinetics solution and provide guidelines for input developers who perform coupled TH/NK analyses.

Additionally, the study is performed to examine the tools, and to qualify the methods and the selected models of the coupled codes for analysis of BWR reactivity transients, including core stability. The evaluations of capabilities and limitations of the existing coupled $\mathrm{TH} / \mathrm{NK}$ analysis is also an opening for improvements of multi-dimensional TH/NK coupling recommendations for effective $\mathrm{TH} / \mathrm{NK}$ coupled treatment.

\subsection{Literature Review}

The problem of mapping has been discussed for many years by many researchers; however none of them has provided a sufficient algorithm or one recommended an approach for mapping. The relevant publications and important conclusions are summarized below.

i) "PWR REA sensitivity analysis using TRAC-PF1/NEM" N. Todorova and K. Ivanov, 2001.

The authors of the paper [1] performed sensitivity studies on spatial mesh overlays for PWR Rod Ejection Accident (REA). It was presented that 
REA simulation shows sensitivity to spatial coupling. Based on the results the authors concluded that $\mathrm{TH}$ feedback is non-linear and therefore cannot be separated in REA analysis.

ii) "Investigation of spatial coupling aspects for coupled code application in PWR safety analysis" - N. Todorova, K. Ivanov, 2002

The authors of the paper [2] performed research on the sensitivity of coupled TH/NK system code's results to the spatial mesh, which was used for PWR transient analysis. To analyze the effect of spatial nodalization authors developed three different models, two in cylindrical geometry (2 models) and Cartesian geometry (1 model), and compared the results for different conditions (BOC - beginning of cycle, EOC end of cycle for four conditions HZP - hot zero power and HFP - hot full power). It was pointed out that in the case of REA (TMI-1 REA Benchmark) simulations show sensitivity to the spatial coupling, especially in the radial plane. Authors demonstrated that in case of asymmetric transients, geometric refinement has large influence on local parameters and control rod worth - NK mesh refinement impacts the local predictions in the same way as the TH refinement impacts global predictions. Because the local and global predictions are also sensitive to the $\mathrm{TH}$ refinement, the proper radial, axial nodalization and mapping (spatial mesh overlays) schemes have to be developed for a given reactor and given transient.

iii) "Using the OECD/NRC PWR MSLB benchmark to study current numerical and computational issues of coupled calculations', $K$. Ivanov, N. Todorova, E. Sartori, 2003

In the following paper [3] authors performed comparative analysis of PWR Main Steam Line Break (MSLB) with a 3D core TH models. 
It was discovered that the source of local parameter deviation is geometry approximation of the core TH. Authors presented one example in which the reference data had a visible power peak at the position of the stuck control rod, but the results obtained from the coupled simulations (18-channel model) didn't show this power peak. Due to incorrect mapping the power peak was not found in obtained results. It was concluded that the power peak was averaged with surrounding assemblies.

iv) "OECD/NRC BWR Turbine Trip Transient Benchmark as a Basis for Comprehensive Qualification and Studying Best-Estimate Coupled Codes', K. Ivanov, A. Olson, E. Sartori, 2004

The article [4] focuses on OECD/NRC BWR coupled code benchmark. Authors mentioned that number of TH channels and spatial mapping is important modeling issue and it was found to be a reason for differences obtained from participant results.

v) Neutronics/Thermal-Hydraulics Coupling in LWR Technology:

State-of-the-art Report (REAC-SOAR), OECD, NEA; 2004, CRISSUE-S-WP2

In the report [5] authors pointed out that a number of different rules must be respected during mapping. It was recommended to group the channels in such a way that different neutronics and thermal-hydraulics information are conserved. The examples of possible groupings were introduced, such as: relative power, coolant flow, void distribution, type of bundle throttling (orificing), type of fuel (enrichment), etc. Authors recommended keeping core symmetry during mapping and concluded that the usual approach is to group fuel assemblies taking into consideration initial steady-state power level (this method is known as "power flattering" mapping). Authors found that incorrect mapping was 
a reason for smoothing of the power distribution and small number of channels causes overestimation of local parameters. In case of BWR stability analysis, especially in the case of regional instability, a different approach was proposed. Authors recommend taking into consideration the neutron flux fundamental and first azimuthal mode obtained from steady-state calculation. It was pointed out that the spatial coupling effect created by the void feedback is important in simulation of regional instability events - the first azimuthal flux mode is deformed. In the regional instability mapping the hot bundles location and higher mode power shape must be properly grouped. One can find information about the significant number of hot bundles - the hot bundles should be isolated as individuals regions and surrounded by regions that have a bigger flow area. The report provides many recommendations and tips that were taken into consideration during this investigation.

vi) "Assessment study of the coupled code RELAP5/PARCS against the Peach Bottom BWR turbine trip test”, A. Salah, G. Galassi, F. D'Auria, B. Kočar, 2005

The article [6] describes the studies of coupled code RELAP5/PARCS behaviour against the Peach Bottom BWR turbine trip test. The authors assumed that 77 heated channels are enough to represent the 764 fuel assemblies. The assemblies are grouped together according the relative power, coolant flow area, bundle type and inlet throttling.

vii) "Coupled $3 D$ neutronic and thermal-hydraulic codes applied to control rod ejection accident in PWR", M. de Carvalho Junior, Osvaldo, University of Pisa, 2005

The thesis [7] is devoted to $3 \mathrm{D}$ analysis of core behavior during a fast REA in a PWR. Author concludes that choosing mapping for a given transient is very difficult and a lot of requirements must be fulfilled. One 
requirement is to map similar neutronics assemblies into one TH channel, taking into consideration their design and other important characteristics such as coolant flow, void distribution, orificing, etc. During fast control rod ejection transient the author used 241 neutronics assemblies that are grouped into $19 \mathrm{TH}$ channels. The geometry grouping with separation of one channel (where control rod is ejected) was applied. The steady-state calculation showed good consistency between the simulated and reference power distribution, which proves that the applied mapping was well chosen.

viii) "Challenges in coupled thermal-hydraulics and neutronics simulations for LWR safety analysis", K. Ivanov, M. Avramova, 2007

The article [8] describes coupled phenomena and challenges on both global (assembly-wise) and local (pin-wise) levels. The authors divided spatial coupling methods into two categories: fixed and flexible. The fixed coupling represents one channel per fuel assembly coupling of $\mathrm{TH}$ and $\mathrm{NK}$ model while flexible coupling is defined by mapping schemes. Authors again pointed out that mapping is challenging task and detailed mapping gives better results in case of coupled calculations.

ix) "Validation of coupled thermal-hydraulic and neutronics codes in international co-operation", K. Ivanov, E. Sartori, E. Royer, S. Langenbuch, K. Velkov, 2007

The paper [9] focuses on OECD/NRC PWR MSLB (Main Steam Line Break) benchmark, which is based on real plant design and operational data for the TMI-1 NPP. The problem of the MSLB Benchmark was also mentioned in the paper [3]. The most important purpose of this benchmark was to identify the capability of coupled system codes for analyzing complex behavior. During this benchmark some discrepancies in the obtained results were found (e.g. the core averaged radial 
distributions, local axial distributions, and maximum nodal Doppler temperature). The authors found that the reason for discrepancies was different spatial coupling schemes: from very detailed spatial mesh overlays (one neutronic node per thermal-hydraulic channel) to coarser mesh overlays (18-channel model). Deviations of up to $15 \%$ in radial power distribution were observed due to the different thermal-hydraulic and heat structure nodalization and spatial mapping of $\mathrm{TH}$ channels to NK assemblies.

In the same paper one can find information about the BWR TT (Turbine Trip) benchmark, which gave an opportunity to study the impact of different $\mathrm{TH}$ and $\mathrm{NK}$ models on code predictions and to identify key parameters for modeling of a TT transient. The results provided by participants allowed evaluations of key parameters and sensitivity studies (performed by CEA Saclay and PSU). The main objective of the sensitivity study was the number of $\mathrm{TH}$ channels and spatial mapping schemes. The sensitivity studies showed that a 33 channels mapping, which was used for TT benchmark was good enough to provide global core behaviour, but detailed information about the local power distribution needed higher number of channels. In addition, the 33 channels were not able to give sufficient accuracy for regional events such as out-of-phase oscillation. The BWR TT benchmark provided valuable information about consequences of insufficient number of $\mathrm{TH}$ channels and about the sensitivity studies. One should be very careful while performing coupled $\mathrm{TH} / \mathrm{NK}$ analysis, as the mapping algorithm and the number of $\mathrm{TH}$ channels have a large impact on the results. This is why sensitivity studies are always needed.

In summary, several researchers (K. Ivanov, N. Todorova, M. Avramova and others) raised a problem of mapping in their publications. They proposed different types of possible mapping strategies and pointed out the key parameters that should be taken into consideration during mapping. 
The improper mapping is found as a reason for many discrepancies between the simulation and reference cases. Despite of many needs, a good and universal mapping approach has not yet been developed.

It is also concluded that the type of a transient determines the mapping scheme. However it is not clear what kind of mapping approach one should apply for different transients.

The low number of publication shows that the area of coupling $\mathrm{TH} / \mathrm{NK}$ codes is still not fully explored - this is why this investigation is devoted to mapping issues. All the mentioned experience and suggestions in the literature are taken into account in this thesis.

\subsection{Thesis Outline}

This thesis consists of the following tasks:

- Identification and review of the spatial coupling approaches for Thermal-Hydraulic/Neutron-Kinetics used by the other researchers.

- Identification of the coupling approach used in RELAP5/PARCS and TRACE/PARCS, with particular focus on effectiveness and accuracy of methods used to group the core fuel assemblies for thermalhydraulic treatment in a full-core 3D NK model in both steady-state and selected transients.

- Application of $\mathrm{TH} / \mathrm{NK}$ code to the reactor transient scenarios of safety significance.

- Review the NK and TH simulations in terms of loss of the significant information due to coupling TH/NK channels.

- Development of requirements and recommendations and new mapping approach for coupled calculations for a set of selected transients. 
The spatial mapping convergence study was performed with the utilization of two different TH codes: RELAP5 and TRACE; both were coupled to the NK code PARCS to get full 3D power prediction. The first part of this thesis is based on RELAP5/PARCS transient calculations where mapping is performed in a "manual way" (by hand). The second part is focused on the development of a new "automatized" mapping methodology, which was then applied to simulate the transients in OECD/NEA Ringhals-1 Stability Benchmark using the coupled TRACE/PARCS code. The insights obtained in the research, together with the proposed new mapping methodology, have resulted in the recommendations concerning choice of mapping scheme that should be used as a guideline for the future TH/NK code users.

The thesis consists of six chapters; in the Chapter 2 the adopted $\mathrm{TH}$ and NK codes, their models and other programs are presented and described. Additionally, the coupling process between $\mathrm{TH}$ and $\mathrm{NK}$ is explained. Mapping definition, types of mapping and a new "automatized" mapping approach are described in Chapter 3. In addition, a problem of proper core inlet orificing for different spatial refinement is explained and an adopted solution is presented. Chapter 4 and Chapter 5 are devoted for presentation of steady-state and transient results, respectively. Selected transient scenarios are described as well. Chapter 6 collects the set of the requirements and recommendations that should be taken into consideration while designing or improving the input model for a new transient code analysis with coupled TH/NK. Finally, the Summary and conclusions in the Chapter 7 concludes the performed research. 


\section{Chapter 2: Computer Programs, Reactors and Models}

This investigation deals with two boiling water reactors (BWR-1 and BWR-2 that represents Ringhals-1 model) and two different ThermalHydraulic (TH) codes, namely RELAP5 and TRACE that were coupled with the Neutron Kinetics (NK) code PARCS. The RELAP5 is a wellknown code but with no plan of further development by U.S. NRC, while TRACE is a new generation code and conceived as future replacement of RELAP5. Since the TRACE code is still under development, some of the capabilities are not yet implemented or tested, and for the time being, it is being verified by comparisons with the RELAP5 or other more verified and validated codes, and validated against experiment. The codes, models and additional tools employed in this thesis are described in this chapter.

\subsection{General BWR Information}

The two reactor models adapted to this work represent two boiling water reactors; the first model, referred to as BWR-1 is a typical BWR-3000 design [10] (Generation 4), while BWR-2 model represents Ringhals-1 [11] plant, which belongs to the early Generation 2 of BWR designs (Generation 1 in Swedish generation nomenclature). The schematic of BWR main components is presented in the Figure 2. The main technical data of both BWR plants are shown in Table 1. 


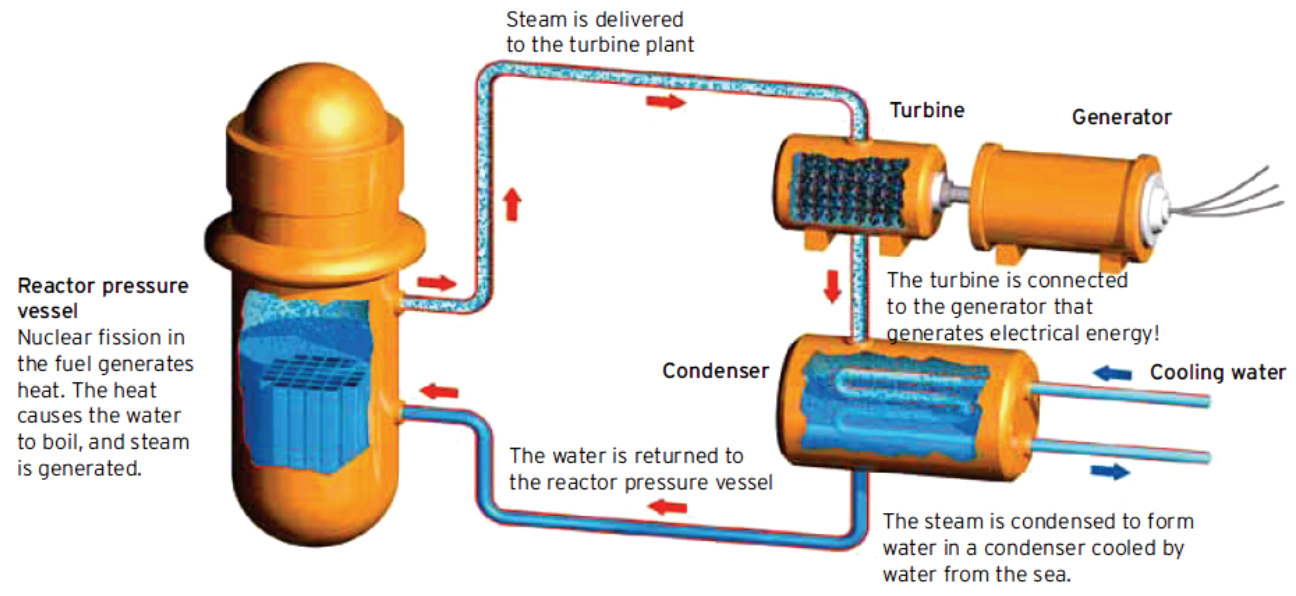

Figure 2: Diagram of BWR plant, the figure comes from [11].

Table 1: Main technical data for BWR.

\begin{tabular}{|l|c|c|}
\hline \multicolumn{1}{|c|}{ PARAMETER } & $\begin{array}{c}\text { BWR-3000 } \\
\text { (BWR-1) }\end{array}$ & $\begin{array}{c}\text { Ringhals-1 } \\
\text { (BWR-2) }\end{array}$ \\
\hline Thermal Power $[\mathbf{M W}$ th] & 3000 & 2540 \\
\hline Steam flow rate $[\mathrm{kg} / \mathbf{s}]$ & 1620 & 1228 \\
\hline Coolant flow rate $[\mathrm{kg} / \mathbf{s}]$ & 11400 & 11500 \\
\hline Operating Pressure $[\mathrm{MPa}]$ & 7.0 & 7.0 \\
\hline Feedwater temperature [ $\left.{ }^{\mathbf{0}} \mathbf{C}\right]$ & 215 & 173 \\
\hline Number of fuel assemblies & 700 & 648 \\
\hline Number of control rods & 169 & 157 \\
\hline $\begin{array}{l}\text { Number of recirculation pumps } \\
\text { (main recirculation system) }\end{array}$ & 8 (internal) & 6 (external) \\
\hline
\end{tabular}

\footnotetext{
${ }^{1}$ The source of technical data is [10].

${ }^{2}$ The source of technical data is [11].
} 


\subsection{RELAP5/PARCS Codes and Models}

\subsubsection{RELAP5 Code Description}

RELAP5, which is the part of U.S. NRC safety analysis code package, is transient thermal-hydraulic analysis code for light water reactors LWR; it is used for rulemaking licensing audit calculations and evaluation of operator guidelines [12].

In addition to calculating the behaviour of a reactor coolant system during a transient, RELAP5 can as a highly general purpose code, be used for simulation of a wide variety of hydraulic and thermal transients in both nuclear and nonnuclear systems involving mixtures of steam, water, noncondensable, and solute. More detailed information can be found in RELAP5 manual [12].

RELAP5 was chosen in the present investigation because it is extensively used by the nuclear power industry for reactor transient investigations and by regulatory bodies (e.g. Swedish Radiation Safety Authority) for independent safety analysis of light water reactors. Thanks to many years of usage and experience, the code has gained trust in capability and fidelity of transient simulations.

\subsubsection{RELAP5 Model Description}

The RELAP5 models (BWR-1 input) employed here are detailed representations of a typical Boiling Water Reactor (BWR). Two BWR-1 models have been developed and applied: Model I and Model II. In both models the number of TH channels varies from 5 to 700 . The model with $700 \mathrm{TH}$ channels corresponds to the Reference Case - one channel per one 
fuel assembly coupling. Because of transient complexity additional refinements were done in Model II: feedwater system, downcomer, recirculation loop and core were divided into four zones. This is needed for transient scenarios with strongly asymmetric conditions, e.g., feedwater transient.

Both BWR-1 models use a fine refinement of the fuel bundle channels and heat structure, with each channel divided into 27 volumes - 25 equidistant axial volumes with node size of $0.1484 \mathrm{~m}$ and 2 unheated nodes representing axial reflector. The fine nodalization is needed to get correct feedback from neutronic code PARCS (nodalization used in PARCS is consistent with $\mathrm{TH}$ nodalization). Using the same axial nodalization in both codes may eliminate the error, which comes from incorrect coupling and scaling of NK fuel bundles to TH channels.

The BWR-1 Model I and II nodalization diagrams are presented in the Figure 3 and Figure 4, respectively; the Figure 5 presents the nodalization of the steam lines for both BWR-1 models. Taking into consideration the conclusions from the reference [13] it is assumed that feedwater mixing in lower plenum is limited (recirculation pumps are not perfect mixers). To model variations of the feedwater temperature at the inlet to the core, four different core zones were separated (small mixing was assumed).

Both BWR-1 models also include safety systems, e.g., auxiliary feedwater system, however during the transients they are usually assumed not to operate. Additional information about the input models can be found in Appendix I, which includes the tables with description of the $\mathrm{TH}$ component numbering scheme (Table A1.1) and description of the components used in both input models (Table A1.2). 


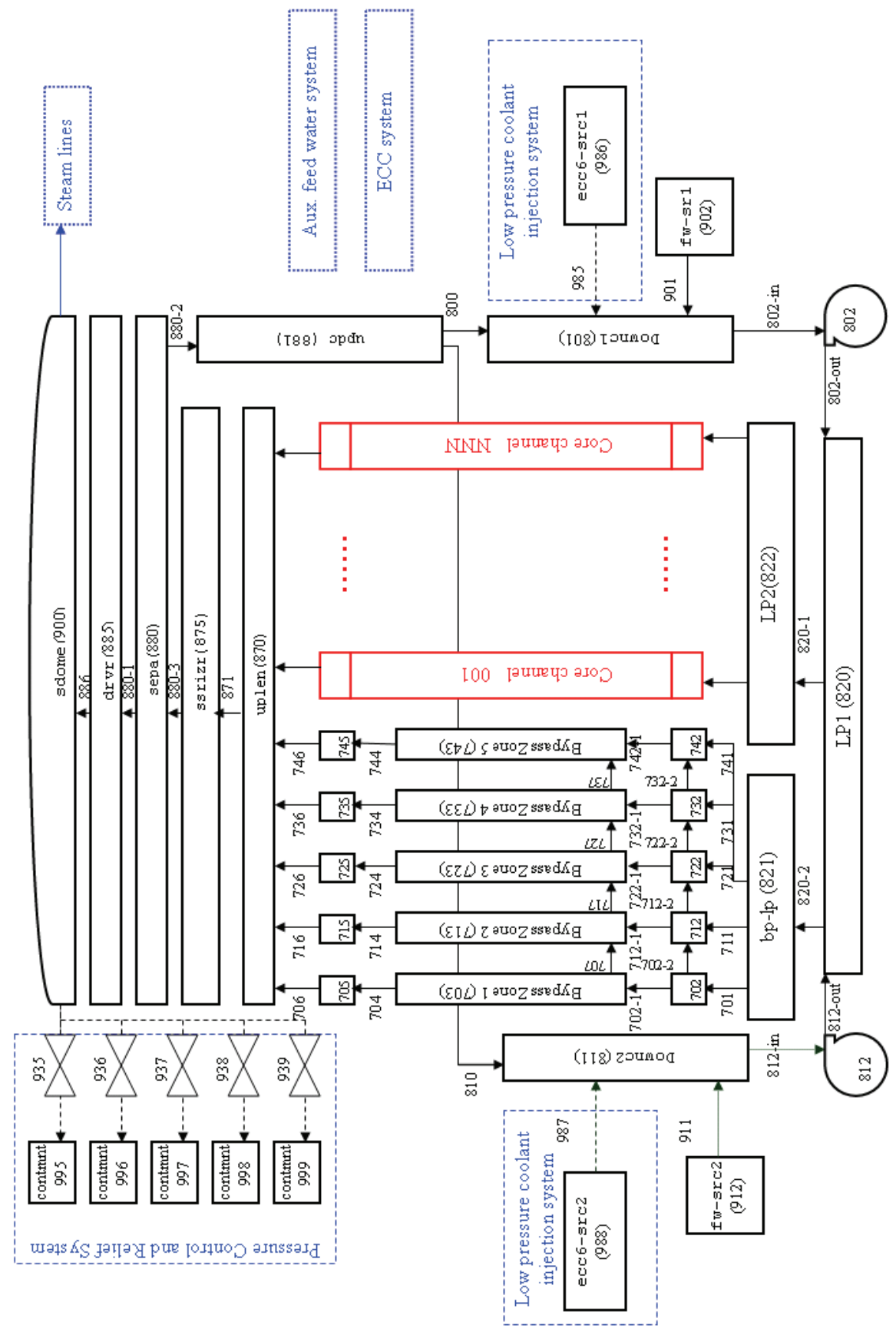

Figure 3: RELAP5 BWR-1 nodalization (Model I). 


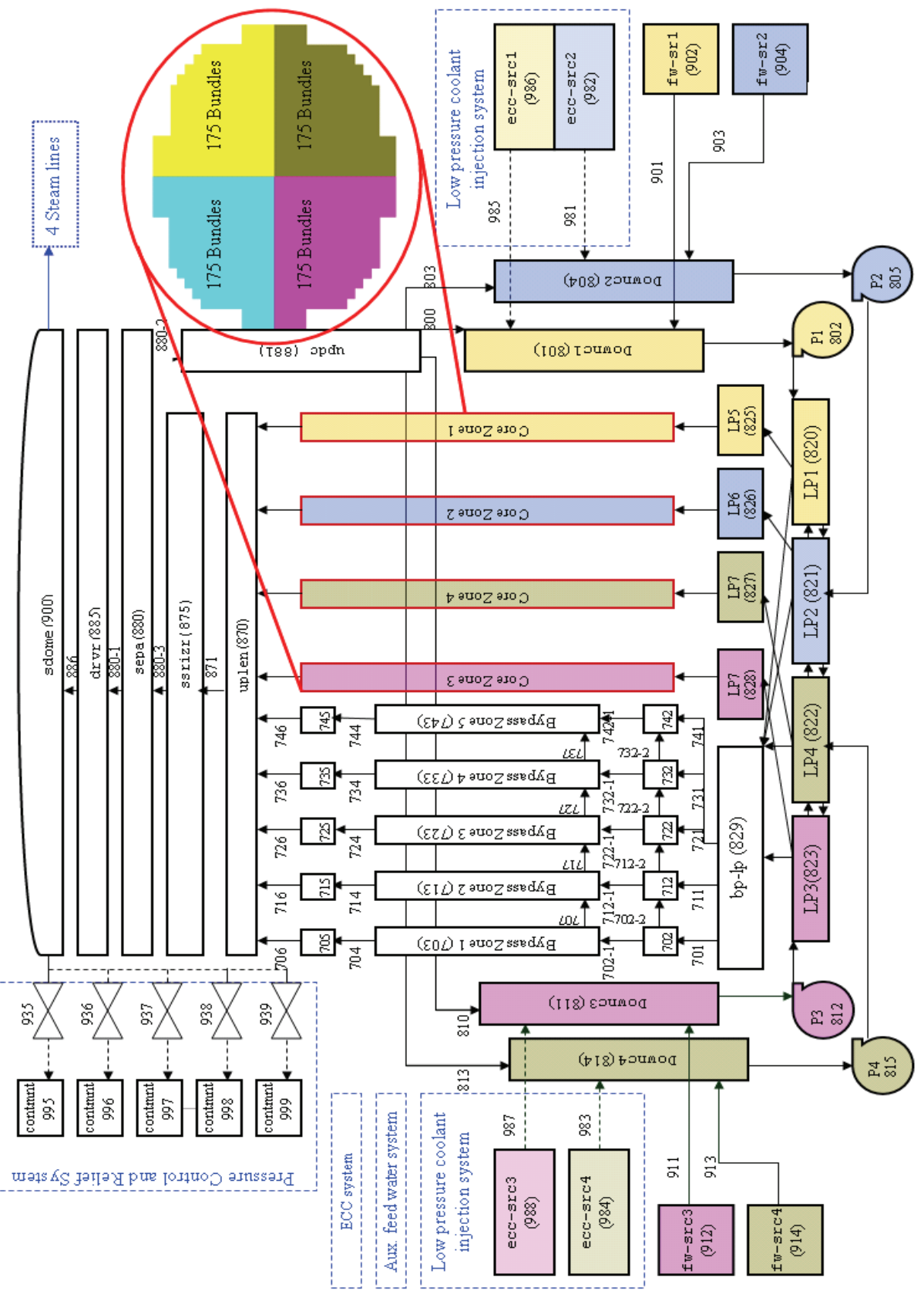

Figure 4: RELAP5 BWR-1 nodalization (Model II). 


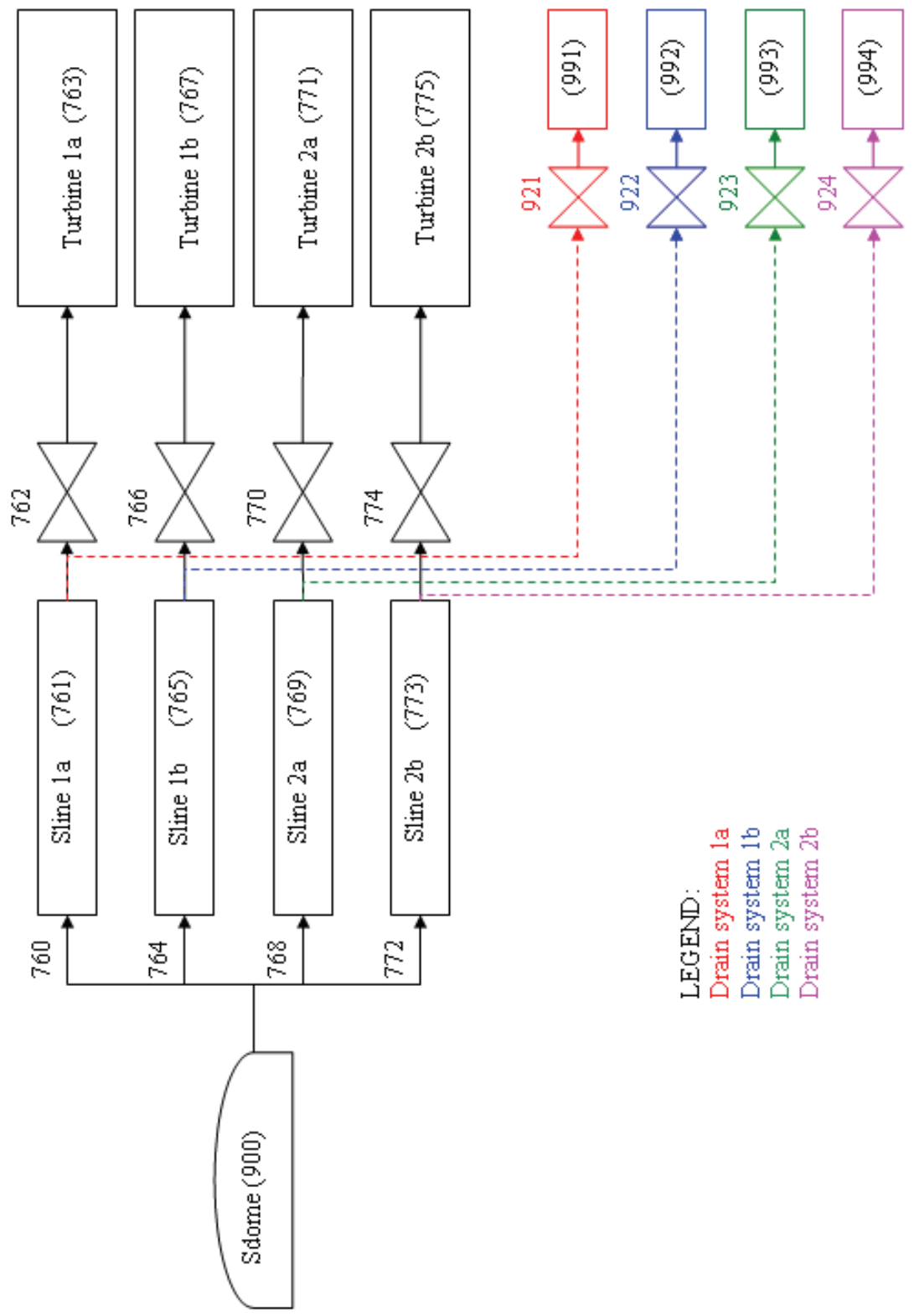

Figure 5: RELAP5 BWR-1 steam lines nodalization (Model I and II). 


\subsubsection{RELAP5 Code Modifications}

\subsubsection{RELAP5 memory increase}

Due to two inherent limits (the total number of words entered in input deck and insufficient memory space for all components) in the official release of RELAP5; a new version of RELAP5 had to be created. Therefore, for the purpose of this work with the help of RELAP5 developers [14], new RELAP5 executable with a larger capacity was created.

\subsubsection{RELAP5 inputs generation}

Due to the need for models with different number of channels a special MATLAB program was developed to generate required number of channels and related heat structures, which can be implemented in the RELAP5 inputs.

\subsubsection{Neutronics Code PARCS}

This study also involves the neutronics code - PARCS. PARCS [15] is a 3D core neutronics simulator developed by Purdue University for the U.S. NRC that solves steady-state and time-dependent multi-group neutron diffusion or SP3 transport equations for LWR, VVER and PBMR reactors. PARCS performs eigenvalue, transient, adjoint flux and depletion calculation. 


\subsubsection{PARCS Model Description}

The neutronics BWR-1 model includes 700 assemblies with a standard library of BWR neutron cross-sections. Depending on the chosen transient, two burnups points were used - beginning or middle of the cycle. All of the transients are performed for the reactor at full power $(109 \%)$. The neutronics axial nodalization is the same as the $\mathrm{TH}$ channel axial nodalization. The location of control rod groups is presented in the Figure 6.

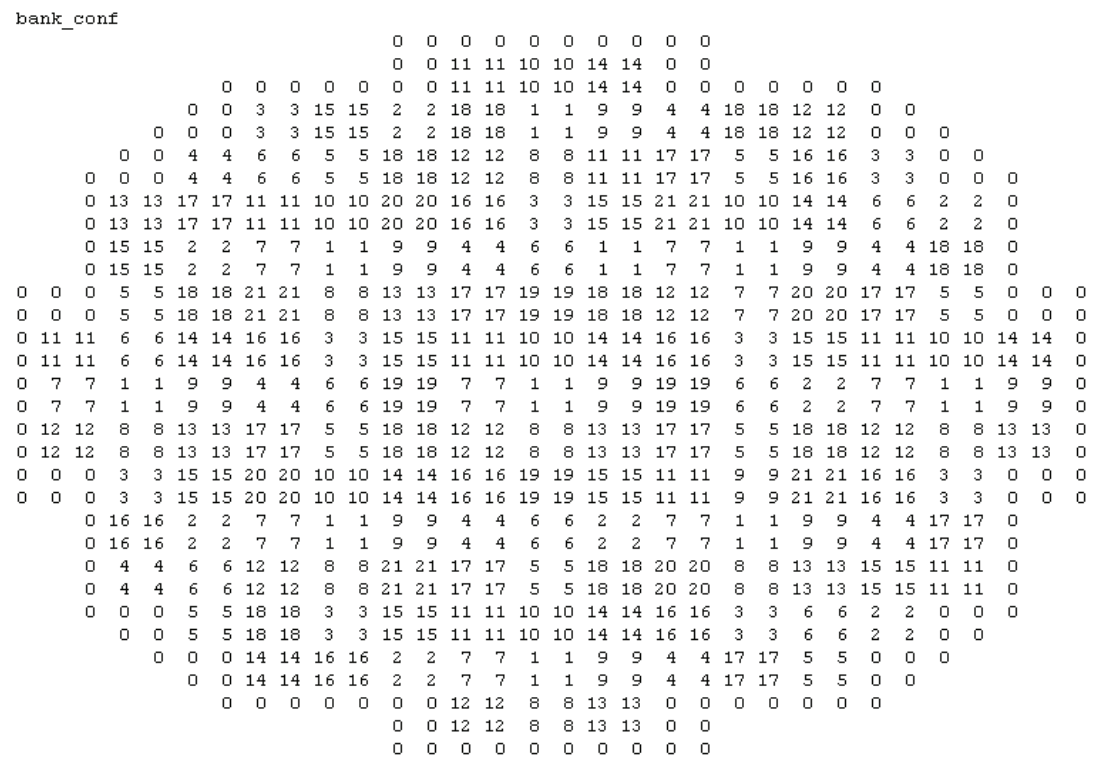

Figure 6: Illustration of Control Rods location (BWR-1).

\subsubsection{PARCS Code Improvements}

The original version of PARCS has default SCRAM option where all of the control rods are inserted. In order to simulate Control Rod Drop Accident, the PARCS source code was modified [16] so that it allows such 
a SCRAM where all the control rods are inserted with exception of the dropped one.

\subsubsection{RELAP5/PARCS Coupling Process}

The RELAP5/PARCS [17] code system simulates BWR with a 3D neutronics model coupled to the 1D RELAP5 thermal-hydraulics. The coupling makes use of an internal integration scheme - the system solution and core TH is obtained by RELAP5 and only spatial kinetic solution is obtained by PARCS. PARCS updates the cross-sections by using TH parameters predicted by RELAP5 and RELAP5 solves the heat conduction by using thermal power calculated by PARCS. The temporal coupling is explicit and is conditionally stable (Figure 7). In addition, there is a fixed order of time steps $\tau_{\text {hydro }}>\tau_{\text {heat }}>\tau_{\text {neut. }}$. The advancement of time step begins with RELAP5 obtaining the solution using the power from the previous time step. At best the complete $\mathrm{TH} / \mathrm{NK}$ system is $1^{\text {st }}$ order accurate. The passing of variables between the two codes is performed with the help of general interface (GI). The GI and PARCS are executed as separate processes that communicate to each other via the message-passing protocol in the Parallel Virtual Machine (PVM). The process of coupling is presented in the Figure 8.

The neutronics node structure is usually different from the $\mathrm{TH}$ node structure. The difference is reconciled by a spatial mapping scheme. The mapping of different $\mathrm{T} / \mathrm{H}$ nodes has to be specified for all the neutronic nodes in a file called MAPTAB.

To make the mapping process easier, a special Matlab program was created. Using mapping matrix as an input, the program generates the MAPTAB file, which includes all the necessary mapping information and is used by PARCS for communication between NK assemblies and TH channels. 


\section{RELAP5/PARCS Temporal Coupling}

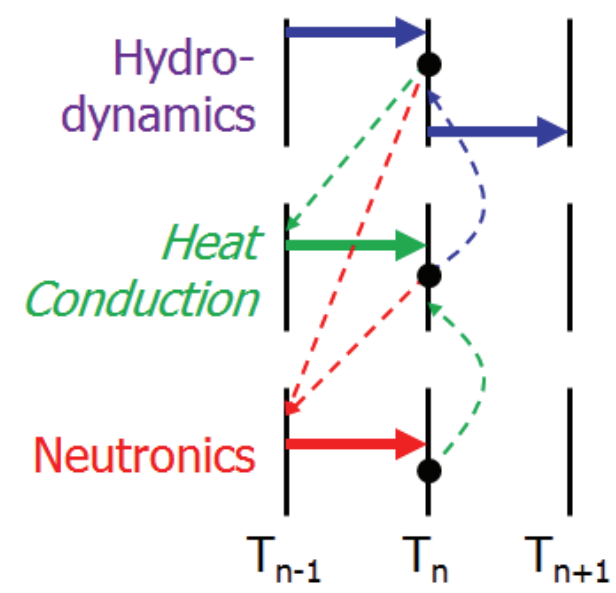

Figure 7. RELAP5/PARCS temporal coupling.

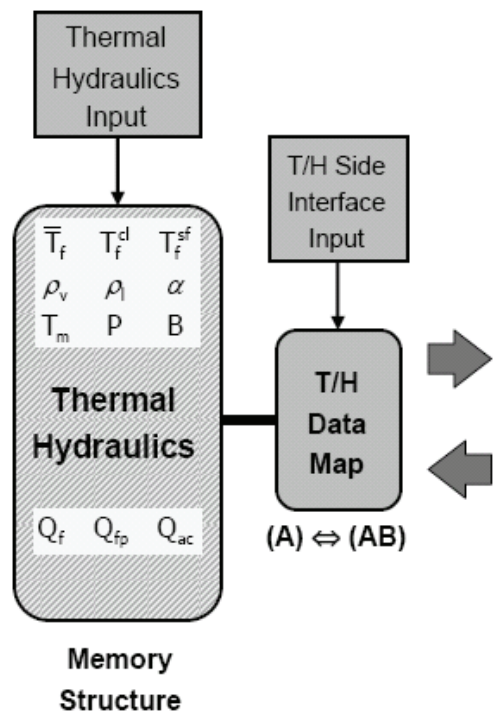

(A)
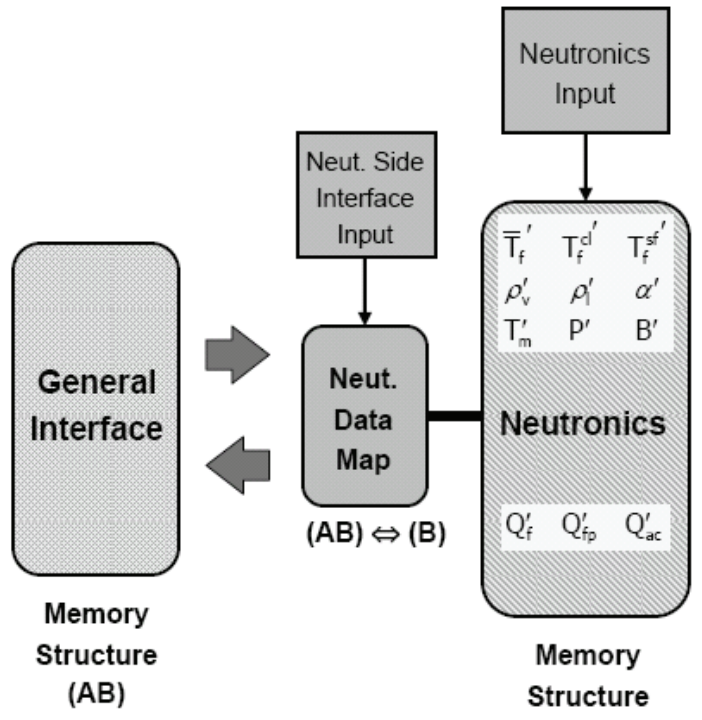

(B)

Figure 8: Coupled code calculation - General Interface. 


\subsection{TRACE/PARCS Codes and Models}

The coupled code TRACE/PARCS was used in the second part of this thesis for simulation of the Ringhals-1 stability scenario. The TRACE is conceived as a code for best-estimate analyses of loss-of-coolant accidents, operational transients and other accident scenarios. More details of the code can be found in the reference [18]. It should be noted that the TRACE code is under development and requires further improvements and validations of its capabilities as well as users' learning of best practices.

The PARCS [15] code has been described already in the previous section. What is important to mention here is that the TRACE/PARCS was integrated into one code, and coupling communication does not need the PVM (Parallel Virtual Machine) as is the case for RELAP5/PARCS coupling.

Similar to RELAP5/PARCS, the spatial mapping between the TRACE/PARCS is performed via the MAPTAB file; however the format of the file is different from that used by RELAP5/PARCS.

It should be mentioned that the original input of Ringhals-1 (BWR-2) TRACE/PARCS model was provided by Professor T. Downar and Dr. Yunlin Xu. The model consists of reactor pressure vessel, fuel bundles, steam separators, steam lines, recirculation loop, and a feed water pipe. The nodalization diagram is as shown in Figure 9. In addition to the thermal-hydraulic model, a neutronics feedback is given by the PARCS [15] code. The details about the model can be found in [19] and [20]. 


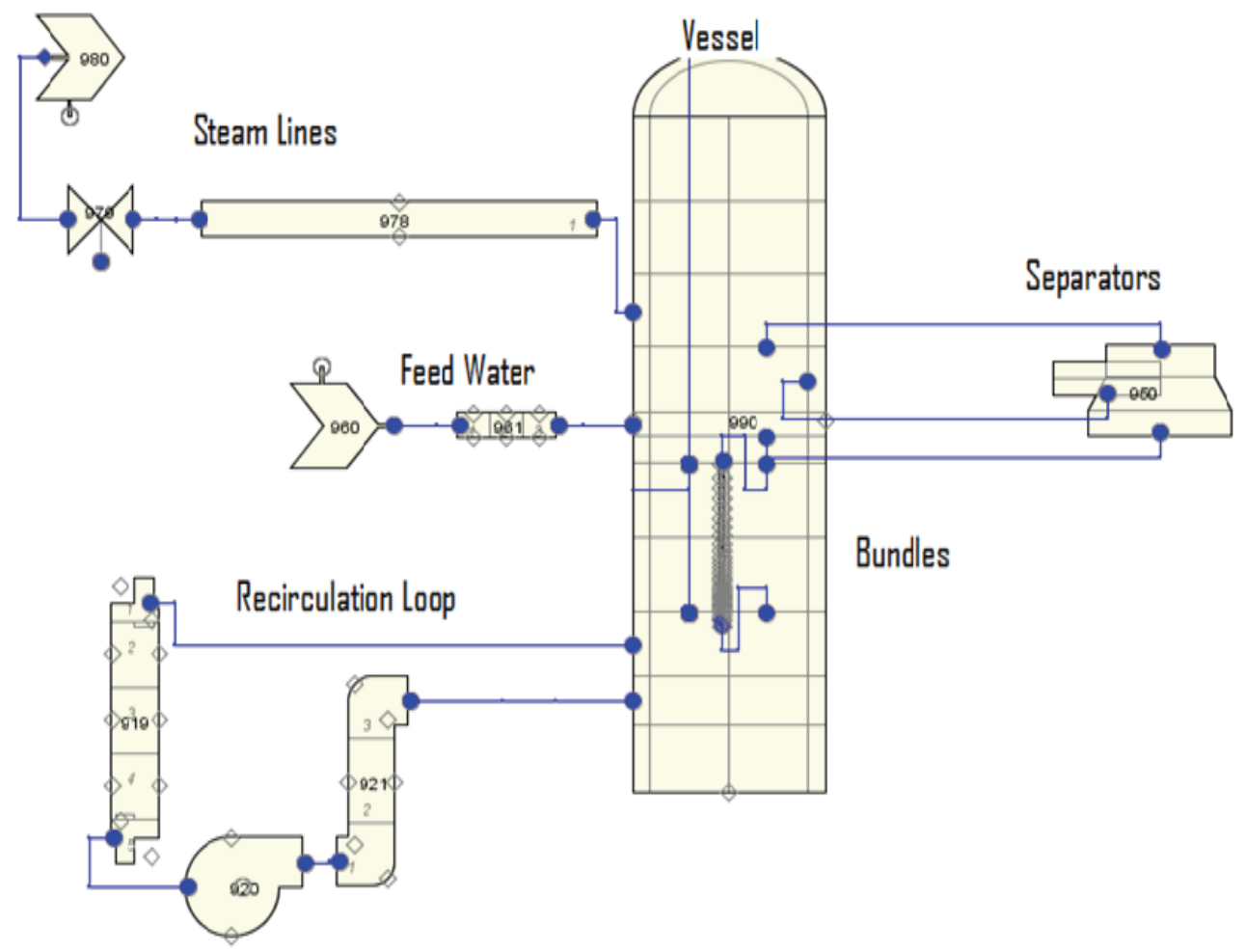

Figure 9: BWR-2 input (Ringhals-1) nodalization scheme.

The TH channels axial nodalization is consistent the neutronic model, similarly as the RELAP5/PARCS model described in the previous section. The main reason for this is to keep the same treatment as has been done in case of RELAP5/PARCS model.

In the associate studies [21] and [22] performed at $\mathrm{KTH}$, the space-time convergence of BWR-2 model has been performed and it has been shown that DR and FR prediction is very sensitive to the time step and nodalization. The author of [21] and [22] used half-symmetric model with $325 \mathrm{TH}$ channels which is enough for obtaining correct prediction for in-phase (global) oscillations. One of the problems pointed out by the author is very long simulation time of fully space-time converged model, which could be reduced by decreasing the number of TH channels and 
application of correct mapping scheme; this is one of the reasons why this case is being used for the mapping convergence study.

The new models with different number of $\mathrm{TH}$ channels and different mapping schemes have been generated with the help of Matlab.

\subsection{Other Tools}

\subsubsection{DRARMAX Toolbox}

The DRARMAX Toolbox [23] is used for evaluating the Decay Ratio (DR) and the Frequency (FR). The Decay Ratio is a measure of the stability of the system and it is calculated as a ratio of the amplitudes of two consecutive oscillations. A system whose response indicates a DR higher than unity is unstable because oscillations increase in amplitude. If DR is equal unity, system will oscillate with constant amplitude. The DR below unity indicates capability of the system for damping oscillations.

The Decay Ratio in DRARMAX Toolbox is calculated by using three approaches:

- Decay Ratio of the output signal (RAW); this method uses the DR definition as average of first two consecutive $B_{i}$ ratios - (1) and Figure 10, [23]. 


$$
D R_{P}=\frac{1}{2}\left(\frac{B_{2}}{B_{1}}+\frac{B_{3}}{B_{2}}\right)
$$

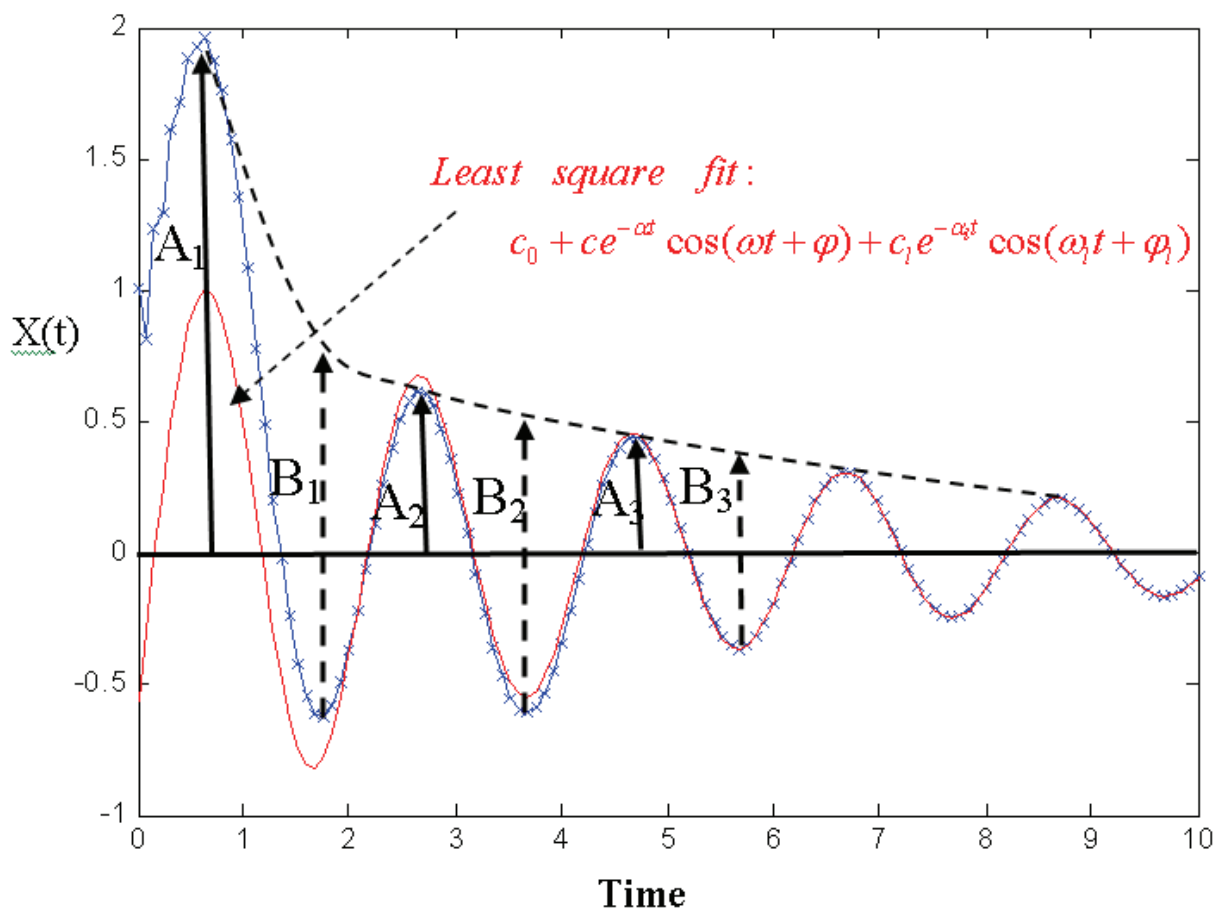

Figure 10: DR definitions (DRARMAX Toolbox Manual [23])

- Decay Ratio of the Autocorrelation Function (ACF); it evaluates the DR with the help of (2).

$$
D R=e^{-\frac{\alpha 2 \pi}{\omega}}
$$

where $\alpha$ (decay constant) and $\omega(\omega=2 \pi f$, the angular frequency) are obtained from least square fitting function of a damping sinusoidal form (3): 


$$
x(t)=c_{0}+c e^{-\alpha t} \cos (\omega t+\varphi)+c_{l} e^{-\alpha_{l} t} \cos \left(\omega_{l} t+\varphi_{l}\right)
$$

where:

c -amplitude,

$\varphi \quad-$ phase,

$t \quad$-time.

- Decay Ratio of the Impulse Response Function (IRF).

More details of the three approaches are described in detail in the Toolbox manual [23]. The Author points out that the first definition of DR is simplest, but may be not accurate. In this investigation Decay Ratio was evaluated by RAW and ACF method. Ideally both methods return the same result, which is often the case.

\subsubsection{Matlab}

Matlab [24], which is developed by MathWorks, is a numerical computing environment and a high-level programming language used for calculations and data processing and visualization. Matlab R2010a was used in this investigation for model pre-processing and results post-processing.

\subsubsection{AptPlot}

AptPlot [25] is a WYSIWYG 2D plotting tool, which allows for plots of numerical data and performing data analysis. It was used for visualization of the results from RELAP5 and TRACE calculations. 


\section{Chapter 3: Mapping}

\subsection{Mapping Definition}

The mapping can be defined as a spatial grouping of neutronic nodes with TH channels. Since in this thesis it is assumed that axial TH nodes are the same as the axial NK nodes, the mapping has a more narrow definition: spatial grouping only in radial direction, when more than one NK fuel assemblies are grouped into one TH channel. The process of mapping is illustrated in Figure 11 where two fuel bundles, B and D are grouped into one TH channel 202.

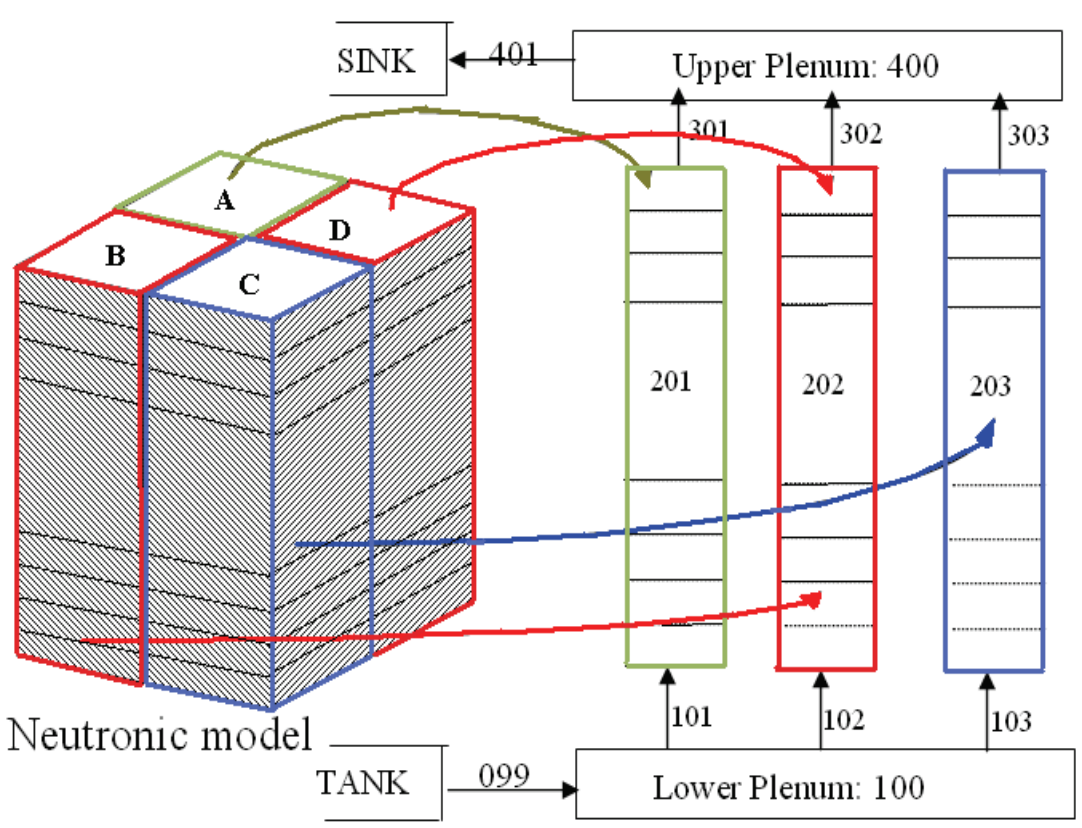

Figure 11: Mapping definition. 


\subsection{Types of Mapping}

It has been found that different researchers use very different types of mapping, starting from the most popular ones, like geometry mapping or exposure mapping through less often used ones, like control rod group mapping or neutron flux fundamental (zero mode) and first mode mapping. Sometimes researchers make an effort to use mixed type of mapping. Some types of mapping (e.g. power) need steady-state calculations before the groups can be created. The possible TH/NK mapping types, which were mentioned by the researchers, are:

- Geometry - the fuel bundles are grouped together according to their geometry and type.

- Location - neighboring assemblies are grouped together, Figure 12.

- Inlet orificing - assemblies with the same inlet orificing $\left(k_{l o s s}\right)$ are grouped together, Figure 12.

- Thermal-Hydraulics - a group of fuel bundles forms a channel that has similar thermal-hydraulic characteristics, e.g., void fraction.

- Exposure - fuel bundles grouping is based on burnup similarity, Figure 13.

- Power - fuel bundles are grouped according to power peaking factors - neutron flux fundamental mode, this type of mapping requires initial steady-state calculation, Figure 14.

- Higher flux mode - fuel bundles grouping is according to the first azimuthal and higher harmonic modes, this type of mapping requires initial steady-state eigenvalue calculation, Figure 15. A more detailed explanation can be found in Appendix II Table A2.1).

- Control Rod Pattern - the fuel bundles are grouped by taking into consideration control rods pattern (Figure 16). 
- Mixed - combination of several approaches, e.g., the combination of location mapping with exposure mapping (in this case, each radial zone is sub-divided according the exposure, Figure 17).

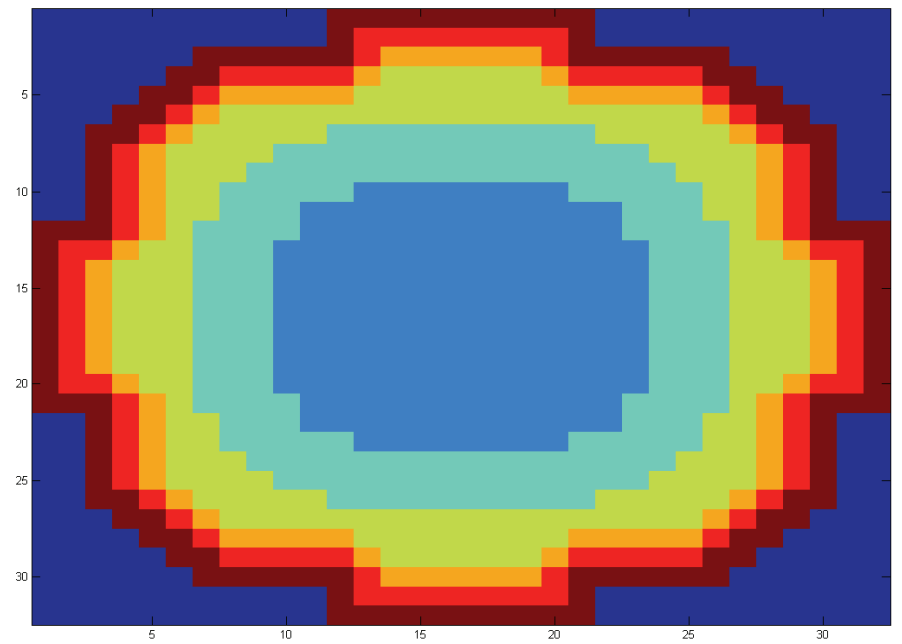

Figure 12: Inlet orificing and location mapping, 5 TH channels.

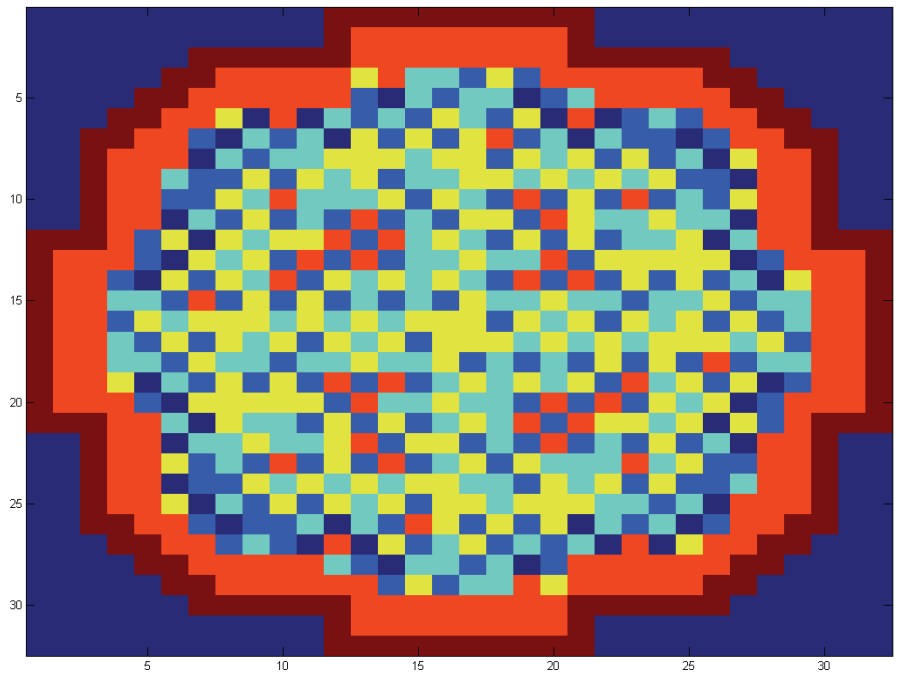

Figure 13: Exposure mapping, 5 TH channels. 


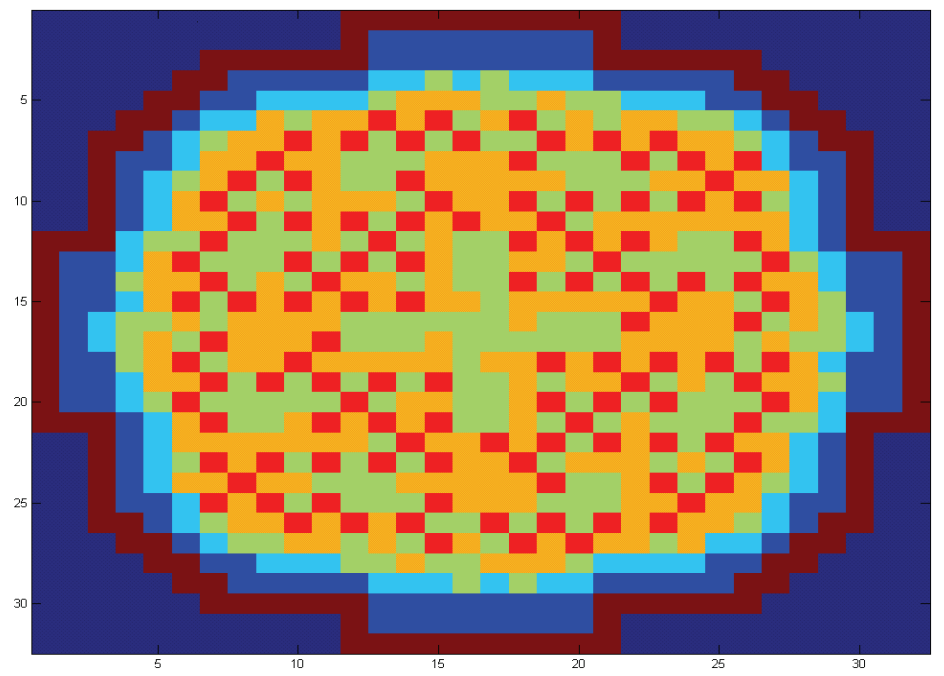

Figure 14: Power mapping, 5 TH channels.

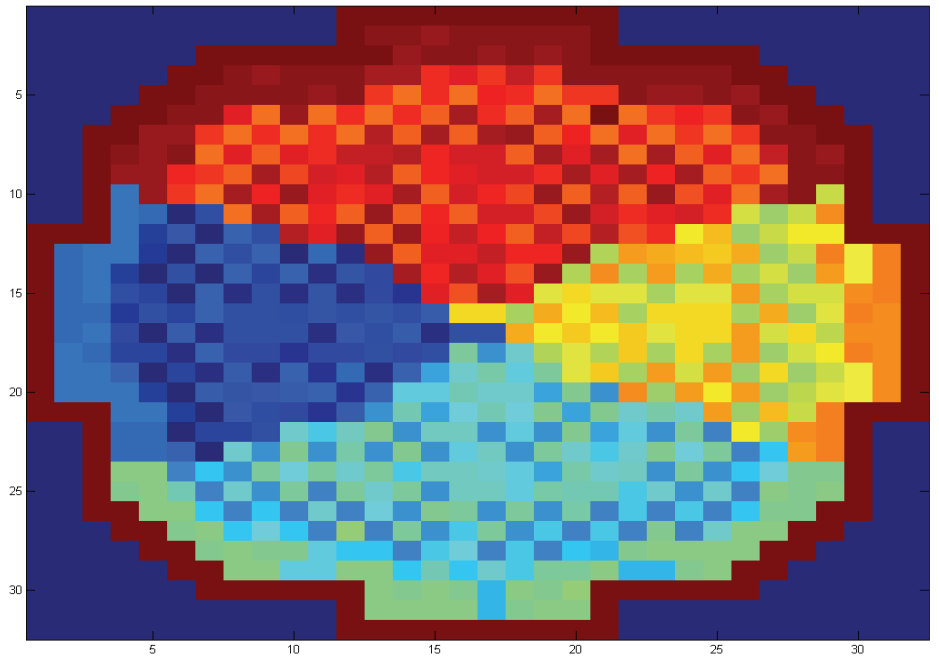

Figure 15: Higher harmonic power mode mapping, 176 TH channels. 


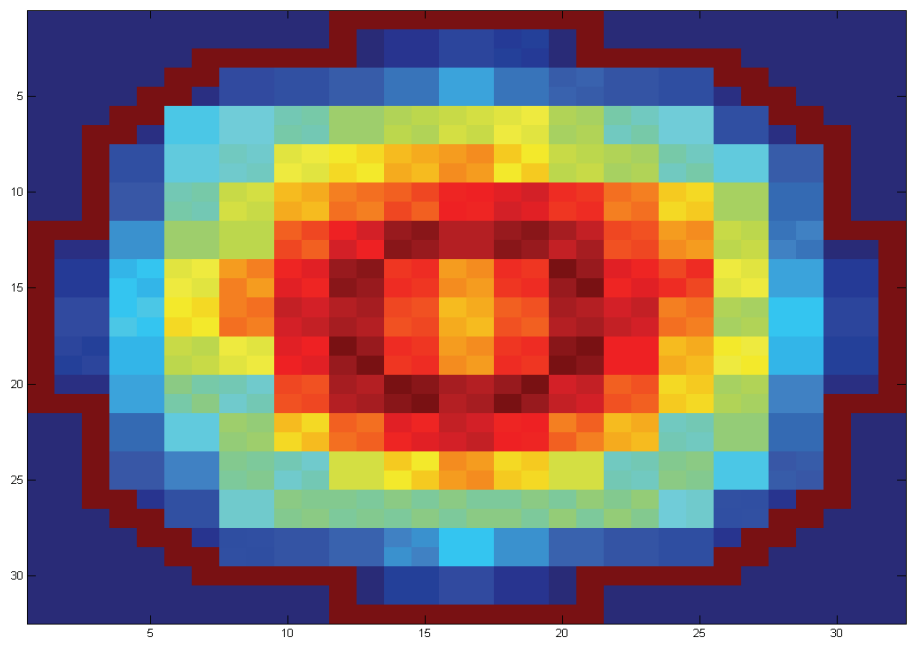

Figure 16: Control Rod pattern mapping, 175 TH channels.

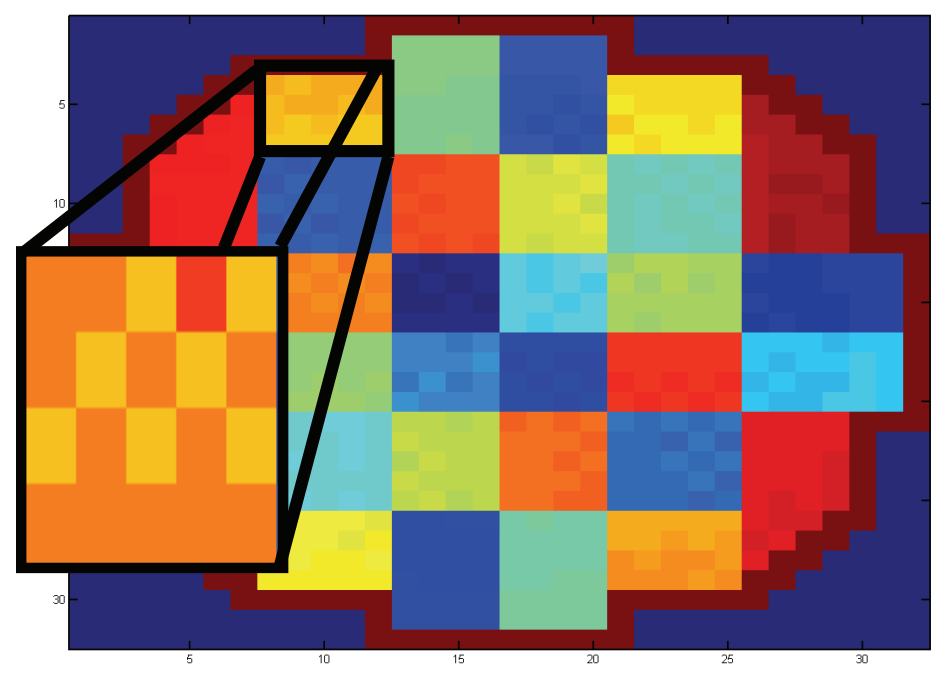

Figure 17: Mixed mapping, 192 TH channels. 


\subsection{New Mapping Methodology}

\subsubsection{Introduction}

To perform an effective spatial coupling, another approach can be used clustering, which is a well-known method of discovering patterns in data with unsupervised learning. The clustering is very useful in many scientific areas, e.g., pattern-analysis, decision-making, machine-learning and data mining. It is used in case of large data bases, where objects are described by more than one features [26][27][28].

The clustering can be defined as a process of assigning the objects into groups according some common features. Therefore, a cluster is a collection of objects that show similar features.

An example of clustering process is presented in the Figure 18 . The picture presents a group of objects which were grouped in to two clusters according their radius.

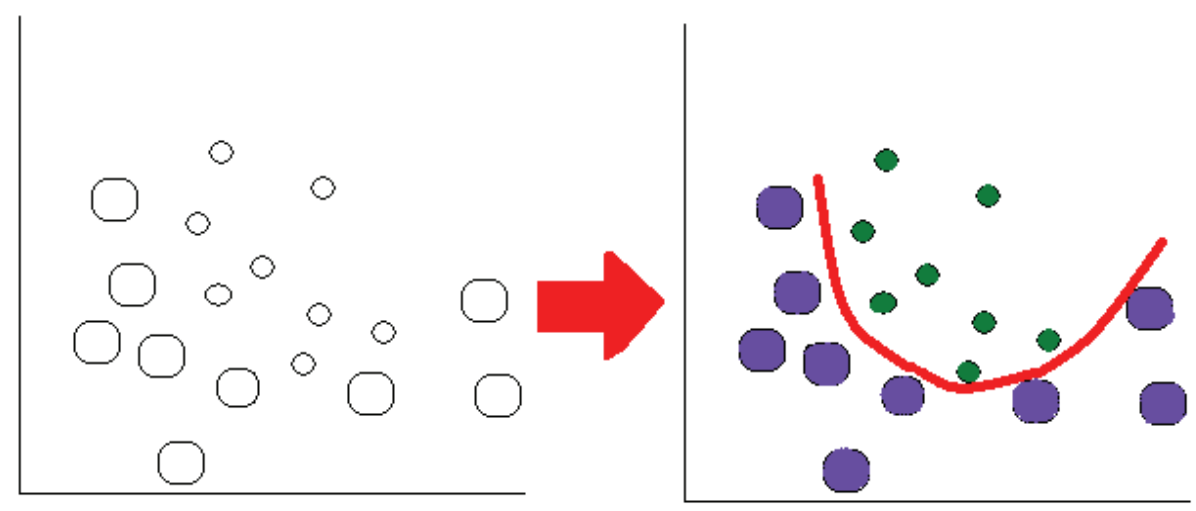

Figure 18: Clustering illustration. 
The main advantage of clustering approach is that one can take into consideration many features of fuel bundles (e.g. exposure, location, $k_{\text {loss }}$, etc.) at once, which is not possible for "manual" mapping. In addition once automatized, the new mapping approach significantly reduces the amount of time needed for preparation of a new input model.

\subsubsection{Clustering Method Selection}

There are four methods of clustering - hierarchical (e.g. agglomerative), partitional (e.g. k-means), density-based and grid-based methods.

The partitioning method requires user provided parameter $k$, which is the number of clusters, and performing iterative membership relocation until membership is no longer changed. The partitional clustering methods quality depends on the value of $k$ and generally it shows difficulty in finding arbitrarily shaped clusters [26][27][28][29].

The density-based algorithms consider clusters as dense objects in the data space and clusters are separated by regions of low density. Each object is associated with a density value. An object with high density (higher than some threshold) forms a cluster itself. Two clusters are merged together if they share a common neighborhood with similar density. Density-based methods are very effective in finding arbitrary shapes but they are computationally very expensive [26][27][28][29].

The grid-based clustering first covers the problem of space with uniform grid mesh. All the features are collected for objects that are located in each individual mesh cell, and clustering is performed on the grid rather than on the objects. The grid-based clustering is computationally very efficient [29]. 
The hierarchical approach is among the best known of unsupervised methods. It has many advantages such as intuitive simplicity, easy implementation and flexibility. The hierarchical method allows for using any similarity or dissimilarity measure and it does not require to define a preliminary number of classes. It is also very practical because input data can be in raw form without any special feature extraction applied to them. Another feature of hierarchical clustering is multi-level hierarchy, where clusters at one level are joined as clusters at the next higher level [26][27][28] that allows for testing the same feature against increasing number of TH channels. Given all advantages, this method was chosen as optimum for the automatic mapping procedure.

\subsubsection{Hierarchical Clustering Method}

Hierarchical clustering organizes elements into a tree; lowest level (leaves) represent fuel assemblies - see Figure 19, and the length of the path between the leaves represent the distances between assemblies. Similar assemblies, with small distances lie within the same sub-cluster on higher level.

The cluster tree, created by this algorithm, is called dendrogram (Figure 20) and it allows for investigation of grouping in a data set, simultaneously over a variety of scales. This allows us to decide what level, scale or complexity of the clustering is the best for particular application [30]. The Figure 20 presents the dendrogram which was created based on the input data that included three vector features: $X \& Y$ coordinates and $k_{\text {loss, }}$ it is visible that 5 major clusters are created (each cluster has different color). 


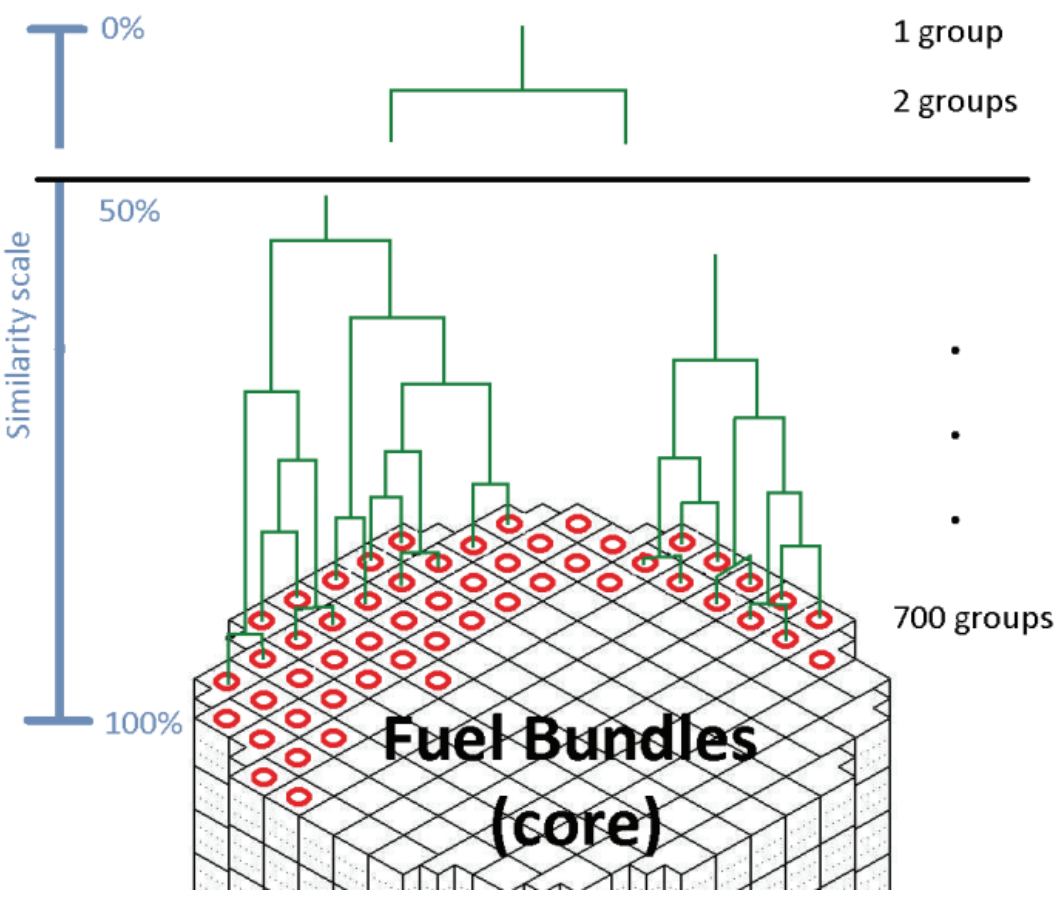

Figure 19: Hierarchical clustering illustration.

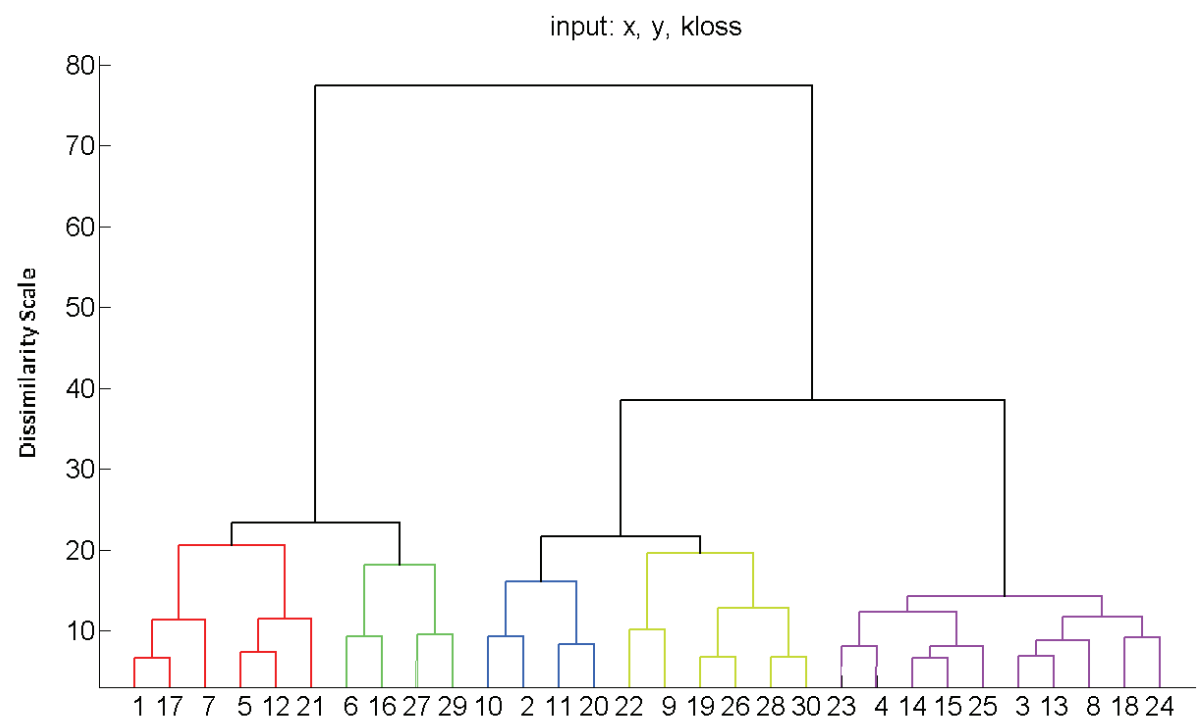

Figure 20: Dendrogram example. 
Unfortunately hierarchical clustering has also disadvantages, which cannot be ignored while using this method:

- Unrelated fuels are eventually joined.

- Hard to define clusters: where to cut the tree?

- Manual interpretation often required.

Input developers usually decide to keep low number of $\mathrm{TH}$ channels, e.g., 5, 20 to test the input convergence and tune all the needed parameters (e.g., space-time convergence) or preliminary transient simulation; the low number of $\mathrm{TH}$ channels allows for low computational time during such tests. Then, if needed, the number of $\mathrm{TH}$ channels should be slowly increased to study the simulation results convergence that will help us to decide how many channels is enough to simulate particular phenomena. If we are not certain about the required number of $\mathrm{TH}$ channels, hierarchical clustering methodology allows us to easily test a few possibilities by cutting the tree in different places e.g. 5, 20, 50, 100, etc. groups (channels), this way mapping convergence study can be fast and efficient.

In addition, it is important to point out that there exist two kinds of hierarchical clustering: agglomerative (bottom-up) and divisive (top-down). The agglomerative starts with n-singleton (e.g., 700 singletons for BWR-1, since there are 700 fuel bundles) clusters and forms the sequence by successively merging clusters; opposite to the agglomerative, the divisive starts with one cluster with all the samples in and forms the sequence by successively splitting clusters. Since the computation needed to run from one level to another is simpler for the agglomerative methods, only these are taken into consideration [26][27][28][30]. 
The agglomerative hierarchical clustering algorithm takes $n x n$ distance matrix $D$ of pair-wise distances between points as an input and [26][27][28][30]:

1) Form $n$ clusters each with one element.

1) Construct a graph $T$ by assigning one vertex ${ }^{3}$ to each cluster

1) While there is more than one cluster:

2) Find the two closest clusters $C 1$ and $C 2$ and merge them into new cluster $C$ with $|C 1|+|C 2|$ elements.

3) Compute distance from $C$ to all other clusters.

4) Add a new vertex $C$ to $T$ and connect to vertices $C 1$ and $C 2$.

5) Remove rows and columns of $\mathrm{d}$ corresponding to $\mathrm{Cl}$ and $\mathrm{C} 2$.

6) Add a row and column to $D$ corresponding to the new cluster $C$.

7) Return $T$.

There exist many different ways to define the distances (metrics) between clusters and different linkage functions (they create hierarchical cluster tree) that results in different hierarchical clustering models - as a consequence of this, different results can be obtained especially when the input data are "non-dividable" in unique way.

To narrow down the possible choices of clustering programs and methods in this thesis, only methods and functions which are implemented in Matlab Statistical Toolbox [24] are used. However, it is important to notice that there exist many different tools for clustering, including open source programs and libraries which can be used with different software.

\footnotetext{
${ }^{3}$ The expression vertex in graph theory means a node and it is a fundamental unit of which graphs are formed.
} 


\subsubsection{Input Data Pre-processing}

There are many options of the preprocessing input data $(X)$ and the choice depends on the data set. The following methods can be used [31]:

- Standardization - (with standard deviation of 1) subtract from each feature vector standard deviation and divide each variable by it.

- Center and Standardize - subtract from each vector its mean and divide by the standard deviation.

- Center and Scale - subtract from each feature vector its mean and divide centered vector by their root mean square.

- Log transformation

- Rank transformation

- No transformation,

In this thesis, three different methods were applied to investigate which approach is the best for mapping purpose:

- Method 1: raw data (no standardization).

- Method 2: standard deviation of one, (4).

$$
X(i)=\frac{X(i)}{\operatorname{std}(X)}
$$

- Method 3: center and scale (zero mean and standard deviation of one), (5).

$$
X(i)=X(i)-\frac{\operatorname{mean}(X)}{\operatorname{std}(X)}
$$

It is important to note that the choice of pre-processing method will influence the clustering results. Method 1 is recommended only if one supplies the input vector with only one feature. However, if there are more features or one would like to keep the core symmetry, it is recommend to 
use data pre-processing Method 3. Supply of more than two features at once, is not recommended. If there is a need for many features, additional feature extraction e.g. multidimensional scaling should be applied; such methods reduce dimensions of the input vector $\mathrm{X}$, while preserving all the feature information.

\subsubsection{Hierarchical Clustering Models}

\subsubsection{Distances}

There is a choice of many kinds of distances (metrics) which can be used for hierarchical clustering. The distances need to have following properties [26][27][28]:

- Non-negativity

$D(a, b) \geq 0$

- Reflexivity

$D(a, b)=0$ only if $a=b$

- Symmetry

$D(a, b)=D(b, a)$

- Triangle inequality

$D(a, b)+D(b, c) \geq D(a, c)$

At any level the distance between the nearest clusters gives the dissimilarity value for each level. Most of the metrics returns similar results if clusters are well separated. However, if the clusters are close to each other, large differences might be obtained, therefore there is a need to investigate which metric is the best for mapping purpose.

The following distances were tested [24][31]:

- Eulidean - also called Pythagorean metric; it is widely used, usually computed from the raw data (without any standardization).

- SEuclidean - Standardized Eulidean distance. Each coordinate between rows in matrix is additionally scaled. 
- City block (Manhattan) ${ }^{4}$ - this distance is an average difference across the dimensions. It examines the absolute differences between objects coordinates.

- Minkowski - it is a generalization of Euclidean and Manhattan distances.

- Chebychev ${ }^{4}$ - it is the maximum metric, which defines the objects as a different if they are different on any of the dimensions.

- Mahalonobis - it is based on correlations between variables; it is scaled invariant.

- $\operatorname{Cosine}^{4}$ - it measures the similarity between two vectors by calculating cosine of the angle between them.

- Correlation ${ }^{4}$ - it is a normalized measure of the linear relationship strength between vectors.

- Spearman ${ }^{4}$ - it is the measure of statistical dependence between two variables.

- Hamming ${ }^{4}-$ it is the percentage of the coordinates that differ.

- Jaccard $^{4}$ - one minus the Jaccard coefficient, which is the percentage of non-zero coordinates.

\subsubsection{Linkages}

The linkage creates a hierarchical agglomerative cluster tree from the distances which were calculated before. The linkages, which were taken into consideration in this thesis, are described in the Table 2 [24][27][28].

\footnotetext{
${ }^{4}$ Non-Euclidean metrics.
} 
Table 2: Types of linkages.

\section{Linkage Description}

Also called furthest neighbor algorithm; it is the maximum algorithm in which the similarity between

Complete clusters is the similarity of the most dissimilar clusters. It works very well if the clusters are compact and similar size. If this is not the true, the results of grouping might be meaningless.

\begin{tabular}{|c|c|}
\hline Single & $\begin{array}{l}\text { Also called nearest neighbor algorithm; it is the } \\
\text { minimum algorithm in which the similarity between } \\
\text { clusters is the similarity of the most similar clusters. } \\
\text { The main disadvantage of this algorithm is } \\
\text { "chaining effect" - the presence of one point which } \\
\text { can create the bridge between the clusters, results in } \\
\text { a not-wanted grouping of all points into one large } \\
\text { cluster. This algorithm is sensitive to noise. }\end{array}$ \\
\hline Average & $\begin{array}{l}\text { The complete and single algorithms are two } \\
\text { extremes which are sensitive to outliers and } \\
\text { wildshots. The use of average algorithm solves } \\
\text { these problems. It uses the average distance } \\
\text { between all pairs of objects in any two clusters. }\end{array}$ \\
\hline Centroid $^{5}$ & $\begin{array}{l}\text { Uses the Euclidean distance between the centroids } \\
\text { of the two clusters. }\end{array}$ \\
\hline Median $^{5}$ & $\begin{array}{l}\text { Uses the Euclidean distance between weighted } \\
\text { centroids of the two clusters. }\end{array}$ \\
\hline Ward $^{5}$ & $\begin{array}{l}\text { Uses the incremental sum of squares; that is, the } \\
\text { increase in the total within-cluster sum of squares as } \\
\text { a result of joining two clusters. The within-cluster } \\
\text { sum of squares is defined as the sum of the squares } \\
\text { of the distances between all objects in the cluster } \\
\text { and the centroid of the cluster. }\end{array}$ \\
\hline
\end{tabular}

Weighted It is weighted average distance.

\footnotetext{
${ }^{5}$ It cannot be applied with non-Euclidean metrics.
} 


\subsubsection{Hierarchical Clustering Evaluation}

Since the choices of hierarchical clustering algorithms are very rich, there was a need of results evaluation of the selected clustering model. There are two tests, which can be helpful in the evaluation of the clustering quality. One of them is a cophenet correlation coefficient, which is very useful for the clustering methods comparison. It is defined as linear correlation coefficient between the cophenetic distances obtained from the tree, and the original distances used to construct the tree. It is the measure of how well the tree represents the dissimilarities between the fuel bundles. If the value is close to 1 , the chosen method itself gives a high-quality solution. More details can be found in [24].

A test which can be helpful in determining the best number of groups is inconsistent function, which computes inconsistency coefficient for each link of the hierarchical cluster tree. It takes each link of the cluster tree and compares their heights with other links in the same level of hierarchy. The higher value of the coefficient the less similar fuel bundles connected by the link [24].

The present study evaluates hierarchical clustering model with the help of cophenet correlation and to the manual interpretation of the results. The number of groups is arbitrary and has been chosen such that it covers all of the common number of TH channels used by the code users such as: $5,20,50,100, \sim 200, \sim 350 \ldots 700$.

\subsubsection{Hierarchical Clustering Approach and Results}

Figure 21 presents a potential clustering result depending where one "cuts the tree". The clustering in this example was performed with the one 
feature as an input - power $1^{\text {st }}$ mode, metric Chebychev and linkage Complete.

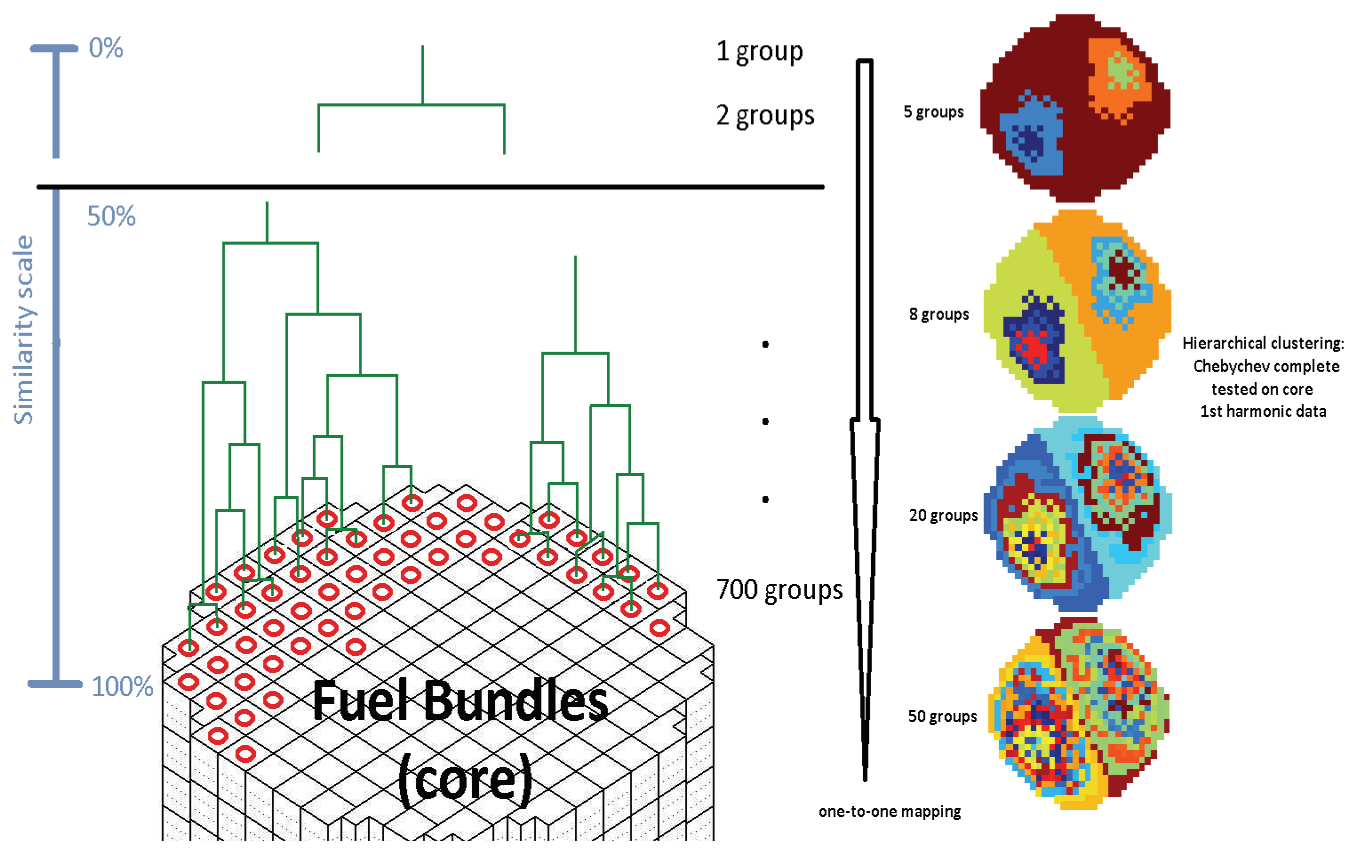

Figure 21: The clustering results example.

A comprehensive test was performed with all possible distances and linkages implemented into Matlab Statistical Toolbox [24], to cover all possible combinations of the hierarchical clustering models. The test includes most possible and common core fuel bundles features and their characteristics in combinations. The features are: $k_{\text {loss }}, \mathrm{X}$ and $\mathrm{Y}$ coordinates, symmetry, exposure, $1^{\text {st }}$ power mode, control rod groups, power peaking factors, fuel kinds (types), core symmetry.

For all cases (feature combinations), all possible hierarchical clustering models were tested, and the decision of choosing "the best" model was 
based on cophenet correlation results and an investigator's judgment. Whenever doubts appeared, additional models were also taken into considerations. In addition to each clustering model and combinations of features the hierarchical clustering tree (dendrogram) was cut in many different places. The selected cuts can be seen as the most common choice of number of TH channels used by model developers: $\sim 5, \sim 20, \sim 50, \sim 100$, $\sim 162$ and 324 groups, to check the performance of grouping and the influence of number of channels on results.

\subsubsection{Clustering shapes}

Table 3 shows most of possible the "mapping shapes" which are a result of clustering algorithms with the input data: $\mathrm{X}$ coordinate and $\mathrm{Y}$ coordinate. These results are a general indication because whenever we take into consideration any other feature (together with $\mathrm{X}$ and $\mathrm{Y}$ coordinates) the shape changes; however, it gives some clue as what can be expected. Generally the "mapping shape" depends mostly on metrics and input data pre-processing, linkage function is a secondary factor (it influences the cluster shape and size).

Table 3: Clustering shapes.

\begin{tabular}{|c|c|c|}
\hline Shape model & Shape description & Example \\
\hline $\begin{array}{c}\text { The "ray" grouping starting } \\
\text { from one corner of the core, this } \\
\text { is very common for cosine } \\
\text { metric and is not dependent on } \\
\text { choice of linkage. }\end{array}$ \\
\hline
\end{tabular}




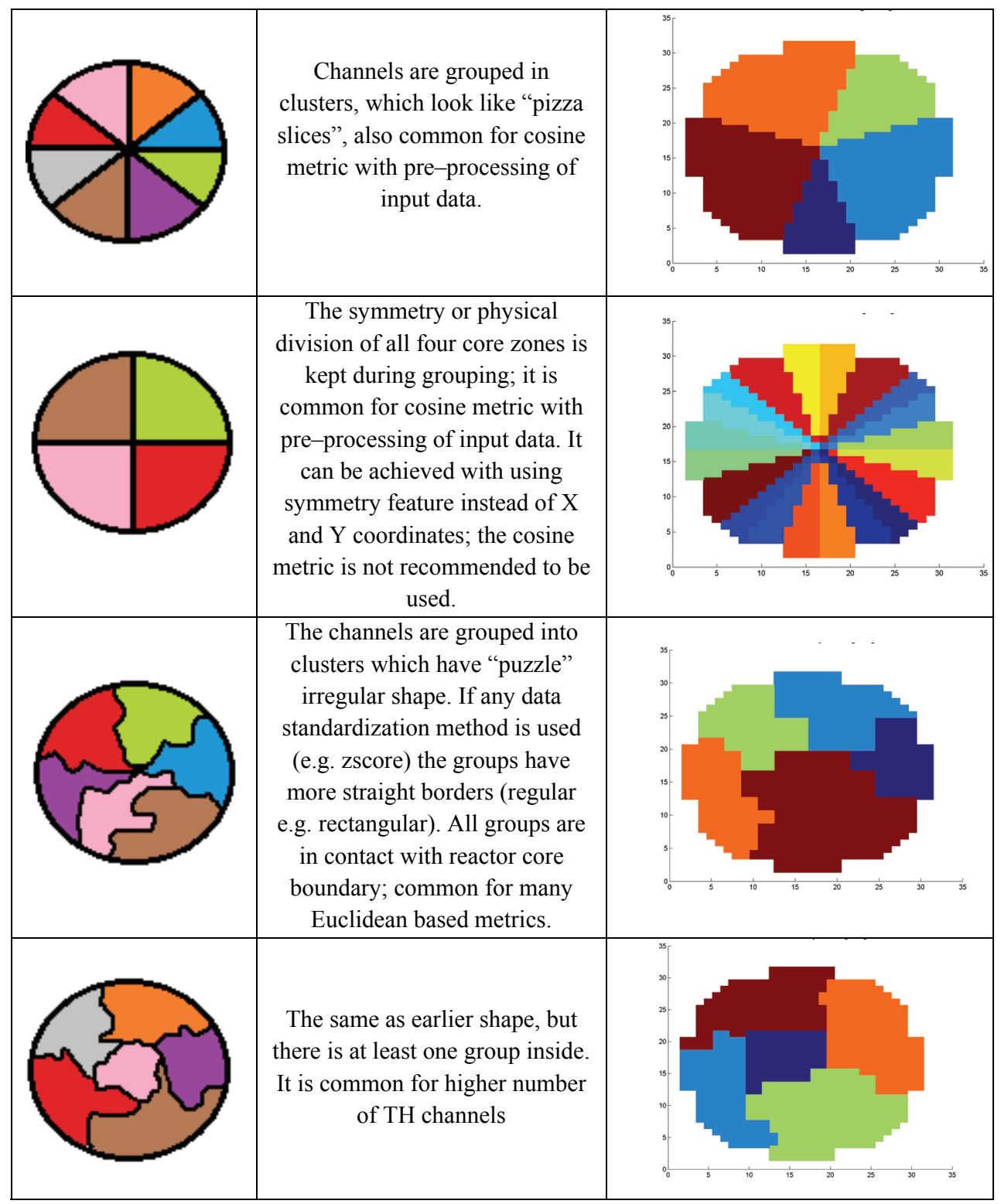




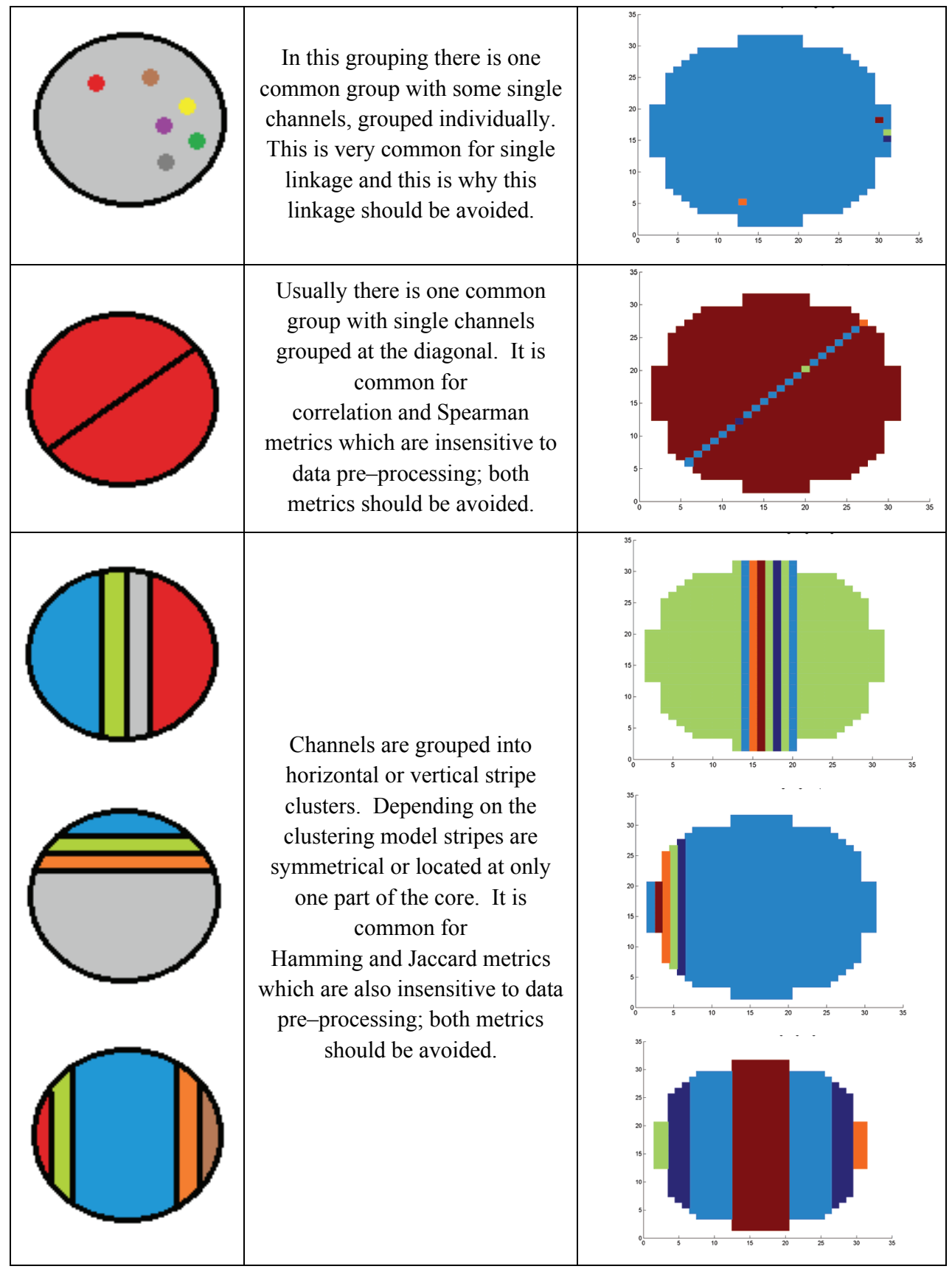




\subsubsection{Clustering results}

After testing all the clustering models the following conclusions were drawn:

- One should avoid using single linkage and also exclude from consideration the following metrics: Spearman, Hamming, Jaccard, cosine and correlation.

- Whenever one wants to combine more than one feature to the input vector, one should also realize that less than $20 \mathrm{TH}$ channels will not reflect all the supplied features; moreover, one should always preprocess the data.

- Almost every kind of hierarchical clustering performs quite well for the exposure grouping (Figure 22); however the cophenet correlation recommended linkage complete with combination of the following metrics: Minkowski, Mahalanobis, City block, Chebychev and Euclidean.
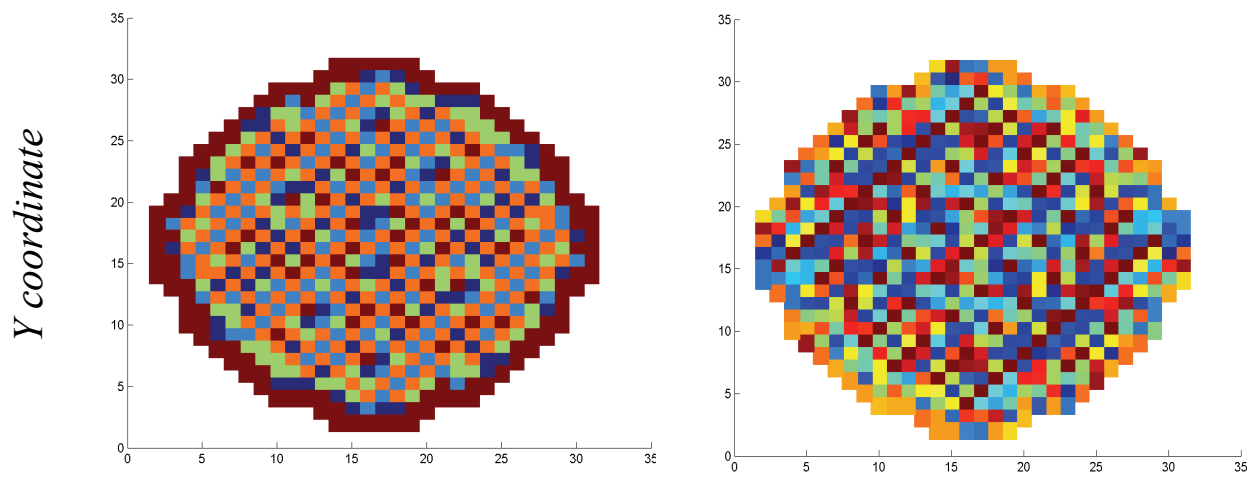

$X$ coordinate

Figure 22: Example of grouping with the exposure input data and number of groups 5 and 50 (metric: city block, linkage: complete). 
- The power peaking factors mapping, which is somewhat similar to exposure mapping, has also quite good performance with most of the clustering models (Figure 23); the cophenet correlation recommended linkages weighted and median with combination of following metrics: Minkowski, Mahalanobis, City block, Euclidean and sEuclidean.
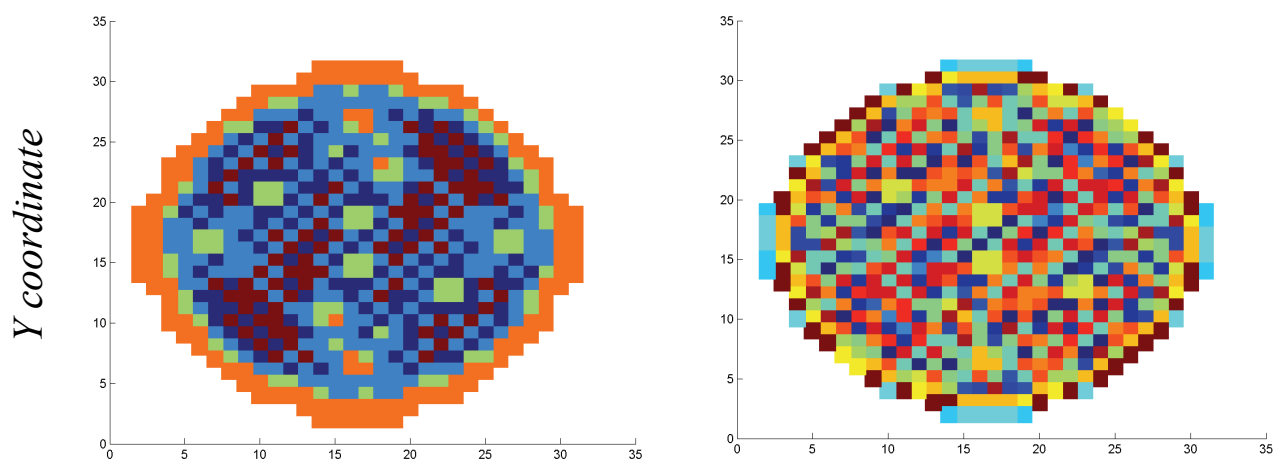

X coordinate

Figure 23: Example of grouping with the power peaking factors input data and number of groups 5 and 20 (metric: Chebychev, linkage: weighted).

- For the $1^{\text {st }}$ mode grouping most of the metrics combined with the linkage complete performs very well (Figure 24); with increasing number of groups other linkages also have good performance.

- To use the advantage of hierarchical clustering algorithm all the features were not treated separately, since they were usually combined with some other features, e.g., fuel type was combined with core symmetry, control rods with power peaking factors, etc. 

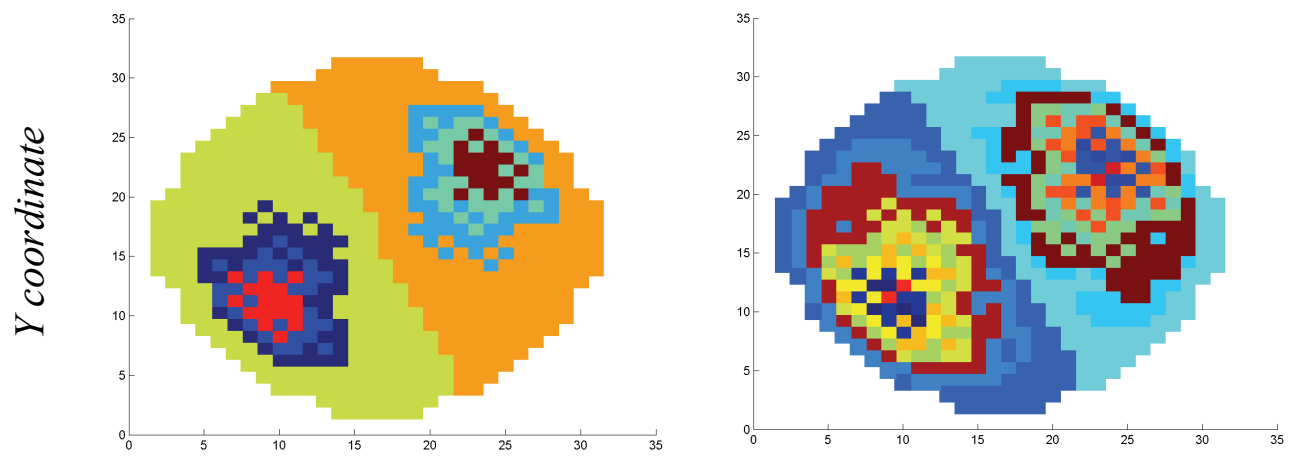

\section{X coordinate}

Figure 24: Example of grouping with the 1st power mode input data and number of groups 8 and 20 (metric: Chebychev, linkage: complete).

\subsubsection{Hierarchical Clustering Summary}

The usage of hierarchical clustering algorithms, which has been investigated here as a new mapping approach, has been shown to be an efficient approach for spatial coupling problem. Once automatized, it does not only speed up the input preparation for the steady-state and transient simulations, but also allows for testing different mapping configurations even if only one feature is taken into consideration. In addition, the method will not cause difficulties if one wants to have one or many channels always separated (e.g. hot channels for LOCA analysis), this can be part of the input matrix as a one of the feature vectors.

The hierarchical clustering algorithm itself is not new and is very well developed and applied by a large number of researchers in different research fields. The author of this thesis made the first attempt to apply it to TH/NK mapping needs, and the results demonstrate that it can be applied with a success, although further efforts are needed for user- 
friendly interface in the input development, e.g., implementing it into SNAP.

This thesis work focuses only on mapping for cores with Cartesian geometry ${ }^{6}$. Thus, it is possible that some of the clustering models which are not recommended here for Cartesian geometry might have better performance with cylindrical or hexagonal core geometry. However, due to time constraints of this project other types of core geometry were not investigated.

\subsection{Types of Mapping Used in the Code Input Models}

\subsubsection{RELAP5/PARCS Models (BWR-1)}

The types of mapping used for RELAP5/PARCS BWR-1 Model I and BWR-1 Model II are presented Table 4 and Table 5, respectively. There is a limitation in mapping used for Model II (more details can be found in Chapter 2). Due to need of core zones separation each TH channel group can be in only one core zone. The core zones are presented in Figure 25. All RELAP5/PARCS mappings were prepared in a "manual" way.

\footnotetext{
${ }^{6}$ In PARCS neutronic code exists also another possibility to express mapping with the help of cylindrical geometry.
} 


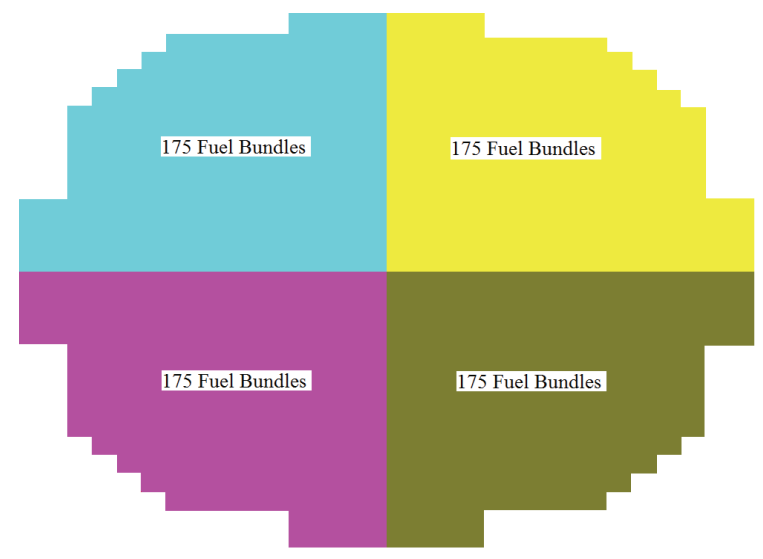

Figure 25: The core zones used in Model II.

Table 4: Mapping schemes used in BWR-1 Model I.

\begin{tabular}{|c|c|}
\hline $\begin{array}{c}\text { Number of TH } \\
\text { channels }\end{array}$ & Kind of mappings \\
\hline 5 & Location and $k_{\text {loss }}$, Exposure, Power \\
\hline 20 & Location and $k_{\text {loss }}$, Exposure, Power \\
\hline 50 & Location and $k_{\text {loss }}$, Exposure, Power \\
\hline 70 & Location and $k_{\text {loss }}$ Exposure, Power \\
\hline 175 & Control Rods Grouping \\
\hline 176 & First mode combined with exposure grouping \\
\hline 192 & Location combined with exposure grouping \\
\hline 350 & Control Rod Grouping \\
\hline $\mathbf{7 0 0}$ & One to One grouping - Reference Case \\
\hline
\end{tabular}

Table 5: Mapping schemes used in BWR-1 Model II.

\begin{tabular}{|c|c|}
\hline $\begin{array}{c}\text { Number of TH } \\
\text { channels }\end{array}$ & Kind of mappings \\
\hline 4 & Geometry \\
\hline 20 & Location and $k_{\text {loss }}$, Exposure, Power \\
\hline 50 & Location and $k_{\text {loss }}$, Exposure, Power \\
\hline
\end{tabular}




\begin{tabular}{|c|c|}
\hline 70 & Location and $k_{\text {loss }}$, Exposure, Power \\
\hline 108 & First mode combined with Exposure grouping \\
\hline 204 & Control Rods Grouping \\
\hline 192 & Location combined with exposure grouping \\
\hline 350 & Control Rod Grouping \\
\hline $\mathbf{7 0 0}$ & One to One grouping - Reference Case \\
\hline
\end{tabular}

\subsubsection{TRACE/PARCS Model (BWR-2)}

The all possible feature combinations and hierarchical clustering models used for TRACE/PARCS BWR-2 model are shown in Table 6. The results of simulations from BWR-2 model presented in next chapters are based on the mapping schemes shown in this table.

Almost all the mappings for this input have been performed with the hierarchical clustering method; exception is last position in the table called "mapping mixed". This was introduced only to compare "automatized" clustering method results with the "manual" ones. The "manual" mappings (marked in figures with the legend of "mapping mixed" in the next chapters) include: $7 \mathrm{TH}$ channels (one channel for each type of assemblies in each ring), $40 \mathrm{TH}$ channels (one channel for each type of assemblies within same control rod bank), $184 \mathrm{TH}$ channels (power grouping) and $325 \mathrm{TH}$ channels (1 channel for two symmetric assemblies). In addition, the extreme all-to-one single channel model and the reference one-to-one (full scale model), model are also calculated. 
Table 6: Fuel bundle feature combinations.

\begin{tabular}{|c|c|c|c|}
\hline \multirow{2}{*}{ Features $^{7}$} & \multicolumn{2}{|c|}{ Hierarchical Clustering model } & \multirow{2}{*}{ Plot legend $^{8}$} \\
\hline & Metrics9 & Linkages & \\
\hline Exposure & City Block & Complete & Mapping exposure \\
\hline $\begin{array}{l}\text { Power peaking } \\
\text { factor }\end{array}$ & $\begin{array}{l}\text { Chebychev (p1) } \\
\text { Euclidean (p6) } \\
\text { Mahalanobis (p9) }\end{array}$ & $\begin{array}{l}\text { Weighted (p1) } \\
\text { Average (p6) } \\
\text { Weighted (p9) }\end{array}$ & Mapping peak fact 1 \\
\hline $\begin{array}{l}\text { Power peaking } \\
\text { factor }\end{array}$ & Mahalanobis & Ward & Mapping peak fact 2 \\
\hline $\begin{array}{l}\text { Power peaking } \\
\text { factor, } \\
\text { X\&Y coordinates }\end{array}$ & $\begin{array}{l}\text { Euclidean (p1) } \\
\text { Minkowski }\end{array}$ & $\begin{array}{l}\text { Ward }(\mathrm{p} 1) \\
\text { Average }\end{array}$ & Mapping peak fact xy 1 \\
\hline $\begin{array}{l}\text { Power peaking } \\
\text { factor, } \\
\text { X\&Y coordinates }\end{array}$ & $\begin{array}{l}\text { Cosine }^{10}(\mathrm{p} 1) \\
\text { Chebychev (p6) } \\
\text { sEuclidean (p9) }\end{array}$ & $\begin{array}{l}\text { Average (p1) } \\
\text { Complete (p6) } \\
\text { Centroid (p9) }\end{array}$ & Mapping peak fact xy 2 \\
\hline $\begin{array}{l}\text { Peaking Factor, } \\
\text { core symmetry }\end{array}$ & $\begin{array}{l}\text { Mahalanobis } \\
\text { Chebychev (p6) }\end{array}$ & $\begin{array}{l}\text { Average } \\
\text { Complete (p6) }\end{array}$ & $\begin{array}{l}\text { Mapping peak fact } \\
\text { symm }\end{array}$ \\
\hline $\begin{array}{l}\text { Exposure, } \\
\text { core symmetry }\end{array}$ & Mahlanobis & Average & Mapping exp symm \\
\hline $\begin{array}{l}\text { Fuel kinds, } \\
\text { core symmetry }\end{array}$ & City Block & Weighted & $\begin{array}{l}\text { Mapping fuel kinds } 1 \\
\text { symm }\end{array}$ \\
\hline $\begin{array}{l}\text { Fuel kinds, } \\
\text { geometry, } \\
\text { core symmetry }\end{array}$ & Mahalanobis & Average & $\begin{array}{l}\text { Mapping fuel kinds } 2 \\
\text { symm }\end{array}$ \\
\hline $\begin{array}{l}\text { Inlet } k_{\text {loss }}, \\
\text { core symmetry }\end{array}$ & Mahalanobis & Weighted & $\begin{array}{l}\text { Mapping inlet orifice } \\
\text { symm }\end{array}$ \\
\hline $\begin{array}{l}\text { Inlet } k_{\text {loss }} \text {, } \\
\text { Peaking Factors }\end{array}$ & Chebychev & Average & $\begin{array}{l}\text { Mapping inlet orifice } \\
\text { peak fact } v 1\end{array}$ \\
\hline $\begin{array}{l}\text { Inlet } k_{\text {loss }}, \text { power } \\
\text { peaking factors }\end{array}$ & City Block & Complete & $\begin{array}{l}\text { Mapping inlet orifice } \\
\text { peak fact v2 }\end{array}$ \\
\hline $\begin{array}{l}\text { Inlet } k_{\text {loss }} \text {, } \\
\text { exposure }\end{array}$ & Mahalanobis & Centroid & $\begin{array}{l}\text { Mapping inlet orifice } \\
\text { exp }\end{array}$ \\
\hline $\begin{array}{l}\text { Control Rods, power } \\
\text { peaking factor }\end{array}$ & Euclidean & $\begin{array}{l}\text { Complete, } \\
\text { Median (p9) }\end{array}$ & $\begin{array}{l}\text { Mapping control rods } \\
\text { peak fact }\end{array}$ \\
\hline
\end{tabular}

${ }^{7}$ The illustrations of the features are in Appendix II (Figure A2.1 - Figure A2.9).

${ }^{8}$ Plot Legend marking concerns the plots legend in the following Chapters: 4 and 5.

${ }^{9}$ Metrics and Linkages depend on the input data; for different points: 1 (p1), 6 (p6) or 9 (p9) of cycle 14, sometimes different combinations were used (marked in bracket).

${ }^{10} \mathrm{I}$ do not recommend this metric, however my curiosity forced me to test it at least once. 


\begin{tabular}{|c|c|c|c|}
\hline $\begin{array}{l}\text { Control Rods, } \\
\text { exposure }\end{array}$ & Euclidean & $\begin{array}{l}\text { Complete }(\mathrm{p} 1) \\
\text { Average (p6) } \\
\text { Median (p9) }\end{array}$ & $\begin{array}{l}\text { Mapping control rods } \\
\text { exp }\end{array}$ \\
\hline $\begin{array}{l}\text { Exposure, } \\
\text { x\&y coordinates }\end{array}$ & City block & Weighted & Mapping exp x y \\
\hline $1^{\text {st }}$ power mode ${ }^{11}$ & $\begin{array}{l}\text { Chebychev } \\
\text { Mahalanobis (p6) }\end{array}$ & Complete & Mapping 1st mode \\
\hline $\begin{array}{l}1^{\text {st }} \text { power mode, } \\
\text { exposure }^{11}\end{array}$ & $\begin{array}{l}\text { Chebychev } \\
\text { City Block (p6) }\end{array}$ & $\begin{array}{l}\text { Average } \\
\text { Weighted (p9) }\end{array}$ & Mapping $1^{\text {st }}$ mode exp \\
\hline $\begin{array}{l}\text { Poles separation }^{12} \text {, } \\
\text { exposure }^{11}\end{array}$ & Chebychev (p9) & Average (p9) & Mapping pole sep exp \\
\hline $\begin{array}{l}1^{\text {st }} \text { power mode, } \\
\text { Inlet kloss }\end{array}$ & City Block (p9) & $\begin{array}{l}\text { Complete }(\mathrm{p} 1) \\
\text { Average }\end{array}$ & $\begin{array}{l}\text { Mapping } 1^{\text {st }} \text { mode inlet } \\
\text { orifice }\end{array}$ \\
\hline $\begin{array}{l}1^{\text {st }} \text { power mode, } \\
\text { Fuel kinds } 11\end{array}$ & $\begin{array}{l}\text { Mahalonobis (p1) } \\
\text { Mahalanobis (p6) } \\
\text { City Block (p9) }\end{array}$ & $\begin{array}{l}\text { Centroid }(\mathrm{p} 1) \\
\text { Average }\end{array}$ & $\begin{array}{l}\text { Mapping } 1^{\text {st }} \text { mode fuel } \\
\text { kinds } 1\end{array}$ \\
\hline $\begin{array}{l}1^{\text {st }} \text { power mode, } \\
\text { Peaking Factor }\end{array}$ & $\begin{array}{l}\text { Mahalnobis (p1) } \\
\text { sEuclidean (p6) } \\
\text { Minkowski (p9) }\end{array}$ & $\begin{array}{l}\text { Centroid } \\
\text { Weighted (p9) }\end{array}$ & $\begin{array}{l}\text { Mapping } 1^{\text {st }} \text { mode peak } \\
\text { fact }\end{array}$ \\
\hline $\begin{array}{l}\text { Poles separation }^{12} \text {, } \\
\text { exposure }^{11}\end{array}$ & Chebychev (p9) & Average (p9) & $\begin{array}{l}\text { Mapping pole sep peak } \\
\text { fact }\end{array}$ \\
\hline $\begin{array}{l}\text { Fuel kinds, } \\
\text { Control rod banks, } \\
\text { Power grouping, } \\
\text { Half-core symmetric }\end{array}$ & - & - & Mixed mapping $^{13}$ \\
\hline
\end{tabular}

\footnotetext{
${ }^{11}$ This mapping was used in purpose to investigate regional instability; the detail explanation is in the Chapter 4.

12 This feature is a special case of $1^{\text {st }}$ power mode and used only for point 9 of cycle 14 ; details in Appendix II - $\quad$ Figure A2.9.

${ }^{13}$ These features were treated in "manual" way.
} 


\subsection{Inlet Orificing and Mapping}

The inlet orificing for the BWR-1 RELAP5/PARCS 700 channels model is presented in the Figure 26. There are three zones in the core with three different inlet $k_{\text {loss }}(140,95$ and 60$)$. The reason for this is to get proper flow distribution in the hot channels area.

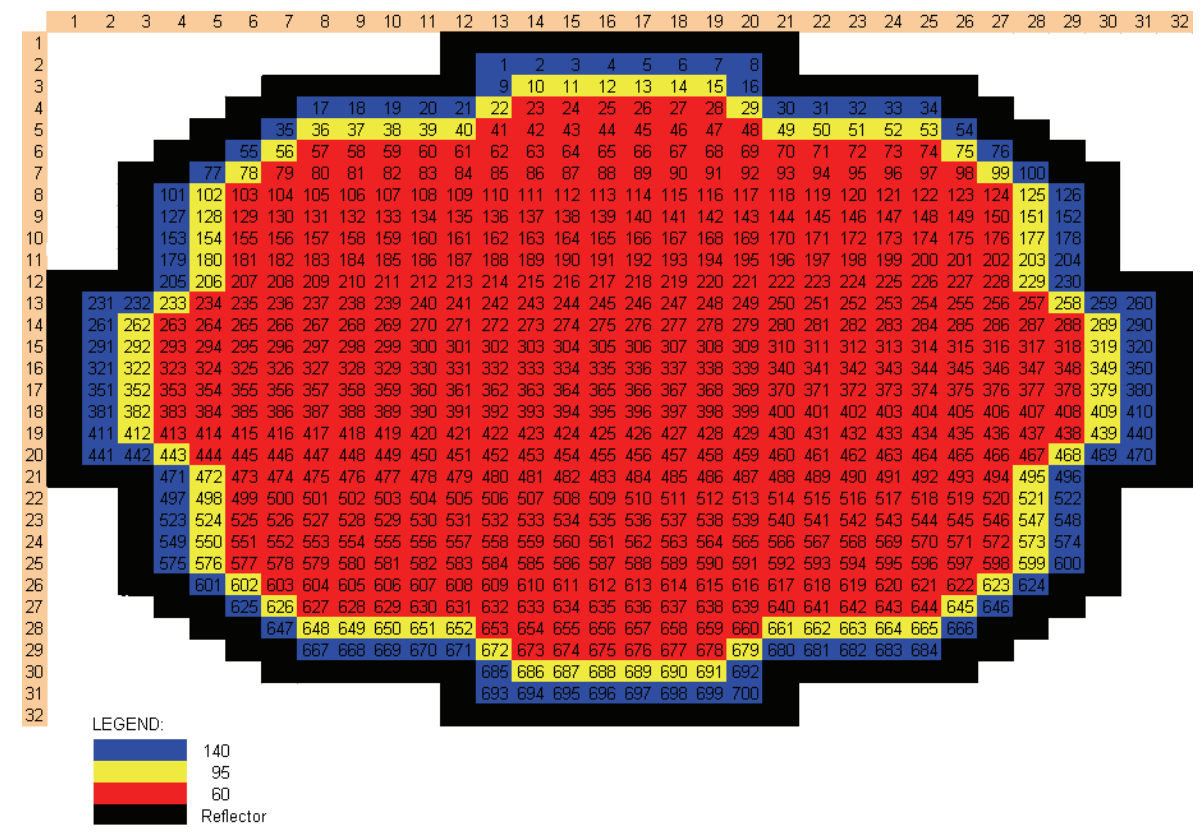

Figure 26: Distribution of inlet $k_{\text {loss }}$ for 700 TH channel model.

One of the challenging tasks is the bundle $k_{\text {loss }}$ and its treatment during spatial refinement. The problem appears when two (or more) different channels with different $k_{\text {loss }}$ are grouped together. The problem is to find $k_{\text {loss }}$ that should be implemented to the newly created channel to get the same total mass flow from channels as before mapping. 
During the grouping it is recommended (if possible) to have "separation" of channels with different $k_{\text {loss. }}$. If the separation is not possible, then for the grouping of channels with different $k_{\text {loss }}$ the "weighted mean" was developed which is expressed by (6).

$$
\bar{K}_{\text {loss }}=n \cdot \frac{\sum_{i=1}^{n} \dot{m}_{i}^{2} K_{\text {lossi }}}{\left(\sum_{i=1}^{n} \dot{m}_{i}\right)^{2}}=n \cdot \frac{\dot{m}_{1}^{2} K_{\text {loss } 1}+\dot{m}_{2}^{2} K_{\text {loss } 2}+\ldots+\dot{m}_{n}^{2} K_{\text {loss } n}}{\left(\dot{m}_{1}+\dot{m}_{2}+\ldots+\dot{m}_{n}\right)^{2}}
$$

where:

$\bar{K}_{\text {loss }}-$ new $K_{\text {loss }}$ applied to grouped TH channel.

$\dot{m} \quad-$ mass flow in the channel $i$.

$K_{\text {loss }}-K_{\text {loss }}$ at the inlet to the channel $i$.

$n \quad-$ number of grouped channels.

$i \quad-$ channel index number; $i=1 \ldots n$

The (6) was derived from numerical experiment. The main idea was to compare two cases. The case number one (reference) includes two fuel bundles with two different $k_{\text {loss }}$ and different power peaking factors. The case number two includes only one channel with the area being sum of the bundles' area from case one. The main objective was to find a mass flow, of the case one (reference) bundles only by choosing appropriate $k_{\text {loss }}$ inlet. Bundles model is presented in the Figure 27 and the results (marked with red color) together with used boundary conditions (marked with green color) are shown in Table 7. The method was also tested and validates for arbitrary number of channels.

Since we have one channel per one fuel assembly model (reference model), we have also the mass flow distribution. Therefore, equation (6) can be used for full-scale models. 


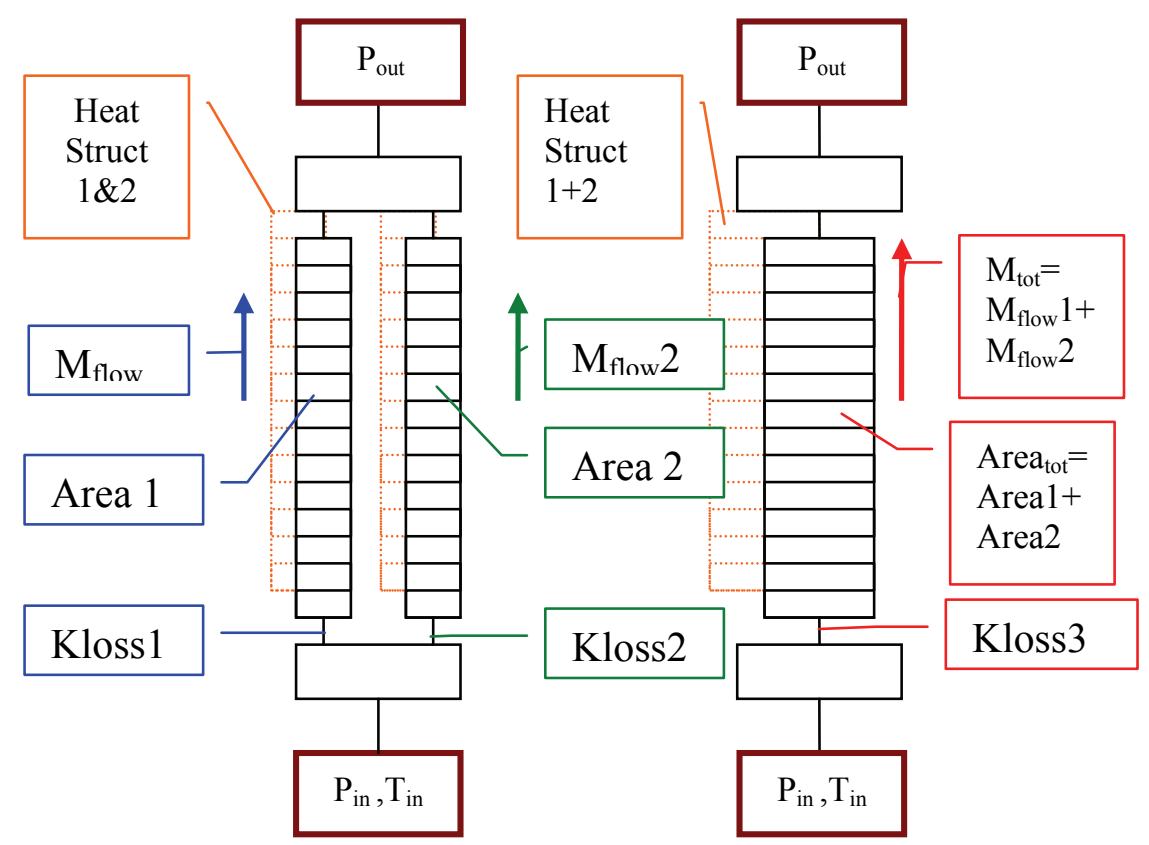

Figure 27: $k_{\text {loss }}$ numerical experiment models.

Table 7: $k_{\text {loss }}$ results from numerical experiment.

\begin{tabular}{|c|c|c|c|c|c|c|c|}
\hline \multirow{2}{*}{ No. } & \multirow{2}{*}{$\begin{array}{c}\text { Description of the } \\
\text { boundary conditions }\end{array}$} & \multicolumn{4}{|c|}{ Case 1} & \multicolumn{2}{|c|}{ Case 2} \\
\hline & & $\dot{m}_{1}$ & $K_{\text {loss } 1}$ & $\dot{m}_{2}$ & $K_{\text {loss } 2}$ & $\dot{m}_{t o t}$ & $K_{\text {loss } 3}$ \\
\hline $1-1$ & $\mathrm{P}_{\mathrm{i}}=7.25 \mathrm{e} 6[\mathrm{~Pa}]$, & 13.03 & 50 & 13.03 & 50 & 26.06 & 50 \\
\hline $1-2$ & $\mathrm{P}_{\mathrm{o}}=6.9 \mathrm{e} 6[\mathrm{~Pa}]$ & 13.29 & 50 & 8.31 & 150 & 21.6 & 82 \\
\hline $1-3$ & $\begin{array}{l}\text { Power }=4.89 \mathrm{e} 6[\mathrm{~W}] \text {, } \\
\text { Power Ratio. } 10 \cdot 10\end{array}$ & 13.29 & 50 & 9.94 & 100 & 23.25 & 69 \\
\hline $1-4$ & Power Profile: inlet-peak. & 9.94 & 100 & 8.31 & 150 & 18.25 & 122 \\
\hline $2-1$ & $\begin{array}{c}\mathrm{P}_{\mathrm{i}}=7.25 \mathrm{e} 6[\mathrm{~Pa}] \\
\mathrm{T}_{\mathrm{i}}=551.75[\mathrm{~K}]\end{array}$ & 9.88 & 100 & 8.34 & 150 & 18.22 & 121.6 \\
\hline $2-2$ & $\begin{array}{c}\mathrm{P}_{\mathrm{o}}=6.9 \mathrm{e} 6[\mathrm{~Pa}], \\
\text { Power=4.89e6 [W], }\end{array}$ & 8.53 & 140 & 10.22 & 95 & 18.75 & 114.39 \\
\hline $2-3$ & $\begin{array}{l}\text { Power Ratio: 1.1:0.9, } \\
\text { Power Profile: inlet-peak. }\end{array}$ & 8.53 & 140 & 12.42 & 60 & 20.95 & 88.6 \\
\hline
\end{tabular}




\begin{tabular}{|c|c|c|c|c|c|c|c|}
\hline $3-1$ & $\begin{array}{c}\mathrm{P}_{\mathrm{i}}=7.25 \mathrm{e} 6[\mathrm{~Pa}], \\
\mathrm{T}_{\mathrm{i}}=551.75[\mathrm{~K}], \\
\mathrm{P}_{\mathrm{o}}=6.9 \mathrm{e} 6[\mathrm{~Pa}]\end{array}$ & 8.67 & 140 & 9.97 & 95 & 18.64 & 114.9 \\
\hline $3-2$ & $\begin{array}{c}\text { Power }=4.89 \mathrm{e} 6[\mathrm{~W}], \\
\text { Power Ratio: } 0.7: 1.3 \text {, } \\
\text { Power Profile: inlet-peak. }\end{array}$ & 8.66 & 140 & 12.5 & 60 & 20.71 & 89.98 \\
\hline $4-1$ & $\begin{array}{l}\mathrm{P}_{\mathrm{i}}=7.21 \mathrm{e} 6[\mathrm{~Pa}], \\
\mathrm{T}_{\mathrm{T}}=551.65[\mathrm{~K}]\end{array}$ & 3.69 & 95 & 3.14 & 140 & 6.83 & 116 \\
\hline $4-2$ & $\begin{array}{c}\mathrm{P}_{\mathrm{o}}=7.15 \mathrm{e} 6[\mathrm{~Pa}] \\
\text { Power=1.9e6 }[\mathrm{W}]\end{array}$ & 4.43 & 60 & 3.14 & 140 & 7.57 & 90.4 \\
\hline $4-3$ & $\begin{array}{l}\text { Power Ratio: } 1.0: 1.0 \text {, } \\
\text { Power Profile: flat. }\end{array}$ & 4.43 & 60 & 3.69 & 95 & 8.12 & 75.2 \\
\hline
\end{tabular}




\section{Chapter 4: Steady-State Calculation}

This chapter is devoted to compare and summarize the obtained steadystate results for both coupled codes RELAP5/PARCS and TRACE/PARCS.

A stable steady-state has been reached for all models (BWR-1 and BWR-2) with different mapping scheme and number of TH channels, which gave a good basis for transient comparisons. The "fixed" variables, which were directly or indirectly boundary conditions e.g. reactor pressure vessel, main recirculation flow, total reactor power, feedwater temperature, etc., were always fully converged to the same value for the all achieved steady-states. It is also important to remember that the RELAP5/PARCS steady-states operating conditions of BWR-3000 with full power at full flow are more favorable for the codes; the obtained steady-states are usually "stable" and well converged. Comparatively, the TRACE/PARCS steady-state cases for Ringhals-1 have reduced flow and power in order to initiate instability events, and the prediction of steady-state parameters is more challenging, e.g., taking a longer calculation time to converge. Since the OECD Ringhals-1 Benchmark supplies data concerning power distributions, the obtained results for BWR-2 are scrutinized in more detail than it is done for RELAP5/PARCS. The parameters affected by the mapping schemes are emphasized in comparisons.

\subsection{RELAP5/PARCS Steady-State Results of BWR-1}

The following parameters are important for steady-state results: $k_{\text {eff }}[-]$, inlet and outlet quality [\%], core outlet temperature $[\mathrm{K}]$, steam dome 
pressure $[\mathrm{MPa}]$, main recirculation flow rate $[\mathrm{kg} / \mathrm{s}]$ and maximum power peaking factor: radial, axial.

\subsubsection{BWR-1 Model I - Steady-State Results}

Table 8 contains the selected average steady-state results. As observed, the integral average values are fully converged and are not dependent on the type of mapping and number of TH channels. This gives a consistent basis for transient comparison.

Looking more into the details of the results, e.g., the radial and axial peaking factors, one can find differences. The radial peaking factors (see Figure 28), rapidly converge to around 1.7, with increasing number of $\mathrm{TH}$ channels. For the number of $\mathrm{TH}$ channels higher than 70 , the mapping induced uncertainty in the radial peaking factor is about $2 \%$, regardless of the spatial mapping method used. For lower number of TH channels, the radial peaking factor is conservatively over-predicted. Similar behavior can be seen for axial peaking factor (Figure 29). This confirms the observations from other researchers [5] that the incorrect mapping may lead to overestimation of power peaking factors. Figure 30 presents the average fuel centerline temperature, it can be noticed that low number of $\mathrm{TH}$ channels results underestimation of fuel temperature by about $\sim 2 \%$, similar behaviour can be seen in average Doppler temperature where underestimation is about $\sim 3 \%$. 


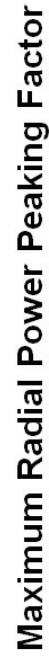

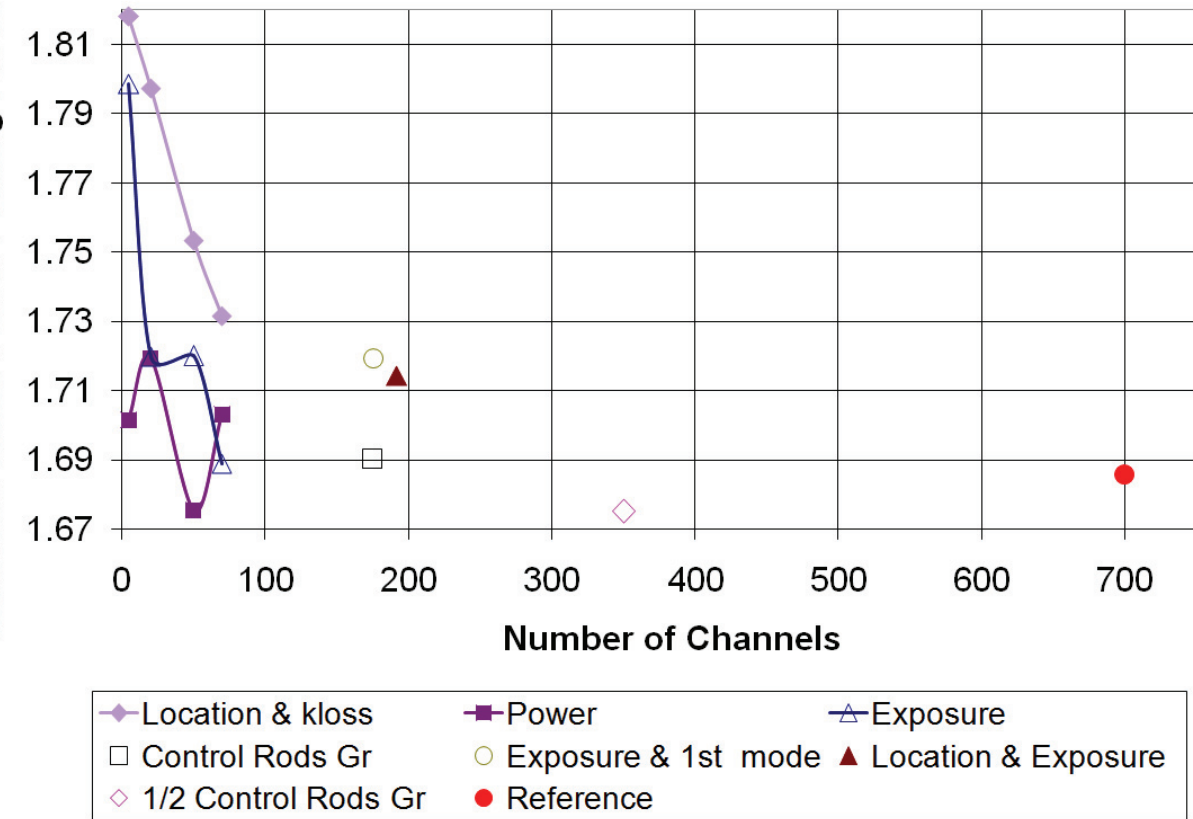

Figure 28: Maximum radial power peaking factor (BWR-1 Model I).

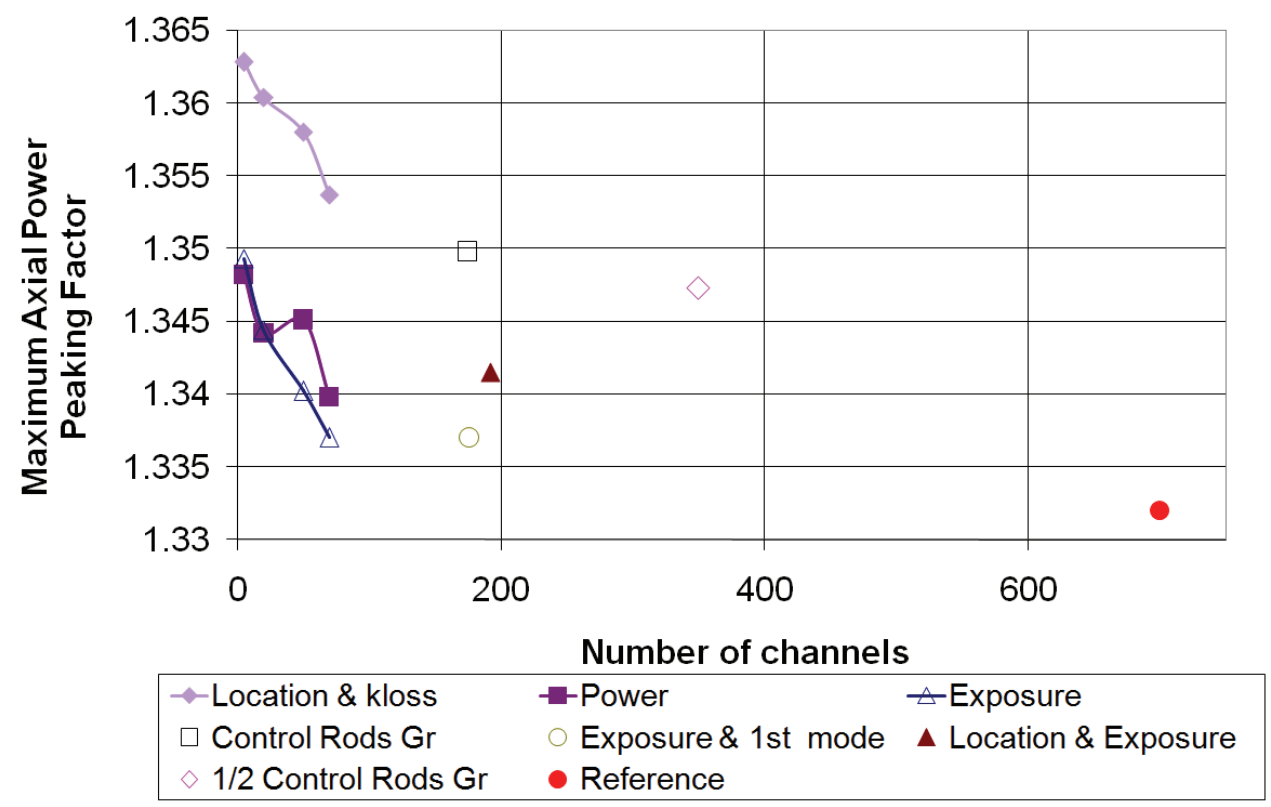

Figure 29: Maximum axial power peaking factor (BWR-1 Model I). 


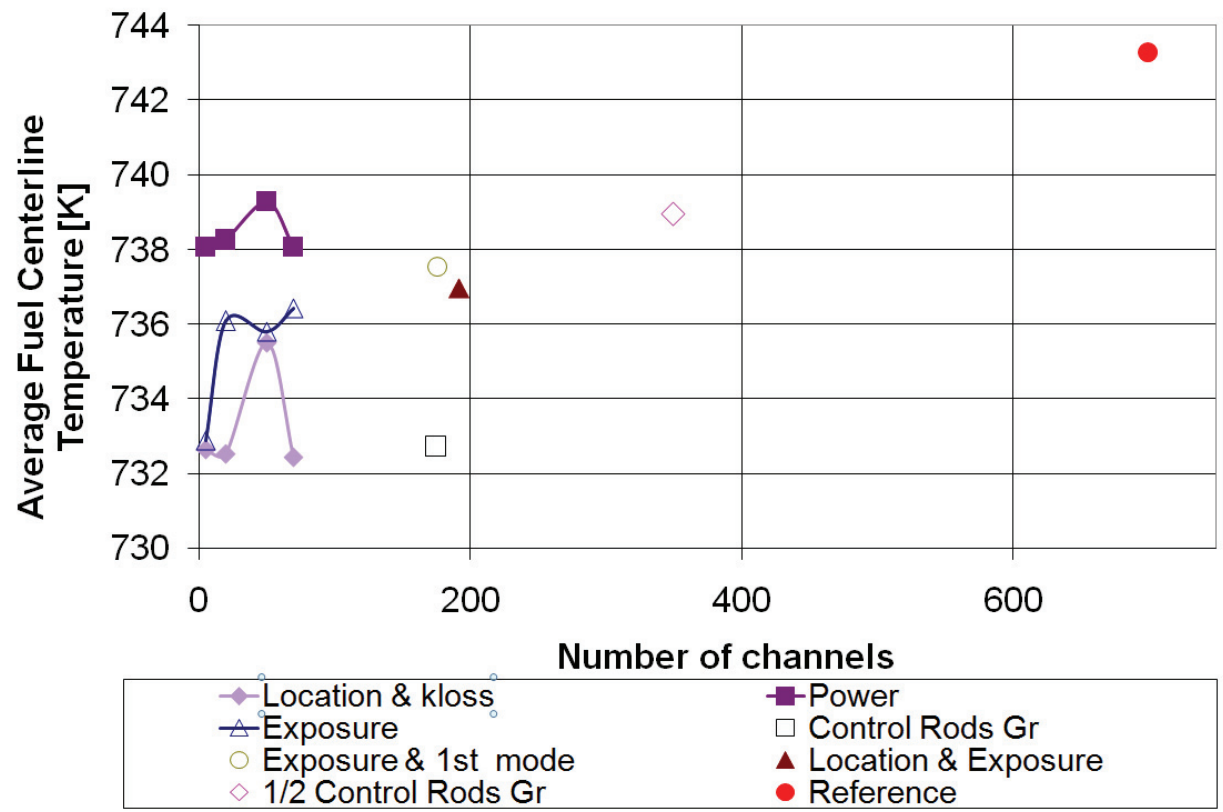

Figure 30: Average Fuel Centerline Temperature (BWR-1 Model I).

Table 8: Comparison of steady-state results (BWR-1 Model I).

\begin{tabular}{|c|c|c|c|c|c|c|}
\hline 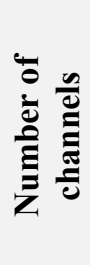 & 泀兰 & 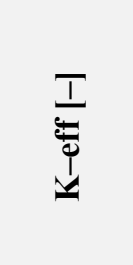 & 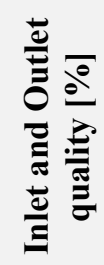 & 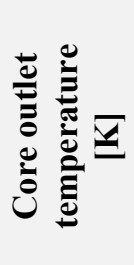 & 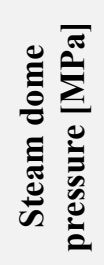 & 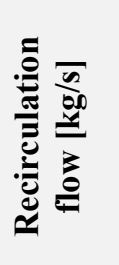 \\
\hline \multirow{3}{*}{5} & $\begin{array}{l}\text { Location } \\
\text { and } k_{\text {loss }}\end{array}$ & 0.98877 & $\begin{array}{l}-4.88 / \\
15.37\end{array}$ & 558 & 7.087 & 11354 \\
\hline & Power & 0.98365 & $\begin{array}{l}-4.81 / \\
15.11\end{array}$ & 558 & 7.087 & 11352 \\
\hline & Exposure & 0.98624 & $\begin{array}{l}-4.86 / \\
15.32\end{array}$ & 558 & 7.087 & 11397 \\
\hline \multirow{2}{*}{20} & $\begin{array}{l}\text { Location } \\
\text { and } k_{\text {loss }}\end{array}$ & 0.98709 & $\begin{array}{l}-4.89 / \\
15.40 \\
\end{array}$ & 558 & 7.087 & 11333 \\
\hline & Power & 0.98318 & $\begin{array}{c}-4.89 / \\
15.38\end{array}$ & 558 & 7.087 & 11348 \\
\hline
\end{tabular}




\begin{tabular}{|c|c|c|c|c|c|c|}
\hline & Exposure & 0.98363 & $\begin{array}{c}-4.87 / \\
15.37\end{array}$ & 558 & 7.087 & 11361 \\
\hline \multirow{3}{*}{50} & $\begin{array}{l}\text { Location } \\
\text { and } k_{\text {loss }}\end{array}$ & 0.98516 & $\begin{array}{c}-4.92 / \\
15.42\end{array}$ & 558 & 7.087 & 11320 \\
\hline & Power & 0.98243 & $\begin{array}{c}-4.89 / \\
15.39\end{array}$ & 558 & 7.087 & 11335 \\
\hline & Exposure & 0.98296 & $\begin{array}{c}-4.88 / \\
15.38\end{array}$ & 558 & 7.087 & 11350 \\
\hline \multirow{3}{*}{70} & $\begin{array}{l}\text { Location } \\
\text { and } k_{\text {loss }}\end{array}$ & 0.98581 & $\begin{array}{c}-4.89 / \\
15.40 \\
\end{array}$ & 558 & 7.087 & 11336 \\
\hline & Power & 0.98233 & $\begin{array}{c}-4.89 / \\
15.40\end{array}$ & 558 & 7.087 & 11333 \\
\hline & Exposure & 0.98260 & $\begin{array}{c}-4.88 / \\
15.39\end{array}$ & 558 & 7.087 & 11346 \\
\hline 175 & $\begin{array}{l}\text { Control } \\
\text { Rods }\end{array}$ & 0.98475 & $\begin{array}{c}-4.89 / \\
15.41\end{array}$ & 558 & 7.087 & 11324 \\
\hline 176 & $\begin{array}{l}1^{\text {st }} \text { Mode }+ \\
\text { Exposure }\end{array}$ & 0.98196 & $\begin{array}{c}-4.89 / \\
15.40\end{array}$ & 558 & 7.087 & 11333 \\
\hline 192 & $\begin{array}{c}\text { Exposure }+ \\
\text { Location }\end{array}$ & 0.98237 & $\begin{array}{c}-4.89 / \\
15.41\end{array}$ & 558 & 7.087 & 11332 \\
\hline 350 & $\begin{array}{l}1 / 2 \text { Control } \\
\text { Rods }\end{array}$ & 0.98251 & $\begin{array}{c}-4.89 / \\
15.42\end{array}$ & 558 & 7.087 & 11321 \\
\hline 700 & Reference & 0.98213 & $\begin{array}{c}-4.94 / \\
15.54\end{array}$ & 558 & 7.087 & 11227 \\
\hline
\end{tabular}

\subsubsection{BWR-1 Model II - Steady-State Results}

Table 9 shows selected average steady-state results obtained from BWR-1 Model II. Similar to Model I results, the integral average values are well converged and are not dependent on the type of mapping and number of TH channels. The largest variation in the steady-state average results is only $2 \%$. Therefore a consistent basis for transient comparison can be assumed.

Similar to the previous model (BWR-1 Model I), detailed results, e.g., radial and axial peaking factors are slightly different. The radial power peaking factors (see Figure 31) rapidly converge to about 1.7 with 
increasing number of $\mathrm{TH}$ channels. For the number of $\mathrm{TH}$ channels higher than 70 , the uncertainty in the radial peaking factor is about $2.5 \%$, regardless of the spatial mapping method used (except for $108 \mathrm{TH}$ channels model with mapping according $1^{\text {st }}$ mode and exposure). For lower number of channels, the radial peaking factor is conservative. Similar behavior can be seen for axial peaking factor (Figure 32). This confirms observation found in BWR-1 Model I and mentioned by other researchers [5].

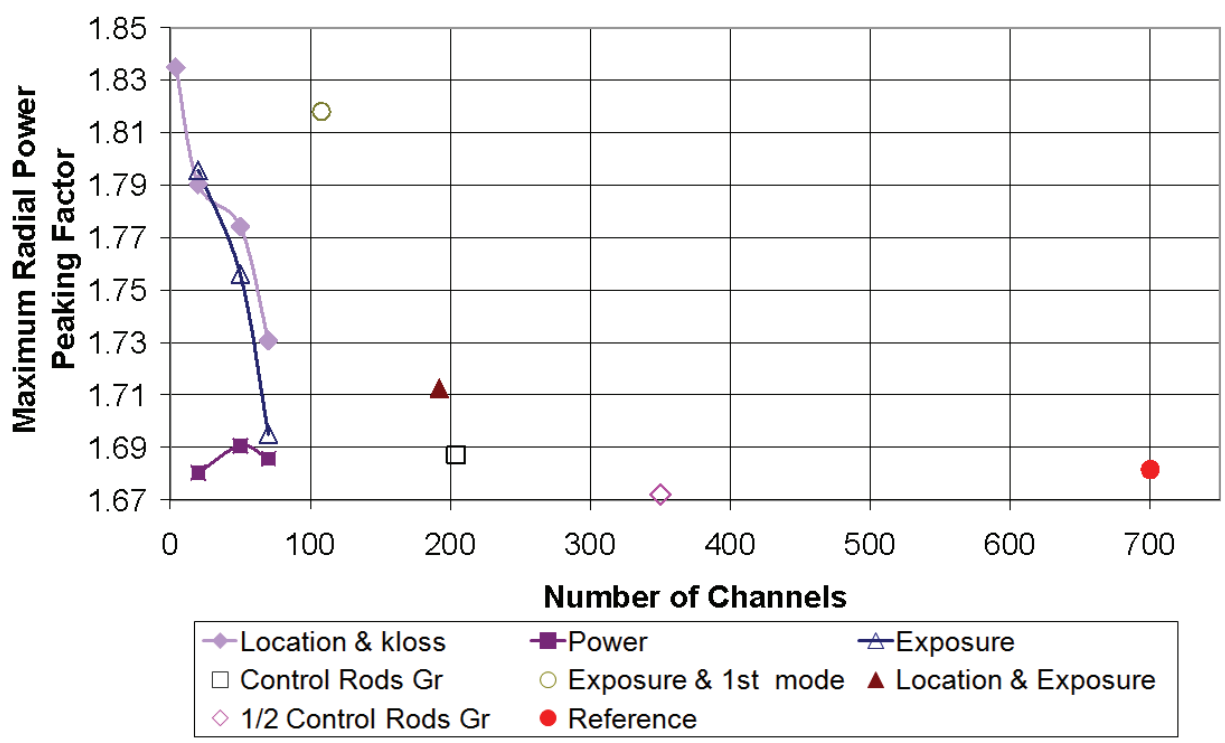

Figure 31: Maximum radial power peaking factor (BWR-1 Model II). 


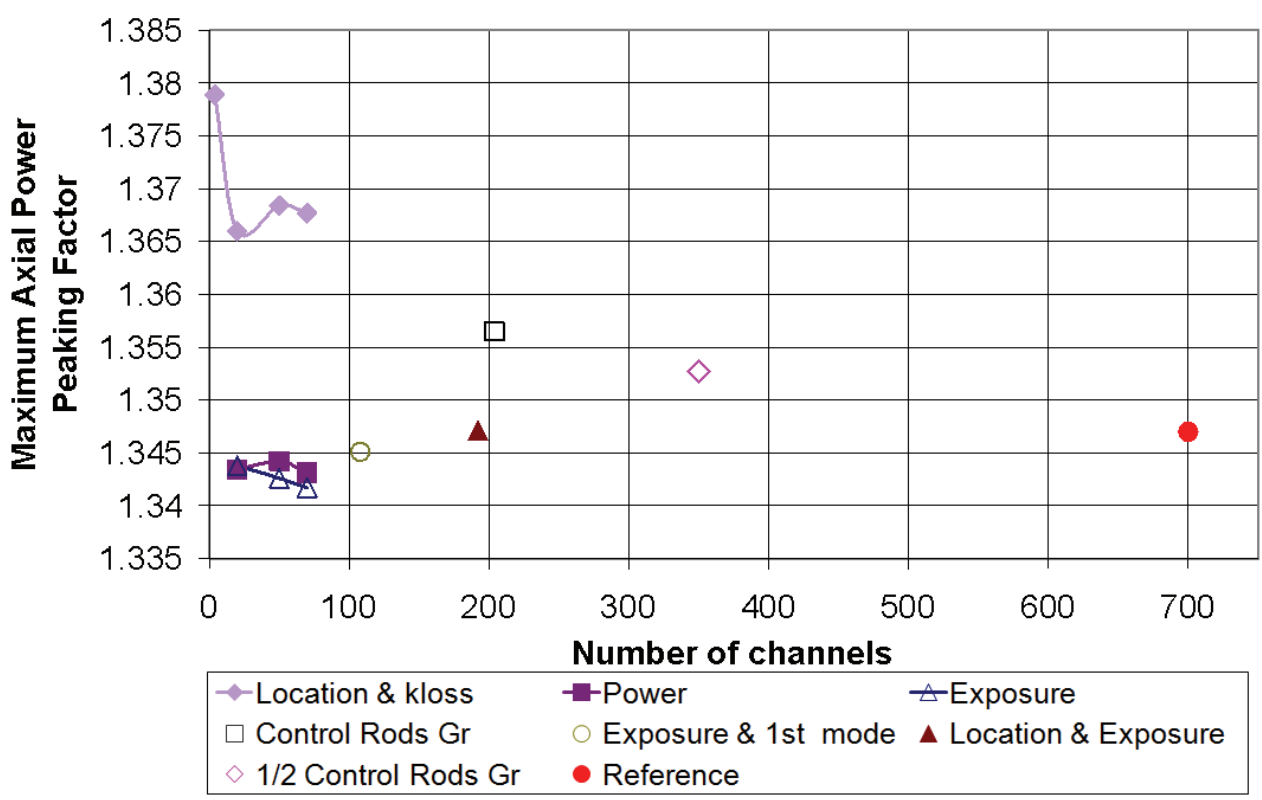

Figure 32: Maximum axial power peaking factor (BWR-1 Model II).

Table 9: Comparison of steady-state results (BWR-1 Model II).

\begin{tabular}{|c|c|c|c|c|c|c|}
\hline 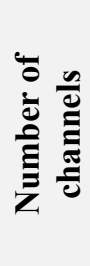 & 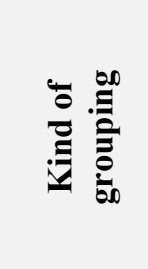 & $\begin{array}{l}T \\
\frac{T}{0} \\
I \\
I\end{array}$ & 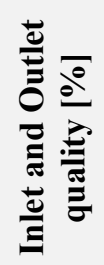 & 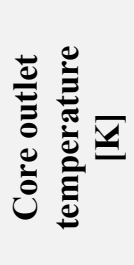 & 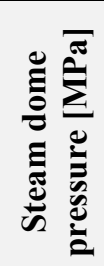 & 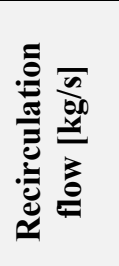 \\
\hline 4 & Location & 0.99868 & $\begin{array}{l}-4.80 / \\
14.86\end{array}$ & 558 & 7.045 & 11732 \\
\hline \multirow{3}{*}{20} & $\begin{array}{l}\text { Location } \\
\text { and } k_{\text {loss }}\end{array}$ & 0.98989 & $\begin{array}{l}-4.87 / \\
15.05 \\
\end{array}$ & 558 & 7.045 & 11571 \\
\hline & Power & 0.98664 & $\begin{array}{l}-4.85 / \\
15.02 \\
\end{array}$ & 558 & 7.045 & 11596 \\
\hline & Exposure & 0.98761 & $\begin{array}{c}-4.84 / \\
14.98\end{array}$ & 558 & 7.045 & 11634 \\
\hline \multirow{2}{*}{50} & $\begin{array}{l}\text { Location } \\
\text { and } k_{\text {loss }}\end{array}$ & 0.98977 & $\begin{array}{l}-4.86 / \\
15.04 \\
\end{array}$ & 558 & 7.045 & 11578 \\
\hline & Power & 0.98553 & $\begin{array}{c}-4.86 / \\
15.05\end{array}$ & 558 & 7.045 & 11574 \\
\hline
\end{tabular}




\begin{tabular}{|c|c|c|c|c|c|c|}
\hline & Exposure & 0.98667 & $\begin{array}{c}-4.85 / \\
15.02\end{array}$ & 558 & 7.045 & 11602 \\
\hline \multirow{2}{*}{70} & $\begin{array}{c}\text { Location } \\
\text { and } k_{\text {loss }}\end{array}$ & 0.98894 & $\begin{array}{c}-4.87 / \\
15.06\end{array}$ & 558 & 7.045 & 11564 \\
\cline { 2 - 7 } & Power & 0.98519 & $\begin{array}{c}-4.87 / \\
15.05\end{array}$ & 558 & 7.045 & 11571 \\
\cline { 2 - 7 } & Exposure & 0.98580 & $\begin{array}{c}-4.85 / \\
15.03\end{array}$ & 558 & 7.045 & 11592 \\
\hline \multirow{2}{*}{108} & $\begin{array}{c}\text { st Mode }+ \\
\text { Exposure }\end{array}$ & 0.98676 & $\begin{array}{c}-4.86 / \\
15.03\end{array}$ & 558 & 7.045 & 11594 \\
\hline 192 & $\begin{array}{c}\text { Exposure }+ \\
\text { Location }\end{array}$ & 0.98527 & $\begin{array}{c}-4.86 / \\
15.06\end{array}$ & 558 & 7.045 & 11569 \\
\hline 204 & $\begin{array}{c}\text { Control } \\
\text { Rods }\end{array}$ & 0.98744 & $\begin{array}{c}-4.87 / \\
15.07\end{array}$ & 558 & 7.045 & 11560 \\
\hline 350 & $\begin{array}{c}1 / 2 \text { Control } \\
\text { Rods }\end{array}$ & 0.98562 & $\begin{array}{c}-4.87 / \\
15.07\end{array}$ & 558 & 7.045 & 11560 \\
\hline 700 & \begin{tabular}{c} 
Reference \\
\multirow{2}{*}{20.98357}
\end{tabular} & $\begin{array}{c}-4.89 / \\
15.12\end{array}$ & 558 & 7.045 & 11514 \\
\hline
\end{tabular}

\subsection{TRACE/PARCS Steady-State Results of BWR-2}

The OECD Ringhals-1 Stability Benchmark [32][33][34] has been chosen to test the new hierarchical clustering mapping approach proposed in Chapter 3. The purpose of this benchmark has been to enable code developers to validate codes' and models' capability for stability analysis.

The availability of reference axial, radial and nodal power distributions which had been reconstructed based on the real Local Power Range Monitors (LPRM) measurements makes this Benchmark attractive for many kinds of code validations. The reconstructed power profiles are marked on figures as Reference.

The Benchmark database consists of measurements for four cycles (cycle 14, 15, 16 and 17). Each cycle includes about 10 operating points with different power and main recirculation flow [32][33]. In this thesis for the 
purpose of comparison, three different stability points with full coverage of DR range were selected; from high (point 9), to medium (point 6) to low (point 1) DR of the cycle 14 were chosen (Figure 33, [33]). The comparison of these points is attractive because of different axial power profile: top-peaked (point 1), bottom-peaked (point 6) and very bottom-peaked (point 9). Since the points have different boundary conditions, the detailed steady-state results were compared.

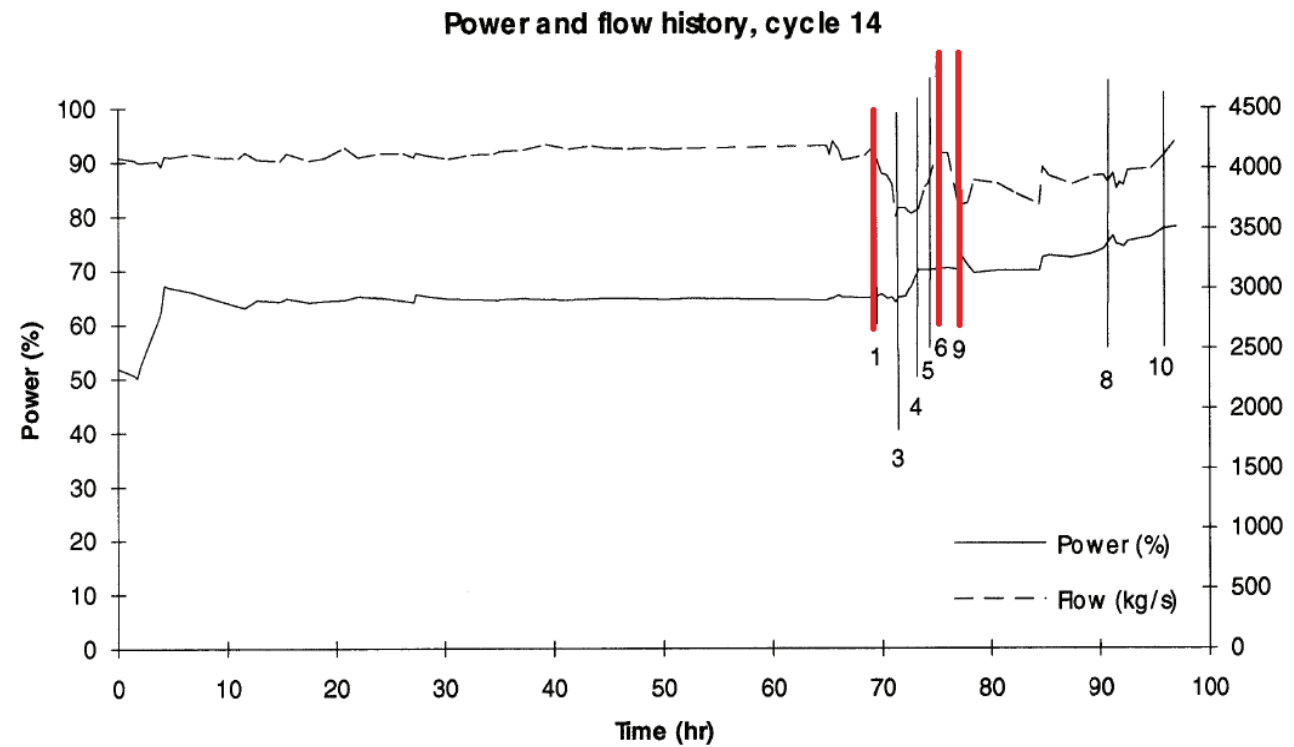

Figure 33: Ringhals-1 Stability Benchmark, power and flow history, c14.

For the stability test of Ringhals-1, the reactor is not at full power and that may influence the steady-state results. It was observed that whenever the operating conditions are out of the common range (full power, full recirculation flow) the steady-state convergence is more difficult. To avoid the convergence problem, the steady-state calculations were performed with small time steps, ranging from $1 . e-6$ to 0.01 seconds, and were carried out for 500 seconds, which was enough to achieve converged steady-state solutions. Additionally to check the steady-state convergence 
quality the null-transients, were run before the beginning of the real perturbation.

Figure 34 presents the growing distortion of axial power profile which depends on spatial refinement (number of $\mathrm{TH}$ channels and mapping schemes). The mapping used to generate these results was "mixed".

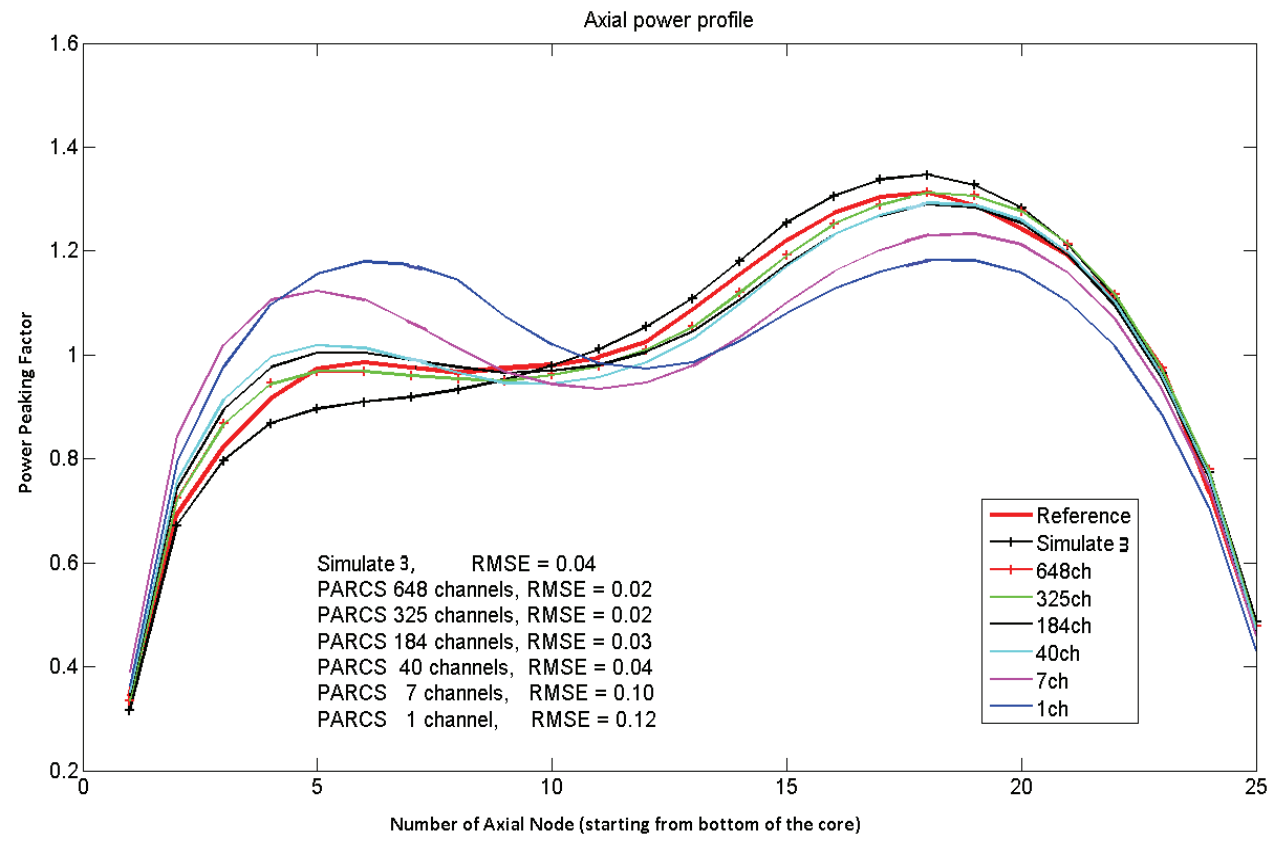

Figure 34: Axial power profile vs. spatial convergence, point 1 of cycle 14.

In order to verify prediction of full-scale BWR-2 model, the results are compared with the Benchmark reference and SIMULATE-3 [32][33]. The comparisons of axial power predictions are presented in the Figure 35, Figure 39 and Figure 43 for all the three points (1,6 and 9, respectively) of cycle 14 . 
The comparisons of radial power TRACE/PARCS predictions with the Benchmark reference are presented in the Figure 36, Figure 40 and Figure 44 for all the three points (1,6 and 9, respectively) of cycle 14 . Figure 37, Figure 41, Figure 45 present comparisons of the radial power predictions of the BWR-2 TRACE/PARCS and SIMULATE-3.

One can see that the TRACE/PARCS and SIMULATE-3 radial power distributions are very close to each other, (Figure 38, Figure 42 and Figure 46). In addition, both codes have similar prediction RMSE, relative to the Benchmark Reference and between themselves (Table 10 provides the deviation results of the power predictions).

Summarizing, it can concluded that the TRACE/PARCS BWR-2 fullscale model is acceptable and can be used as a reference for further comparison of other parameters that are not supplied in the Benchmark itself.

Table 10: Steady-state RMSE of TRACE and SIMULATE-3 for the full scales models.

\begin{tabular}{|c|c|c|c|c|c|c|c|c|c|}
\hline \multirow{3}{*}{$\begin{array}{c}\text { Cycle } \\
\text { point }\end{array}$} & \multicolumn{9}{|c|}{$\mathrm{RMSE}^{14}$} \\
\hline & \multicolumn{3}{|c|}{$\begin{array}{l}\text { SIMULATE-3 - } \\
\text { Reference }\end{array}$} & \multicolumn{3}{|c|}{$\begin{array}{c}\text { TRACE/PARCS - } \\
\text { Reference }\end{array}$} & \multicolumn{3}{|c|}{$\begin{array}{l}\text { SIMULATE-3 - } \\
\text { TRACE/PARCS }\end{array}$} \\
\hline & Axial & Radial & Nodal & Axial & Radial & Nodal & Axial & Radial & Nodal \\
\hline $\begin{array}{c}1 \\
(65 \% / \\
58.64 \%)\end{array}$ & 0.036 & 0.030 & 0.060 & 0.024 & 0.025 & 0.049 & 0.043 & 0.013 & 0.053 \\
\hline $\begin{array}{c}6 \\
(70.2 \% / \\
58.94 \%)\end{array}$ & 0.028 & 0.028 & 0.055 & 0.076 & 0.026 & 0.094 & 0.057 & 0.008 & 0.068 \\
\hline $\begin{array}{c}9 \\
(72.6 \% / \\
52.77 \%)\end{array}$ & 0.099 & 0.021 & 0.114 & 0.041 & 0.018 & 0.056 & 0.081 & 0.009 & 0.094 \\
\hline
\end{tabular}

\footnotetext{
${ }^{14}$ The used RMSE (Root Mean Square Error) equation (3.1) is supplied in Appendix III.
} 


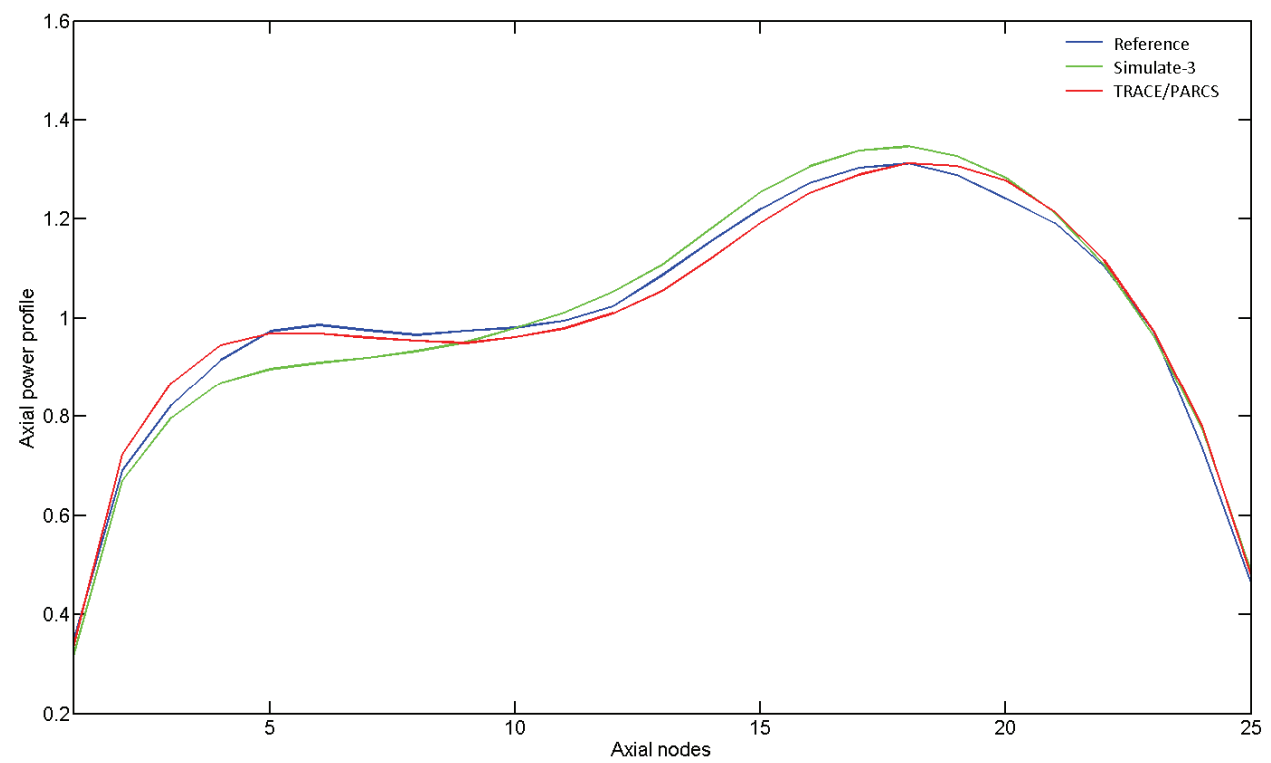

Figure 35: Comparison of axial power profile, point 1 of cycle 14.

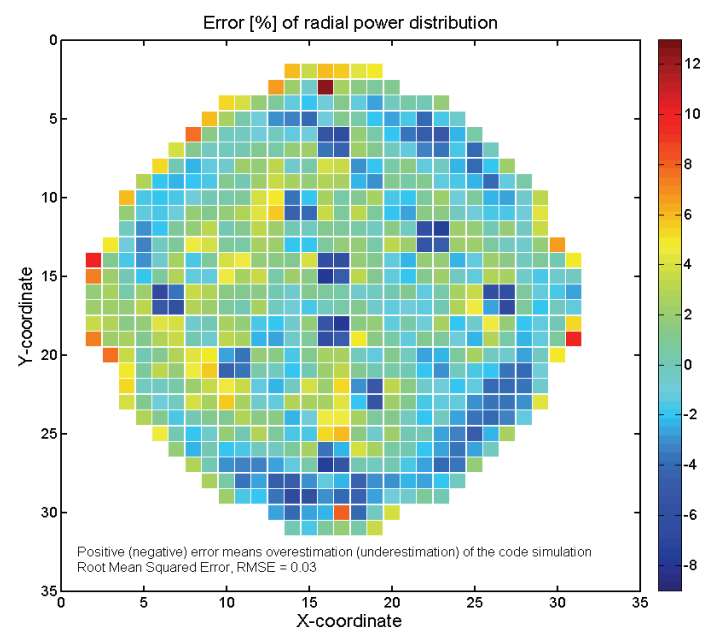

Figure 36: Comparison of radial power distribution of TRACE/PARCS $B W R-2$ full-scale with the reference, point 1 of cycle 14.

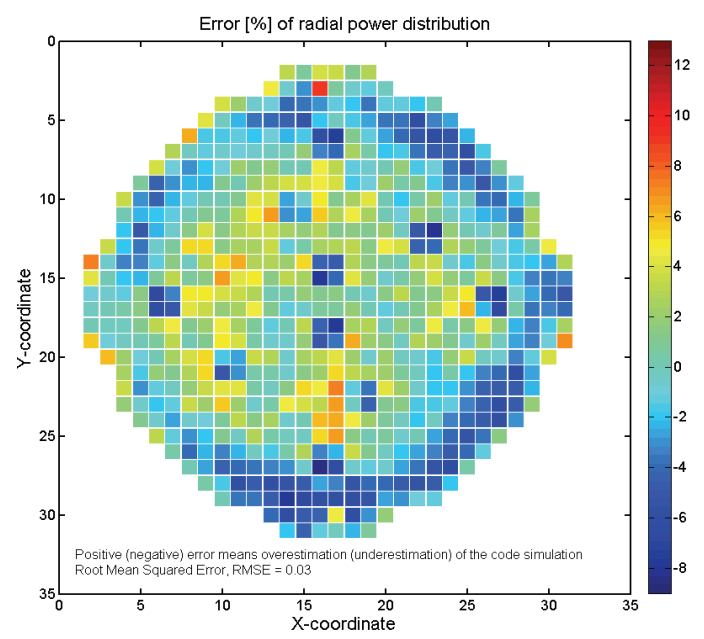

Figure 37: Comparison of radial power distribution of SIMULATE-3 with the reference, point 1 of cycle 14. 


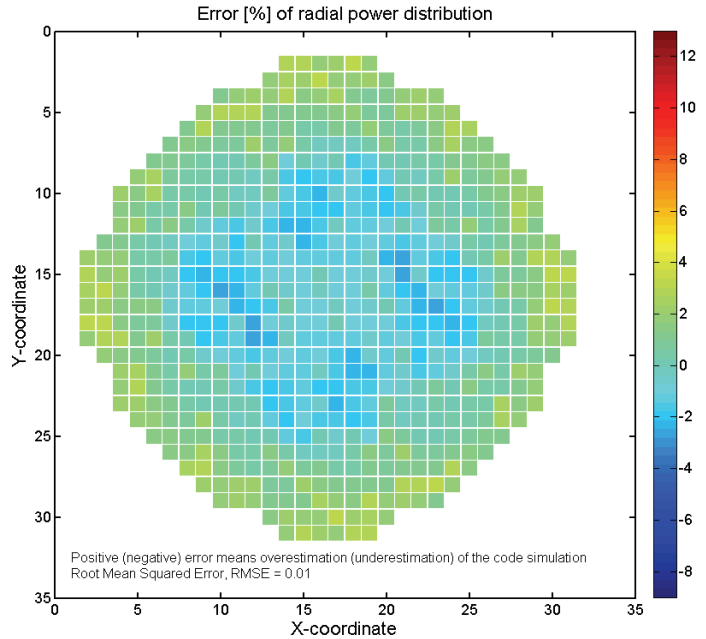

Figure 38: Comparison of radial power distribution of SIMULATE-3 with the BWR-2 TRACE/PARCS, point 1 of cycle 14.

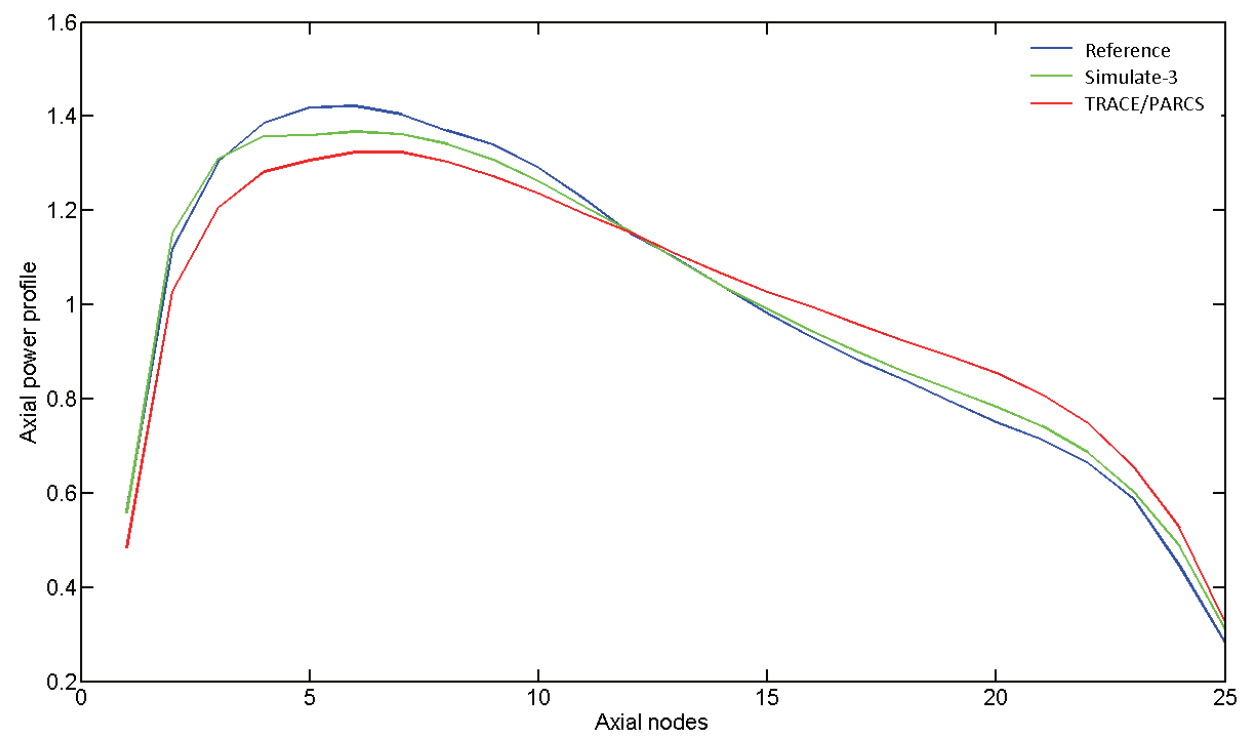

Figure 39: Comparison of axial power profile, point 6 of cycle 14. 


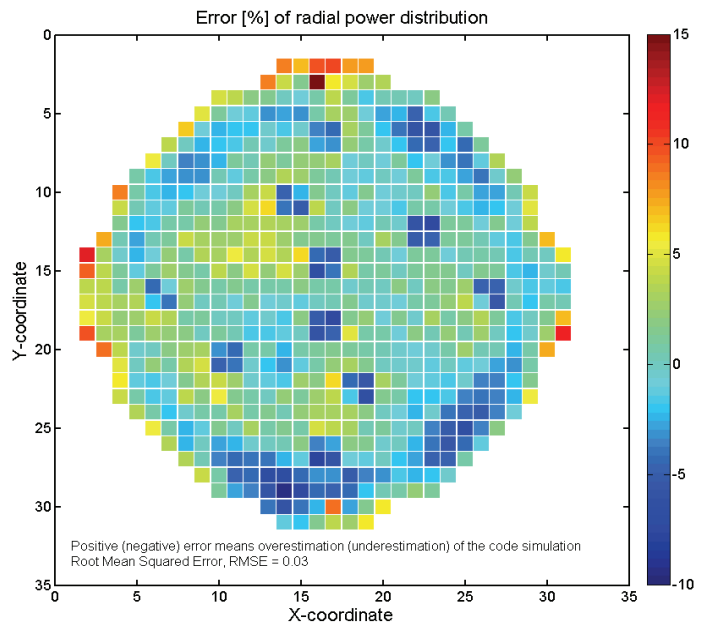

Figure 40: Comparison of radial power distribution of TRACE/PARCS $B W R-2$ full-scale with the reference, point 6 of cycle 14.

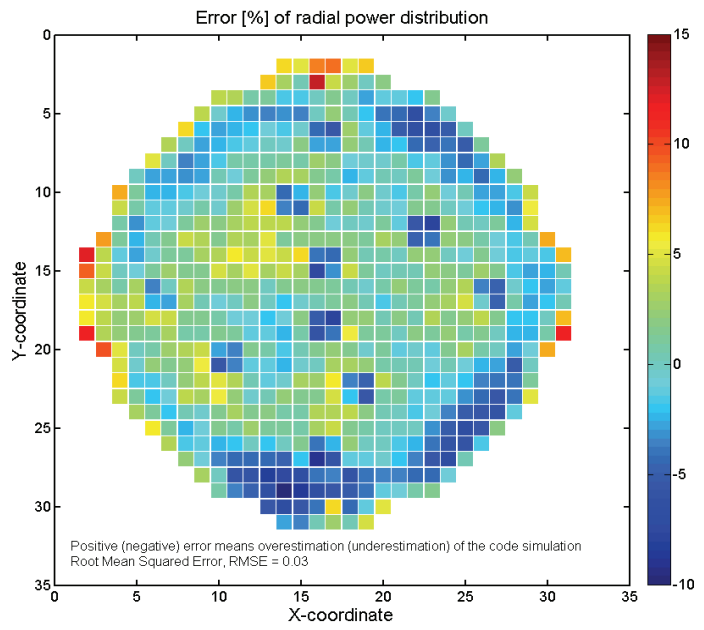

Figure 41: Comparison of radial power distribution of SIMULATE-3 with the reference, point 6 of cycle 14.

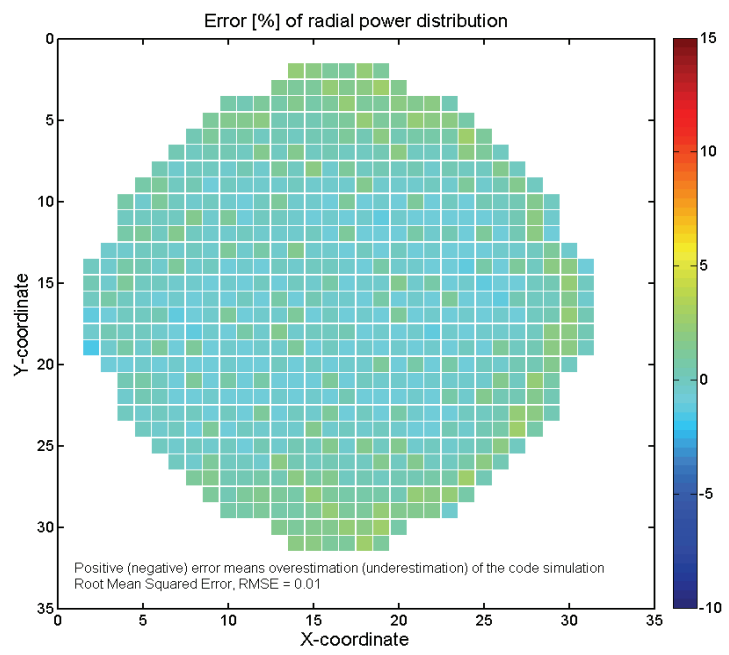

Figure 42: Comparison of radial power distribution of SIMULATE-3 with the BWR-2 TRACE/PARCS full-scale, point 6 of cycle 14. 


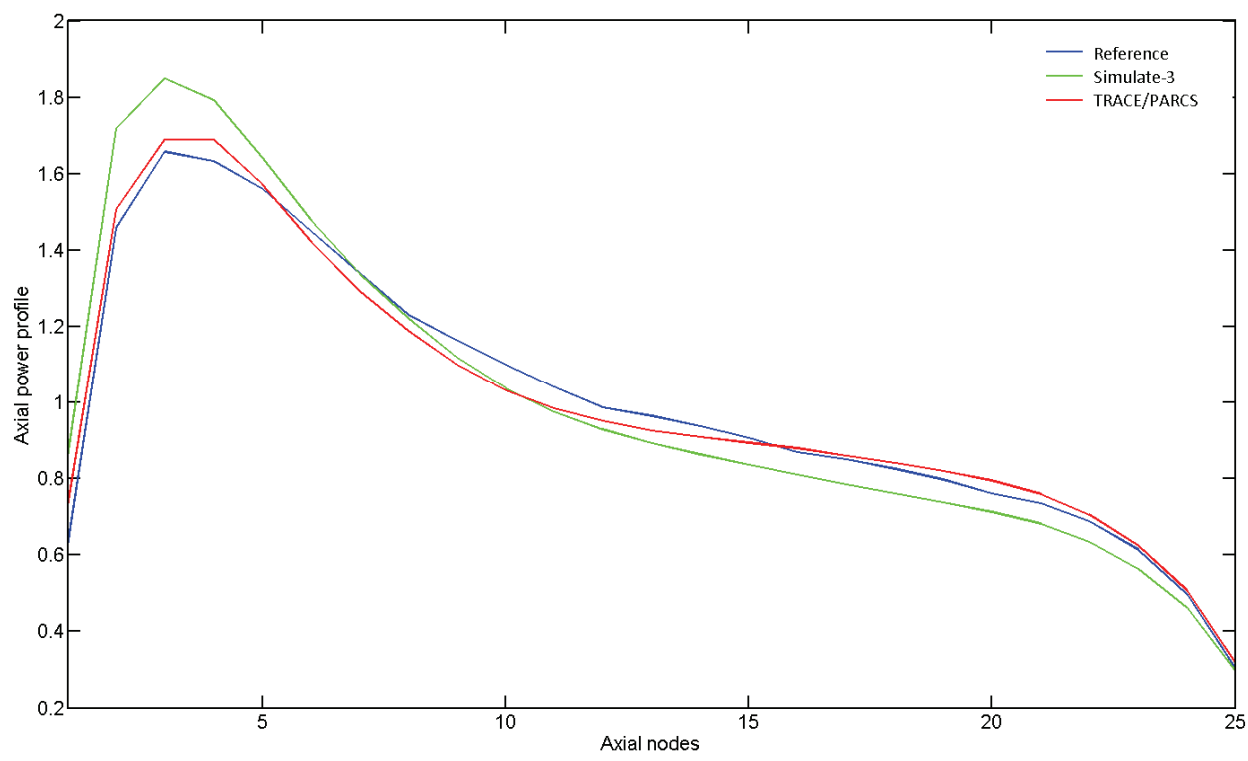

Figure 43: Comparison of axial power profile, point 9 of cycle 14.

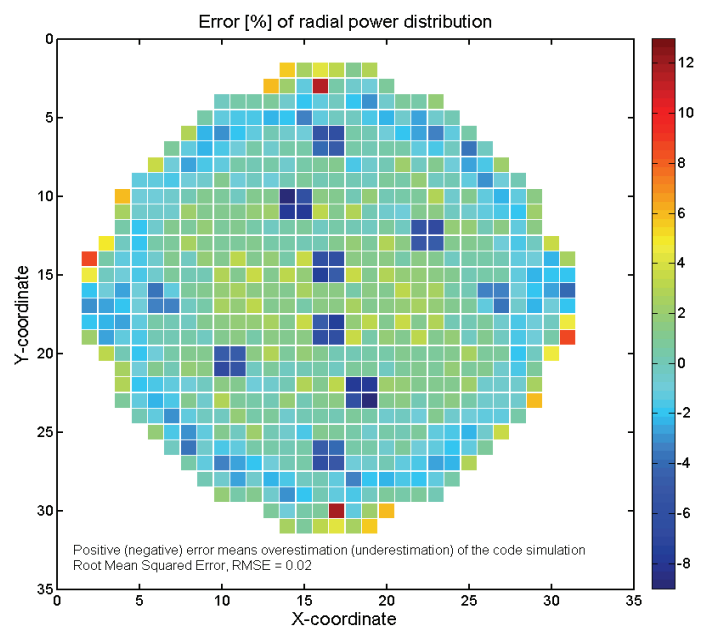

Figure 44: Comparison of radial power distribution of $B W R-2$ TRACE/PARCS full scale with the reference, point 9 of cycle 14.

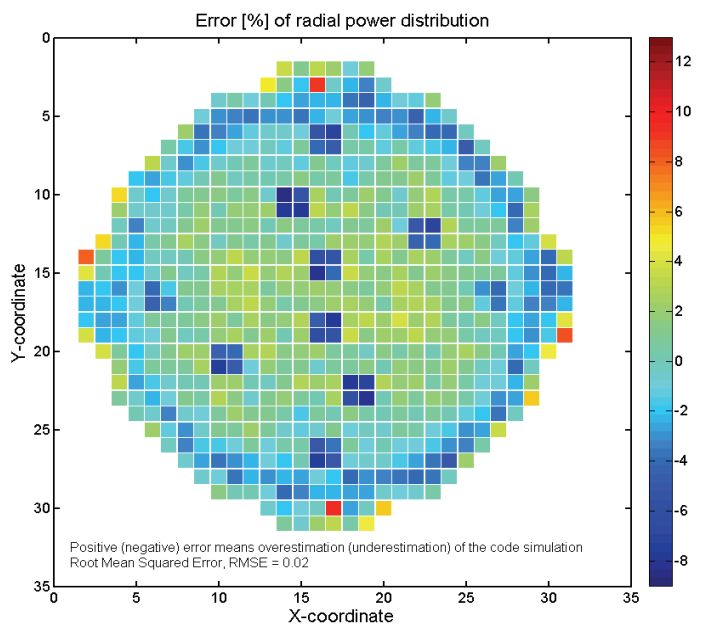

Figure 45: Comparison of radial power distribution of SIMULATE-3 with the reference, point 9 of cycle 14. 


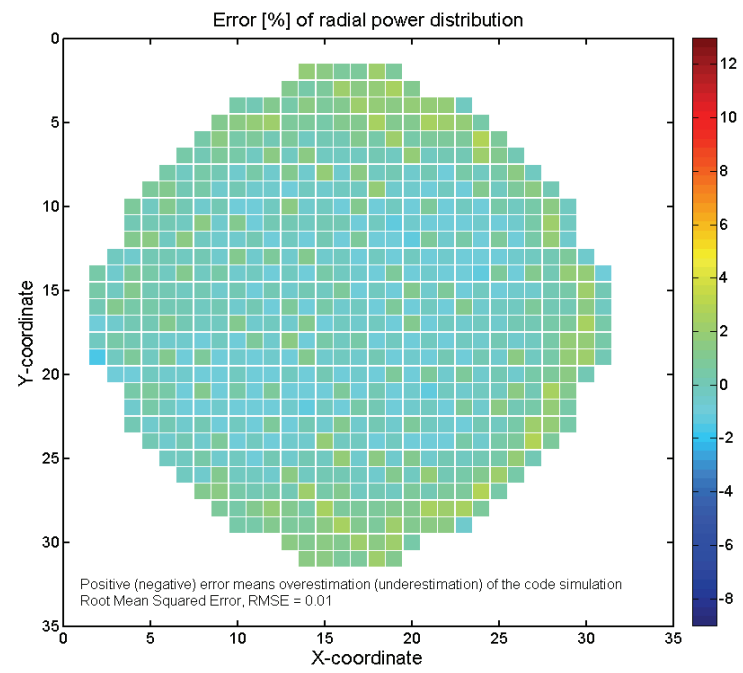

Figure 46: Comparison of radial power distribution of SIMULATE-3 with the BWR-2 TRACE/PARCS full-scale, point 9 of cycle 14.

The $\mathrm{RMSE}^{14}$ versus number of TH channels for different mapping schemes is supplied in Appendix III (starting from Figure A3.1 to Figure A3.9). It was found that the RMSE of the point 9 (bottom-peaked power profile) has the fastest converge ${ }^{15}$, and only 5 channels can be enough to obtain accurate axial power profile. In the case of radial and nodal power profiles, the RMSE with 50 channels was improved by about 50\%. A similar behavior of RMSE of radial and nodal power profiles can be observed for the point 1 (top-peaked axial power profile), however the axial power needs at least 40 channels to reach the similar accuracy as the full-scale prediction $^{15}$. Point 6 (bottom-peaked) does not show univocal results, namely, the RMSE of the radial and nodal power increases for some mappings (low number of TH channels) and decreases for the others. From about $60 \mathrm{TH}$ channels and up, the RMSE for all mapping cases converges - the results are sensitive to mapping scheme. Surprisingly,

\footnotetext{
${ }^{15}$ The observation is valid only for some mapping schemes.
} 
instead of converging to zero, the RMSE of axial power for point 6 increases by about $50 \%$ for the full-scale model; Figure 47 shows the axial power comparisons for this case. This is because the full-scale model underestimates axial power peak, while few-channel models overestimate the axial power peak.

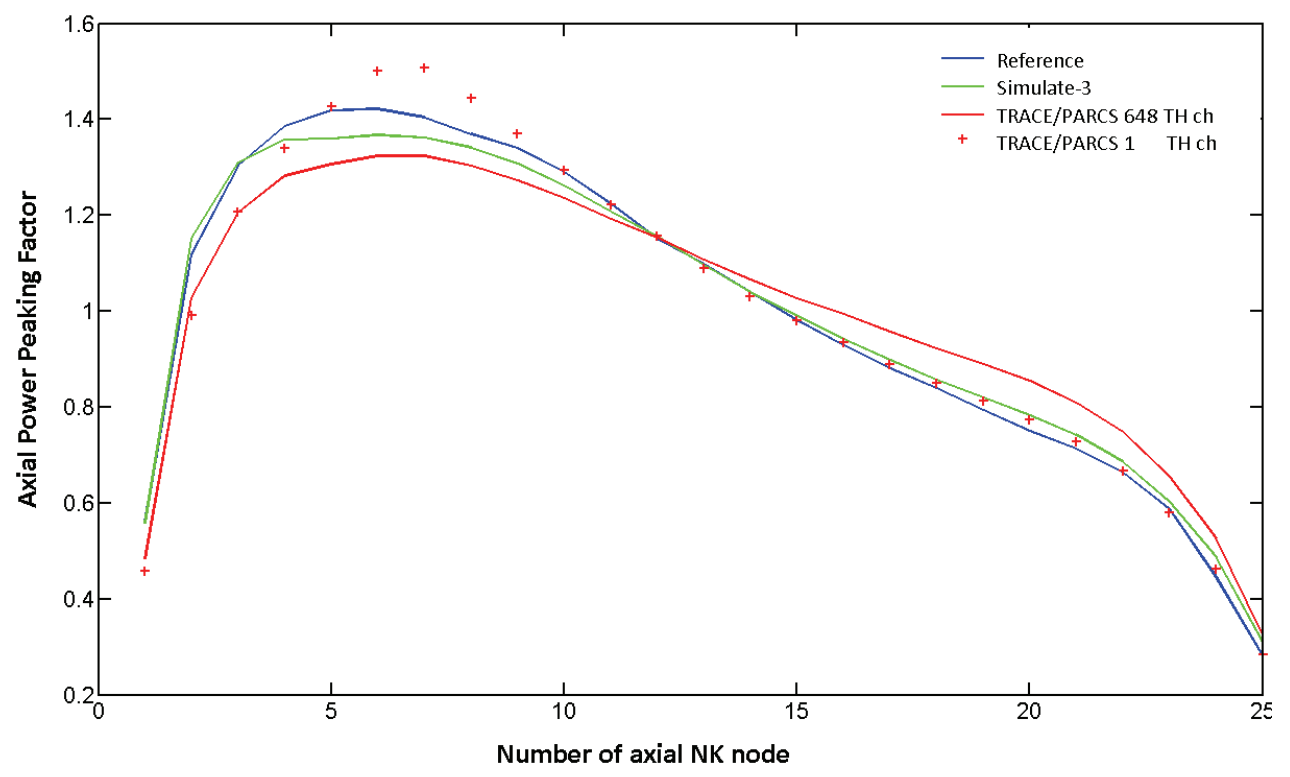

Figure 47: Comparison of axial power profile, point 6 of cycle 14.

Other parameters which were compared are: radial power peaking factor (Pxy), axial power peaking factor (Pz), centerline fuel temperature (max), average fuel Doppler temperature, average moderator density and $k_{\text {eff }}$.

The maximum radial power peaking factor (Pxy, Figure A3.10 Figure A3.12 of Appendix III) is overestimated ( $50 \%)$ for the model with low number of TH channels. It is also very mapping dependent, and the uncertainty of less than $10 \%$ is reached with at least $81 \mathrm{TH}$ channels for points 1 and 6 , and $40 \mathrm{TH}$ channels for point 9 (the observation is valid 
only for some mappings). The maximum axial peaking factor $\mathrm{Pz}$ (as provided in Figure A3.13 - Figure A3.15 of Appendix III) for the model with low number of TH channels, is over-predicted up to $12 \%$ for the axial bottom power peaking factor (points 6 and 9), and underestimated with 10 channels for the top-peak axial power profile (point 1).

The maximum centerline fuel temperature (see Figure A3.16 Figure A3.18 in Appendix III) is under-predicted for the case with low number of $\mathrm{TH}$ channels by $30 \%$ for all the three points. It has also tendency to converge fast to full-scale model, and for some mapping cases even $50 \mathrm{TH}$ channels are sufficient to reach the full-scale model accuracy. This parameter will influence the local cladding temperature, which is extremely important in fast dry-out transients and LOCA (Loss-ofCoolant-Accident) calculations, where the fuel cladding temperature is one of the safety criteria. To avoid any unnecessary averaging during this particular transient, pre-defined hot channels are used. In addition, it is important to remember that this parameter is sensitive to not only mapping scheme but also number of $\mathrm{TH}$ channels.

The average Doppler fuel temperature (Figure A3.19 - Figure A3.21 in Appendix III) are over-predicted by about $1 \%$, it shows extremely fast convergence to full-scale value (from 5 channels) and is slightly sensitive to mapping and not sensitive to number TH channels.

The average moderator density (Figure A3.22 - Figure A3.24 in Appendix III) is under-predicted by $\sim 10 \%$ for low number of $\mathrm{TH}$ channels and converges faster with bottom power peak cases, depending on mapping type. Even with $5 \mathrm{TH}$ channels the error in prediction can be reduced significantly.

The core $k_{\text {eff }}$ value systematically decreases with increasing number of TH channels (Figure A3.25 - Figure A3.27 are provided in Appendix III). 


\subsection{Summary of Steady-State Results}

Summarizing the steady-state results from both TH codes, RELAP5 and TRACE, it has been found that some parameters are constantly overpredicted with a low number of $\mathrm{TH}$ channels e.g. axial and radial power peaking factors. The reason for this is TH feedback, which due to low number of TH channels delivers the same average information to each fuel bundle, e.g., average void fraction, which for low number of TH channels is over-predicted. This average information causes that the non-uniformity of local TH parameters distribution vanishes and this is a reason for incorrect predictions e.g. the high power assembly will get higher moderator density (average moderator density) and lower fuel temperature than it really should, in consequence of that, the fuel peaking factor will be even higher. On the other hand some parameters are always underpredicted e.g. average and centerline fuel temperatures. Some parameters show fast convergence and always low prediction uncertainty e.g. average fuel Doppler temperature with its maximum uncertainty of 3\%. In addition, the value of $k_{\text {eff }}$ seems to decrease with the increasing number of $\mathrm{TH}$ channels, which is reasonable taking into consideration that other $\mathrm{TH}$ parameters are also changing, e.g., the fuel temperature is increasing with the increasing number of TH channels; the higher temperature of the fuel contributes larger amounts of negative reactivity (Doppler Effect) and that adds to continues decrease of $k_{\text {eff. }}$.

At least $324 \mathrm{TH}$ channels (one channel per two fuel bundles) are needed to get ideal predictions of nodal, radial and axial power profiles in the reduced power and flow conditions of Ringhals- 1 . Some of the parameters converge faster, while the others need more detailed model, but in general the models with $\sim 100 \mathrm{TH}$ channels and up return satisfactory results. For the detail information of steady-state spatial coupling convergence of the TH and NK parameters see Table 11. 
Scrutinizing the mapping performance, the best predictions for steady-state conditions are the mappings which include the power peaking factor feature alone or with any combination of $\left(k_{\text {loss }}\right), \mathrm{X}$ and $\mathrm{Y}$ coordinates, fuel types and $1^{\text {st }}$ harmonic mode, as well as the values to keep the core symmetry (symmetry feature). The peaking factor mapping is not easy to implement since it needs full-scale steady-state pre-calculations. The worse performance has mapping with $1^{\text {st }}$ harmonic mode feature alone and therefore it is not recommended, except for combination with peaking factors and fuel types.

In addition, no meaningful difference in results was found between the "automatized" and "manual" mappings. However, there is a difference in simulation time needed to achieve well-converged steady state. The fastest are those using pre-calculated features, e.g., power peaking factor, while those with location (e.g., X \& Y coordinates) or exposure features need more time.

Table 11: Steady-state spatial coupling convergence of TH and NK parameters.

\begin{tabular}{cccc}
\hline Parameter & $\begin{array}{c}\text { Number of } \\
\text { minimum } \\
\text { recommended } \\
\text { TH channels }\end{array}$ & $\begin{array}{c}\text { Recommended mapping } \\
\text { type }\end{array}$ & Comments \\
\hline $\begin{array}{c}\text { Steam dome } \\
\text { pressure }\end{array}$ & Any & Any & $\begin{array}{c}\text { Parameter is not } \\
\text { influenced by spatial } \\
\text { coupling }\end{array}$ \\
$\begin{array}{c}\text { Steam flow in } \\
\text { steam lines }\end{array}$ & Any & Any & $\begin{array}{c}\text { Parameter is not } \\
\text { influenced by spatial } \\
\text { coupling }\end{array}$ \\
$\begin{array}{c}\text { Core inlet and } \\
\text { outlet }\end{array}$ & Any & Any & $\begin{array}{c}\text { Parameter is not } \\
\text { influenced by spatial } \\
\text { coupling }\end{array}$ \\
$\begin{array}{c}\text { Inlet and } \\
\text { outlet quality }\end{array}$ & Any & Any & $\begin{array}{c}\text { Parameter is not } \\
\text { influenced by spatial } \\
\text { coupling }\end{array}$ \\
\hline
\end{tabular}




\begin{tabular}{|c|c|c|c|}
\hline $\begin{array}{l}\text { Recirculation } \\
\text { flow rate }\end{array}$ & Any & Any & $\begin{array}{l}\text { Parameter is not } \\
\text { influenced by spatial } \\
\text { coupling }\end{array}$ \\
\hline $\begin{array}{c}\text { Average } \\
\text { moderator } \\
\text { temperature }\end{array}$ & Any & Any & $\begin{array}{l}\text { Parameter is not } \\
\text { influenced by spatial } \\
\text { coupling; the } \\
\text { temperature variation is } \\
\text { less than } 1^{\circ} \text {. }\end{array}$ \\
\hline $\begin{array}{l}\text { RMSE of } \\
\text { nodal power } \\
\text { distribution }\end{array}$ & $\begin{array}{l}40^{16} \text { and up, } \\
100^{17} \text { and up }\end{array}$ & $\begin{array}{l}\text { Combination of power } \\
\text { peaking factors with x\&y } \\
\text { coordinates or symmetry } \\
\text { feature, alternatively } \\
\text { combination of fuel types } \\
\text { with core symmetry. }\end{array}$ & $\begin{array}{c}\text { Parameter is strongly } \\
\text { dependent on spatial } \\
\text { coupling }\end{array}$ \\
\hline $\begin{array}{c}\text { RMSE of } \\
\text { radial power } \\
\text { distribution }\end{array}$ & 80 and up & $\begin{array}{l}\text { Combination of power } \\
\text { peaking factors with x\&y } \\
\text { coordinates or symmetry } \\
\text { feature, alternatively } \\
\text { combination of fuel types } \\
\text { with core symmetry or } \\
\text { inlet orifice with } \\
\text { symmetry feature. }\end{array}$ & $\begin{array}{c}\text { Parameter is strongly } \\
\text { dependent on spatial } \\
\text { coupling }\end{array}$ \\
\hline $\begin{array}{c}\text { RMSE of } \\
\text { axial power } \\
\text { distribution }\end{array}$ & $\begin{array}{l}5 \text { and up, } \\
30^{17} \text { and up }\end{array}$ & $\begin{array}{l}\text { Peaking power factor } \\
\text { alone or with combination } \\
\text { of x\&y coordinates or } \\
\text { symmetry feature, or inlet } \\
\text { orificing, alternatively } \\
\text { combination of fuel types } \\
\text { with core symmetry or } \\
\text { inlet orifice with } \\
\text { symmetry feature. } \\
\text { Exposure mapping with } \\
\text { or without symmetry } \\
\text { feature. }\end{array}$ & $\begin{array}{l}\text { Parameter is strongly } \\
\text { dependent on spatial } \\
\text { coupling }\end{array}$ \\
\hline $\begin{array}{l}\text { Maximum } \\
\text { radial power } \\
\text { peaking factor }\end{array}$ & 81 and up & $\begin{array}{l}\text { Combination of power } \\
\text { peaking factors with } \\
\text { symmetry feature, } \\
\text { alternatively combination } \\
\text { of fuel types with } \\
\text { symmetry feature. }\end{array}$ & $\begin{array}{l}\text { Parameter is strongly } \\
\text { dependent on spatial } \\
\text { coupling }\end{array}$ \\
\hline
\end{tabular}

\footnotetext{
${ }^{16}$ This true for bottom-peaked axial power profiles.

${ }^{17}$ This is true for less common axial power profiles e.g., top-peaked.
} 


\begin{tabular}{|c|c|c|c|}
\hline $\begin{array}{l}\text { Maximum } \\
\text { axial power } \\
\text { peaking factor }\end{array}$ & 81 and up & $\begin{array}{l}\text { Combination of power } \\
\text { peaking factors with } \\
\text { symmetry feature or with } \\
\text { x\&y coordinates, } \\
\text { alternatively combination } \\
\text { of fuel types with } \\
\text { symmetry feature. }\end{array}$ & $\begin{array}{c}\text { Parameter is strongly } \\
\text { dependent on spatial } \\
\text { coupling }\end{array}$ \\
\hline
\end{tabular}

\section{Fuel centerline temperature}

Combination of control rods with peaking factors or exposure;

Parameter converges fast and for more than 160 TH channels it has reached its reference value and it is not more mapping dependent. For a top-peaked power profile every mapping with combination of power peaking factor over-estimates the temperature.

\section{Parameter converges} very fast and for more than $5 \mathrm{TH}$ channels it

Average fuel

Doppler temperature

\section{$>5$}

Power peaking factors without or with combination of inlet orifice or $1^{\text {st }}$ power mode, or symmetry feature. has reached its reference value for some mappings type. Usually it is overpredicted by about $1 \%$

Converges rather fast for some mapping kinds.

$\begin{array}{cc}\text { Average } & \\ \text { moderator } & >9^{16} \\ \text { density (core } & >81^{17} \\ \text { void fraction) } & \end{array}$

Power peaking factors without or with combination of inlet orifice or $1^{\text {st }}$ power mode, or symmetry feature, or control rods.

There is a need of bigger number of TH channels for less common power profiles. The void fraction is overpredicted for low number of TH channels.

\section{Parameter is dependent} on spatial coupling and is systematically decreasing with $\boldsymbol{k}_{\text {eff }}>20 \quad \begin{gathered}\text { control or exposure, or } \\ \mathrm{x} \& \mathrm{y} \text { coordinates, or }\end{gathered}$

Combination of power peaking factors with symmetry feature, or inlet orifice. increasing number of $\mathrm{TH}$ channels. 


\section{Chapter 5: Transient Calculations}

\subsection{RELAP5/PARCS Simulations of Transients}

RELAP5/PARCS has an ability to accurately evaluate reactivity feedback for localized perturbation including asymmetric flow conditions over a wide range of operating conditions. But in many cases obtained results may not be accurate enough due to mapping, which causes incorrect parameter averaging. To check the transient sensitivity to a mapping approach, the set of transients was chosen to cover a wide range of perturbations: global, regional and local; the following transients were simulated:

- Control Rods Perturbation (Model I),

- Local perturbation: Control Rod Drop Accident (Model I),

- Global perturbation: Turbine Trip without hydraulic SCRAM and bypass (Model I),

- Regional perturbation: Feedwater Transient (Model II).

Model I and II and the reason for differences are described in Chapter 2.

\subsubsection{Control Rods Perturbation Transient (CRP)}

\subsubsection{Introduction}

The purpose of this transient is to check Decay Ratio dependency on the TH/NK mapping. The system is perturbed by quick movement of control rods (CR are moved during 1 second - 
Table 12) groups 1, 2, 3, 4 and 5. Figure 48 presents the location of each control rod bank, which was used for perturbation (highlighted in a colored square - each color corresponds to one CR group).

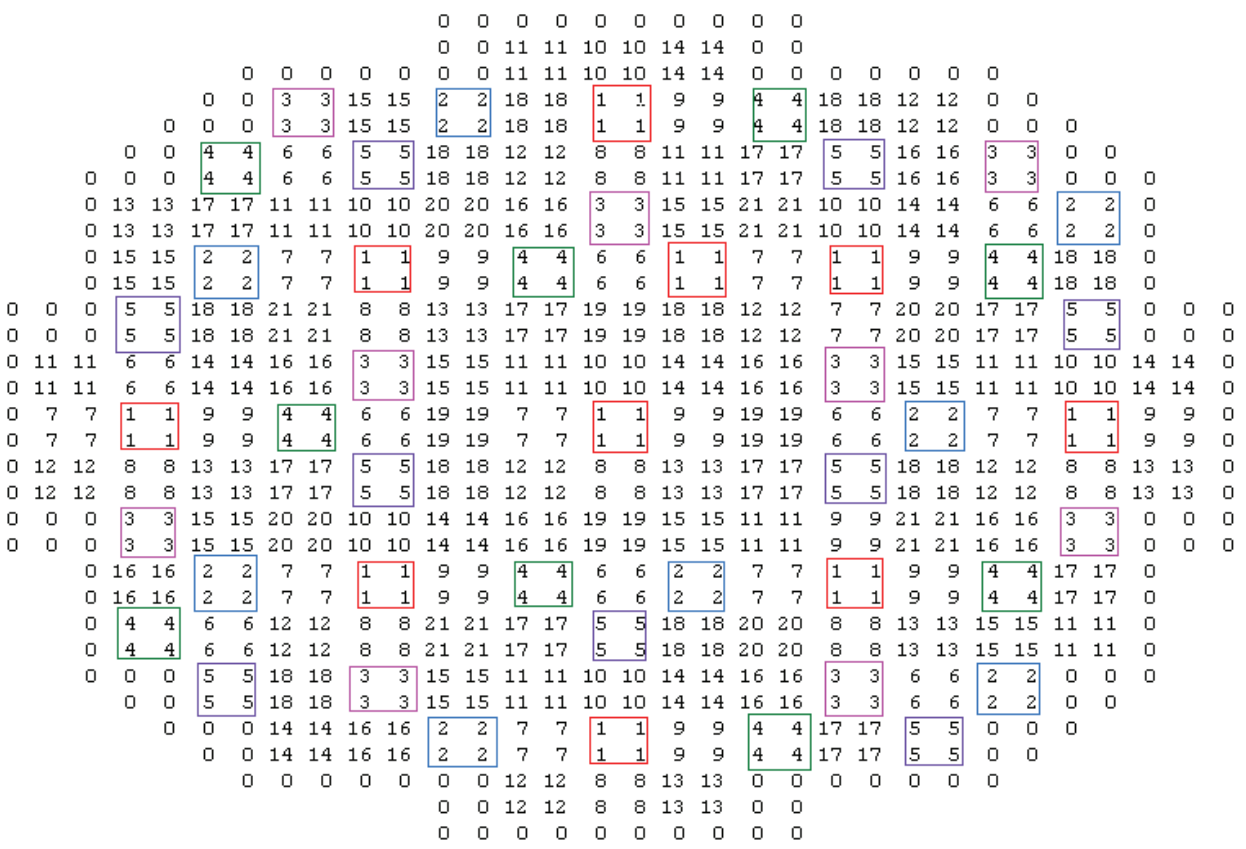

Figure 48: Groups of Control Rods involved in the CRP transient.

Table 12: Control Rods movement during CRP transient.

\begin{tabular}{|c|c|}
\hline Time [s] & $\begin{array}{c}\text { Control Rods Position } \\
{[\text { [steps] }]^{\mathbf{8}}}\end{array}$ \\
\hline 0 & 100 \\
\hline 0.5 & 90 \\
\hline 1 & 100 \\
\hline
\end{tabular}

${ }^{18}$ Control Rods Position: 100 - fully withdrawn, 0 - fully in. 


\subsubsection{Results comparison}

To compute the Decay Ratio (DR) and Frequency DRARMAX toolbox [23] was used. The results for various coupling strategies are shown in Figure 49 and Figure 50 for the Decay Ratio (DR) and Frequency (FR), respectively.

As can be seen on Figure 49, the DR slowly converges to the reference (a certain trend is visible) and it is sensitive to the number of $\mathrm{TH}$ channels. For the low number of channels, one can obtain an error up to $25 \%$, but the error is always conservative, i.e. the predicted DR is always higher than the reference DR. One of the many reasons for DR being over-prediction is that maximum power peaking factor is over-predicted for low number of $\mathrm{TH}$ channels and DR is dominated by high power assemblies. The correct frequency (see Figure 50) cannot be captured with any mapping, but the mean error is very small, $3 \%$ to $7 \%$, depending on the mapping strategy.

The location-based discretization appears to have the fastest convergence for the DR, but the worst for the FR. The exposure and power groupings show potential for inducing or sustaining oscillations. 


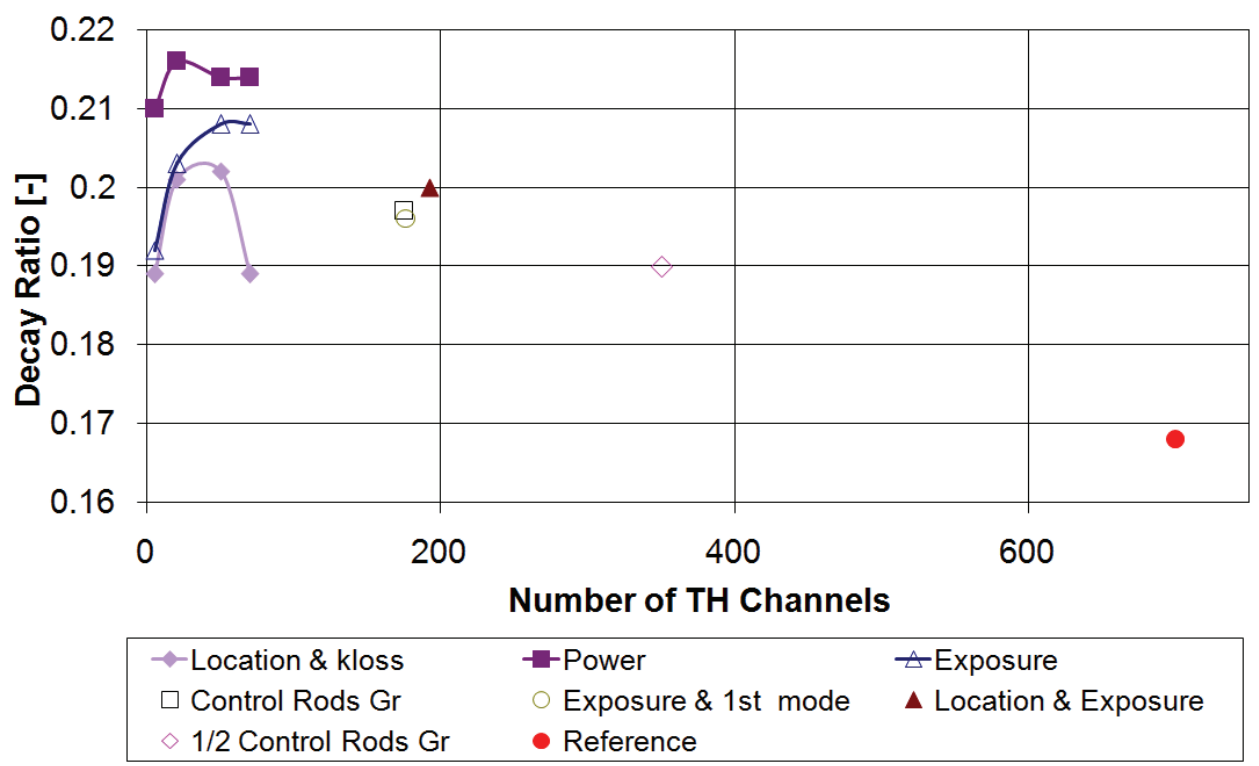

Figure 49: Decay Ratio-CRP transient.

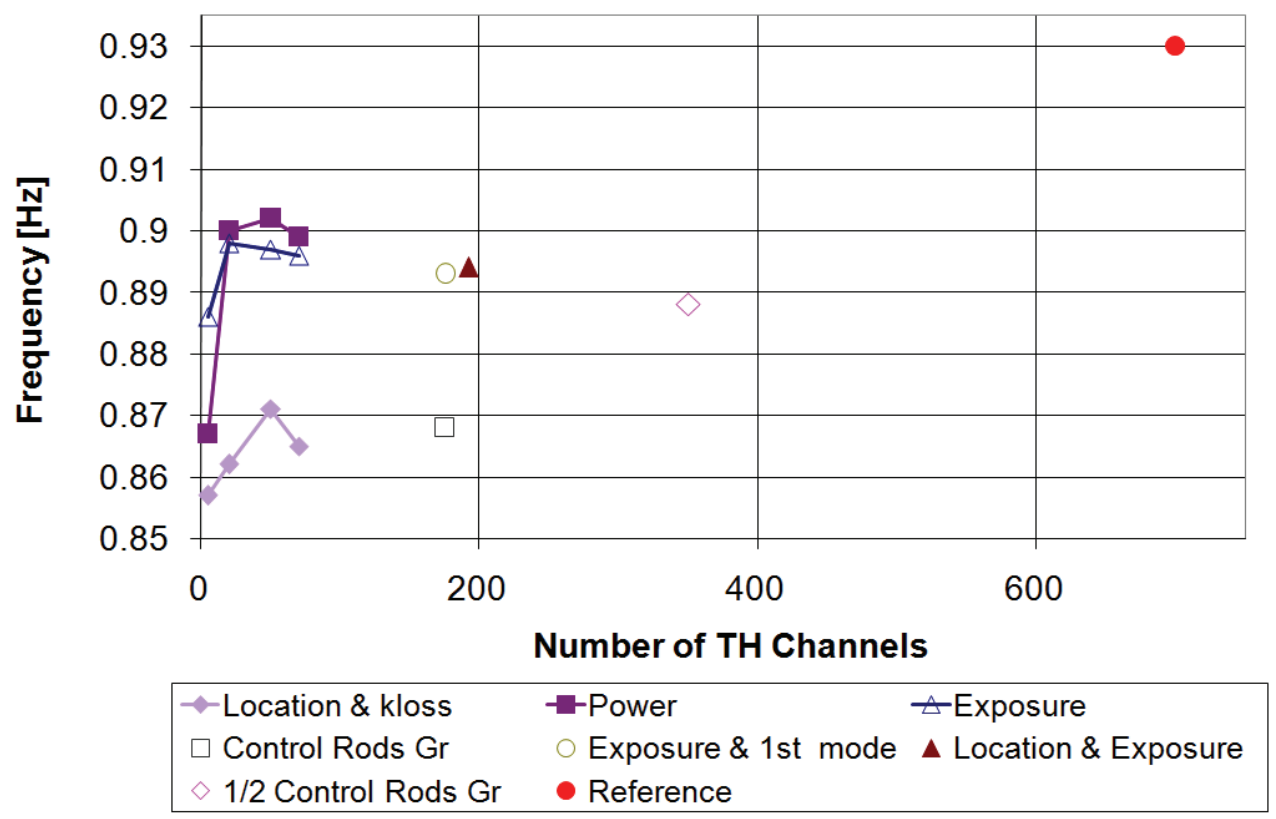

Figure 50: Frequency-CRP transient. 


\subsubsection{Control Rod Drop Accident (CRDA)}

\subsubsection{Introduction}

The CRDA is a reactivity event, which is localized to the position of the dropped control rod and the surrounding fuel assemblies. It is assumed that during one and half seconds, one control rod drops from initial fullyinserted position, causing reactivity increase (see Table 13). The transient was calculated for full power reactor. The location of the dropped control rod is presented in Figure 51.

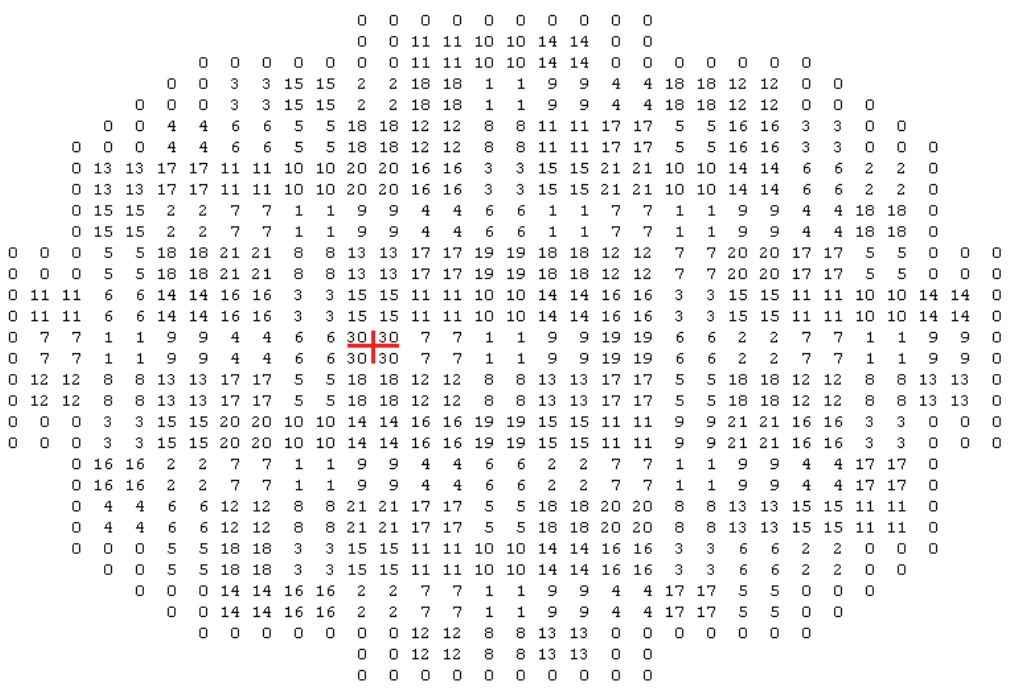

Figure 51: Location of Control Rod drop.

Table 13: Control Rod movement during CRDA.

\begin{tabular}{|c|c|}
\hline Time [s] & $\begin{array}{c}\text { Control Rod Position } \\
{\left[\text { steps] }{ }^{\mathbf{1 9}}\right.}\end{array}$ \\
\hline 0.0 & 9.0 \\
\hline 5.0 & 9.0 \\
\hline 6.5 & 100 \\
\hline
\end{tabular}

${ }^{19}$ Control Rods Position: 100 - fully withdrawn, 0 - fully in. 


\subsubsection{Results comparison}

The parameters, which are important for this transient, are:

- Maximum power peak,

- Fuel enthalpy $[\mathrm{J} / \mathrm{g}]$.

The maximum fuel enthalpy [35] limit is $970[\mathrm{~J} / \mathrm{g}]$ for fresh fuel. This limit is a safety criterion for RIA (Reactivity Insertion Accident) fragmentation. The enthalpy rise is found to be important for mechanical pellet-cladding interaction, too.

Figure 52 and Figure 53 present obtained results. The maximum power peak (Figure 52) quickly converges to the reference and for the number of channels higher than 50 the uncertainty is very small, about $2 \%$. Below 50 TH channels the results are always conservative.

In the case of fuel enthalpy rise (Figure 53) results are not as unequivocal. For low number of $\mathrm{TH}$ channels the enthalpy rise can be underestimated by as much as $50 \%$, and this is strongly dependent on the mapping approach. In the case of power grouping the enthalpy rise quickly converges to the reference value. Other types of mapping, like location and $k_{\text {loss }}$ and exposure, show non-monotonic convergence.

Another important observation is that in the case of control rod mapping (175 TH channels) the obtained maximum power peak is close to the reference but the enthalpy rise is underestimated by $50 \%$. That means that the type of mapping should not only be dependent on the transient scenario, but also on the search variable. The channel where the accident happens should always be treated separated from the rest. 


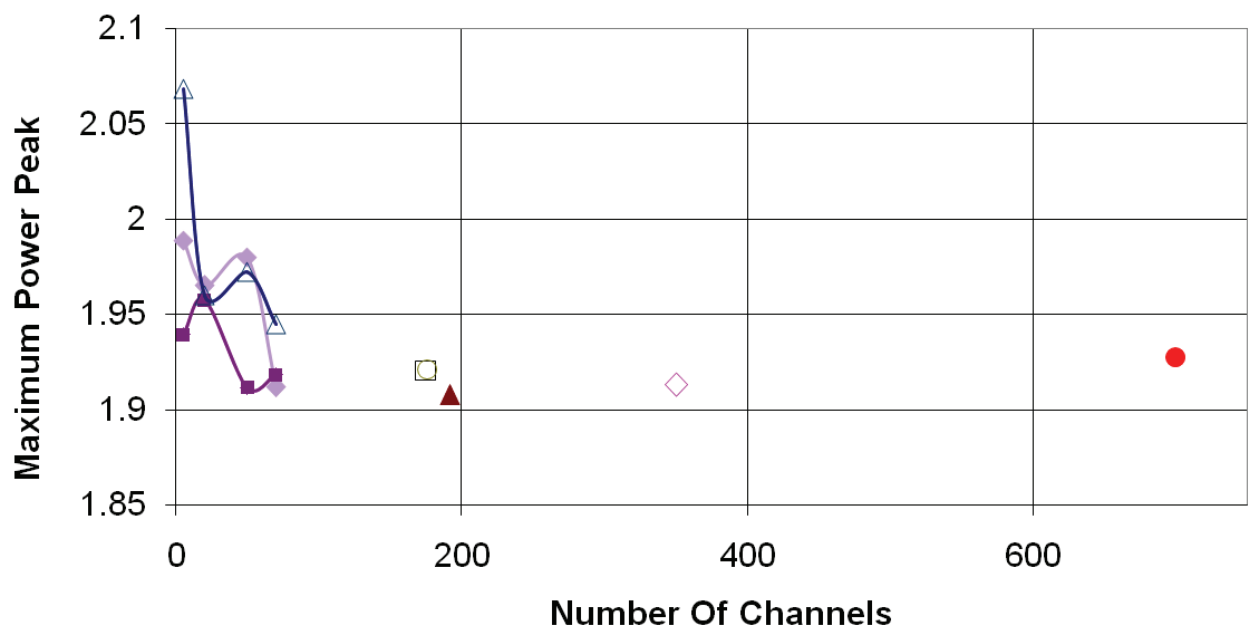

\begin{tabular}{ll|}
\hline$\diamond$-Location \& kloss & $\rightarrow$-Power \\
$\triangle$ Exposure & $\square$ Control Rods Gr \\
$\bigcirc$ Exposure \& 1st mode & $\Delta$ Location \& Exposure \\
$\diamond 1 / 2$ Control Rods Gr & $\bullet$ Reference \\
\hline
\end{tabular}

Figure 52: Maximum power peak during CRDA.

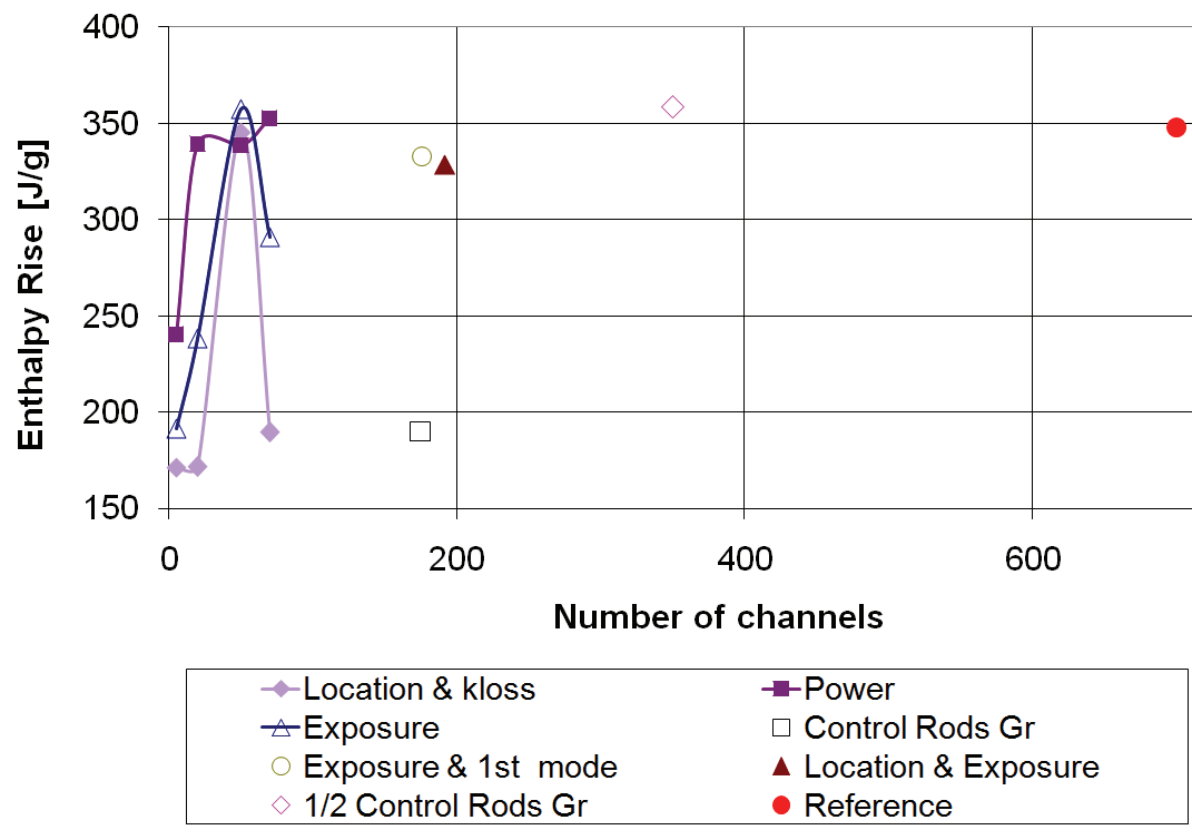

Figure 53: Maximum enthalpy rise during $C R D A$. 


\subsubsection{Turbine Trip Transient (TT)}

\subsubsection{Introduction}

The Turbine Trip (TT) transient without bypass in a BWR is a global perturbation with pressurization event in which the coupling $\mathrm{TH}$ and $\mathrm{NK}$ is very important.

The TT transient scenario, which is used in this investigation is complex and belongs to the group of Anticipated Transient Without Scram (ATWS). At time zero, it is assumed sudden closure of all four turbine valves. Turbine bypass valves are assumed not to open. The closure of all four steam line valves increases the pressure in the steam dome, which causes core void to collapse. The collapse of void results in positive reactivity insertion into the core - power increases and reaches the SCRAM line. Because it is also assumed malfunction of SCRAM hydraulic drive mechanism, the shutdown of the reactor is achieved with screw drive mechanism, which takes $250 \mathrm{~s}$ to fully insert all CR. The pressure control and pressure relief valves are assumed to operate - these are responsible for power fluctuation visible in the Figure 54.

\subsubsection{Results comparison}

The obtained results were compared and no large differences have been found in the average behavior between the cases with small number of TH channel and the reference case. Figure 54 presents the power evolution during the transient for two selected cases, one with $5 \mathrm{TH}$ channels and the reference case (700 channels). The difference appears in small time shifts and power peak magnitude, but the general plant response is recreated and it is not dependent on the number of TH channels or mapping strategy. 
However, one can find differences while scrutinizing local behavior: e.g., power increase (Figure 55) due to collapse of void fraction and positive reactivity insertion.

In summary, the global perturbation transient is very well predicted even with small number of TH channels. The predicted global parameters do not depend strongly on the mapping strategy: the largest over-prediction (conservative) for the reactor's peak power is $12 \%$.

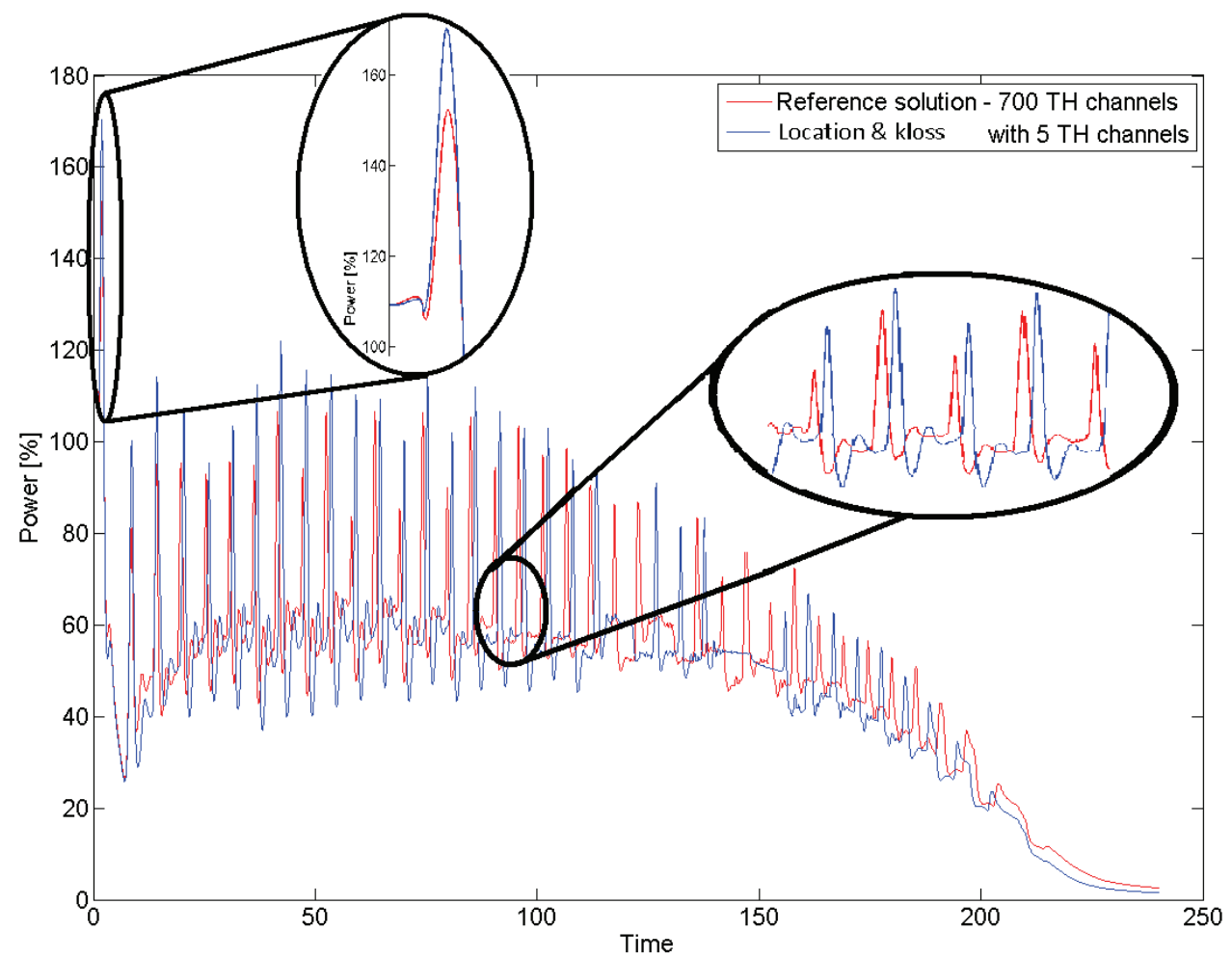

Figure 54: Power fluctuation during TT transient. 


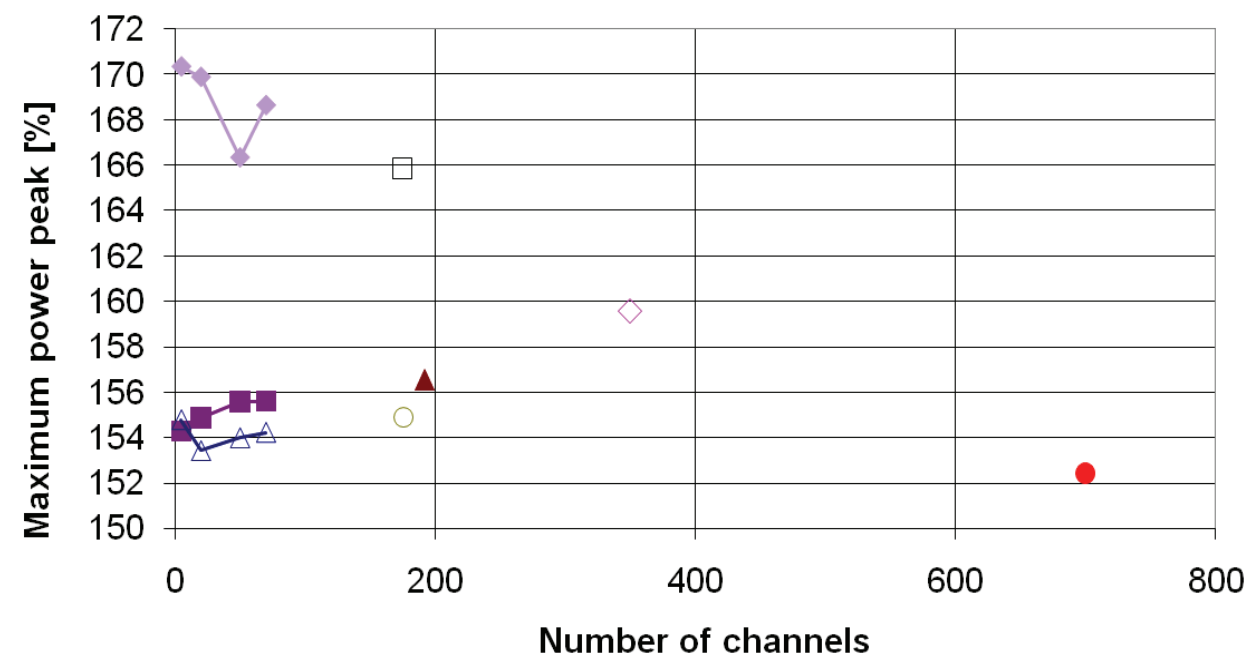

\begin{tabular}{ll|}
$\rightarrow \rightarrow$-Location \& kloss & - -Power \\
$\triangle$ Exposure & $\square$ Control Rods Gr \\
$\triangleright$ Exposure \& 1st mode & $\Delta$ Location \& Exposure \\
$\diamond 1 / 2$ Control Rods Gr & $\bullet$ Reference \\
\hline
\end{tabular}

Figure 55: Maximum power peak during TT transient.

\subsubsection{Feedwater Transient (FT)}

\subsubsection{Introduction}

The Feedwater Transient (FT) can be a regional perturbation. The significant decrease of feedwater temperature due to loss of high pressure pre-heaters is assumed (temperature drops about $80^{\circ} \mathrm{C}$ during 50s). Cold water entering the core decreases void fraction, causing positive reactivity insertion. Due to positive reactivity reactor power increases reaching the SCRAM line (120\% power). The malfunction of the SCRAM system is assumed - no control rods insertion is performed, only flow reduction of the core recirculation pump is executed (from about 11000 to about $4000 \mathrm{~kg} / \mathrm{s}$ which corresponds to minimum pump speed). 
The recirculation flow reduction increases the void in the core causing power to decrease. Gradually, with the slow power increase and low the flow reactor goes into the unstable area (reactor power about $50 \%$ and $30 \%$ flow).

It is assumed beginning of the cycle (fresh fuel) and 109\% power level when the FT occurs. In addition, different Feedwater Transient scenarios are assumed:

- Scenario I: cold water is postulated to enter from 1 feedwater sparger, resulting in fully unsymmetrical conditions,

- Scenario II: cold water enters from 4 feedwater spargers.

\subsubsection{Results and comparison}

\subsection{Scenario I results}

Figure 56 presents core average power from 4 up to $700 \mathrm{TH}$ channels. As it can be observed, due to low feedwater temperature, core power increases but power increase does not hit the SCRAM line and a new steady-state with new higher power level is reached. Figure $57 a$ shows the radial power distribution before the occurrence of the transient and Figure 57b presents asymmetrical change of radial power profile, which is caused by the cold water entering into one quadrant of the core.

The correct behaviour is reproduced by all types of mapping. Results obtained in this scenario do not depend on the number of TH channels and mapping type but it is recommended that the number of $\mathrm{TH}$ channels is more than four. 


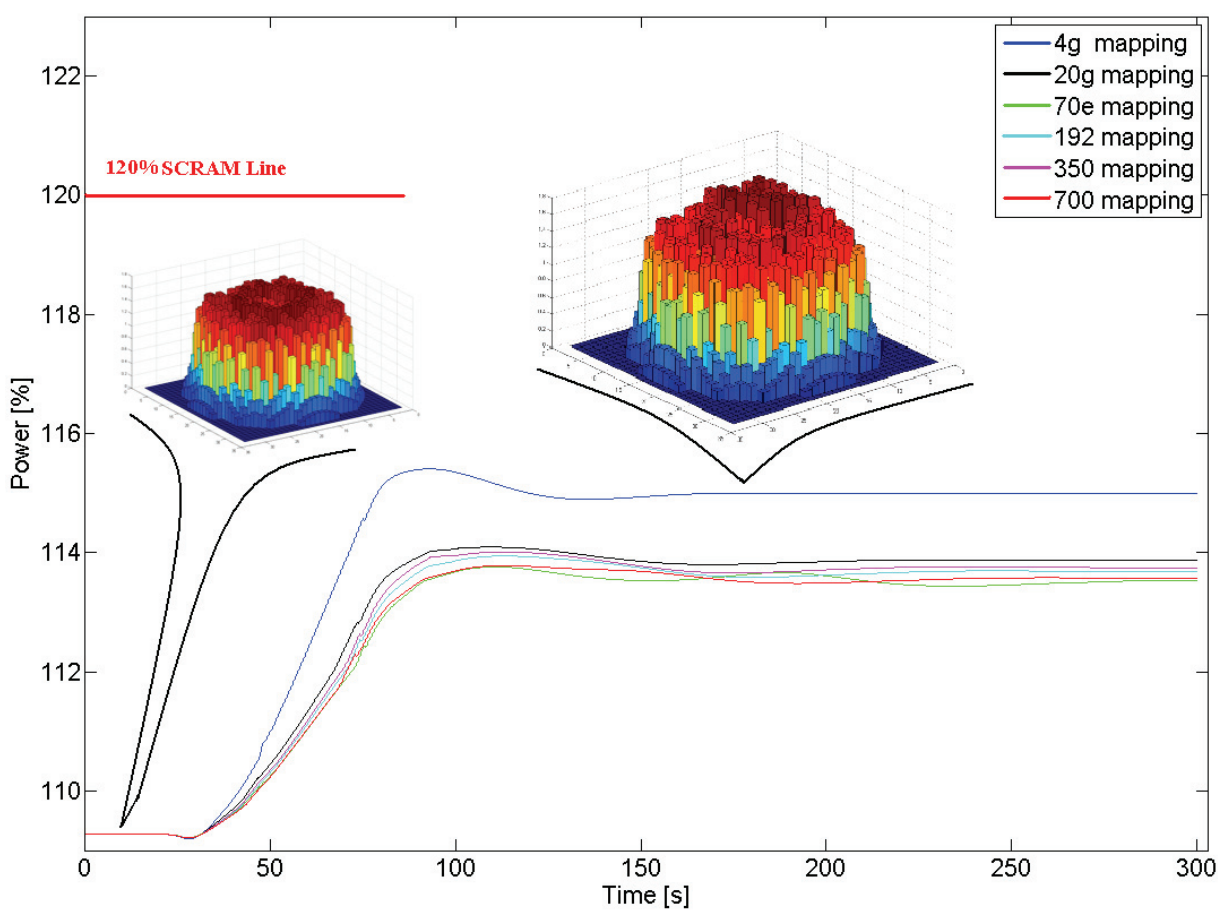

Figure 56: Average power during FT-Scenario I (the " $g$ " stands for location \& kloss, " $e$ " for exposure).

a)

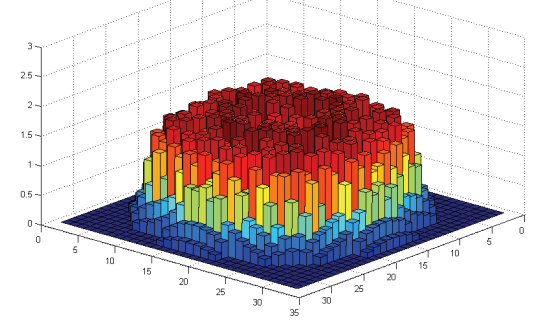

b)

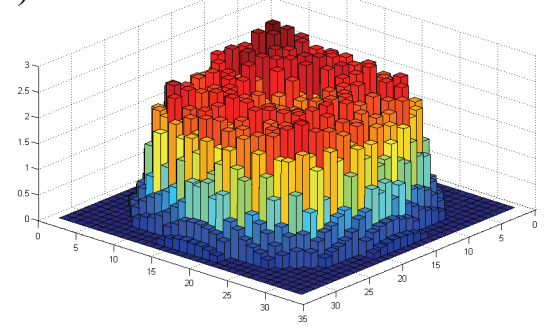

Figure 57: Radial power distribution during FT-Scenario I. 


\subsection{Scenario II results}

Figure 58 presents core power from 4 up to $700 \mathrm{TH}$ channels. Due to low feedwater temperature, core power increases and hits the SCRAM line. The recirculation pump flow is reduced and the reactor goes into the unstable area. From the reactor power curve it is easy to distinguish the onset of limit cycle, which is very different for each mapping type. One can observe also different kinds of limit cycle - regular or chaotic oscillations. Some mapping types show large power peak which reaches high level SCRAM line.

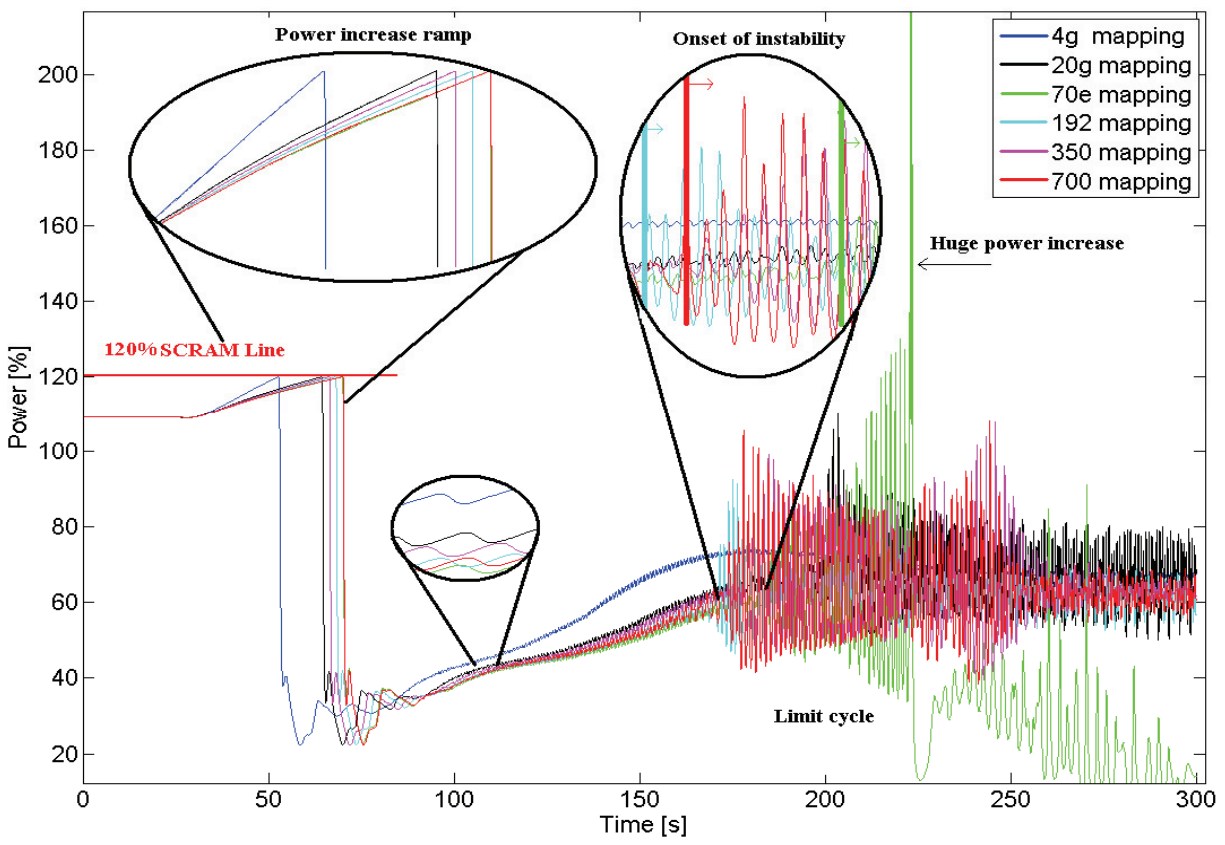

Figure 58: Average power during FT-Scenario II (the " $g$ " stands for location \& kloss, " $e$ " for exposure). 
Figure 59 presents mass flow rate of a few randomly selected TH channels (reference model $-700 \mathrm{TH}$ channels, location of the channels is presented in Figure 60) - where out-of-phase mass flow oscillations were observed. Out-of-phase oscillations of the mass flow induce small excitation of power but it is dominated by in-phase mode. Small out-of-phase oscillations were observed in each model.

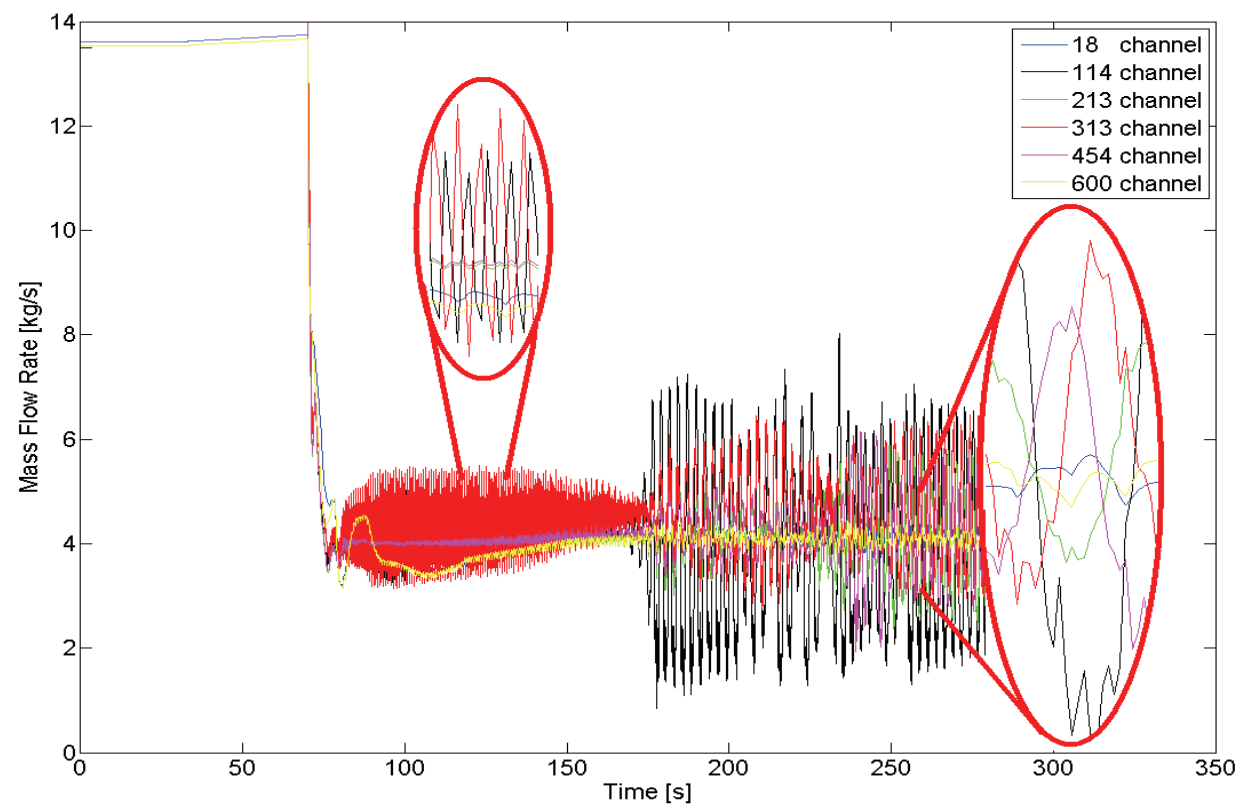

Figure 59: Mass flow rate oscillations in selected channels during FTScenario II.

This transient scenario is dependent on mapping type, which is a reason of different power increase ramp, different time of instability onset, different development of limit cycle. Table 14 collects results comparison for each mapping case. As it can be seen, only a few mappings managed to reproduce the reference results. Despite of some small discrepancies, combined mapping of $1^{\text {st }}$ mode and exposure (108 TH channels), and also 
$1 / 2$ control rods mapping (350 $\mathrm{TH}$ channels) produce good results. Surprisingly, power peaking factor mapping scheme was not found good enough for this transient - it results in an incorrect prediction even with a large number of TH channels. It confirms finding of other researchers [2] that there is not a one universal mapping for every transient and mapping should be chosen based on each transient type.

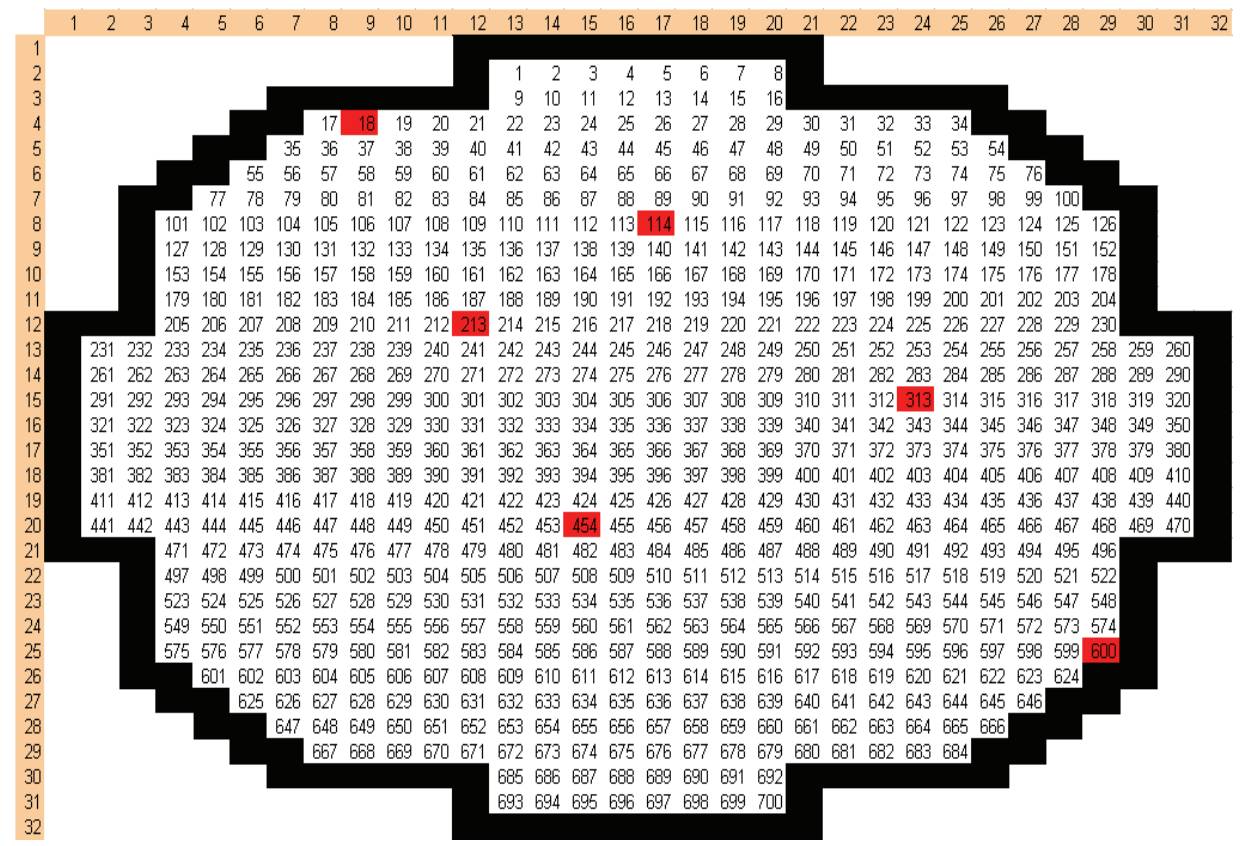

Figure 60: Location of selected channels in the core. 
Table 14: Feedwater Transient results - Scenario II.

\begin{tabular}{|c|c|c|c|c|c|c|}
\hline 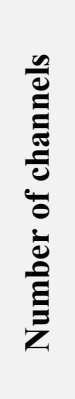 & 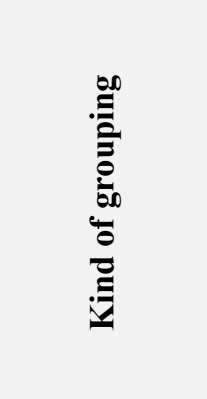 & 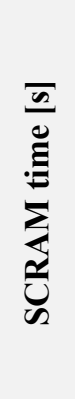 & 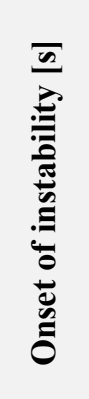 & 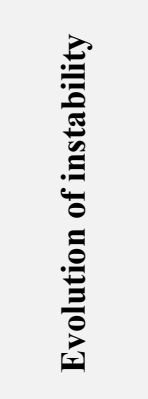 & 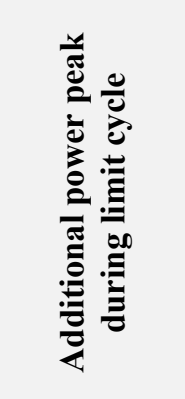 & 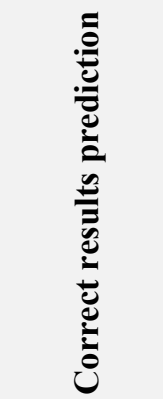 \\
\hline 4 & Location & 53 & No & No & No & Failed \\
\hline \multirow{3}{*}{20} & $\begin{array}{c}\text { Location \& } \\
k_{\text {loss }}\end{array}$ & 64 & 195 & Regular & No & Partly \\
\hline & Power & 69 & 208 & Chaotic & Yes $(219 \mathrm{~s})$ & Failed \\
\hline & Exposure & 68 & 206 & Regular & No & Partly \\
\hline \multirow{3}{*}{50} & $\begin{array}{c}\text { Location \& } \\
k_{\text {loss }}\end{array}$ & 62 & 179 & Regular & Yes (184 s) & Failed \\
\hline & Power & 69 & 180 & Chaotic & Yes $(184 \mathrm{~s})$ & Failed \\
\hline & Exposure & 67 & 160 & Chaotic & Yes (187s) & Failed \\
\hline \multirow{3}{*}{70} & $\begin{array}{c}\text { Location \& } \\
k_{\text {loss }}\end{array}$ & 62 & 169 & Chaotic & No & Partly \\
\hline & Power & 69 & 182 & Chaotic & Yes (184 s) & Failed \\
\hline & Exposure & 70 & 192 & Chaotic & Yes $(223 \mathrm{~s})$ & Failed \\
\hline 108 & $\begin{array}{l}1^{\text {st }} \text { Mode }+ \\
\text { Exposure }\end{array}$ & 66 & 174 & Regular & No & OK \\
\hline 192 & $\begin{array}{c}\text { Exposure }+ \\
\text { Location }\end{array}$ & 68 & 170 & Chaotic & No & Partly \\
\hline 204 & Control Rods & 64 & 180 & Chaotic & Yes (219 s) & Failed \\
\hline 350 & $\begin{array}{c}1 / 2 \text { Control } \\
\text { Rods }\end{array}$ & 66 & 175 & Regular & No & OK \\
\hline 700 & Reference & 70 & 174 & Regular & No & Reference \\
\hline
\end{tabular}




\subsection{TRACE/PARCS Simulations of Transients}

The OECD/NEA Ringhals-1 Stability Benchmark supplies the measurements of the global and regional DR. Here, the coupled TRACE/PARCS is employed to reproduce both global and regional responses. However, more attention was paid to the in-phase instability results since the capability of predicting global core response by the system code has been proven by other researchers [36][37][38][39][40]. Nevertheless, it is also interesting to investigate out-of-phase oscillations since they have not been fully understood yet.

The core is perturbed with movements of control rods. For the global oscillation cases, the perturbing control rods move all in-phase, while for the regional oscillations, the perturbing control rods move out-of-phase. After a perturbation, the response of the reactor has an oscillatory behavior and the decay ratio and the frequency of the oscillation are evaluated. The DR and FR are obtained with assistance of the DRARMAX toolbox [23].

The investigation performed in the OECD/NEA Benchmark [34] shows that the stable cores with low DR are difficult to measure and simulate. The code prediction results supplied by the participants in the Benchmark have the biggest deviations from the measurements for the cases with the low DR.

Table 15: Ringhals-1 BOC cycle 14 Stability Test Results.

\begin{tabular}{|c|c|c|c|c|c|c|c|}
\hline Cycle & \multirow{2}{*}{$\begin{array}{c}\text { Power } \\
\mathbf{1 4}\end{array}$} & Core Flow & \multicolumn{2}{|c|}{ Global } & \multirow{2}{*}{ Error $^{\mathbf{2 0}}$} & \multicolumn{2}{|c|}{ Regional } \\
\cline { 4 - 5 } & {$[\mathbf{k g} / \mathbf{s}]$} & DR & FR & or - & DR & FR \\
\hline Point 1 & 65.0 & 4105 & 0.30 & 0.43 & 0.12 & - & - \\
\hline Point 6 & 70.2 & 4126 & 0.64 & 0.52 & 0.07 & 0.59 & 0.50 \\
\hline Point 9 & 72.6 & 3694 & 0.80 & 0.56 & 0.05 & 0.99 & 0.54 \\
\hline
\end{tabular}

${ }^{20}$ Uncertainty in estimating DR [20][34] derived from Ringhals-1 Benchmark results. 
The Table 15 presents measured DR and FR for three selected points of Ringhals-1 Beginning of the Cycle (BOC). The reasons why these points are selected for the present study are given in Chapter 4 .

\subsubsection{Global Instability}

Table 16 presents comparison of global core responses for full-scale models with the Benchmark measurements. As it can be seen, the worst prediction falls for point 6 of cycle 14 with slight bottom-peak axial power profile; DR is under-predicted by about $\sim 17 \%$ and FR by $\sim 12 \%$ with the full-scale model. This prediction does not even lie within the Benchmark measurement uncertainty. The detailed characteristics of DR and FR for the point 6 is presented in Figure 61 and Figure 62; from Figure 61, it can be found that for this case the DR is more dependent on mapping scheme than the number of $\mathrm{TH}$ channels, and that for some mappings the same results can be obtained for low number of TH channels. However, this is not the case with the FR (Figure 62), which does not converge fast to the full-scale FR value. On the other hand, the deviations of FR predictions are relatively narrow, they are mapping dependent if the number of $\mathrm{TH}$ channels is low.

Table 16: In-phase oscillation results for full-scale models.

\begin{tabular}{|c|c|c|c|c|c|c|}
\hline \multirow{2}{*}{$\begin{array}{c}\text { Cycle } \\
\text { 14 }\end{array}$} & \multirow{2}{*}{$\begin{array}{c}\text { Power } \\
{[\%]}\end{array}$} & $\begin{array}{c}\text { Core Flow } \\
{[\mathbf{k g} / \mathbf{s}]}\end{array}$ & \multicolumn{2}{|c|}{$\begin{array}{c}\text { TRACE/PARCS } \\
\text { Simulation } \\
\text { Global }\end{array}$} & \multicolumn{2}{|c|}{$\begin{array}{c}\text { Benchmark } \\
\text { Reference } \\
\text { Global }\end{array}$} \\
\cline { 4 - 7 } & & & DR & FR & DR & FR \\
\hline Point 1 & 65.0 & 4105 & 0.35 & 0.45 & 0.30 & 0.43 \\
\hline Point 6 & 70.2 & 4126 & 0.53 & 0.46 & 0.64 & 0.52 \\
\hline Point 9 & 72.6 & 3694 & 0.81 & 0.51 & 0.80 & 0.56 \\
\hline
\end{tabular}




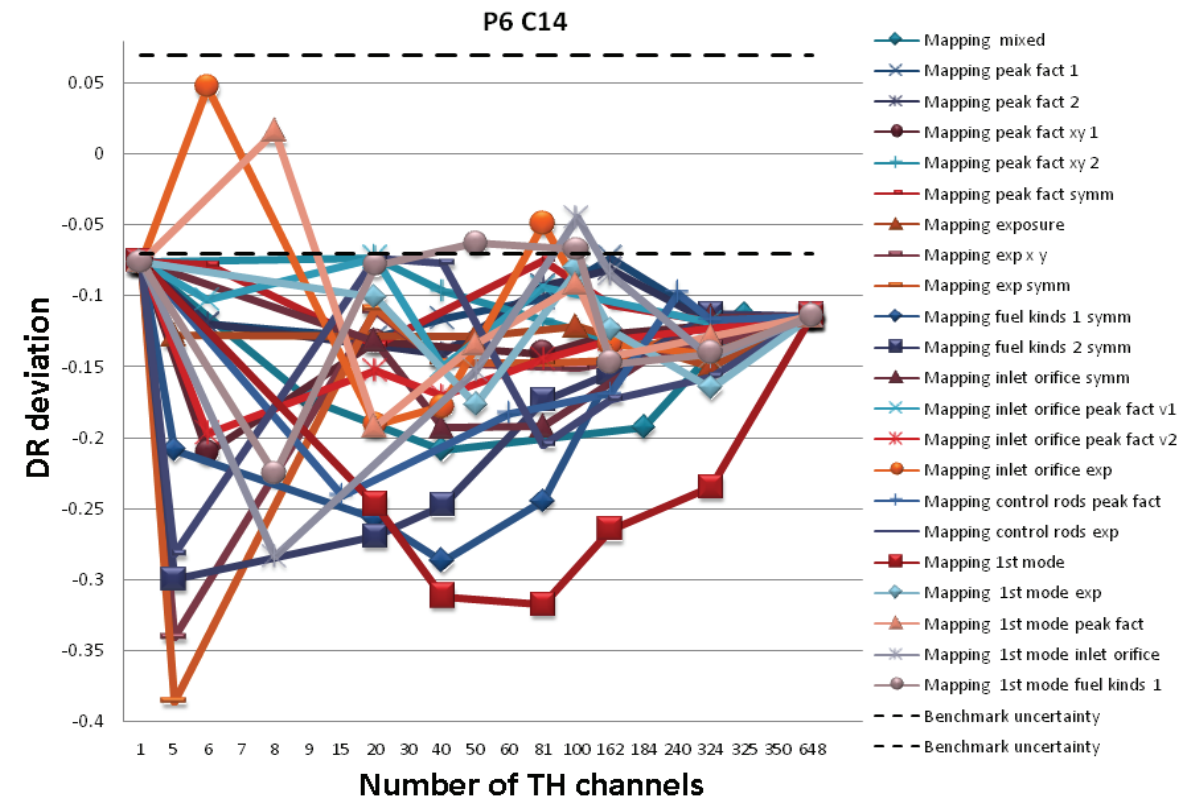

Figure 61: DR deviation, point 6 of cycle 14.

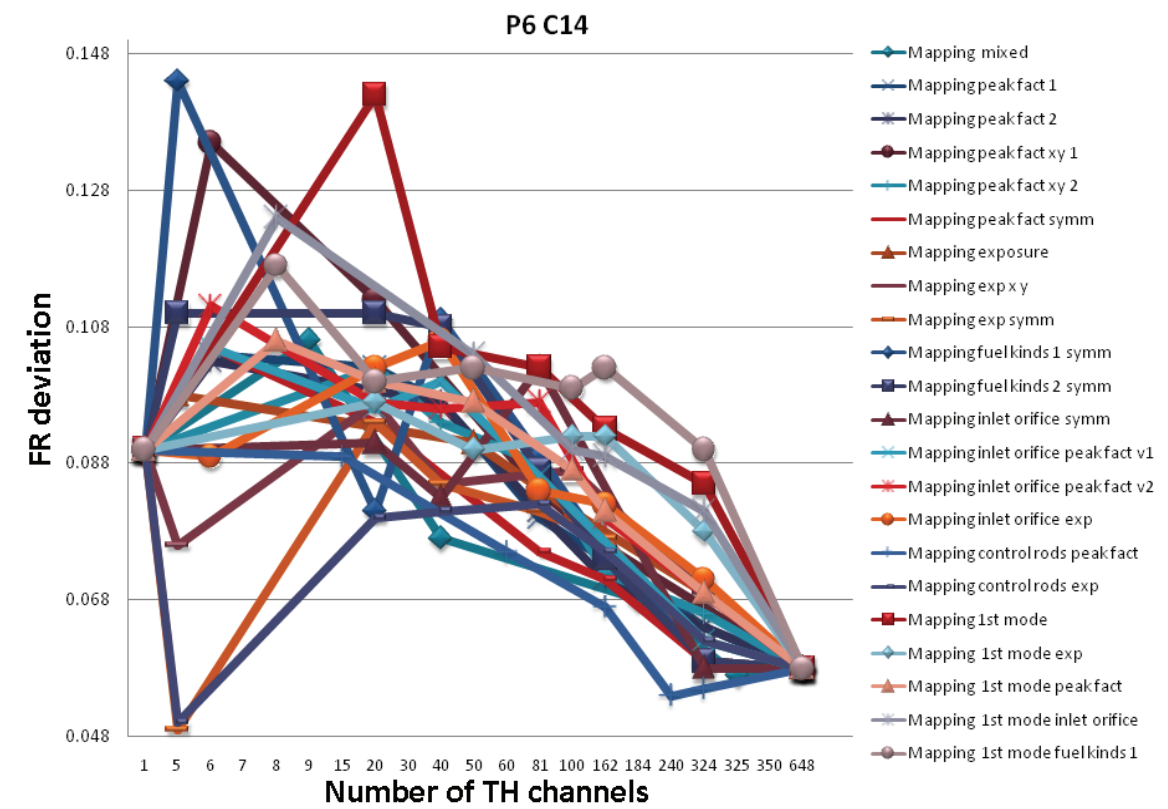

Figure 62: FR deviation, point 6 of cycle 14. 
Point 1 of cycle 14 was the most difficult one to predict for many codes in the Benchmark. First, it does not have common axial power profile - it is top-peaked, which may be one of the causes for difficulty in power prediction by the codes using mapping. Second, it is relatively stable, so calculating DR from stable response with low amplitude of oscillations is not as easy as it is in the opposite case. The full-scale code prediction overestimates the DR by $\sim 17 \%$ and the FR by $\sim 5 \%$. The DR and FR responses versus different mapping schemes, and numbers of TH channels are presented in the Figure 63 and Figure 64, respectively. It is satisfying to see that despite of the uncertainty in the DR prediction, for most of the cases the result lies within the Benchmark uncertainty range [20]. Here, the FR converges fast, but it also shows a strong dependence on the mapping scheme. The correct stable response can be predicted even with a low number of TH channels.

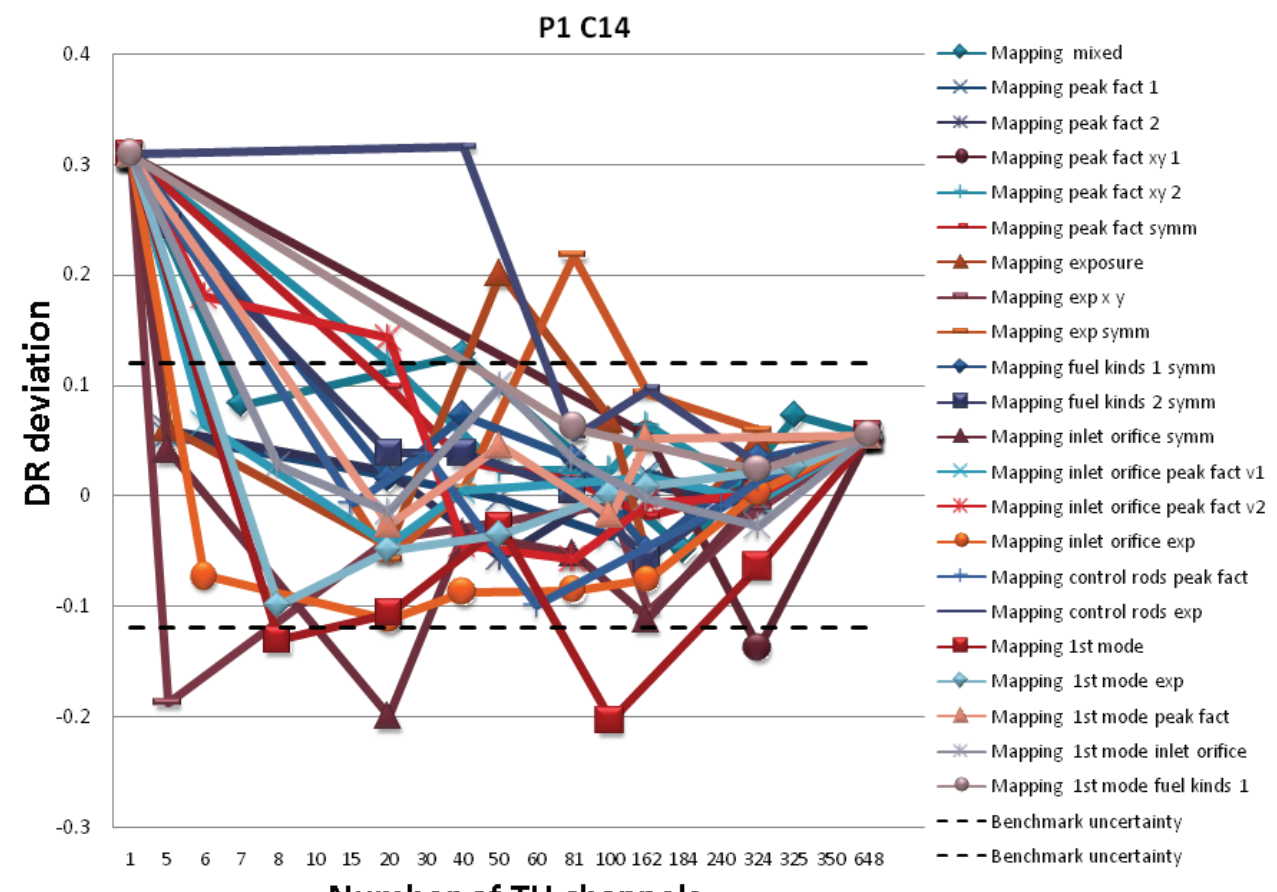

Number of TH channels

Figure 63: DR deviation, point 1 of cycle 14. 


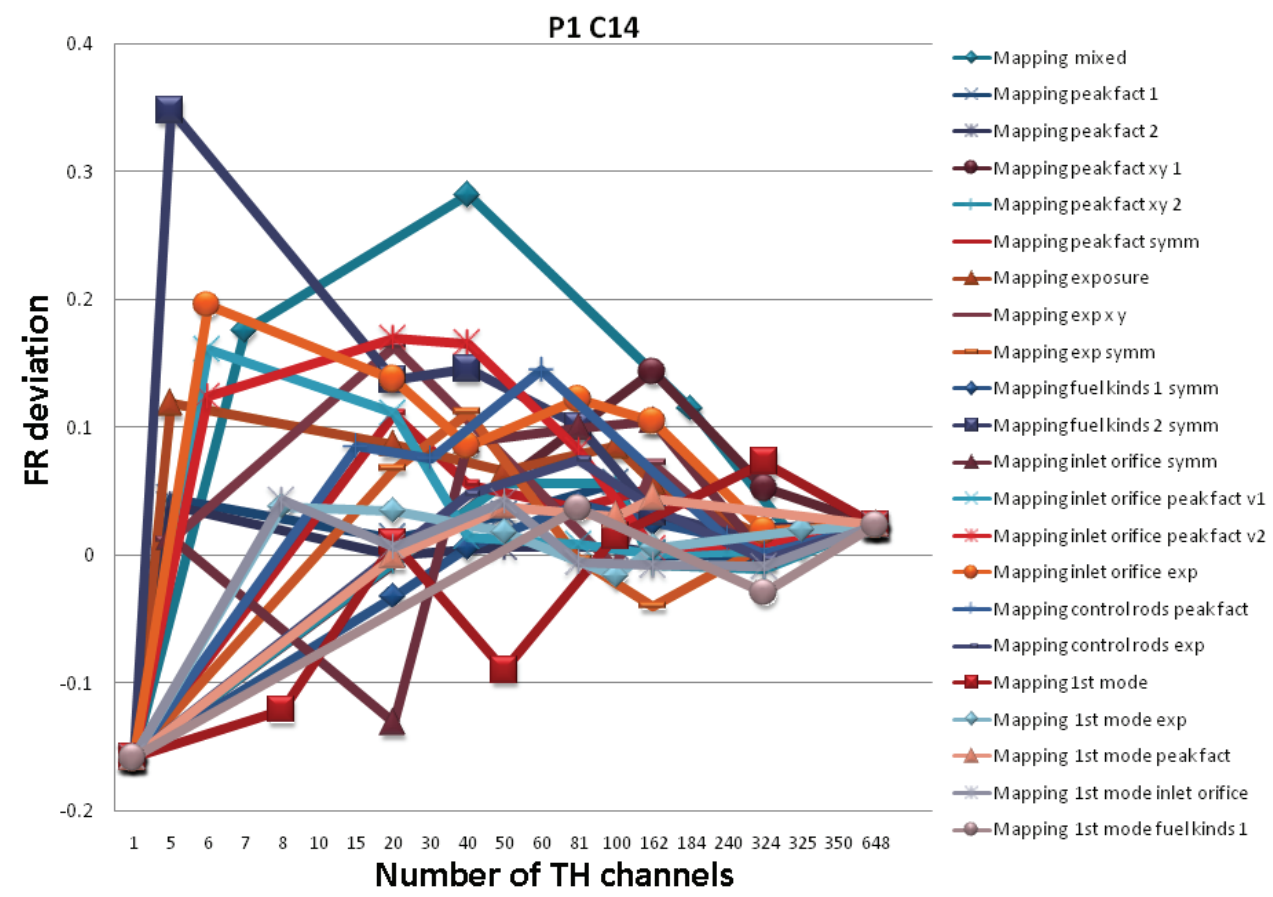

Figure 64: FR deviation, point 1 of cycle 14.

Point 9 of cycle 14, the most unstable point, has the largest deviation in predictions. For instance, even for the full-scale model, the deviations of the DR and FR results are $\sim 1 \%$ and $\sim 9 \%$, respectively.

From Figure 65 and Figure 66, it can be found that the number of TH channels plays a major role here. It indicates that for a low number of TH channels the core is fully stable. To catch the correct response of unstable core, a minimum of $81 \mathrm{TH}$ channels is needed, but for the best results 324 TH channels (half of core bundles) should always be used.

Additionally, it is noticed that the full-scale model of point 9 of cycle 14 had both in-phase and out-of-phase oscillations, which also had been observed by other benchmark participants [34]. 


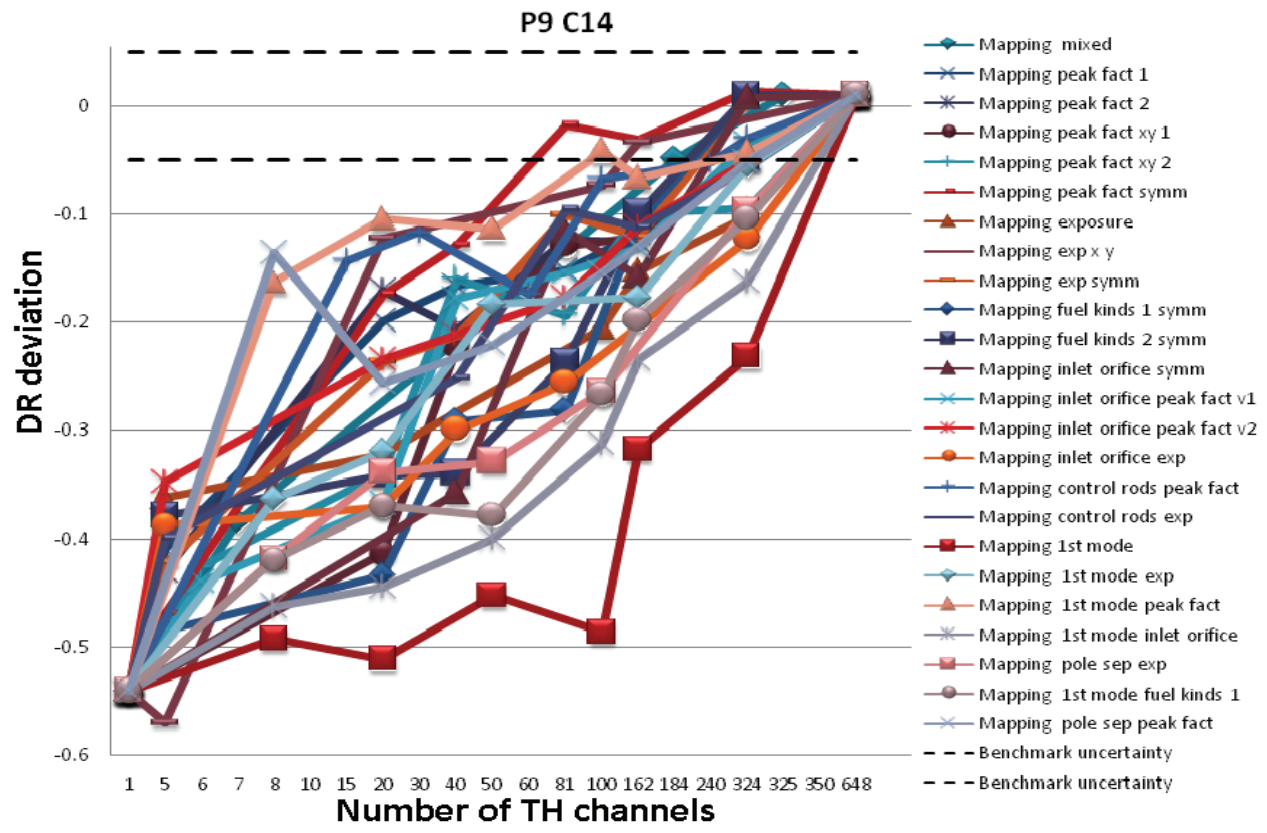

Figure 65: DR deviation, point 9 of cycle 14.

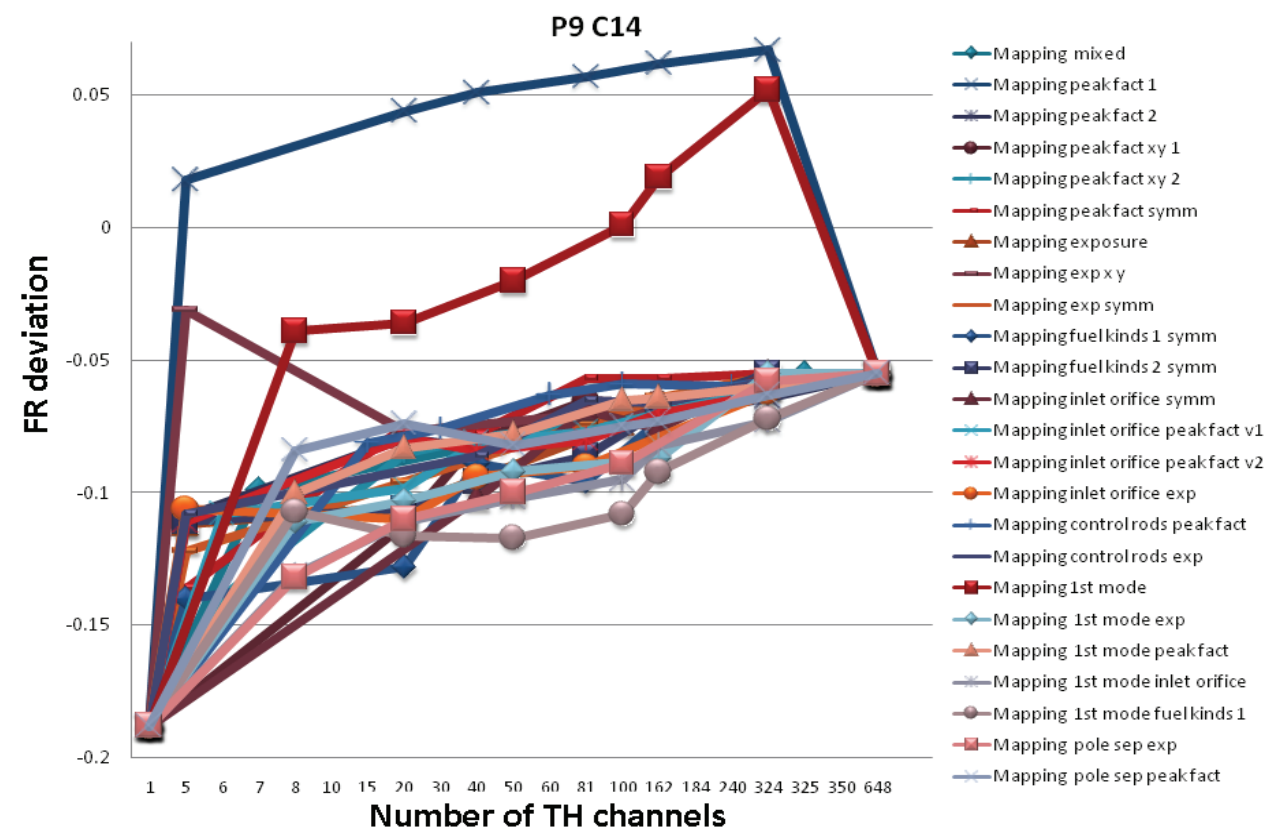

Figure 66: FR deviation, point 9 of cycle 14. 
All the mappings which are made with power peaking factor feature alone, or in combination with other features, return better results than the others. In addition, the mappings with the features of the fuel type, symmetry and exposure, give rather good results and therefore they are also recommended for global stability study. The combination of the $1^{\text {st }}$ mode feature with other features also returns good results, but it is not recommend for studying in-phase oscillations because, a weak spatial power coupling in the core radial direction may cause other problems during simulations.

\subsubsection{Regional Instability}

For all the three points of cycle 14 considered, when the core was perturbed with control rods out-of-phase, the out-of-phase core response with different DR and FR was obtained (see details in Table 17). For point 9 of cycle 14 such response has been seen even with in-phase control rods perturbation, and therefore this point has the largest potential regional instability; the illustration of the out-of-phase oscillations, which were obtained for point 9 (full-scale nodalization) are presented in Figure 67; where the figures of $a$ ), $b$ ) and c) present the differences of the radial core power distribution form initial values at the $0,4,5$ and 6 seconds of the transient respectively. Figure $67 d$ ) shows the out-of-phase core behaviour where two different peaking factors $v s$. time for two different fuel bundles, are presented. The first two seconds of the transient belong to control rod perturbations and were neglected.

Table 17 gathers the out-of-phase results comparisons for the three points (1, 6 and 9) obtained with the full-scale models. The Benchmark specifications [32] [33] do not supply the regional DR measurement for point 1 of cycle 14, however from the final summary of the Benchmark [34] it can be found that the benchmark participants have also predicted the 
regional DR within the value interval of $<0.2,0.31>$ and the regional FR of $<0.35,0.46>$. The participants' results for point 6 are $\mathrm{DR}<0.48,0.74>$ and $\mathrm{FR}<0.46,0.53>$, and for point 9 are $\mathrm{DR}<0.89,1.28>$ and $\mathrm{FR}<0.44,0.54>$. It should be noted that not all of the participants delivered the regional DR and FR, while focusing only on global (in-phase) mode.

Table 17: Out-of-phase results for full-scale models.

\begin{tabular}{|c|l|l|c|c|c|c|}
\hline \multirow{2}{*}{$\begin{array}{c}\text { Cycle } \\
\mathbf{1 4}\end{array}$} & \multirow{2}{*}{$\begin{array}{c}\text { Power } \\
{[\%]}\end{array}$} & $\begin{array}{c}\text { Core Flow } \\
{[\mathbf{k g} / \mathbf{s}]}\end{array}$ & \multicolumn{2}{|c|}{$\begin{array}{c}\text { TRACE/PARCS } \\
\text { Simulation } \\
\text { Regional }\end{array}$} & \multicolumn{2}{c|}{$\begin{array}{c}\text { Benchmark } \\
\text { Reference } \\
\text { Regional }\end{array}$} \\
\cline { 4 - 7 } & & & DR & FR & DR & FR \\
\hline Point 1 & 65 & 4105 & 0.32 & 0.45 & - & - \\
\hline Point 6 & 70.2 & 4126 & 0.38 & 0.53 & 0.59 & 0.50 \\
\hline Point 9 & 72.6 & 3694 & 0.70 & 0.51 & 0.99 & 0.54 \\
\hline
\end{tabular}

a) Time: $4 \mathrm{~s}$

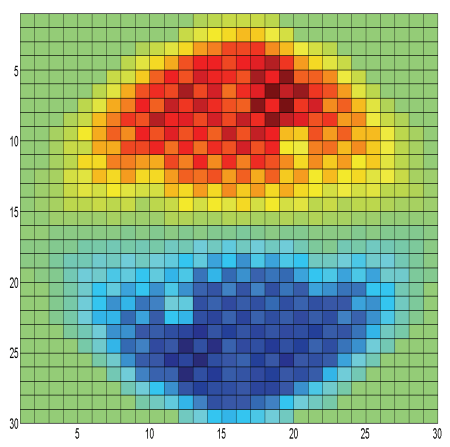

b) Time: $5 \mathrm{~s}$

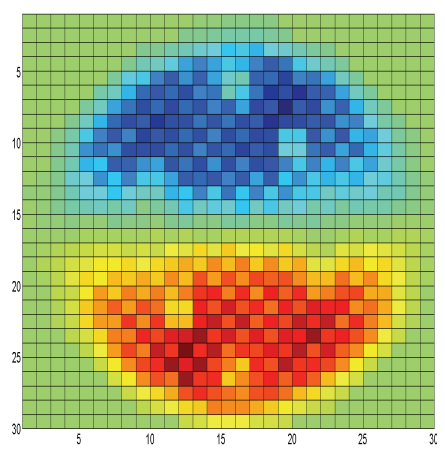

c) Time: $6 \mathrm{~s}$

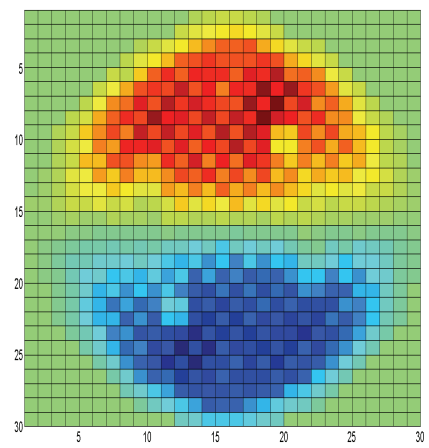


d)

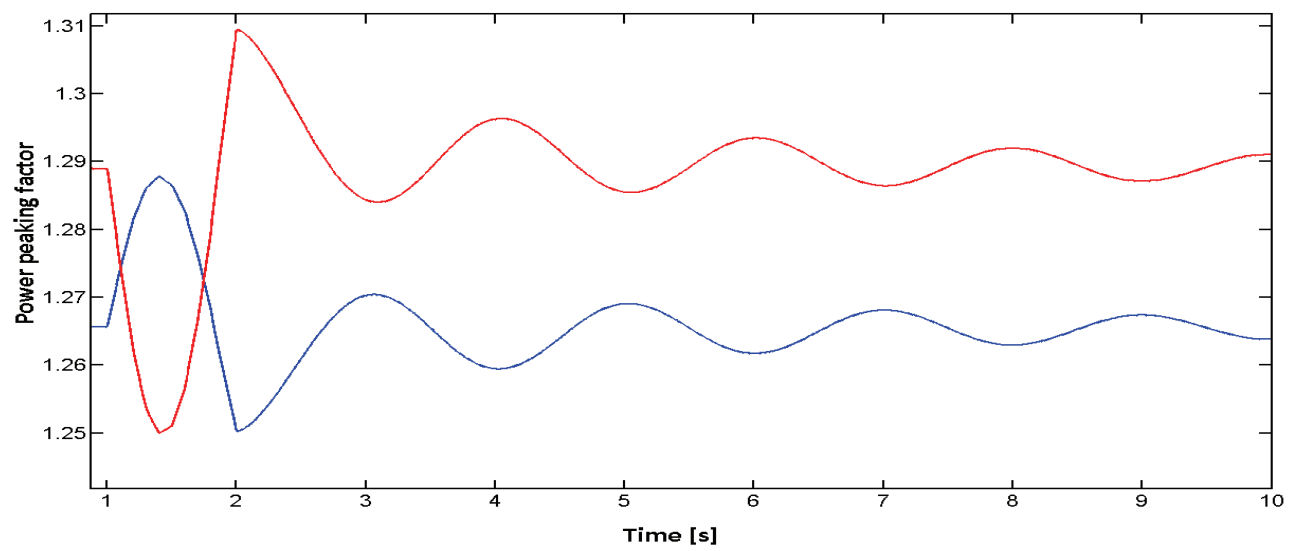

Figure 67: Out-of-phase oscillations, point 9 of cycle 14.

The TRACE/PARCS full-scale results for the regional mode show about $30 \%$ of underestimation in the DR and about $6 \%$ in the FR. As the other researchers show in [21][22], the prediction could be improved with the help of time and space converged model. However, only spatial mapping convergence is the focus of this thesis work. Other benchmark participants [34] had more problems in obtaining correct FR (deviation up to 14\%). However, their DR prediction was better and usually conservatively overpredicted.

Additionally, it has been found with the help of full-scale models that outof-phase oscillations always follow the $1^{\text {st }}$ mode core separation, so using a mapping that groups two or more fuel bundles lying on two different "poles" will definitely damp or even prevent the out-of-phase response. Similar observation was seen in Ringhals-1 1990 event; the core was divided into different zones with the aid of the control rods, the different zones lost the coupling of the neutronics with each other and each zone started to act "independently" [40]. This effect was important for the regional oscillations that were observed and measured. While performing out-of-phase perturbation calculations in the present study, it was also 
noticed that, while using mappings without clear "poles" separation, the out-of-phase response is minimal if any at all. This is why, if one wants to analyze out-of-phase response using clustering or any other mapping approach, it is recommended to always supply the $1^{\text {st }}$ mode feature; on the other hand it has been found that while scrutinizing steady-state results with $1^{\text {st }}$ mode feature alone it returns rather large result bias. Thus, it is important that this feature is not used alone but with combination of other core features, e.g., power peaking factor. Further study of out-of-phase core behavior placed the emphasis on the two points: 9 and 6 from cycle 14, since one of the points is clearly prone to out-of-phase instability, and second has some potential for out-of-phase behavior. Additionally, only mappings including $1^{\text {st }}$ power mode feature have "weak spatial coupling for the neutronics".

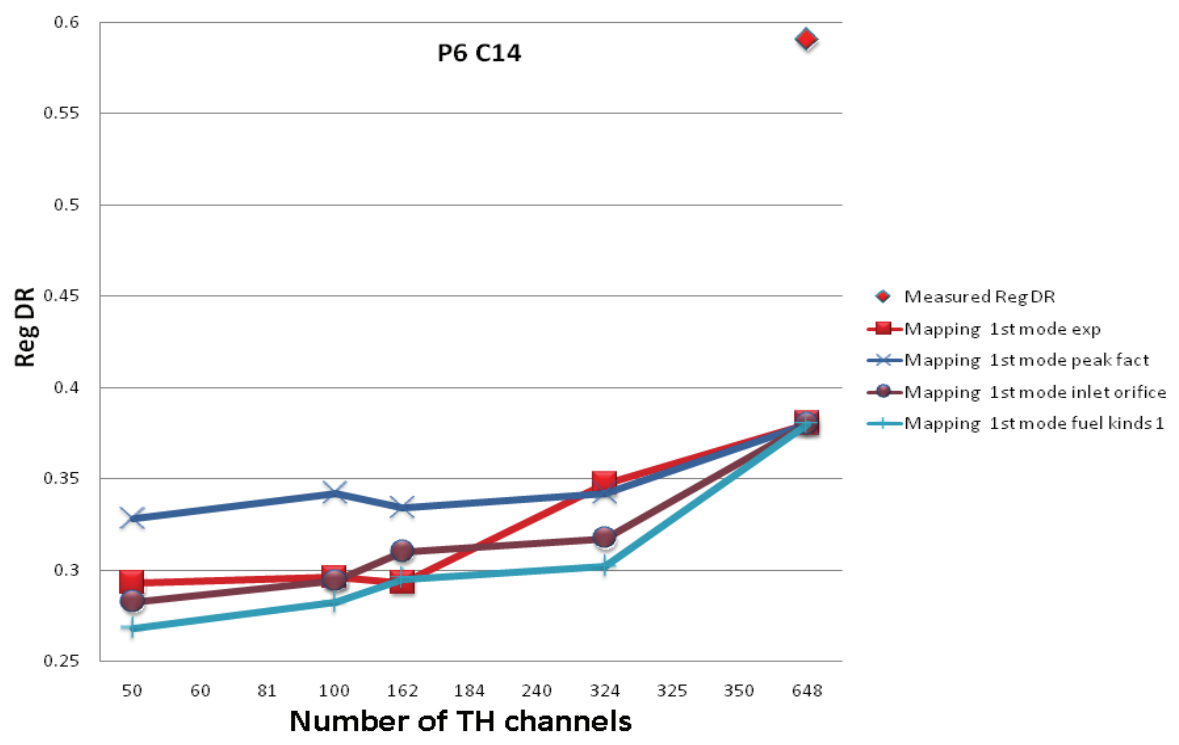

Figure 68: Regional DR calculations, point 6 of cycle 14. 


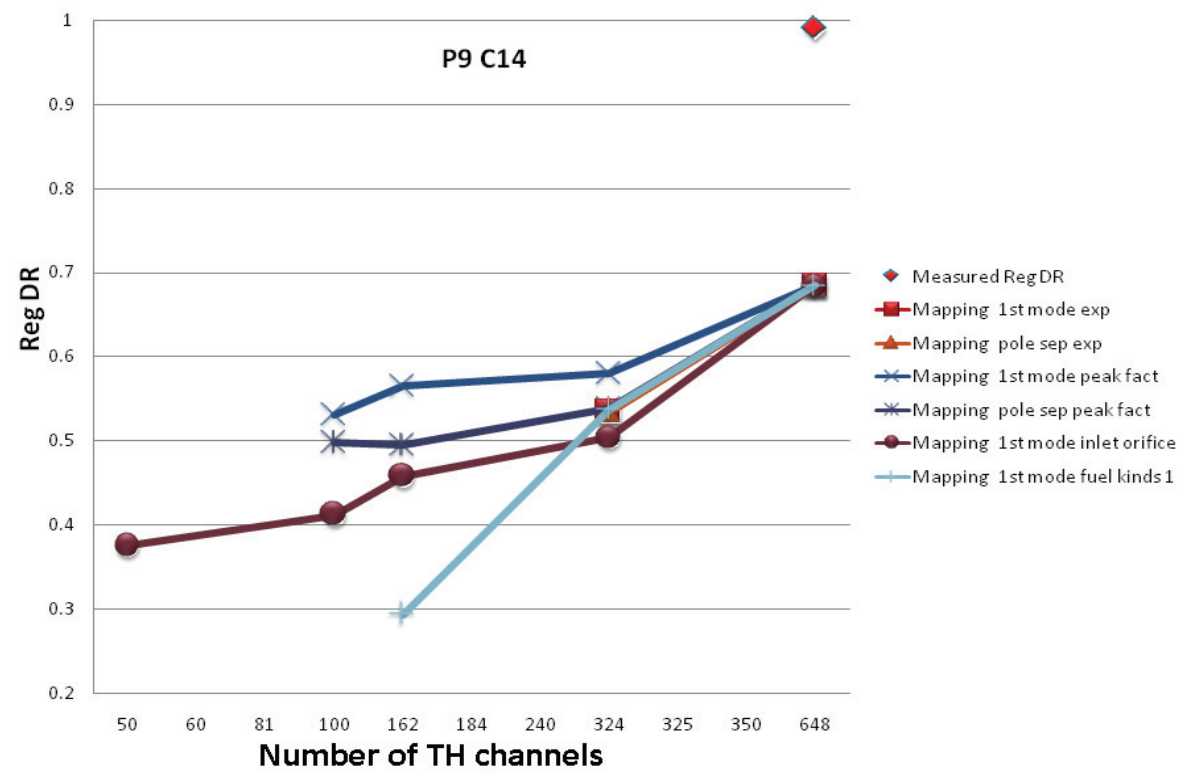

Figure 69: Regional DR calculations, point 9 of cycle 14.

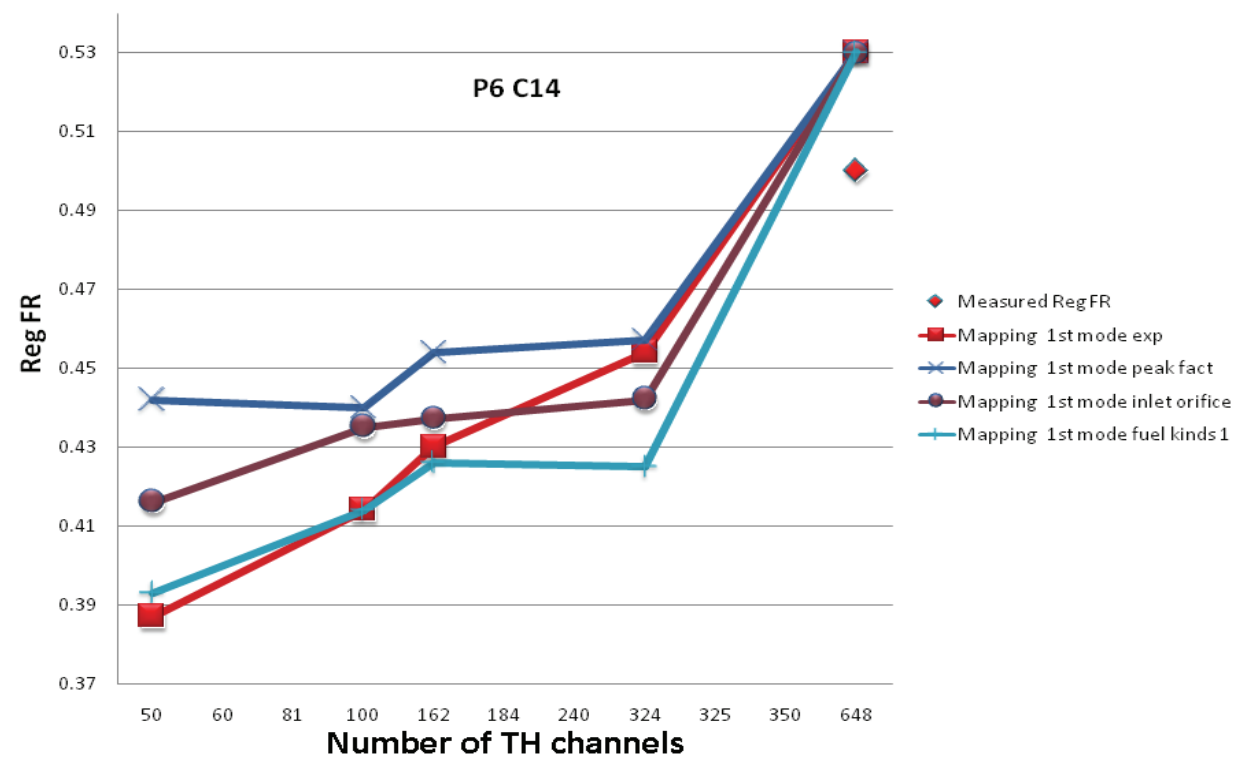

Figure 70: Regional FR, point 6 of cycle 14. 


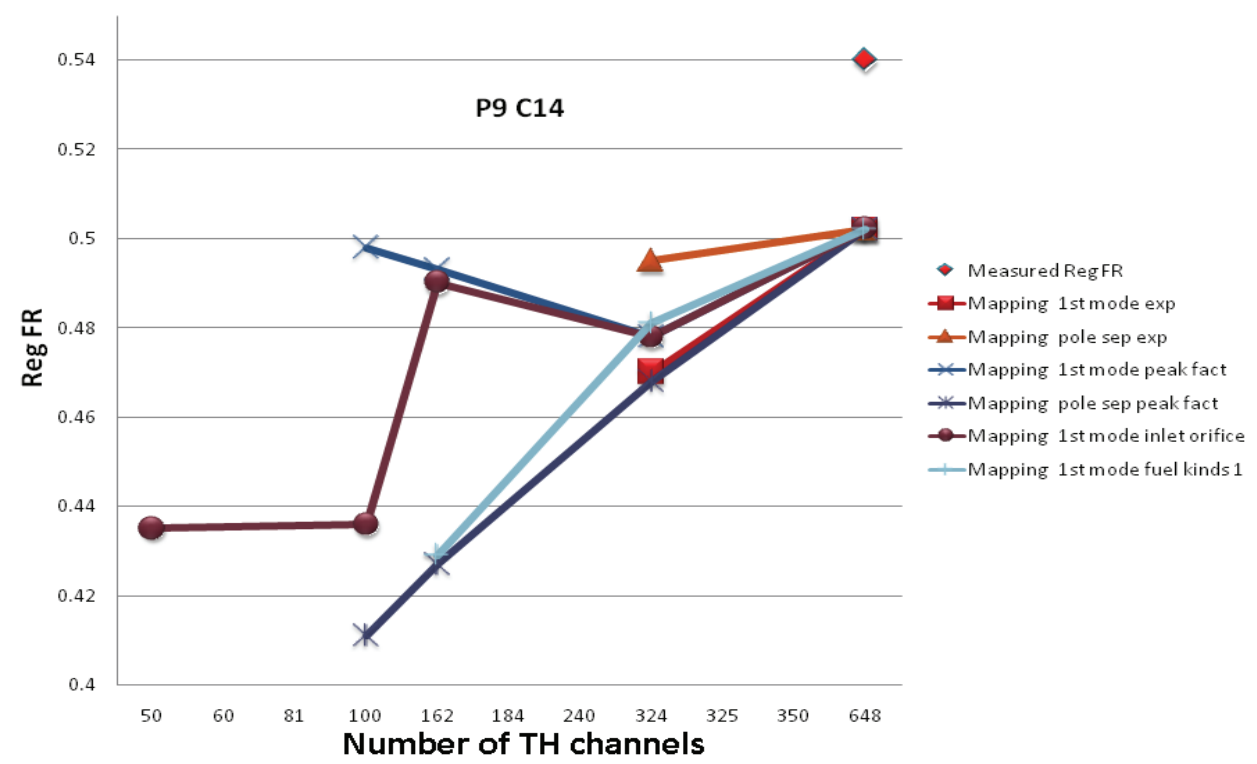

Figure 71: Regional FR, point 9 of cycle 14.

Figure 68 and Figure 69 present the regional DR values for points 6 and 9, respectively. The regional FR values for both points are represented in Figure 70 and Figure 71 . As it can be observed, there is more than $30 \%$ underestimation in the regional DR for full-scale model predictions, and the under-prediction is pronounced with decreasing number of $\mathrm{TH}$ channels. Similar to the global DR and FR, the results could be further improved with the space-time converged models [21][22].

It can be observed that the biggest potential for out-of-phase oscillation has mapping including $1^{\text {st }}$ power mode feature and the power peaking factor feature. Significantly better results were achieved with the regional FR, where the maximum deviation for the full-scale nodalization is up to $7 \%$; also here the combination of $1^{\text {st }}$ power mode and peaking factor features performs the best. 
The amplitude of the oscillation decreases with the decreasing number of $\mathrm{TH}$ channels, when the number of TH channels reaches below 50 the oscillations are not clearly visible. This is the reason why the $X$ scale of the graphs starts from the number 50 .

In summary, in order to get correct prediction for out-of-phase oscillations, it is recommended to use full-scale model. If this is not possible, the mapping which is a mixture of $1^{\text {st }}$ power mode and power peaking factors, should be used. 


\section{Chapter 6: Recommendations}

\subsection{General Recommendations}

Based on the experience collected during this investigation, the general rules for the designing mapping for transient analysis can be given:

i) Always be aware of the limitations connected with TH/NK coupling.

ii) The analyzed transient has to be well understood in relation to physics and sequences of events before correct mapping model can be chosen.

iii) The selection of suitable mapping scheme should not be only dependent on kind of transient but also on the investigated variable, accuracy of secondary results sometimes have to be compromised if they are not the purpose of the analysis.

iv) While designing new mapping type for a NPP model it is worth to keep in mind that it is of value to keep core symmetry and if possible use mapping according power peaking factors, or fuel types. In addition, it is recommended to have "separation" of channels with different $k_{\text {loss. }}$

v) The number of TH channels should be kept as small as possible since it has the biggest impact on computational time. In most of the analysis small number of TH channels (around 100) is enough to return satisfactory results, but if one is interested in detailed radial, axial and nodal prediction with minimum error, full $700 \mathrm{TH}$ channels model has to be used.

vi) Before going to full-scale model with complicated transient scenario, a lot of model testing and parameters tuning can be made 
with the help of low-number of TH channels model, which will save code users' time.

\subsection{Specific Recommendations for Steady-State Predictions}

Taking into consideration steady-state results comparison from both codes, there are no special requirements, which have to be fulfilled to get wellconverged steady-state. Almost all the mappings will converge to the reference value, full-scale case; question is only how many channels are needed. To get good nodal power predictions in reduced power and flow conditions at least half core (324 channels) is needed. During spatial mapping convergence study some of the parameters converge faster and some need more detailed input, but in general the models with $\sim 100 \mathrm{TH}$ channels and up return satisfactory results. For the detail information of steady-state spatial coupling convergence of the $\mathrm{TH}$ and $\mathrm{NK}$ parameters see Table 11.

Scrutinizing the mapping performance the best for steady-state predictions are all the mappings which include the peaking factor feature with or without any combination of inlet $k_{\text {loss }}, \mathrm{X} \& \mathrm{Y}$ coordinates, fuel types and $1^{\text {st }}$ power mode. In addition, it is of value to keep the core symmetry (symmetry feature). The mapping with $1^{\text {st }}$ power mode feature alone is not recommended, except when it is combined with peaking factor or fuel types.

If one is interested in a certain steady-state variable e.g. distribution of the void fraction or radial power distribution, one has to choose mapping, which is appropriate for this kind of investigation. Engineering judgment is sufficient to make a selection. 


\subsection{Specific Recommendations for Transient Simulations}

When choosing the correct mapping scheme for a specific transient, judgment is more complicated because core state may vary significantly locally in time, while mapping is predefined as a "static". The consequence of this can be that some information is lost. In this investigation, local, regional and global perturbations of the core were investigated. The transient selection was done such that it covers a wide range of transients, and gathered knowledge may be used for many other types transient. In particular, to get a full scale of transients range, global and regional core stability tests were performed, too.

\subsubsection{Local Perturbation}

The sensitivity of a local perturbation on type of mapping and number of TH channels was investigated using Control Rod Drop Accident. The following observations were made:

$\checkmark$ Number of TH channels is less important than the type of mapping.

$\checkmark$ High number of TH channels does not guarantee better results.

$\checkmark$ The lowest recommended number of TH channels is 20 .

$\checkmark$ Power mapping is the one which is recommended.

$\checkmark$ To avoid unnecessary averaging and get the best prediction, channel and core zone where accident happens should always be separated from the rest.

\subsubsection{Regional Perturbation}

The Feedwater Transient was an example of regional perturbation. Two different scenarios were calculated. In the scenario I where the level of 
regional perturbation is "small" all observations are in a good agreement with the observations for global perturbation. However for scenario II the following recommendations can be made:

$\checkmark$ While choosing type of mapping one should take into consideration that regional core zones in the model should be "separated" (see description of Model II - Chapter 2).

$\checkmark$ This transient scenario is dependent on the mapping type; type of mapping affects the power increase ramp, SCRAM time, instability onset time, development of limit cycle, etc.

$\checkmark$ High number of TH channels does not guarantee the quality of results; however, minimum recommended number of TH channels is 100 .

$\checkmark$ Only combined mappings can be recommended for this kind of transient.

\subsubsection{Global Perturbation}

The global perturbation was investigated with the Turbine Trip transient. The following observations were made:

$\checkmark$ The number of TH channels and type of mapping does not have a significant impact on the average plant behaviour - general plant response is always recreated. ${ }^{21}$

$\checkmark$ The difference appears while scrutinizing local behaviour - choice of mapping should be performed according to searched local variable.

\footnotetext{
${ }^{21}$ Observation does not concern models with number of TH channels less than 5 .
} 


\subsubsection{Core Stability}

Core stability was also a part of this investigation, three different investigations were made: stability at operating conditions, global core instability and regional core instability; the last two were made with the help of Ringhals-1 Benchmark. To calculate DR and frequency, control rods were used to perturb the reactor. The following observations were made:

$\checkmark$ The DR can be predicted satisfactorily with low number of TH channels for stable cores, in this case the results are more mapping dependent and even with low number of TH channels satisfactory results can be obtained.

$\checkmark$ In case of unstable cores due to operating conditions, the results might not indicate instability at all, due to low number of TH channels - DR is very much under-predicted. For these cases number of TH channels is very important; for unstable cores, at least half of the core has to be modeled to have a confidence in predicted $D R$ and FR.

$\checkmark$ The power mapping shows potential for inducing or sustaining oscillations while location mapping has damping potential.

$\checkmark$ In case of out-of-phase oscillations, in order to get correct performance of out-of-phase oscillations, it is recommended to use full-scale model. If this is not possible, the mapping which is a mixture of $1^{\text {st }}$ power mode and power peaking factors, should be used.

$\checkmark$ The amplitude of the out-of-phase oscillations, which is the core response to the given perturbation, decreases with the decreasing the number of TH channels. 


\subsection{Mapping Convergence Recommendations}

It is recommended to perform mapping convergence study of the input model with the help of hierarchical clustering algorithms. The usage of hierarchical clustering algorithms, which has been investigated here as a new mapping approach, has been shown to be an efficient approach for spatial coupling problem. Once automatized, it does not only speed up the input preparation for the steady-state and transient simulations, but also allows for testing different mapping configurations even if only one feature is taken into consideration. In addition, the method will not cause difficulties if one wants to have one or many channels always separated (e.g. hot channels for LOCA analysis), this can be part of the clustering input matrix as a one of the feature vectors.

It is also recommended to take into consideration a possibility of implementing hierarchical clustering algorithm into user-friendly interface for the input development e.g. SNAP. 


\section{Chapter 7: Summary}

This thesis presents the development of an effective treatment for the problem of spatial coupling, which appears while coupling TH and NK codes. The topic of spatial coupling was found to be a problem by many researchers who were dealing with nuclear reactor simulations. The previous key findings from literature are pointed out and taken into consideration in this investigation. The obtained results are compared with the previous author's findings and agreement between them was found.

Chapter 3 of this thesis was devoted to mapping issues. Mapping definition was formed and all the existing mapping approaches were gathered and presented in this chapter. Additionally, to increase the efficiency and applicability of spatial mapping convergence study, new mapping methodology has been proposed. The new mapping approach is based on hierarchical clustering method; the method of unsupervised learning that thanks to its potential is adopted by many researchers in many scientific fields. The proposed new mapping method turned out to be very successful for spatial coupling problem and once automatized, it does not only speeds up the input preparation for the steady-state and transient simulations, but also allows for testing different mapping configurations. In addition, the method will not cause difficulties if one wants to have one or many channels always separated (e.g. hot channels in LOCA analysis). Further efforts are needed for user-friendly interface in the input development, e.g., implementing it into SNAP.

The steady-state results obtained from three plant models, namely BWR-1 Model I and II, and BWR-2, for all the investigated cases are presented in Chapter 4. All models achieved well converged steady-state, the local 
parameters were compared and it was concluded that solid basis for further transient analysis was found. Scrutinizing the local parameters, it was found that at least $324 \mathrm{TH}$ channels (one channel per two fuel bundles) are needed to get perfect predictions of nodal power profile in the reduced power and flow conditions of Ringhals-1. It has been observed that some of the parameters converge faster while the others need more detailed input, but generally the models with $\sim 100 \mathrm{TH}$ channels and up will return satisfactory results. For the detail information of steady-state spatial coupling convergence of the $\mathrm{TH}$ and $\mathrm{NK}$ parameters see Table 11. It has been also found that the models with low number of $\mathrm{TH}$ channels constantly over-predict some parameters e.g., axial and radial power peaking factors. The reason for this is TH feedback, which due to low number of TH channels delivers the same average information to each fuel bundle, e.g., average void fraction, which for low number of TH channels is over-predicted. This average information causes that the non-uniformity of local TH parameters distribution vanishes and this is a reason for incorrect predictions e.g. the high power assembly will get higher moderator density (average moderator density) and lower fuel temperature than it really should, in consequence of that, the fuel peaking factor will be even higher. On the other hand some parameters are always underpredicted e.g. average and centerline fuel temperatures. Some parameters show fast convergence and always low prediction uncertainty e.g. average fuel Doppler temperature with its maximum uncertainty of 3\%. In addition, the value of $k_{\text {eff }}$ seems to decrease with the increasing number of $\mathrm{TH}$ channels, which is reasonable taking into consideration that other $\mathrm{TH}$ parameters are also changing, e.g., the fuel temperature is increasing with the increasing number of TH channels; the higher temperature of the fuel contributes larger amounts of negative reactivity (Doppler Effect) and that adds to continues decrease of $k_{\text {eff. }}$.

Analyzing the mapping performance the best predictions for steady-state conditions are the mappings which include the power peaking factor feature alone or with any combination of $k_{\text {loss }}, \mathrm{X}$ and $\mathrm{Y}$ coordinates, fuel 
types and $1^{\text {st }}$ power mode, as well as the values to keep the core symmetry (symmetry feature). The peaking factor mapping is not easy to implement since it needs steady-state pre-calculations or detailed core fuel knowledge. The worst performance has mapping with $1^{\text {st }}$ power mode feature alone and therefore is not recommended, except for combination with peaking factor and sometimes with fuel types.

There is also a difference between mappings in simulation time needed to achieve well-converged steady state. The fastest are those using precalculated features, e.g., power peaking factor, while those with location (e.g., X \& Y coordinates) or exposure features need more time.

Chapter 5 is devoted to transient analysis. In this thesis, in addition to investigation of core stability performance, the local, the regional and the global perturbation of the core were also included. The transient selection was done such that it covers a wide range of transients and gathered knowledge may be used for other types of transients. As a representative of local perturbation, Control Rod Drop Accident was chosen. A specially prepared Feedwater Transient was investigated as a regional perturbation and a Turbine Trip is an example of global one.

In the case of local perturbation, it has been found that number of $\mathrm{TH}$ channels is less important than type of mapping, so the high number of TH channels does not guarantee better results. To avoid unnecessary averaging and get the best prediction, channel and core zone where accident happens should be always separated from the rest. The best performance has mapping according power peaking factors, and therefore this one is recommended for such type of perturbation.

The regional perturbation has been found to be the most challenging from all the others. This kind of perturbation is strongly dependent on mapping type that affects the power increase ramp, SCRAM time, instability onset time, development of limit cycle, etc. It has been also concluded that the 
special effort needs to be paid in input model preparation (see description of BWR-1 Model II - Chapter 2). In addition, choice of mapping type should include the information about regional separation of the core ("weak spatial coupling"), otherwise the development of the core regional behaviour can be suppressed.

In contrast to the regional perturbation, the global perturbation finds to be the least demanding transient. Here, the number of TH channels and type of mapping do not have a large impact on the average plant behaviour general plant response is always recreated. However, the difference appears while scrutinizing local behaviour - choice of mapping should be performed according searched local variable.

A special effort has also been paid to investigate the core stability performance, in both global and regional mode. It has been found that in the case of unstable cores due to operating conditions, the results might not indicate any instability due to low number of TH channels - DR is very much under-predicted. For these cases, the number of TH channels is very important and therefore at least half of the core has to be modeled to have a confidence in predicted DR and FR. It has also been found that the mapping according to power peaking factors shows potential for inducing or sustaining oscillations while location mapping has damping effect.

In case of out-of-phase oscillations, in order to get best out-of-phase performance it is recommended to use full-scale model. If this is not possible, the mapping which is a mixture of $1^{\text {st }}$ power mode and power peaking factors should be used. It is also important to remember that for regional mode the amplitude of the oscillations, which is the core response to the given perturbation, decreases with the decreasing number of $\mathrm{TH}$ channels.

The obtained results for all transients are described and illustrated in detail in Chapter 5. 
The general conclusions and recommendations were gathered in Chapter 6 and here in the Summary. Development of these recommendations was the main purpose of this investigation and they should be taken into consideration while designing new coupled TH/NK models and choosing mapping strategy for a new transient analysis. 


\section{References}

[1] N. Todorova, K. Ivanov, 2001, "PWR REA sensitivity analysis using TRAC-PF1/NEM". In: Proceedings of ICONE-9 Conference, CD (Electronic Publication), Nice, France.

[2] N. Todorova, K. Ivanov, 2002, "Investigation of spatial coupling aspects for coupled code application in PWR safety analysis"; Annals of Nuclear Energy 30 (2003) 189-209.

[3] K. Ivanov, N. Todorova, E. Sartori, 2003;' 'Using the OECD/NRC PWR MSLB benchmark to study current numerical and computational issues of coupled calculations', Nuclear Technology 142 (2), 95-115.

[4] K. Ivanov, A. Olson, E. Sartori, 2004, “OECD/NRC BWR Turbine Trip Transient Benchmark as a Basis for Comprehensive Qualification and Studying Best-Estimate Coupled Codes", Nuclear Science and Engineering 148, 195-207.

[5] OECD, NEA; 2004, CRISSUE-S - WP2, Neutronics/ThermalHydraulics Coupling in LWR Technology: State-of-the-art Report (REAC-SOAR), Nuclear Science, ISBN 92-64-02084-5.

[6] A. Salah, G. Galassi, F. D’Auria, B. Kočar, 2005, “Assessment study of the coupled code RELAP/PARCS against the Peach Bottom BWR turbine trip test", Nuclear Engineering and Design 235 (2005), 1727-1736. 
[7] M. de Carvalho Junior, Osvaldo, 2005, "Coupled 3D neutronic and thermal-hydraulic codes applied to control rod ejection accident in PWR", Master thesis, University of Pisa - etd11212005-103204.

[8] K. Ivanov, M. Avramova, 2007; "Challenges in coupled thermal-hydraulics and neutronics simulations for LWR safety analysis"; Annals of Nuclear Energy 34 (2007) 501-513.

[9] K. Ivanov, E. Sartori, E. Royer, S. Langenbuch, K. Velkov, 2007, "Validation of coupled thermal-hydraulic and neutronics codes in international co-operation".

[10] B. Pershagen, 1996, "Light Water Reactor Safety", Studsvik AB, Nyköping, Sweden.

[11] Vattenfall, "General Information on Ringhals", (http://www.vattenfall.se/sv/file/Technical_information_on_Rin g 8459796.pdf 17581720.pdf)

[12] "RELAP3.3/MOD3.3 Code Manual, Volume Code Structure, System Models, and Solution Methods", NUREG/CR5535/Rev P3 (2006).

[13] H. Tinoco, S. Ahlinder, 2007, "Mixing Conditions in the Lower Plenum and Core Inlet of Forsmark 3", Forsmarks Kraftgrupp AB.

[14] D. Barber, Information Systems Laboratories, Rockville Pike, USA, personal communication.

[15] T. Downar, D. Lee, Y. Xu, T. Kozlowski, 11/9/04 "PARCS v2.6 U.S. NRC Core Neutronics Simulator THEORY MANUAL".

[16] A. Kubarev, Division of Nuclear Power Safety, Royal Institute of Technology (KTH), Stockholm, Sweden, personal communication.

[17] D. Barber, T. Downar, 1998, "Software Requirements Specification for the General Interface in the Coupled Code", School of Nuclear Engineering, Purdue University, W. Lafayette, IN 47907-1290, PU/NE-98-8. 
[18] TRACE V5.0, User's Manual, Volume 1: Input Specification; Volume 2: Modeling Guidelines, 2010.

[19] J. Vedovi, “TRACE Input Deck for Ringhhals Unit 1 Cycle 14 Point 10”, Report RDFMG-JV-R-001(04), January 2004

[20] R. A. Walls, "Boiling Water Reactor Transient Instability Studies of Ringhals 1 Reactor using TRACE coupled with PARCS ”, MSc Thesis, PSU, Pennsylvania, USA 2009.

[21] I. Gajev, "Sensitivity and Uncertainty Analysis of BWR Stability", Lic Thesis, KTH, Stockholm, Sweden 2010.

[22] I. Gajev, "Sensitivity and Uncertainty Analysis of Boiling Water Reactor Stability", PhD Thesis, KTH, Stockholm, Sweden 2012.

[23] Y. Xu, 2005 “DRARMAX MANUAL”, Purdue University.

[24] Matlab, Mathworks (http://www.mathworks.com/)

[25] AptPlot (http://www.aptplot.com/).

[26] A. Jain, M. Murty, P. Flynn, 1999, "Data Clustering: A Review", ACM Computing Surveys, Vol. 31, No. 3.

[27] R. Duda, P. Hart, D. Stork, "Pattern Classification", $2^{\text {nd }}$ edition, John Wiley \& Sons INC.,2001.

[28] C. Bishop, "Pattern Recognition and Machine Learning", Springer, 2009.

[29] W. Liao, Y. Liu, A. Choudhary, "A Grid-based Clustering Using Adaptive Mesh Refinement", Appears in the $7^{\text {th }}$ Workshop on Mining Scientific and Engineering Datasets, 2004.

[30] G. Carlsson, F. Mémoli, "Characterization, Stability and Convergence of Hierarchical Clustering”, Journal of Machine Learning Research 11 (2010), s.1425-1470. 
[31] R. Andrews, "Cluster Analysis", Document, April 2005 \& revised, April 2011.

[32] T. Lefvert, "OECD/NEA Nuclear Science Committee, BWR STABILITY BENCHMARK, final specifications”, NEA/NSC/DOC(94)15, March 1994.

[33] P. Höglind, "Data for stability benchmark calculations Ringhals unit 1 cycles 14, 15, 16 and 17", Vattenfall Ringhal Report, nr. 0120/94, 1994.

[34] T. Lefvert, "Ringhals 1 Stability Benchmark, final report”,NEA/NSC/DOC(96)22, November 1996.

[35] NEA/CSNI/R(2003)10, 2003, "Fuel Safety Criteria in NEA Member Countries", JT00147506.

[36] Y. Xu, et al., "Application of TRACE/PARCS to BWR stability analysis," Annals of Nuclear Energy, Volume 36, Issue 3, 2009

[37] R. Hu, et al., "Boiling Water Reactor Stability Analysis by TRACE/PARCS: Modeling Effects and Case Study of Time versus Frequency Domain Approach," Nuclear Technology, Vol. 177,No.1, 2012.

[38] A. Wysocki "Oskarshamn-II Stability Analysis with TRACE/PARCS,” Master Thesis, University of Michigan 2010.

[39] Y. $\mathrm{Xu}$, et al., "Analysis of the OECD/NEA Ringhals InstabilityBenchmark with TRACE/PARCS," $M \& C 2005$, Avignon 2005.

[40] Y. Xu et al., "Methodologies for BWR Stability Analysis with TRACE/PARCS," M\&C 2005, Avignon 2005.

[41] B. - G. Bergdahl, R. Oguma, J. Karlsson, “Textbook BWRstability”, GSE Power Systems AB, Nyköping 2007. 
Appendixes 


\section{Appendix I}

Table A1.1: Component number series used in RELAP5 input deck.

\begin{tabular}{|c|c|c|}
\hline $\begin{array}{c}\text { Reserved } \\
\text { Number } \\
\text { Series }\end{array}$ & Components & $\begin{array}{c}\text { Used } \\
\text { Number } \\
\text { Series }\end{array}$ \\
\hline $1-700$ & $\underline{\text { Reactor Core }}$ & $\begin{array}{c}31-35 \\
51-55 \\
71-75 \\
231-235 \\
251-255 \\
271-275 \\
331-335\end{array}$ \\
\hline $701-750$ & $\underline{\text { Reactor Core Bypass }}$ & $\begin{array}{l}701-707 \\
711-717 \\
721-727 \\
731-737 \\
741-747\end{array}$ \\
\hline $751-799$ & Steam Lines/Turbines & $760-775$ \\
\hline $800-900$ & $\begin{array}{l}\text { Reactor Vessel (without core): } \\
\bullet \quad \text { Below core }(801-850) \\
\text { Junction to the core }(830-839) \\
-\quad \text { Above core }(850-900) \\
\text { - Junction from the core }(850-859)\end{array}$ & $\begin{array}{c}800-805 \\
810-815 \\
820-829 \\
830-839 \\
850-859 \\
870-871 \\
875 \\
880-881 \\
885-886 \\
900\end{array}$ \\
\hline
\end{tabular}




\begin{tabular}{|c|c|c|}
\hline $901-920$ & Feedwater Systems & $\begin{array}{l}901-904 \\
911-914\end{array}$ \\
\hline $921-999$ & $\begin{array}{c}\text { Safety Systems: } \\
\text { - Drains systems: (921-930) } \\
\text { - Pressure control \& relief system: } \\
(931-940) \\
\text { - Aux. feed water system 327: (941-960) } \\
\text { - } \quad \text { ECC system 323: (961-980) } \\
\text { - Low pressure coolant injection system } \\
\text { 323: (981-990) } \\
\text { - Containment systems: (991-999) }\end{array}$ & $\begin{array}{l}921-924 \\
935-939 \\
941-948 \\
951-952 \\
961-968 \\
971-972 \\
981-988 \\
991-999\end{array}$ \\
\hline
\end{tabular}

Table A1.2: Component description and numbers used in RELAP5 input deck.

\begin{tabular}{|c|c|c|c|c|}
\hline $\begin{array}{l}\text { Component } \\
\text { Series }\end{array}$ & $\begin{array}{l}\text { Component } \\
\text { Number }\end{array}$ & $\begin{array}{l}\text { Component } \\
\text { Name }\end{array}$ & Туре & $\begin{array}{l}\text { Nr of } \\
\text { Cells }\end{array}$ \\
\hline $1-700$ & $1 \ldots .700$ & Fuel bundles & pipe & 27 \\
\hline \multirow{6}{*}{$701-750$} & $\begin{array}{c}701,711,721 \\
731,741\end{array}$ & $\begin{array}{c}\text { Bypass inlet } \\
\text { junctions }(1-5)\end{array}$ & sngljun & - \\
\hline & $\begin{array}{c}702,712,722 \\
732,742\end{array}$ & $\begin{array}{c}\text { Bypass inlet } \\
\text { volumes at inactive } \\
\text { core inlet }(1-5)\end{array}$ & branch & 1 \\
\hline & $\begin{array}{c}703,713,723 \\
733,743 \\
\end{array}$ & $\begin{array}{l}\text { Bypass at core level } \\
\text { active length (1-5) }\end{array}$ & pipe & 25 \\
\hline & $\begin{array}{c}704,714,724 \\
734,744\end{array}$ & $\begin{array}{c}\text { Bypass outlet } \\
\text { junctions from } \\
\text { bypass at core level } \\
\text { active length }(1-5)\end{array}$ & sngljun & - \\
\hline & $\begin{array}{c}705,715,725 \\
735,745\end{array}$ & $\begin{array}{c}\text { Bypass outlet } \\
\text { volumes at inactive } \\
\text { core inlet }(1-5)\end{array}$ & snglvol & 1 \\
\hline & $\begin{array}{c}706,716,726 \\
736,746\end{array}$ & $\begin{array}{l}\text { Bypass outlet } \\
\text { junctions }(1-5)\end{array}$ & sngljun & - \\
\hline
\end{tabular}




\begin{tabular}{|c|c|c|c|c|}
\hline & $\begin{array}{c}707,717,727, \\
737\end{array}$ & $\begin{array}{c}\text { Introduce multiple } \\
\text { cross flow junctions } \\
\text { for bypass pipes } \\
(1-5)\end{array}$ & mtpljun & - \\
\hline \multirow{4}{*}{$751-799$} & $\begin{array}{c}760,764,768 \\
772\end{array}$ & $\begin{array}{c}\text { Junctions from } \\
\text { sdome to steam } \\
\text { lines }(1 \mathrm{a}, 1 \mathrm{~b}, 2 \mathrm{a}, 2 \mathrm{~b})\end{array}$ & sngljun & - \\
\hline & $\begin{array}{c}761,765,769, \\
773\end{array}$ & $\begin{array}{c}\text { Steam lines } \\
(1 \mathrm{a}, 1 \mathrm{~b}, 2 \mathrm{a}, 2 \mathrm{~b})\end{array}$ & snglvol & 1 \\
\hline & $\begin{array}{c}762,766,770 \\
774\end{array}$ & $\begin{array}{l}\text { Valves between } \\
\text { steam lines } \\
\text { and turbines } \\
(1 \mathrm{a}, 1 \mathrm{~b}, 2 \mathrm{a}, 2 \mathrm{~b})\end{array}$ & valve & - \\
\hline & $\begin{array}{c}763,767,771, \\
775\end{array}$ & $\begin{array}{c}\text { turbines } \\
(1 \mathrm{a}, 1 \mathrm{~b}, 2 \mathrm{a}, 2 \mathrm{~b})\end{array}$ & tmdpvol & - \\
\hline \multirow{14}{*}{$800-900$} & $\begin{array}{c}800,803,810 \\
813\end{array}$ & $\begin{array}{l}\text { Junctions from } \\
\text { upde to downc } 1 \text {, } \\
2,3 \text { and downc } 4\end{array}$ & sngljun & - \\
\hline & $\begin{array}{c}801,804,811, \\
814\end{array}$ & Downc1, 2, 3, 4 & annulus & 8 \\
\hline & $\begin{array}{c}802,805,812, \\
815\end{array}$ & Pump1, 2, 3, 4 & pump & - \\
\hline & $820-823$ & LP1 - 4 & branch & 1 \\
\hline & 821 & $\mathrm{Bp}-1 \mathrm{p}$ & snglvol & 1 \\
\hline & $825-828$ & LP $5-7$ & snglvol & 1 \\
\hline & 870 & Uplen & snglvol & 1 \\
\hline & 871 & $\begin{array}{l}\text { Junction from uplen } \\
\text { to ssrizr }\end{array}$ & sngljun & - \\
\hline & 875 & Ssrizr & pipe & 2 \\
\hline & 880 & Sepa & separatr & - \\
\hline & 881 & Updc & annulus & 1 \\
\hline & 885 & Dryr & snglvol & 1 \\
\hline & 886 & $\begin{array}{l}\text { Junction from dryr } \\
\text { to sdome }\end{array}$ & sngljun & - \\
\hline & 900 & sdome & snglvol & 1 \\
\hline
\end{tabular}




\begin{tabular}{|c|c|c|c|c|}
\hline \multirow[b]{2}{*}{$901-920$} & $\begin{array}{c}902,904,912, \\
914\end{array}$ & $\begin{array}{c}\text { feedwater system } 1 \text {, } \\
2,3 \text { and } 4\end{array}$ & tmdpvol & 1 \\
\hline & $\begin{array}{c}901,903,911 \\
913\end{array}$ & $\begin{array}{c}\text { Junction from } \\
\text { feedwater system } 1 \text {, } \\
2,3,4 \text { Downc1, } 2 \\
3,4\end{array}$ & tmdpjun & - \\
\hline \multirow{10}{*}{$921-999$} & $921-924$ & $\begin{array}{c}\text { The drain system } \\
1 \mathrm{a}, 1 \mathrm{~b}, 2 \mathrm{a}, 2 \mathrm{~b} .\end{array}$ & valve & - \\
\hline & 991-994 & $\begin{array}{c}\text { The drain system } \\
1 \mathrm{a}, 1 \mathrm{~b}, 2 \mathrm{a}, 2 \mathrm{~b} \text {. }\end{array}$ & tmdpvol & 1 \\
\hline & $935-939$ & $\begin{array}{c}\text { Pressure Control } \\
\text { and Relief system } \\
(1-5)\end{array}$ & valve & - \\
\hline & 995-999 & $\begin{array}{c}\text { Pressure Control } \\
\text { and Relief system } \\
(1-5)\end{array}$ & tmdpvol & 1 \\
\hline & $\begin{array}{c}941,943,945 \\
947\end{array}$ & $\begin{array}{l}\text { system } 327 \text {, aux. } \\
\text { feed water system } \\
\text { Injection to core } \\
\text { zones } 1-4\end{array}$ & tmdpjun & - \\
\hline & 951 & $\begin{array}{l}\text { system } 327 \text {, aux. } \\
\text { feed water system } \\
\text { Injection to bypass }\end{array}$ & tmdpjun & - \\
\hline & $\begin{array}{c}942,944,946 \\
948\end{array}$ & $\begin{array}{l}\text { system } 327 \text {, aux. } \\
\text { feed water system } \\
\text { (core) }\end{array}$ & tmdpvol & 1 \\
\hline & 952 & $\begin{array}{c}\text { system } 327 \text {, aux. } \\
\text { feed water system } \\
\text { (bypass) }\end{array}$ & tmdpvol & 1 \\
\hline & $\begin{array}{c}961,963,965 \\
967\end{array}$ & $\begin{array}{l}\text { system } 323, \mathrm{ECC} \\
\text { system, Injection to } \\
\text { core zones } 1-4\end{array}$ & tmdpjun & - \\
\hline & 971 & $\begin{array}{c}\text { system } 323, \mathrm{ECC} \\
\text { system, } \\
\text { Injection to bypass }\end{array}$ & tmdpjun & - \\
\hline
\end{tabular}




\begin{tabular}{|c|c|c|l|c|}
\hline & $\begin{array}{c}962,964,966, \\
968\end{array}$ & $\begin{array}{c}\text { system 323, ECC } \\
\text { system, (core) }\end{array}$ & tmdpvol & 1 \\
\cline { 2 - 5 } & 972 & $\begin{array}{c}\text { system 323, ECC } \\
\text { system,(bypass) }\end{array}$ & tmdpvol & 1 \\
\cline { 2 - 5 } & $\begin{array}{c}\text { system 323, low } \\
\text { pressure coolant } \\
\text { injection system, } \\
\text { Injection into } \\
\text { downc1,2,3,4 }\end{array}$ & tmdpjun & - \\
\hline $987,983,985$, & $\begin{array}{c}\text { system 323, low } \\
\text { pressure coolant } \\
\text { injection system }\end{array}$ & tmdpvol & 1 \\
\cline { 2 - 5 } & $982,984,986$, & & \\
\hline
\end{tabular}




\section{Appendix II}

Table A2.1: Fundamental and higher flux mode explanations.

\begin{tabular}{|c|c|c|c|}
\hline \multirow{2}{*}{ Mode No. } & \multicolumn{2}{|c|}{ Schematic Diagram } & \multirow[b]{2}{*}{ Remarks } \\
\hline & Radial plane & $\begin{array}{l}\text { Axial } \\
\text { plane }\end{array}$ & \\
\hline $\begin{array}{c}\text { Fundamental mode } \\
\text { (Zero mode) }\end{array}$ & & + & $\begin{array}{l}\text { The fundamental mode } \\
\text { (positive everywhere) } \\
\text { has physical meaning } \\
\text { and it represents the } \\
\text { power distribution in } \\
\text { both directions radial } \\
\text { and axial. In case of } \\
\text { instability, in-phase } \\
\text { oscillations are always } \\
\text { associated with the } \\
\text { fundamental mode. }\end{array}$ \\
\hline First mode & & + & $\begin{array}{l}\text { The first mode does not } \\
\text { have physical } \\
\text { explanation however in } \\
\text { case of instability; } \\
\text { out-of-phase } \\
\text { oscillations are always } \\
\text { associated with the first } \\
\text { mode. }\end{array}$ \\
\hline \multicolumn{4}{|l|}{ REMARK: } \\
\hline \multicolumn{4}{|c|}{$\begin{array}{l}\text { Higher modes than first mode exist also (axial power profile is also divided on two } \\
\text { zones) however since they do not have physical explanations in the investigated } \\
\text { context and PARCS is not able to calculate higher modes; the problem has been } \\
\text { limited only to the fundamental and first mode. }\end{array}$} \\
\hline
\end{tabular}




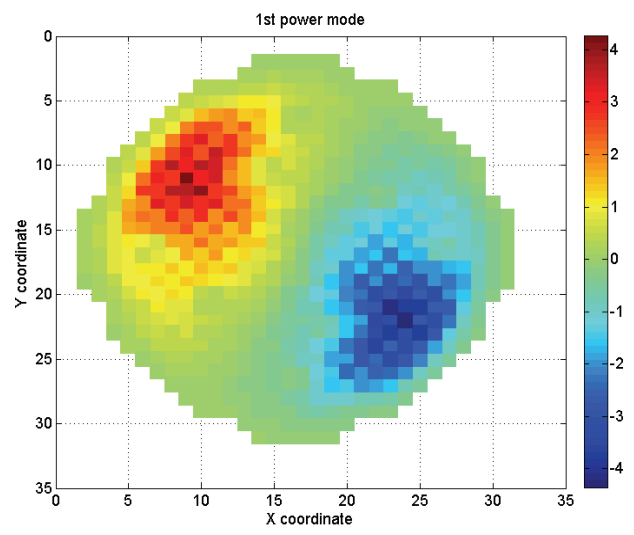

Figure A2.1: Feature: power $1^{\text {st }}$ mode, point 1 of cycle 14.

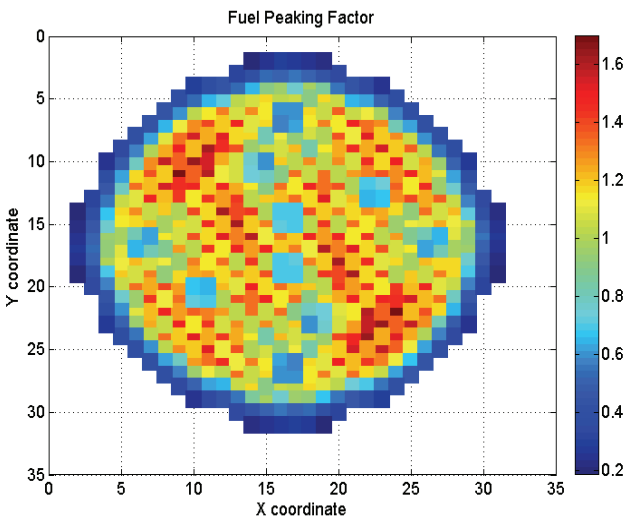

Figure A2.3: Feature: power peaking factor, point 1 of cycle 14.

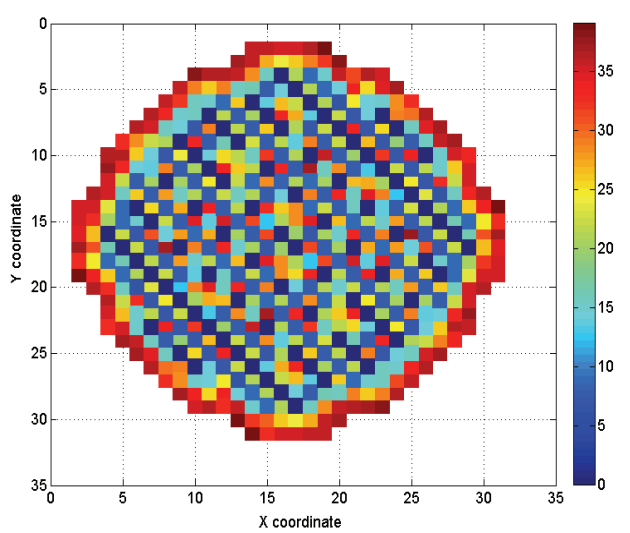

Figure A2.2: Feature: exposure, cycle 14.

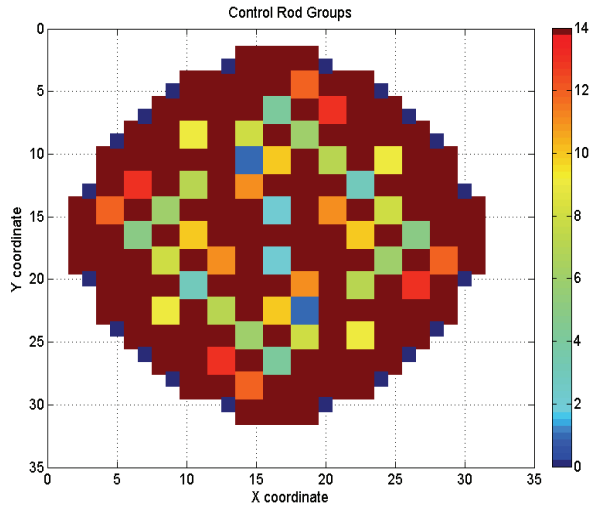

Figure A2.4: Feature: control rod groups, cycle 14. 


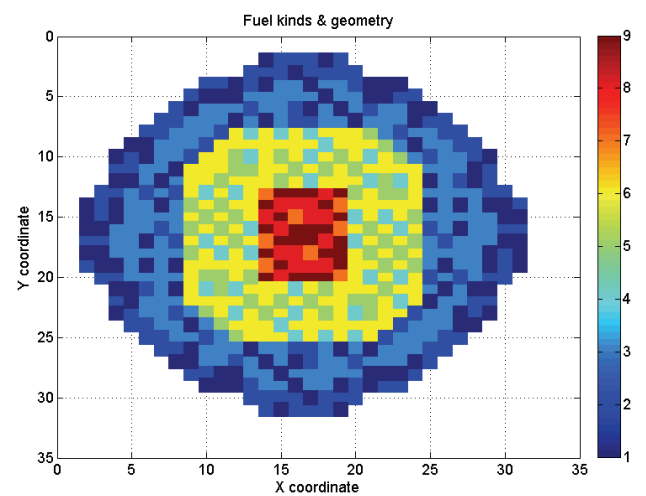

Figure A2.5: Feature: fuel kinds and geometry.

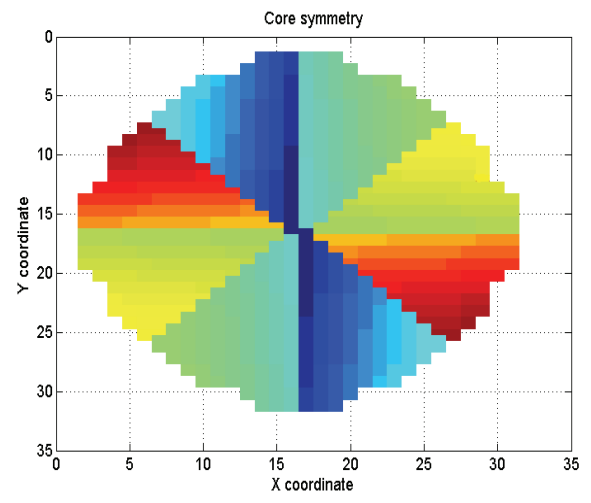

Figure A2.7: Feature: core symmetry.

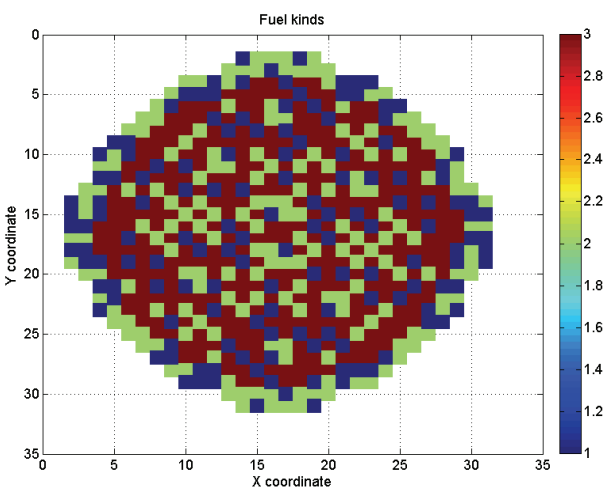

Figure A2.6: Feature: fuel kinds, cycle 14.

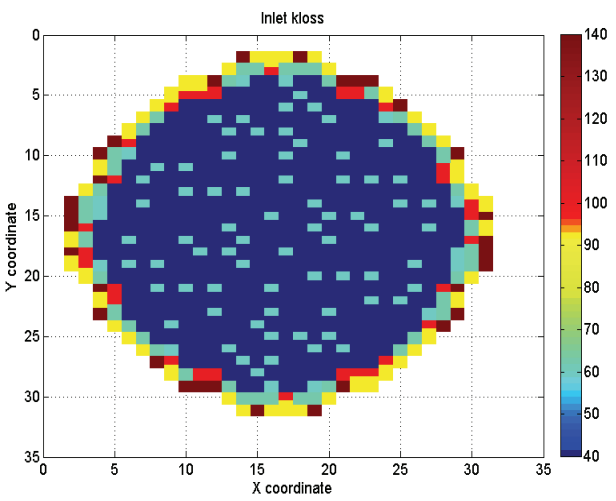

Figure A2.8: Feature: inlet $k_{\text {loss. }}$ 


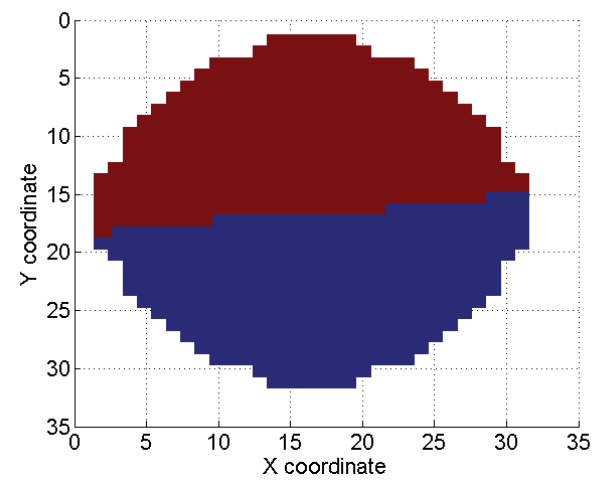

Figure A2.9: Feature: poles separation - special case of $1^{\text {st }}$ power mode, point 9 of cycle 14 . 


\section{Appendix III}

The RMSE (Root Mean Square Error) is a measure of the differences between values predicted by a model and the values actually observed (measured). Since the RMSE is a good measure of accuracy, it is ideal if it is small. The RMSE is calculated with the help of equation (3.1).

$$
R M S E=\sqrt{\frac{\sum_{i=1 \ldots n}\left(p_{i}-r_{i}\right)^{2}}{n}}
$$

where: $p_{i}$ is $i^{\text {th }}$ predicted value and $r_{i}$ is $i^{\text {th }}$ reference value for $i=1 \ldots n$ observations.

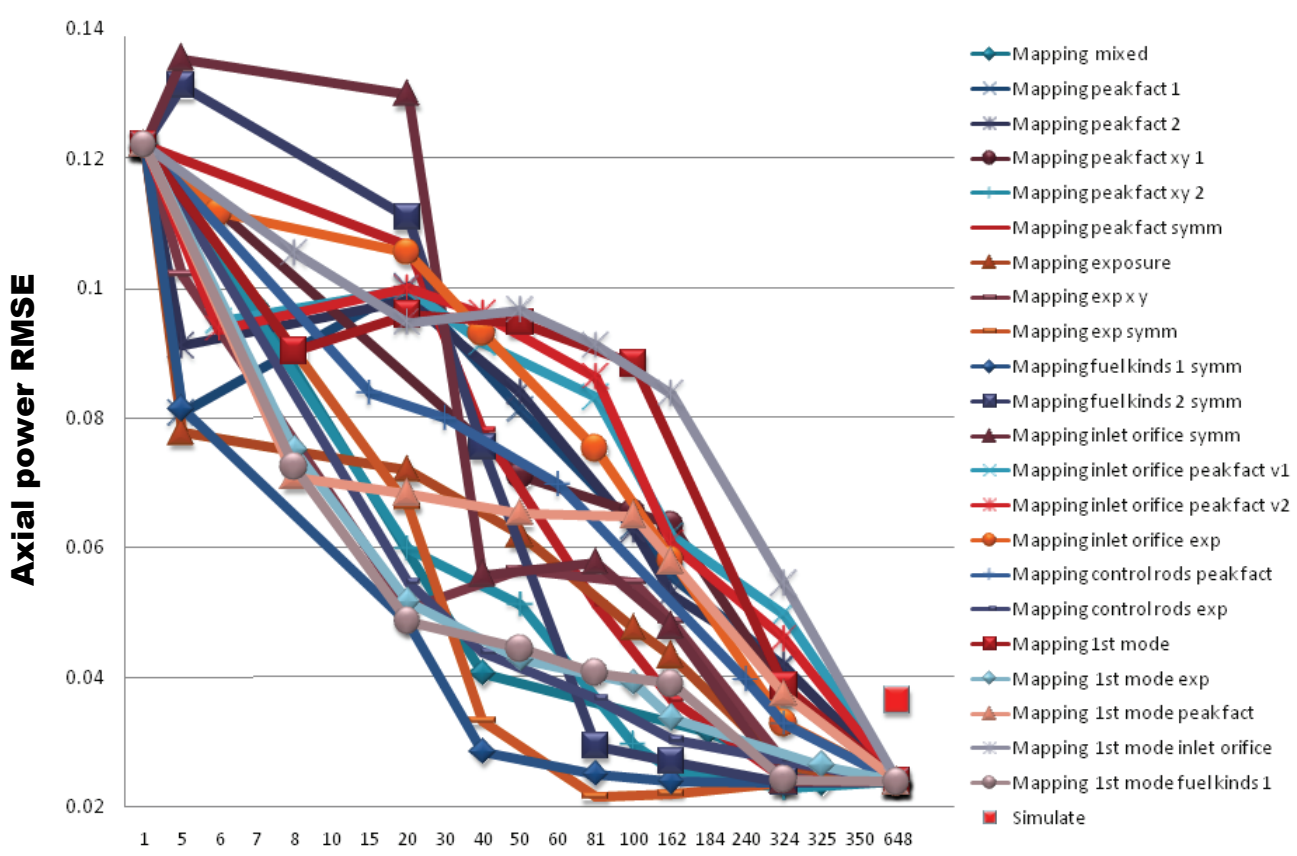

Number of TH channels

Figure A3.1: RMSE Axial Power, point 1 of cycle 14. 


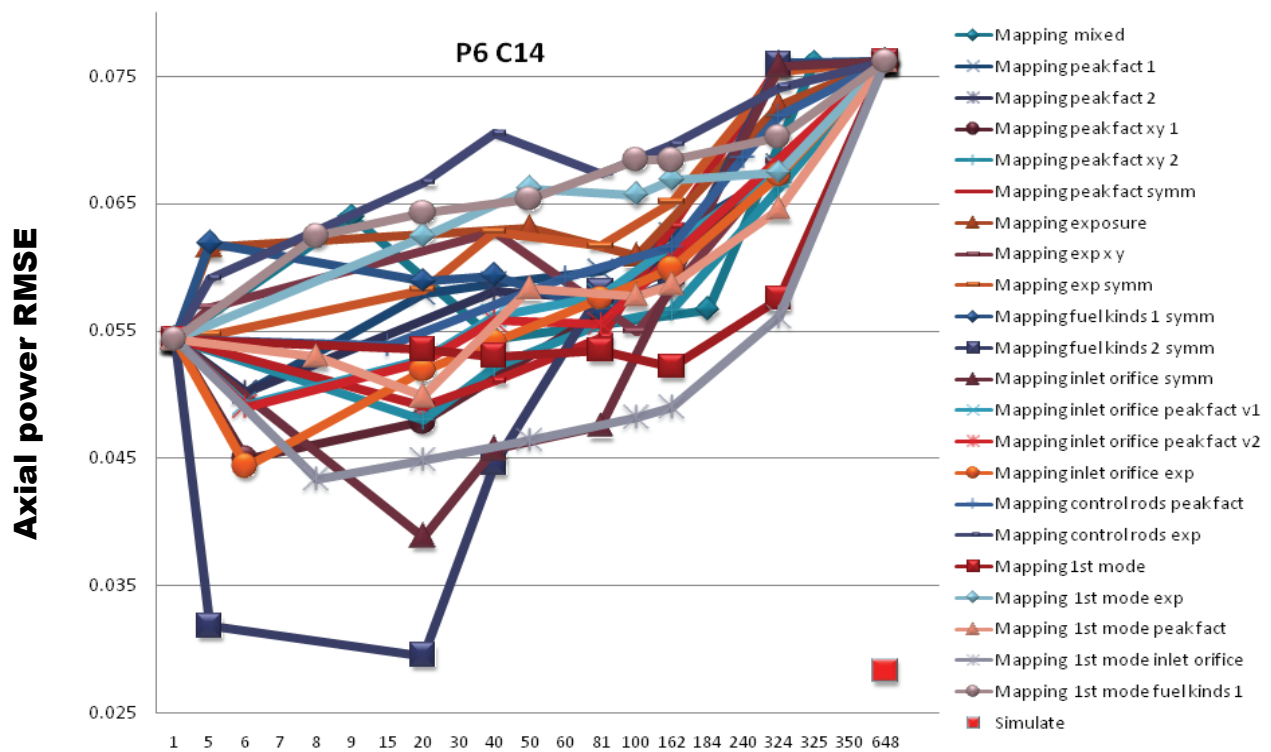

Number of TH channels

Figure A3.2: RMSE Axial Power, point 6 of cycle 14.

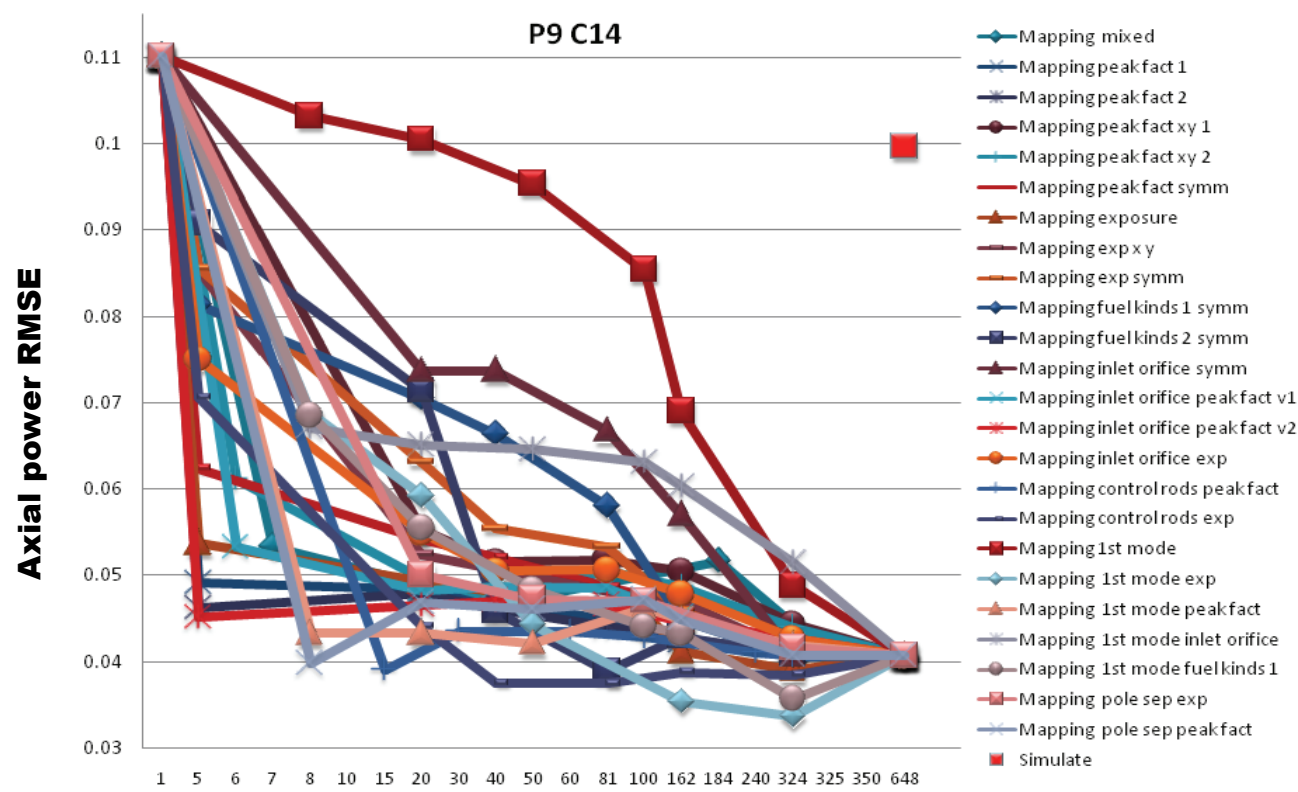

Number of TH channels

Figure A3.3: RMSE Axial Power, point 9 of cycle 14. 


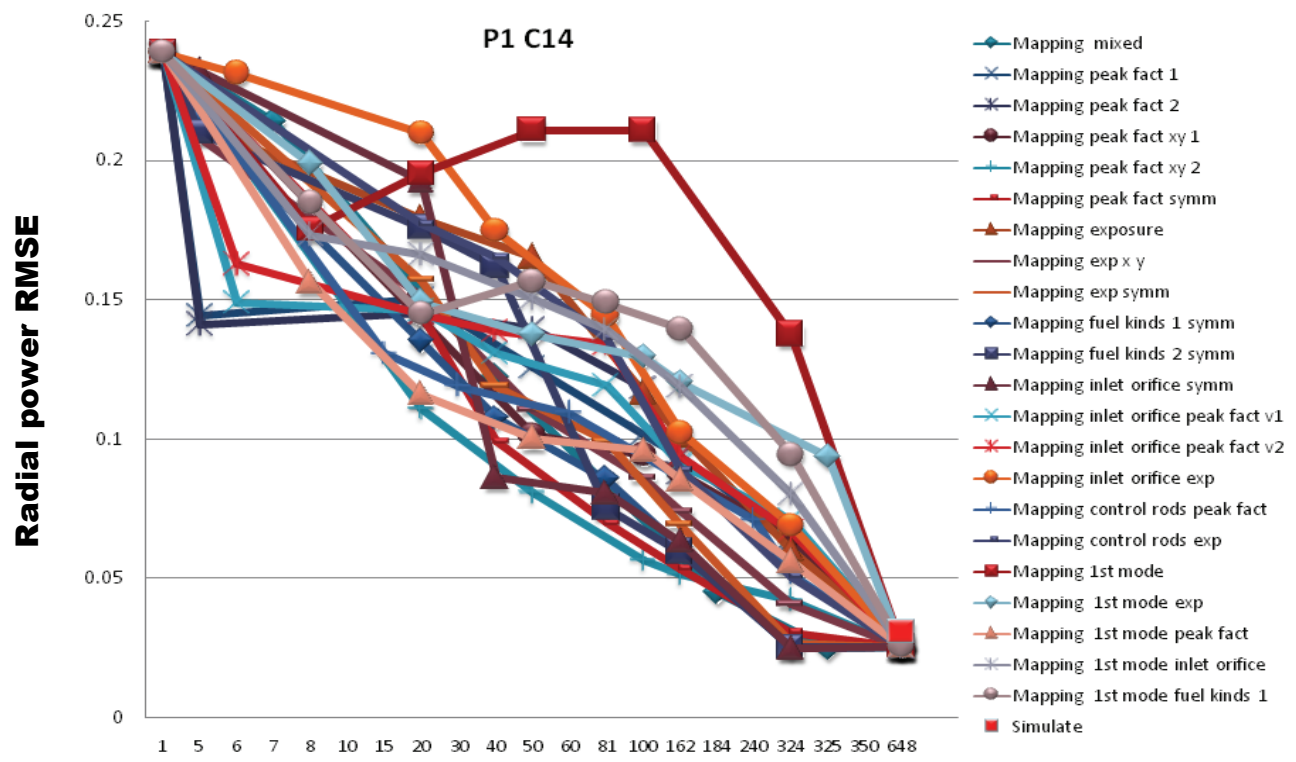

Number of TH channels

Figure A3.4: RMSE Radial Power, point 1 of cycle 14.

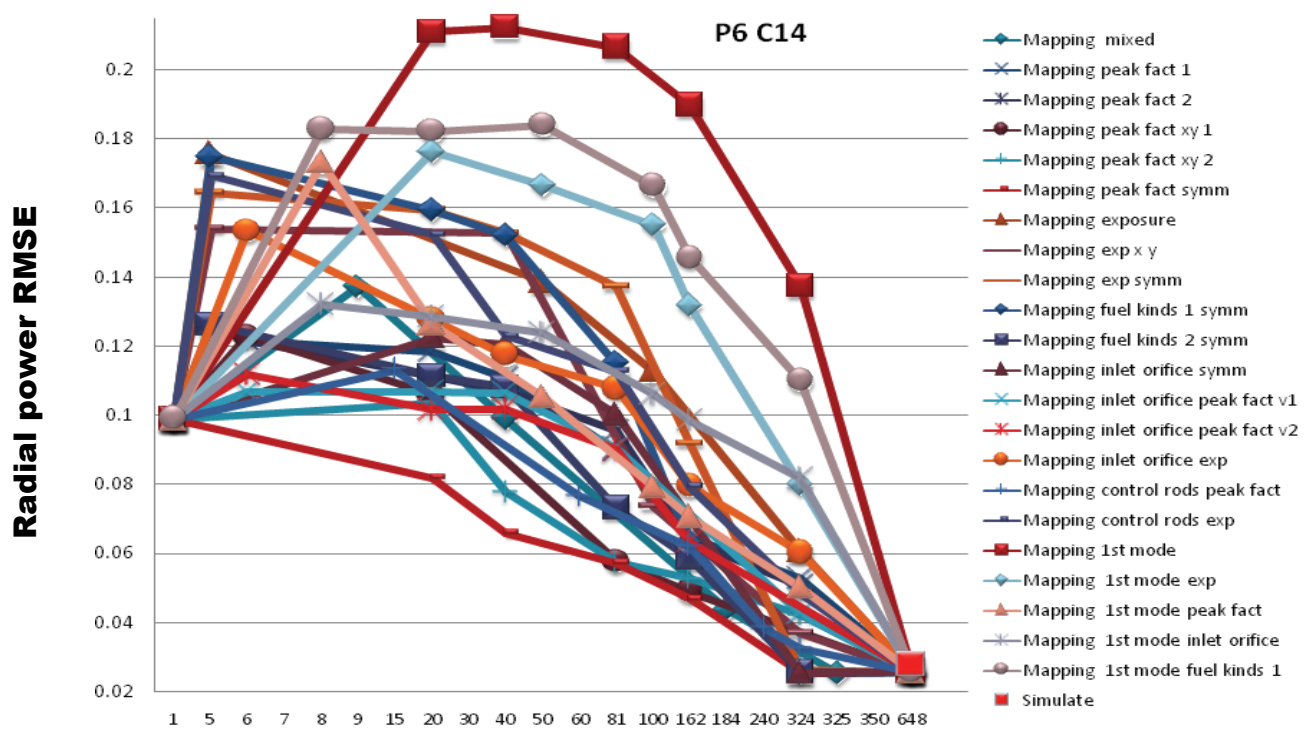

Number of TH channels

Figure A3.5: RMSE Radial Power, point 6 of cycle 14. 


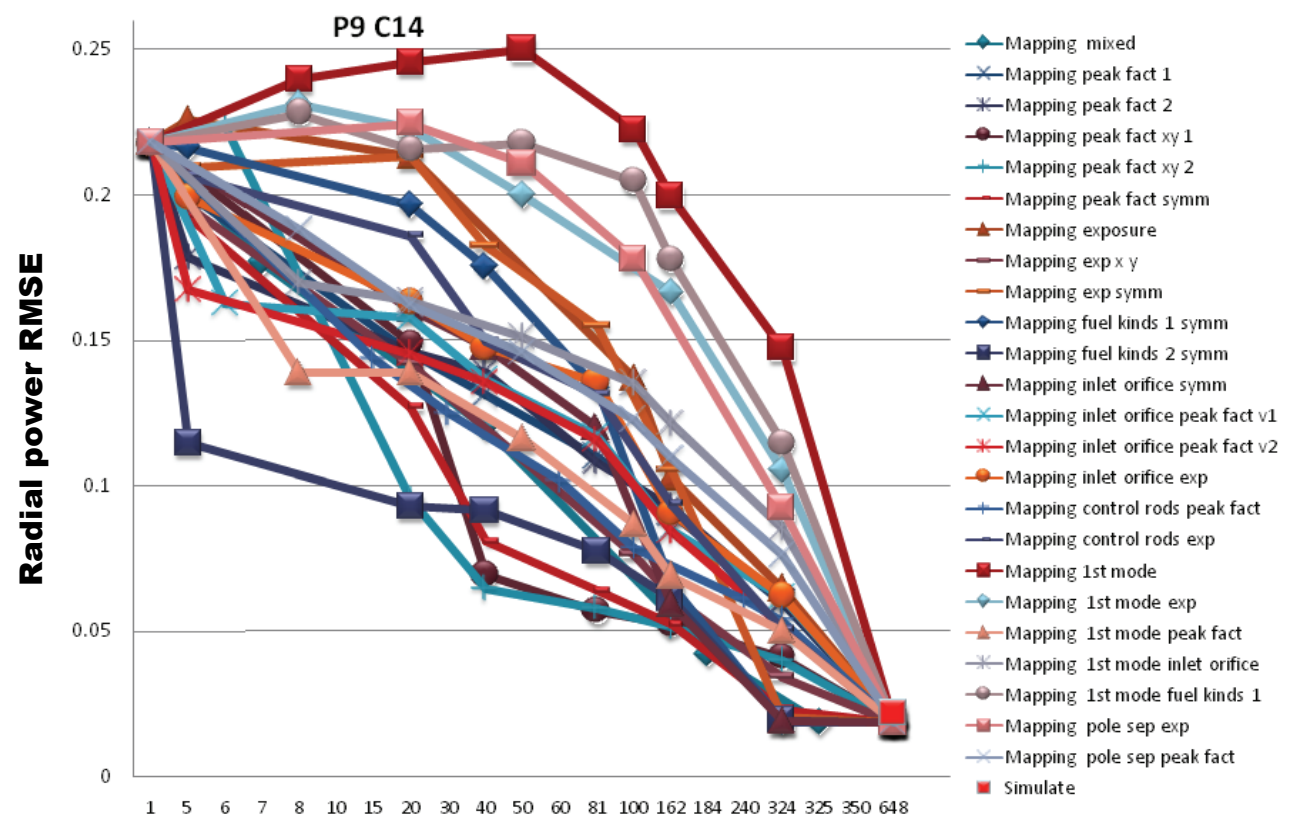

Number of TH channels

Figure A3.6: RMSE Radial Power, point 9 of cycle 14.

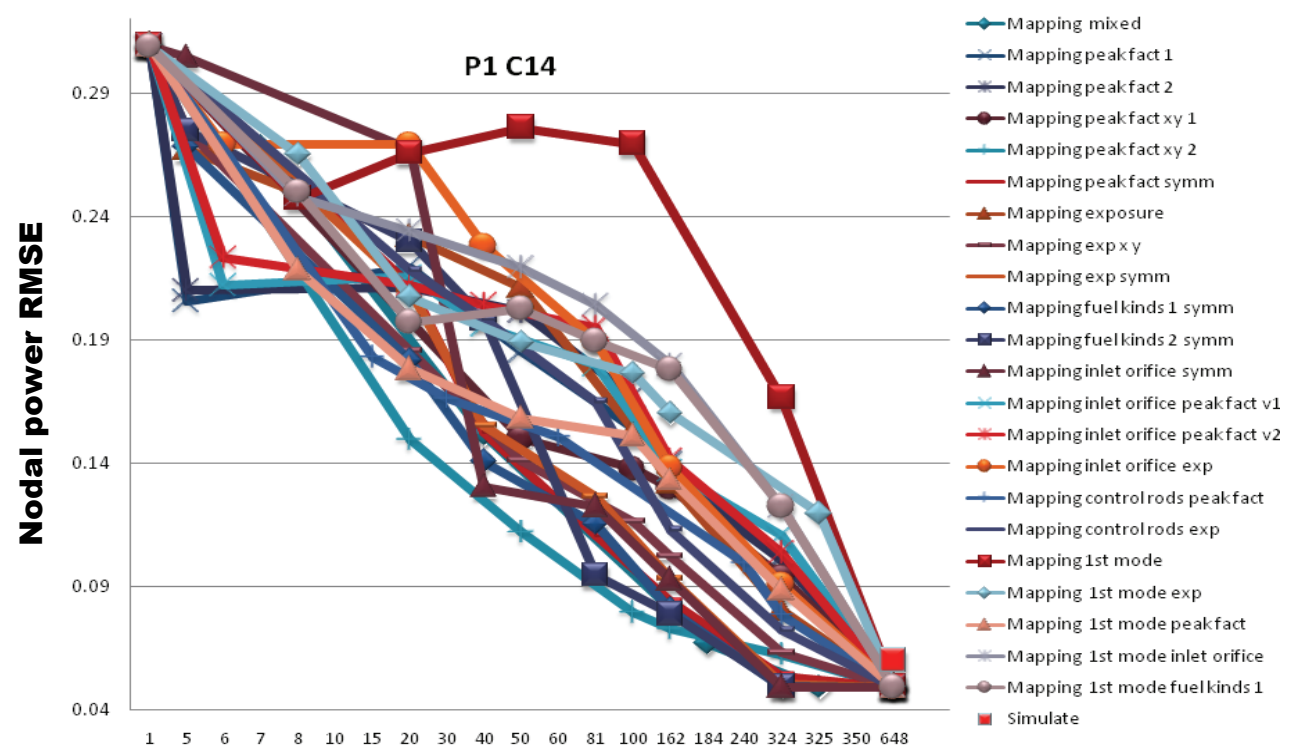

Number of TH channels

Figure A3.7: RMSE Nodal Power, point 1 of cycle 14. 


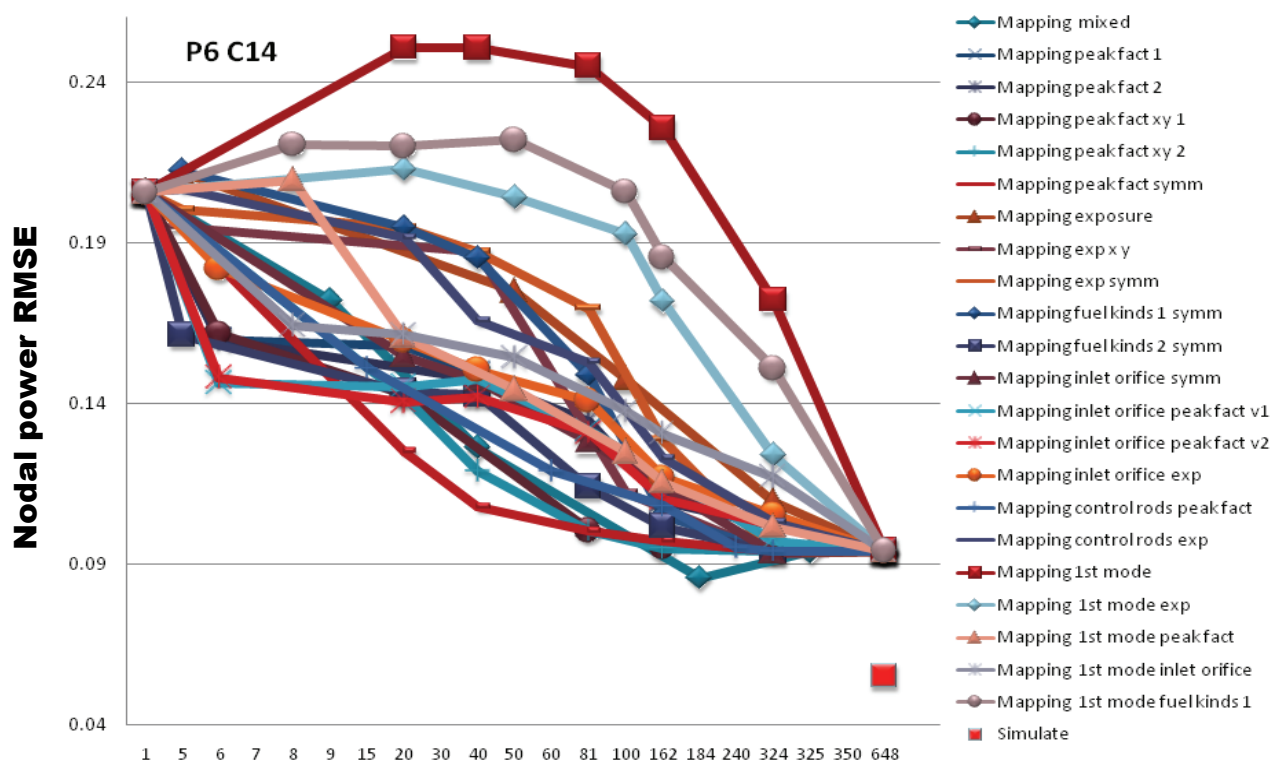

Number of TH channels

Figure A3.8: RMSE Nodal Power, point 6 of cycle 14.

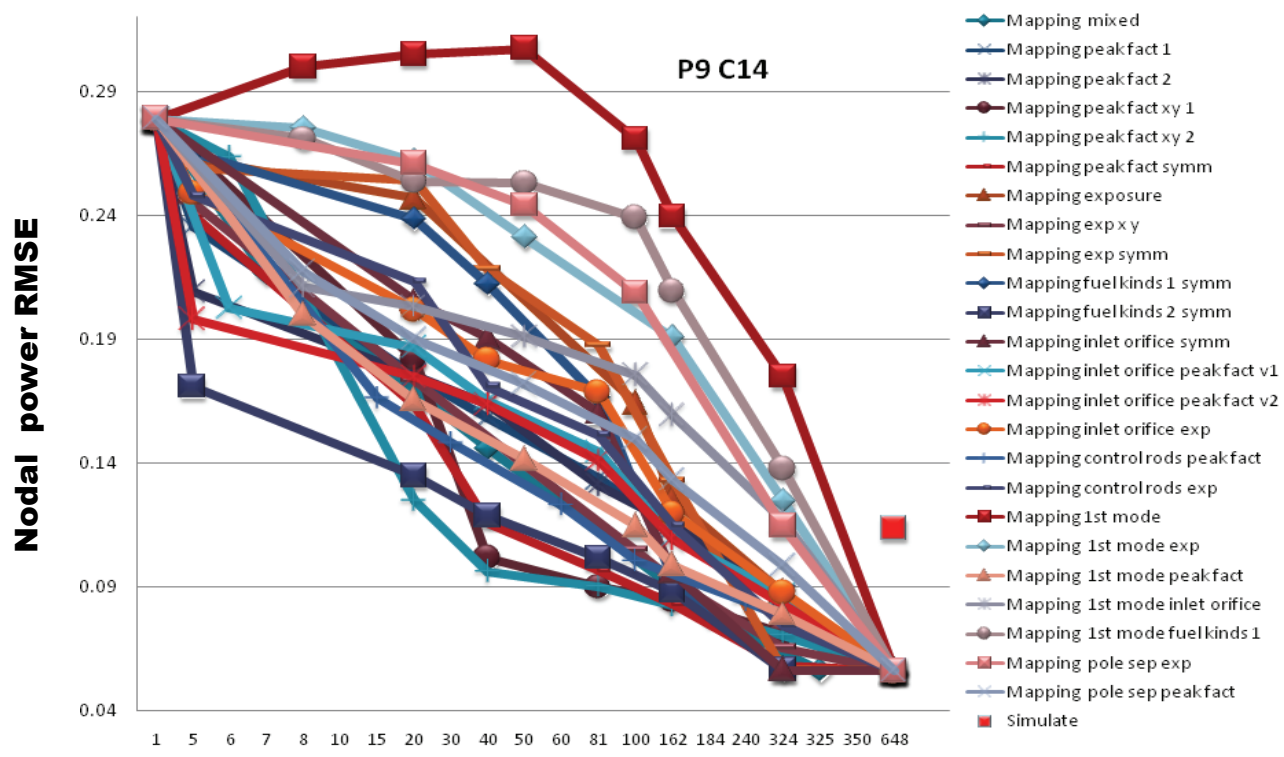

Number of TH channels

Figure A3.9: RMSE Nodal Power, point 9 of cycle 14. 

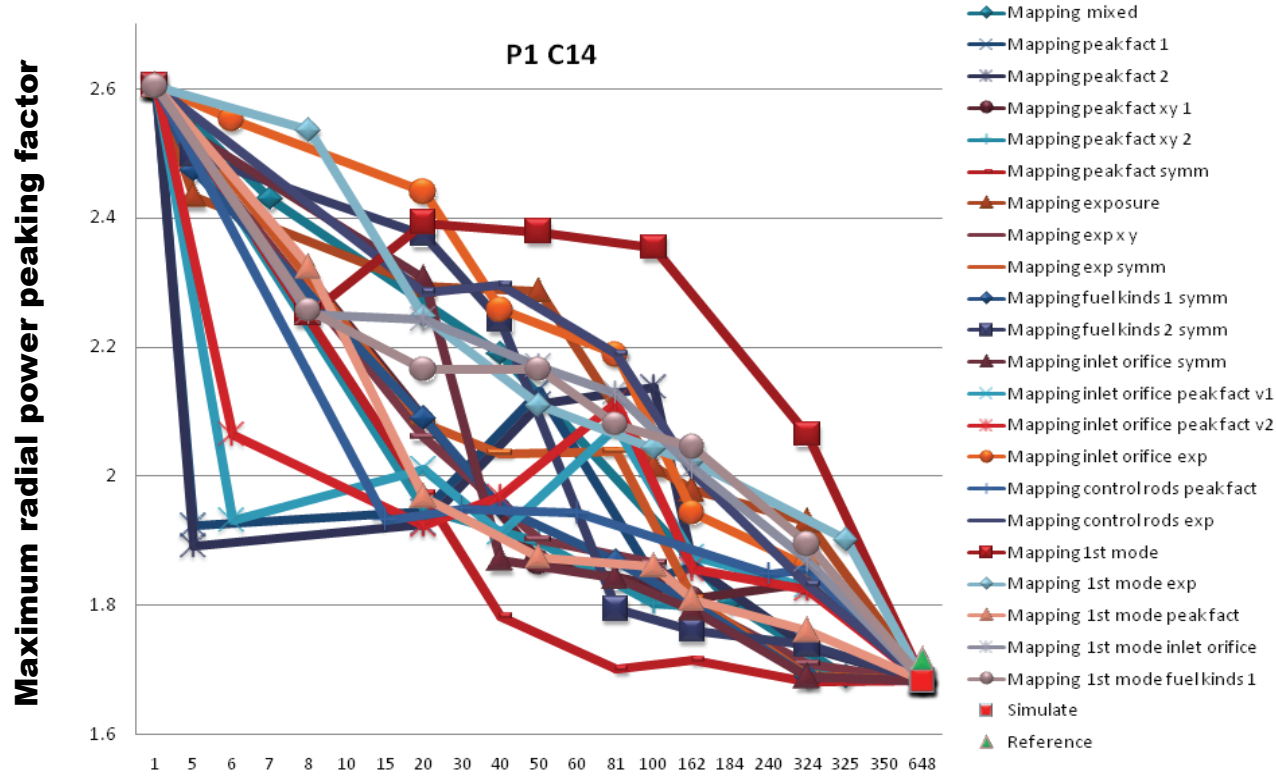

Number of TH channels

Figure A3.10: Maximum radial peaking factor (Pxy), point 1 of cycle 14.
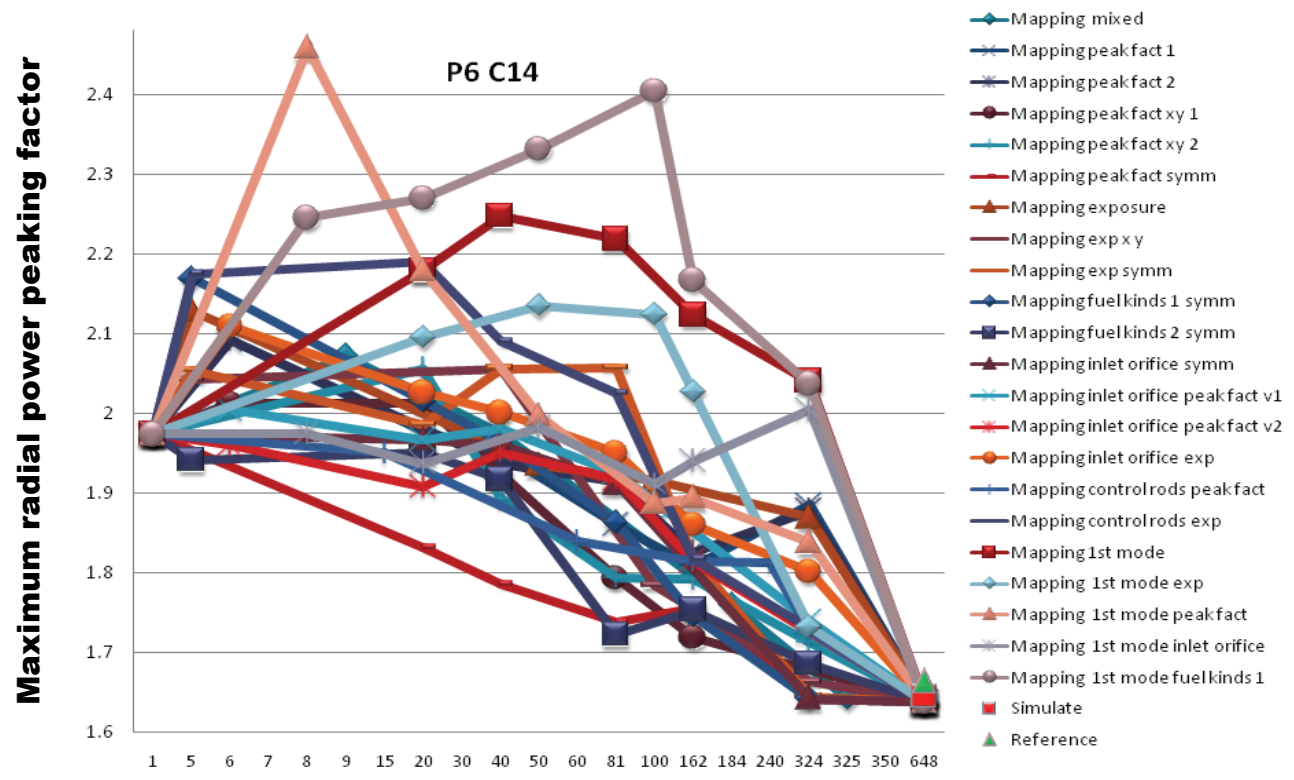

Number of TH channels

Figure A3.11: Maximum radial peaking factor (Pxy), point 6 of cycle 14. 

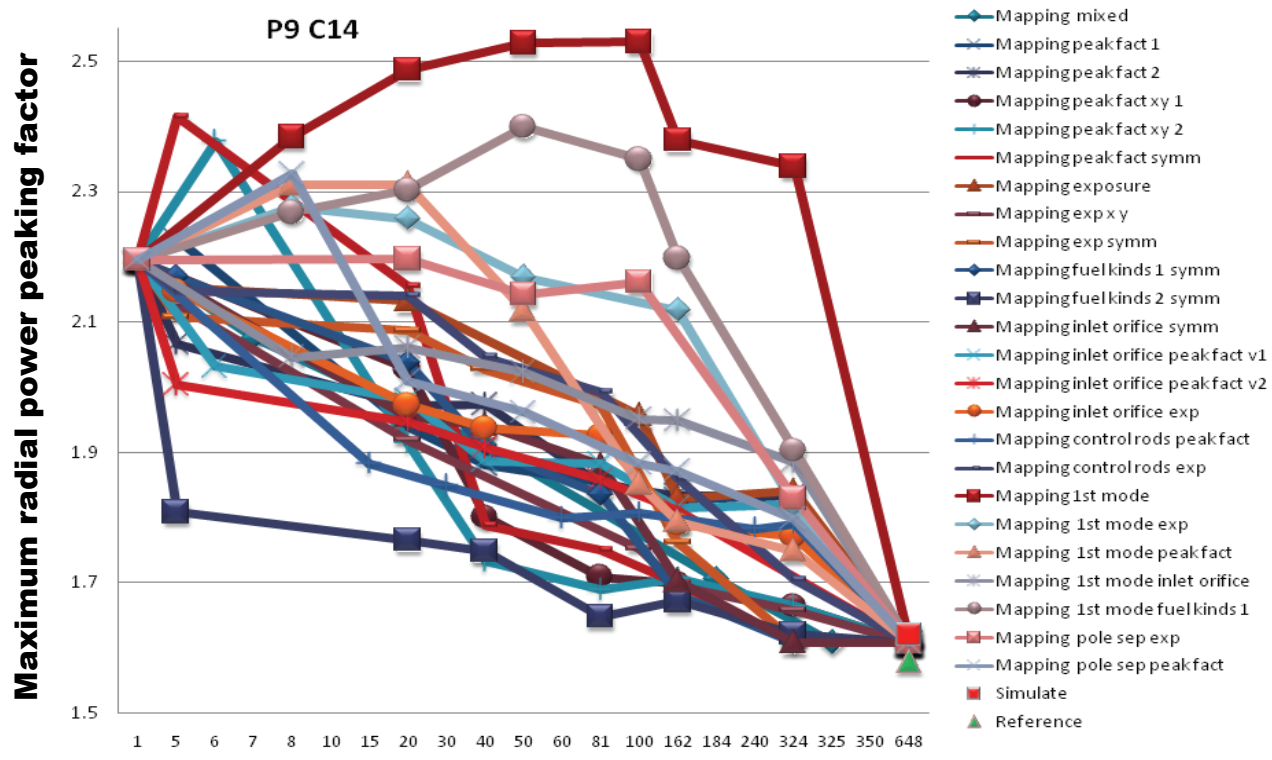

\section{Number of TH channels}

Figure A3.12: Maximum radial peaking factor (Pxy), point 9 of cycle 14.

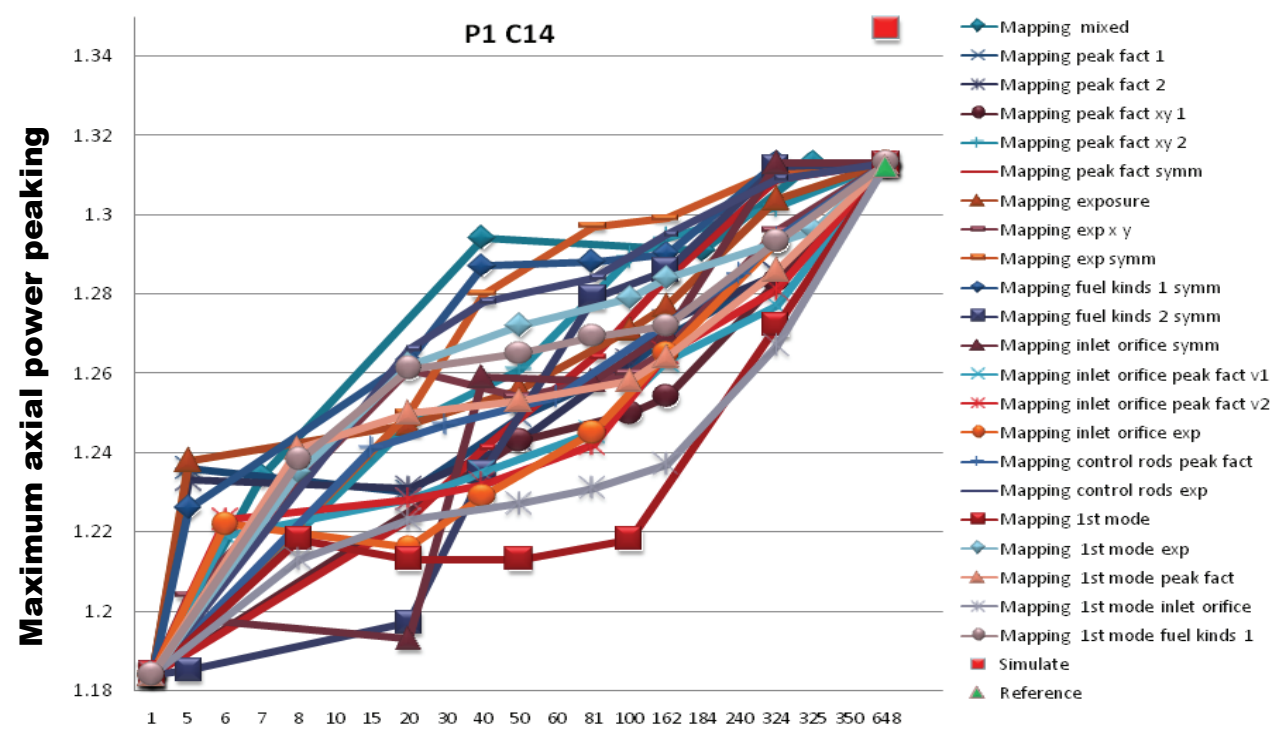

Number of TH channels

Figure A3.13: Maximum axial peaking factor (Pz), point 1 of cycle 14. 


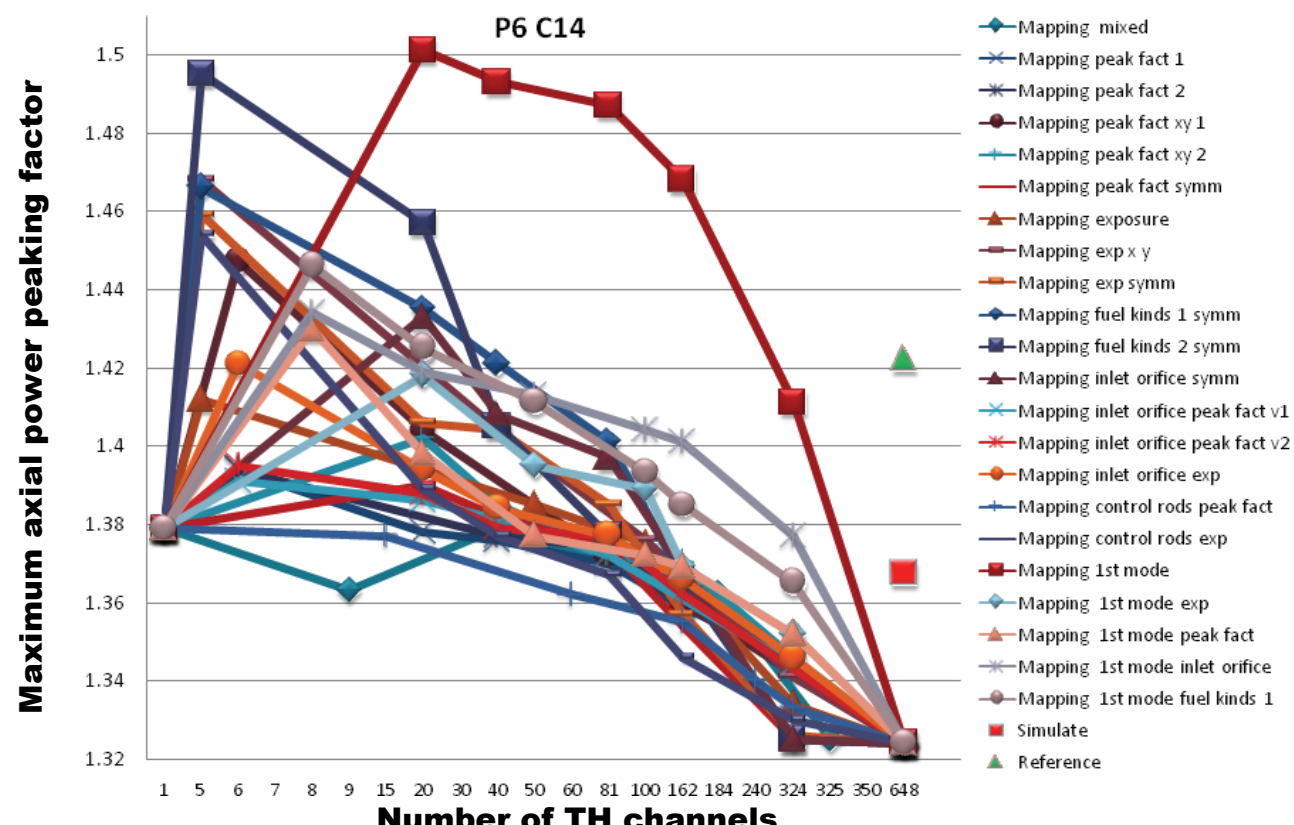

Figure A3.14: Maximum axial peaking factor (Pz), point 6 of cycle 14.
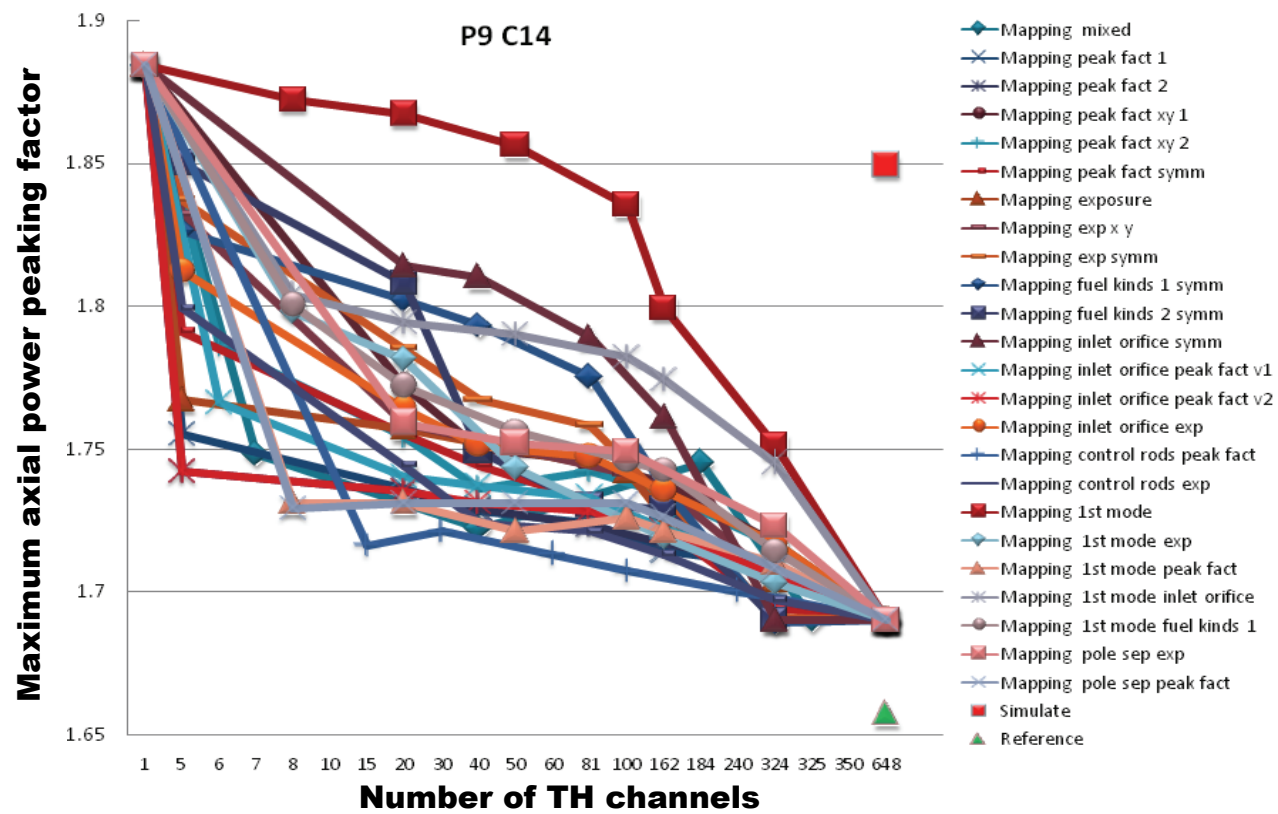

Figure A3.15: Maximum axial peaking factor (Pz), point 9 of cycle 14. 


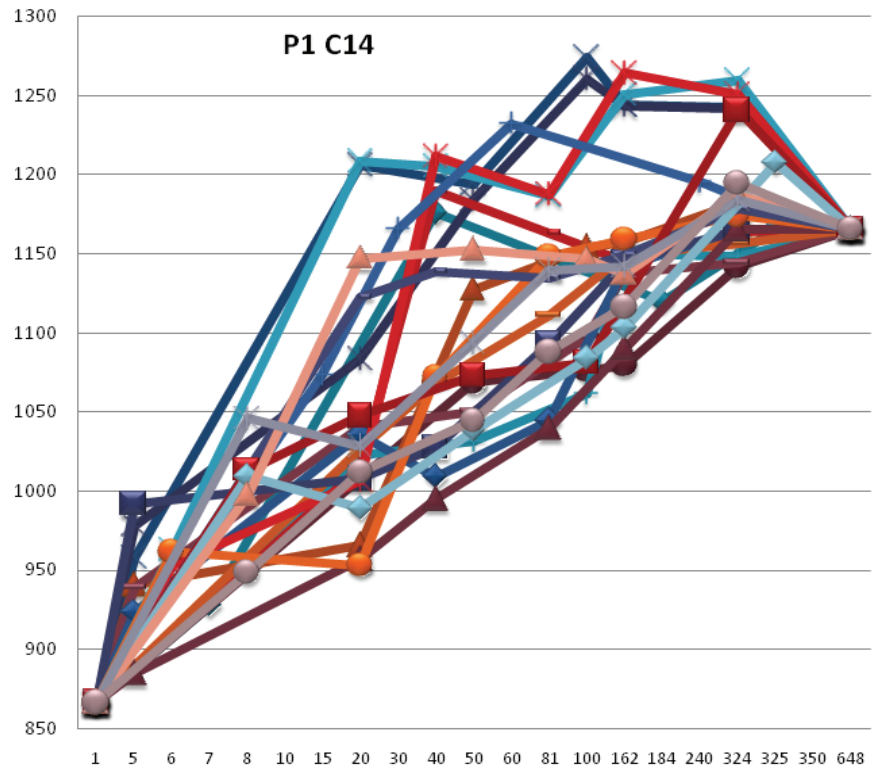

$\leadsto$ Mapping mixed

-Mapping peakfact 1

-Mapping peakfact 2

-Mapping peakfact xy 1

-Mapping peakfact xy 2

-Mapping peakfact symm

-Mapping exposure

-Mapping exp xy

-Mapping exp symm

$\neg$ Mappingfuelkinds 1 symm

$\rightarrow$ Mappingfuelkinds 2 symm

-Mapping inlet orifice symm

- Mapping inlet orifice peakfact v1

—Mapping inlet orifice peakfact v2

-Mapping inlet orifice exp

-Mapping control rods peakfact

-Mapping control rods exp

$\rightarrow$ Mapping 1st mode

$\neg$ Mapping 1st mode exp

-Mapping 1st mode peakfact

-Mapping 1st mode inlet orifice

$\multimap$ Mapping 1st mode fuel kinds 1

\section{Number of TH channels}

Figure A3.16: Maximum centerline fuel temperature, point 1 of cycle 14.
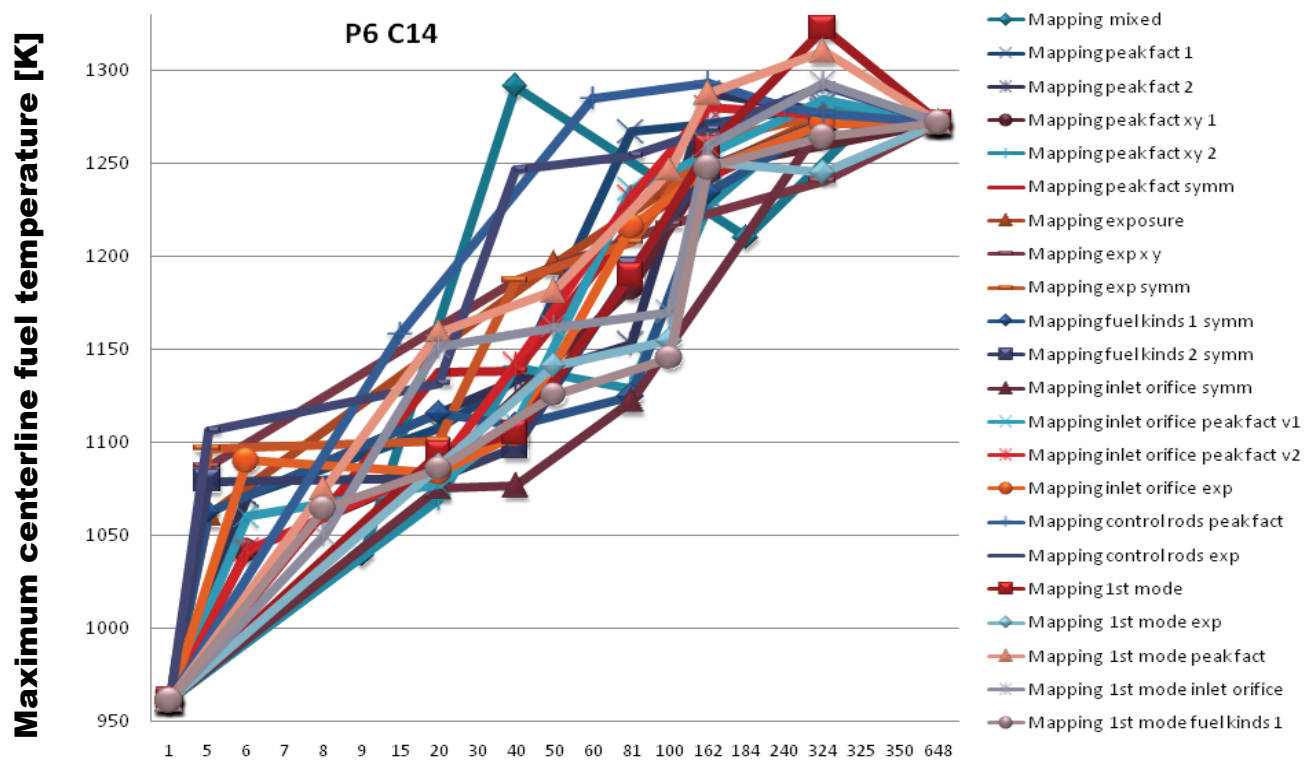

Number of TH channels

Figure A3.17: Maximum centerline fuel temperature, point 6 of cycle 14 . 


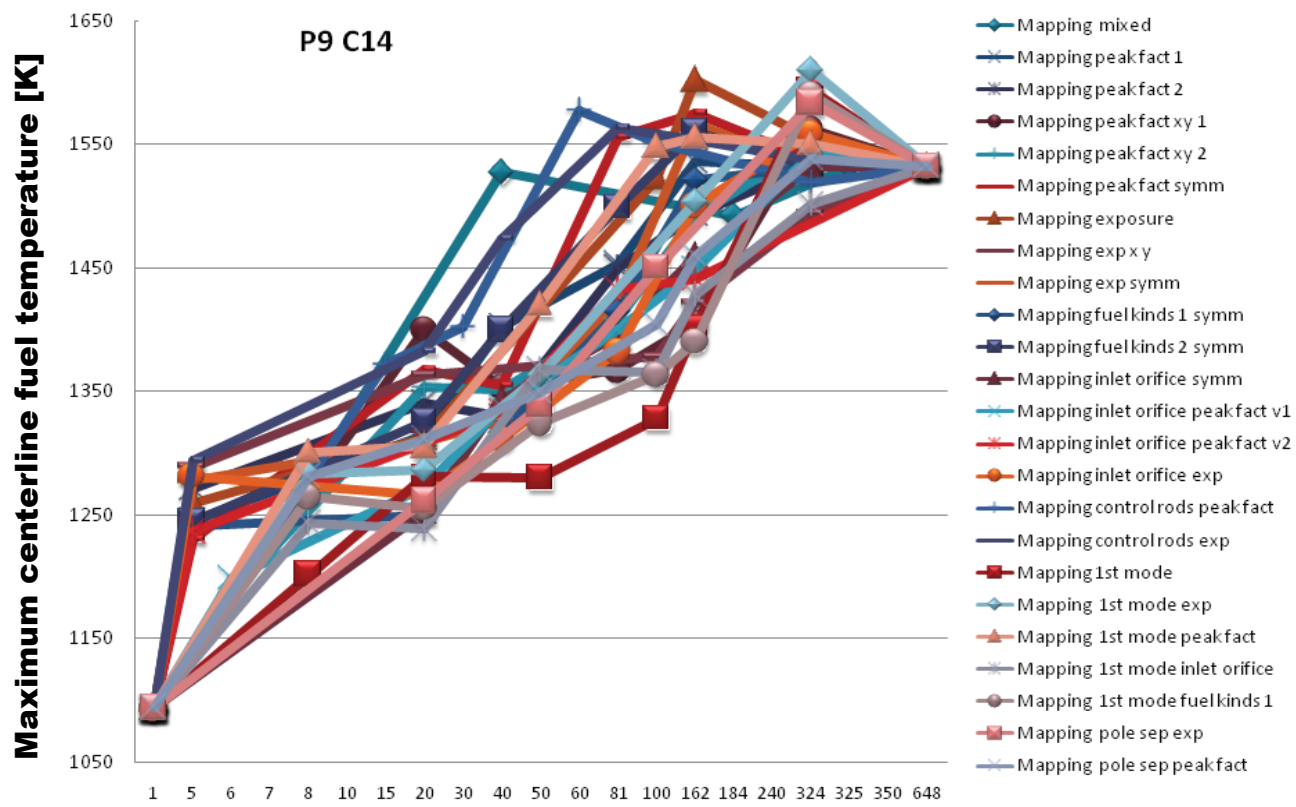

\section{Number of TH channels}

Figure A3.18: Maximum centerline fuel temperature, point 9 of cycle 14.
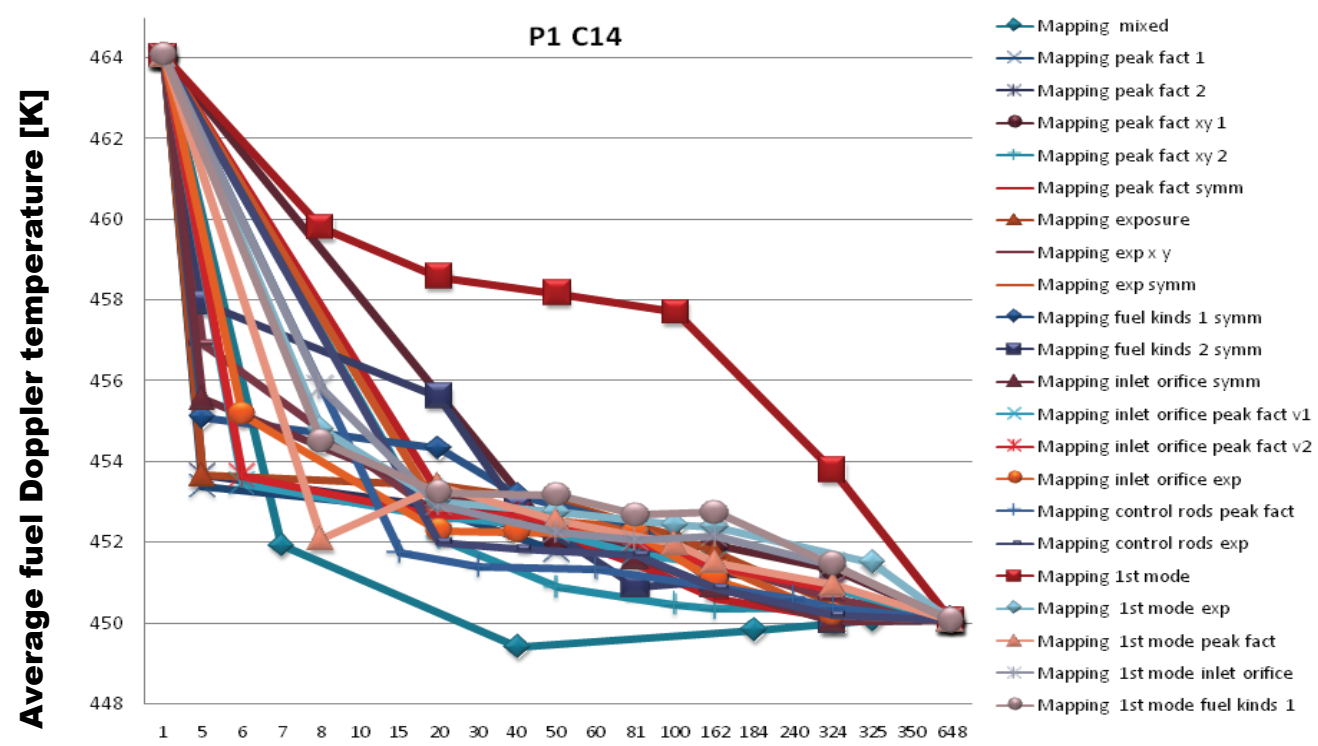

Number of TH channels

Figure A3.19: Average fuel Doppler temperature, point 1 of cycle 14. 


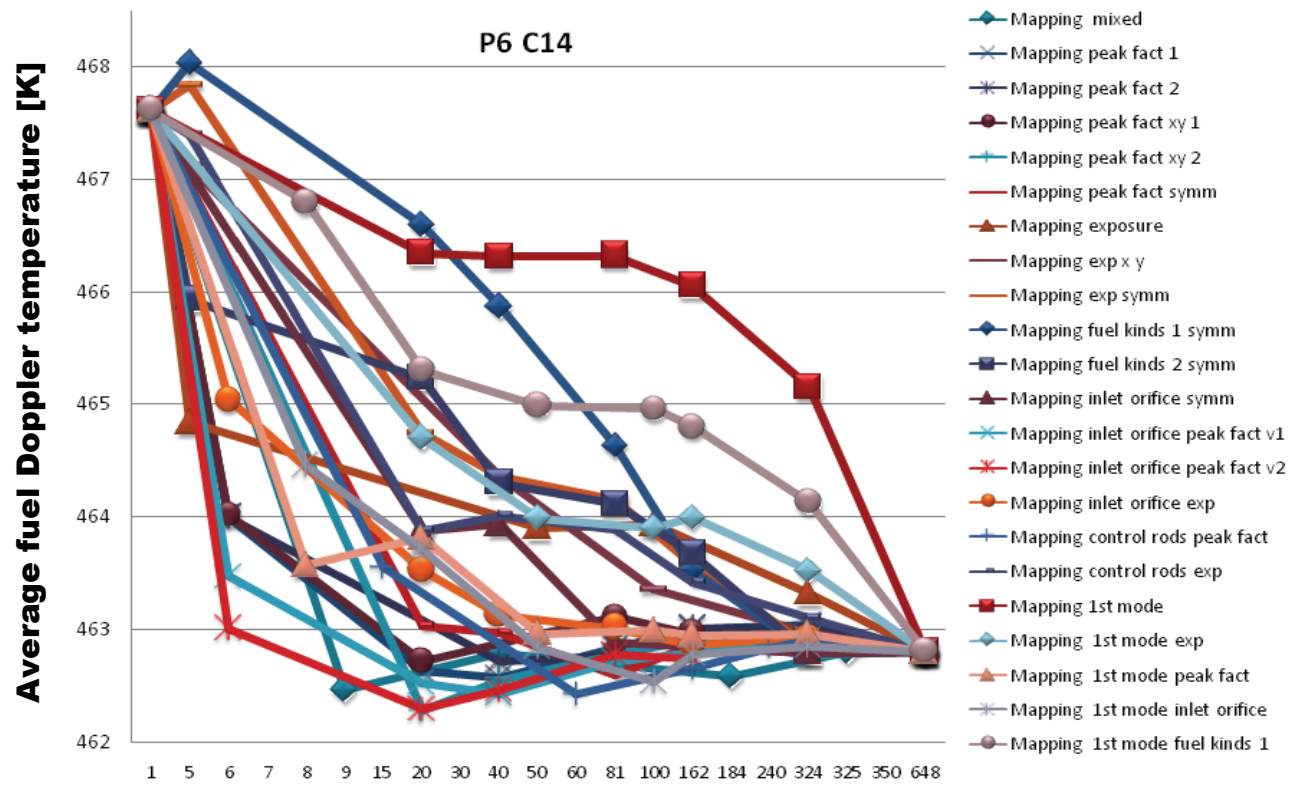

\section{Number of TH channels}

Figure A3.20: Average fuel Doppler temperature, point 6 of cycle 14.
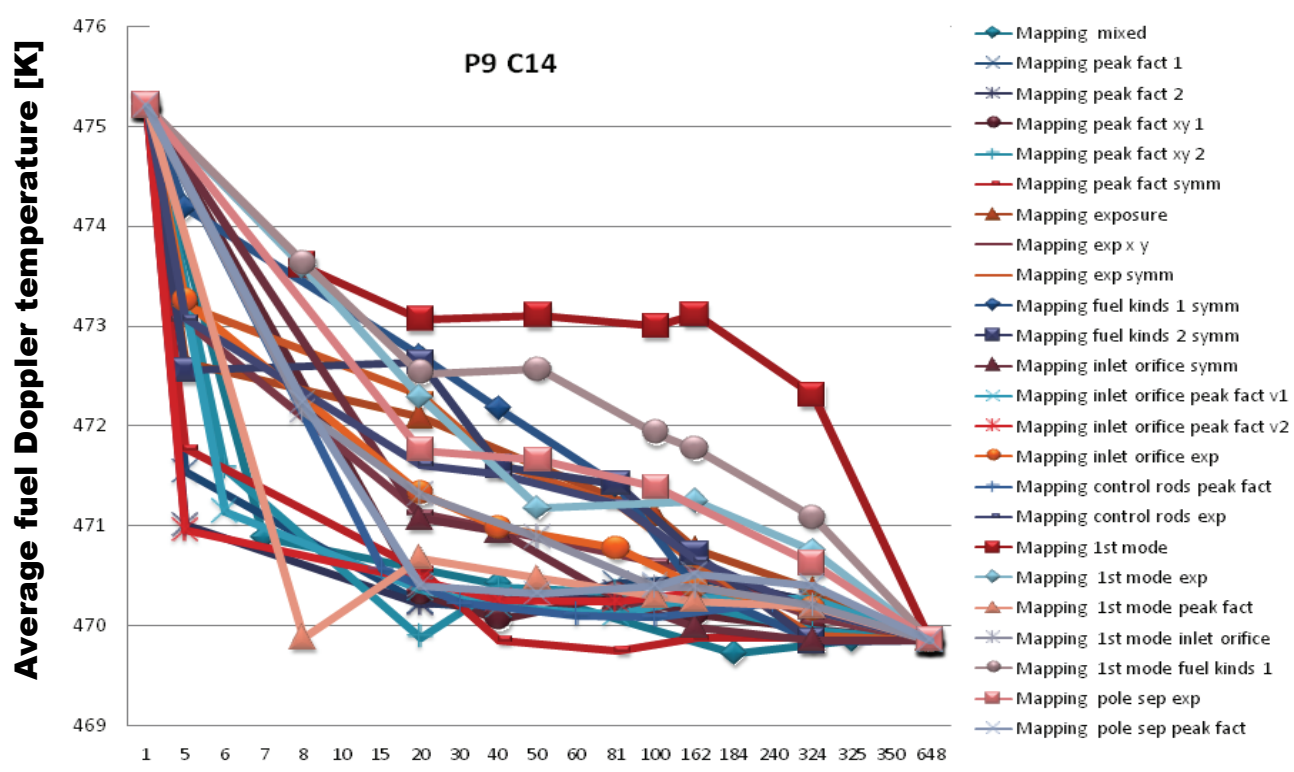

\section{Number of TH channels}

Figure A3.21: Average fuel Doppler temperature, point 9 of cycle 14. 


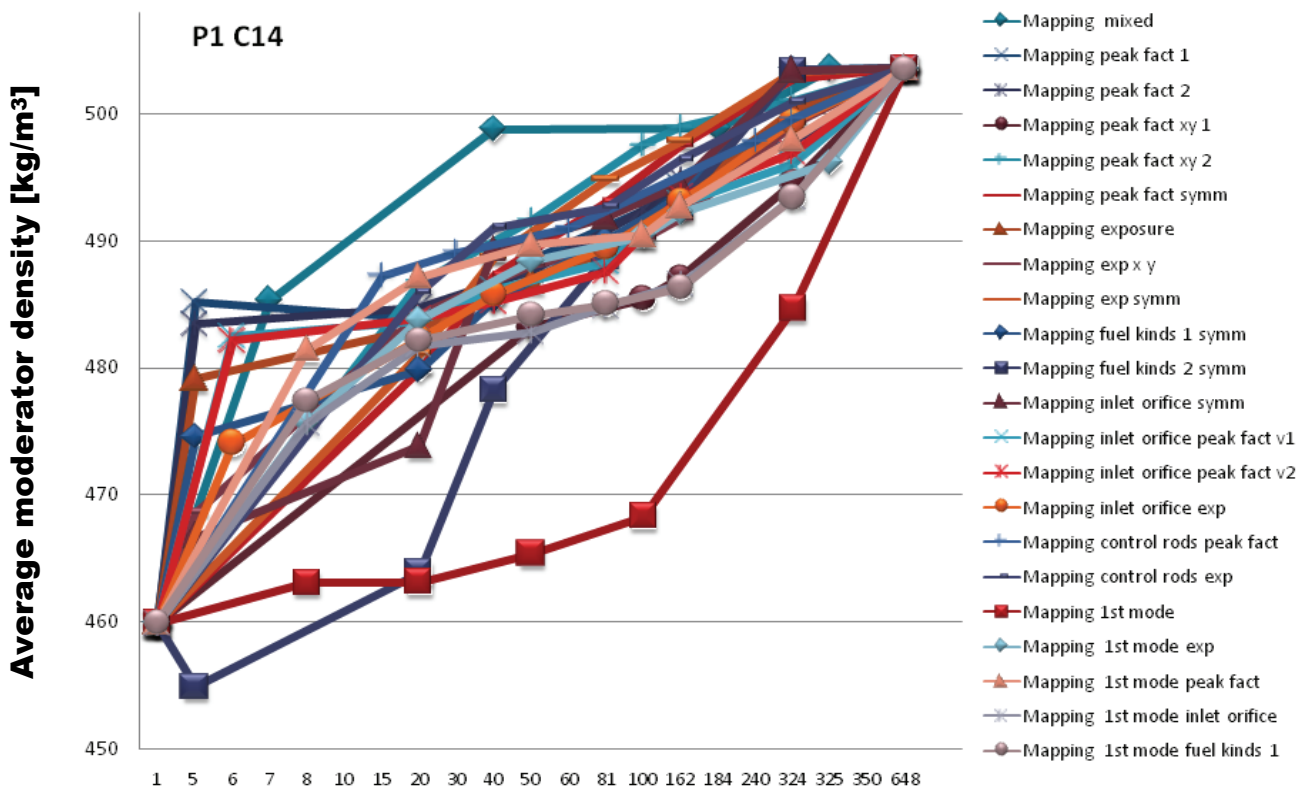

Number of TH channels

Figure A3.22: Average moderator density, point 1 of cycle 14.

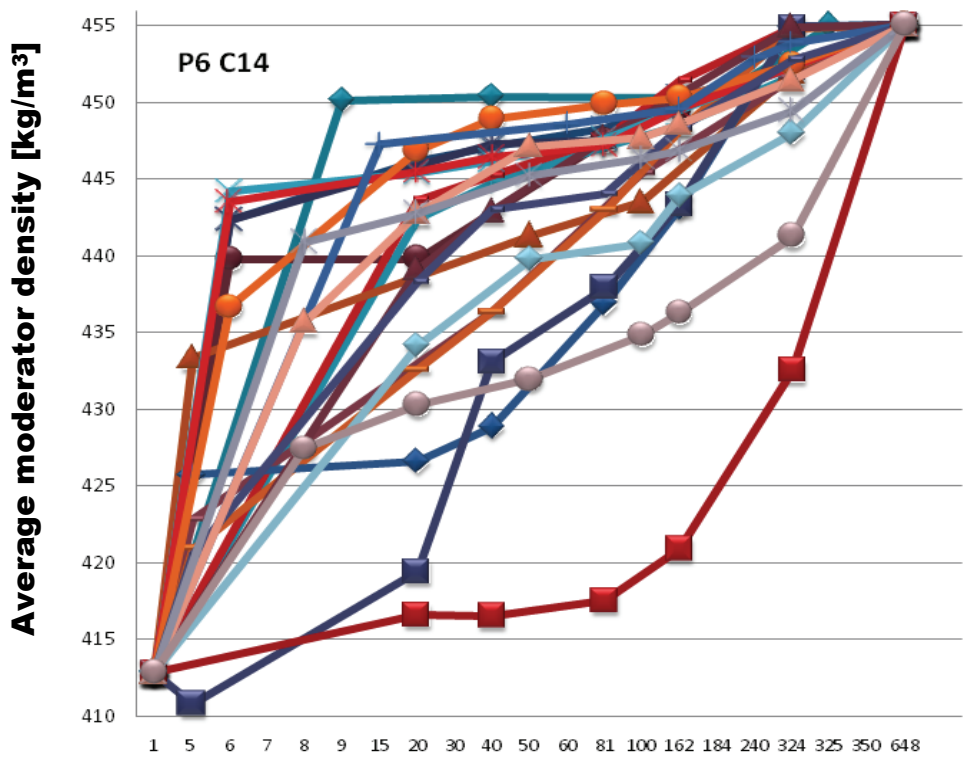

$\rightarrow$ Mapping mixed -Mapping peak fact 1 *-Mapping peak fact 2 $\rightarrow-$ Mapping peak fact xy 1 -Mapping peak fact $x y 2$ -Mapping peak fact symm -Mapping exposure -Mapping exp xy -Mapping exp symm $\neg$ Mapping fuel kinds 1 symm $\rightarrow-$ Mapping fuel kinds 2 symm -Mapping inlet orifice symm

-Mapping inlet orifice peak fact $\mathrm{v} 1$ * Mapping inlet orifice peak fact $\mathrm{v} 2$ - Mapping inlet orifice exp + Mapping control rods peak fact -Mapping control rods exp $\rightarrow-$ Mapping 1st mode $\diamond-$ Mapping 1st mode exp - Mapping 1st mode peak fact *-Mapping 1st mode inlet orifice - - Mapping 1st mode fuel kinds 1

\section{Number of TH channels}

Figure A3.23: Average moderator density, point 6 of cycle 14. 

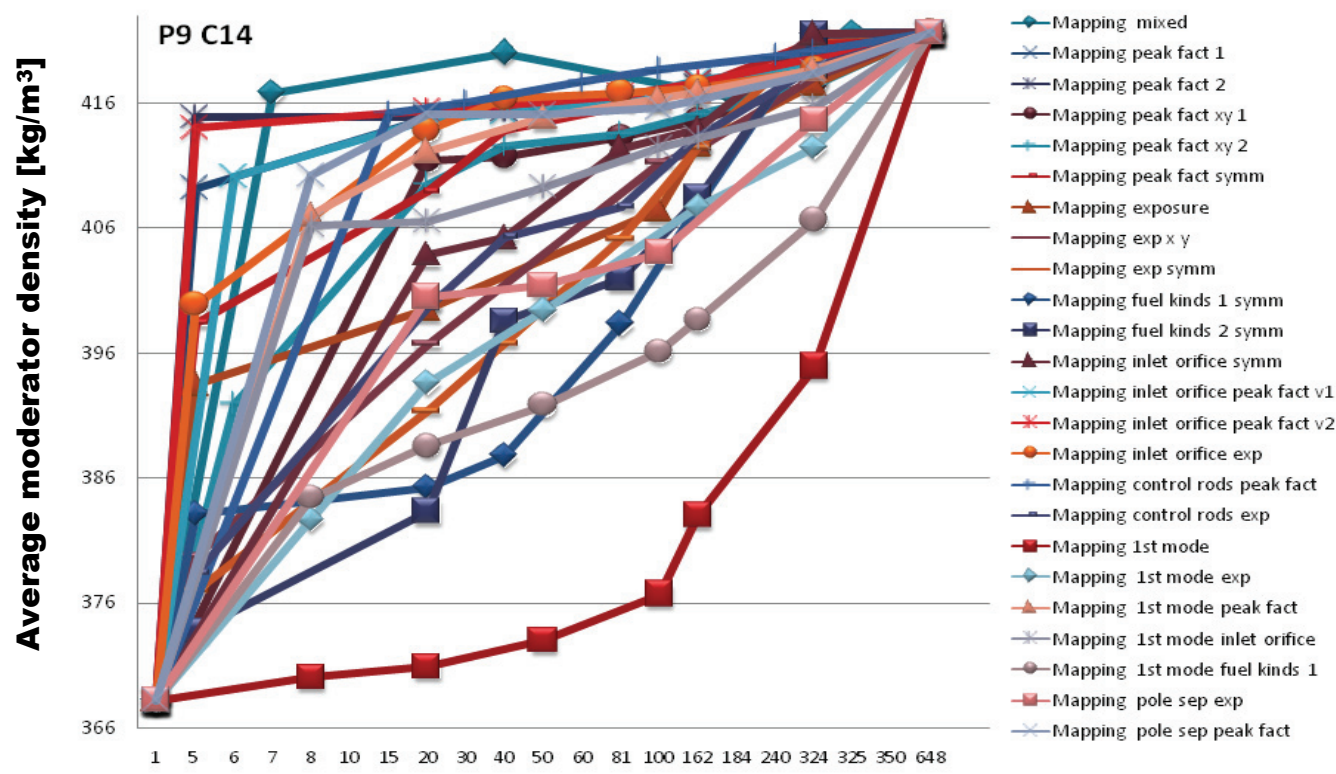

Number of TH channels

Figure A3.24: Average moderator density, point 9 of cycle 14.

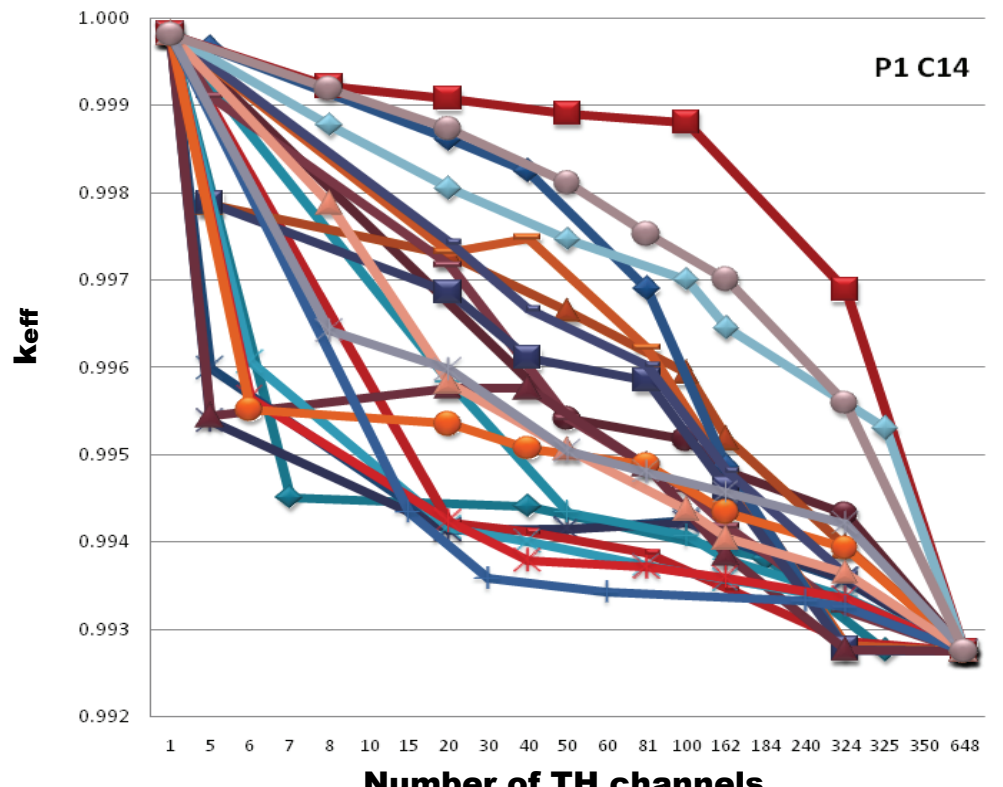

$\leadsto$ Mapping mixed

-Mapping peakfact 1

Mapping peakfact 2

$\rightarrow$ Mapping peakfact xy 1

-Mapping peakfact xy 2

-Mapping peakfact symm

-Mapping exposure

-Mapping exp xy

-Mapping exp symm

$\leadsto$ Mappingfuel kinds 1 symm

$\rightarrow$ Mappingfuel kinds 2 symm

-Mapping inlet orifice symm

-Mapping inlet orifice peakfact $v 1$

—Mapping inlet orifice peakfact $v 2$

-Mapping inlet orifice exp

-Mapping control rods peakfact

-Mapping control rods exp

$\rightarrow$ Mapping 1st mode

$\neg$ Mapping 1st mode exp

-Mapping 1st mode peakfact

-Mapping 1st mode inlet orifice

- Mapping 1st mode fuel kinds 1

\section{Number of TH channels}

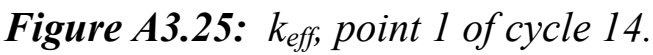




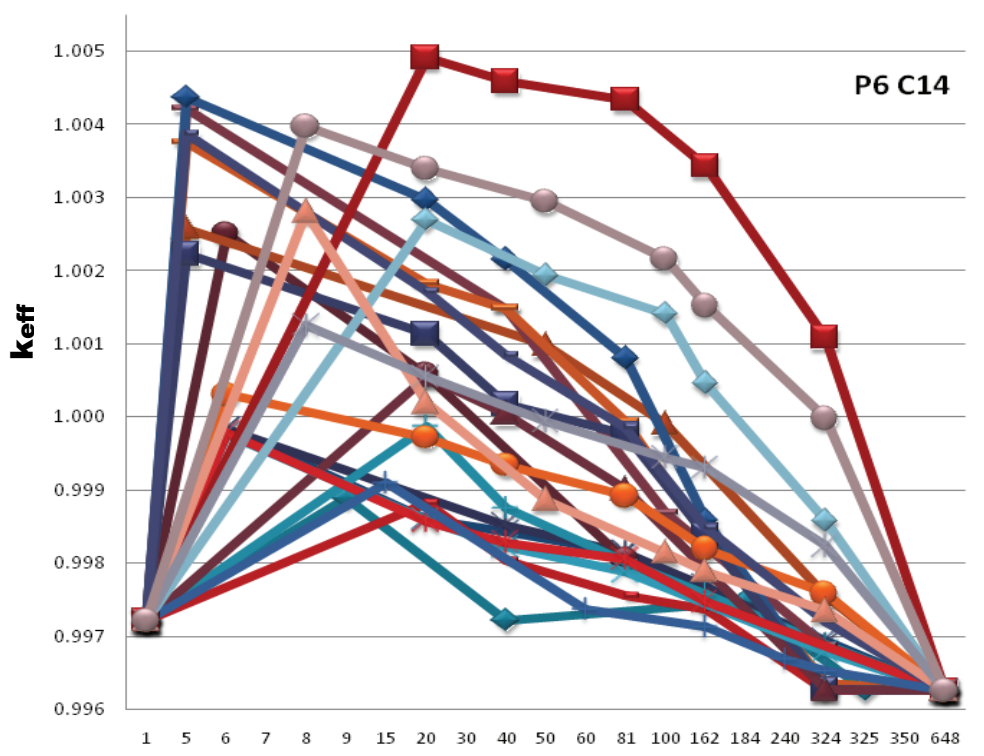

Number of TH channels

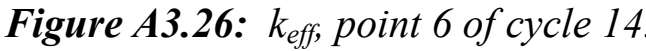

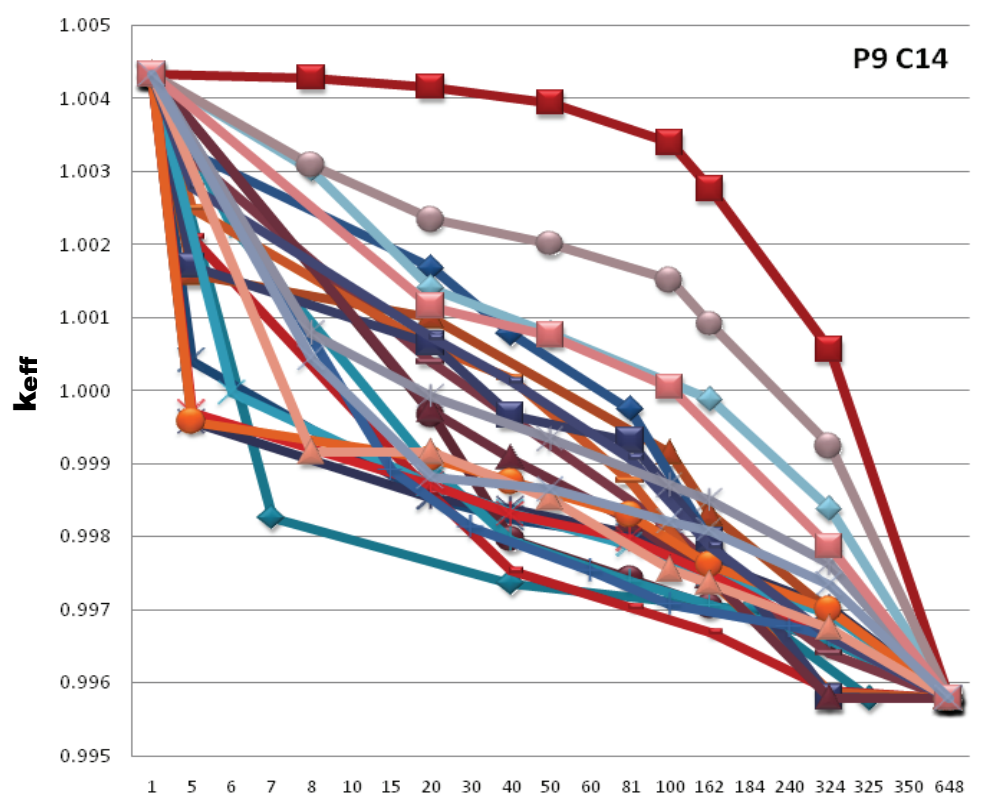

$\neg$ Mapping mixed

-Mapping peakfact 1

-Mapping peakfact 2

-Mapping peakfact xy 1

-Mapping peakfact xy 2

-Mapping peakfact symm

-Mapping exposure

-Mapping exp xy

-Mapping exp symm

$\neg$ Mappingfuelkinds 1 symm

-M Mappingfuelkinds 2 symm

-Mapping inlet orifice symm

Mapping inlet orifice peakfact $\mathrm{v} 1$

-Mapping inlet orifice peakfact $\mathrm{v} 2$

- Mapping inlet orifice exp

Mapping control rods peakfact

-Mapping control rods exp

$\rightarrow$-Mapping 1st mode

$\checkmark$ Mapping 1st mode exp

-Mapping 1st mode peakfact

-Mapping 1st mode inlet orifice

- Mapping 1st mode fuel kinds 1

\section{Number of TH channels}

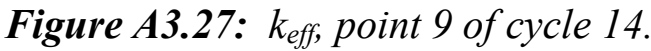

